\title{
AN IMPROVED DESIGN METHODOLOGY \\ FOR MODELING THICK-SECTION COMPOSITE \\ STRUCTURES USING A MULTI-SCALE APPROACH
}

\author{
by \\ Jeffrey Staniszewski
}

\begin{abstract}
A thesis submitted to the
Faculty of the University of Delaware in partial fulfillment of the requirements for the degree of Master of Science in Mechanical Engineering
\end{abstract}

Summer 2010

Copyright 2010 Jeffrey Staniszewski

All Rights Reserved 


\title{
AN IMPROVED DESIGN METHODOLOGY \\ FOR MODELING THICK-SECTION COMPOSITE \\ STRUCTURES USING A MULTI-SCALE APPROACH
}

\author{
by \\ Jeffrey Staniszewski
}

Approved:

Michael Keefe, Ph.D.

Professor in charge of thesis on behalf of the Advisory Committee

Approved:

Anette M. Karlsson, Ph.D.

Chair of the Department of Mechanical Engineering

Approved:

Michael J. Chajes, Ph.D.

Dean of the College of Engineering

Approved:

Debra Hess Norris, M.S.

Vice Provost for Graduate and Professional Education 


\section{ACKNOWLEDGMENTS}

First, I would like to thank my family for their support and encouragement throughout my degree program. I would like to thank my advisor, Dr. Michael Keefe, for the guidance and expertise he has provided me over the past two years. I wish to thank Dr. Travis Bogetti for guidance as well as encouraging me to continue my education and giving me the opportunity to further my career. I would also like to thank him for his continued support of me as a contractor at the Army Research Laboratory throughout my graduate studies.

I wish to thank Dr. Brian Powers for his input and expertise on the modeling and programming work that was needed to complete my research. I would like to acknowledge the staffs of the Maryland Office of Oak Ridge Associated Universities, the Weapons and Materials Research Division of the Army Research Laboratory, and the Center for Composite Materials for their assistance throughout my graduate studies.

The research was supported in part by an appointment to the Postgraduate Research Participation Program at the U.S. Army Research Laboratory administered by the Oak Ridge Institute for Science and Education through an interagency agreement between the U.S. Department of Energy and USARL. 


\section{TABLE OF CONTENTS}

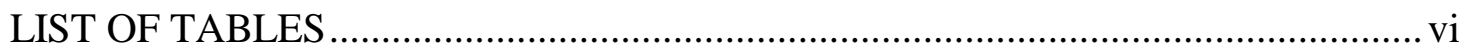

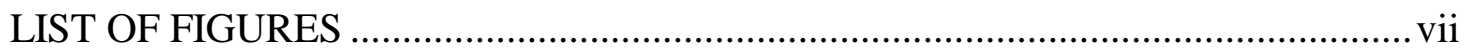

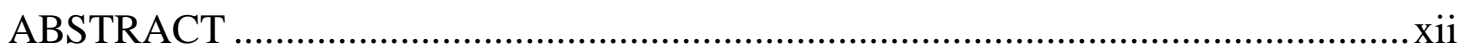

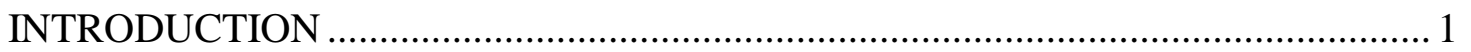

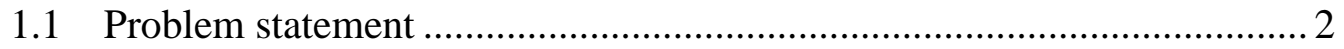

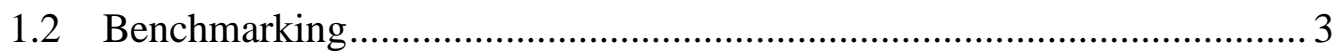

1.2.1 State-of-the-art commercial composite models .............................. 3

1.2.2 State-of-the-art for other software products …………………....... 5

1.2.3 Literature review................................................................... 7

1.2.4 Selection of FEA software....................................................... 10

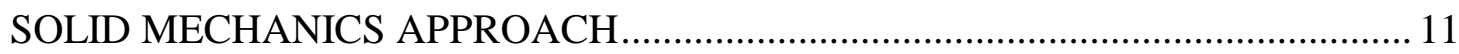

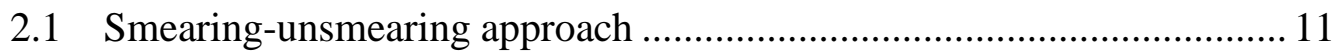

2.2 Background of the "LAM" codes .......................................................... 12

2.3 Laminated media methodology ……………….................................... 16

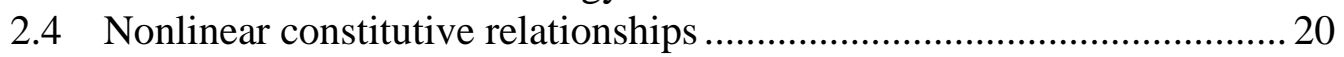

2.5 Incremental approach to predicting nonlinear laminate response …........22

2.6 Progressive ply failure methodology ……………………………....... 24

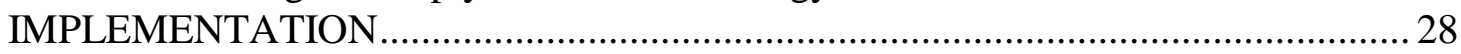

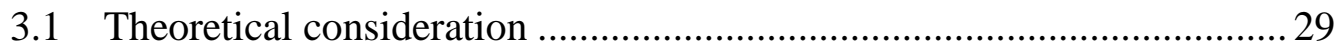

3.1.1 Ply-level stress and strain calculations ......................................29

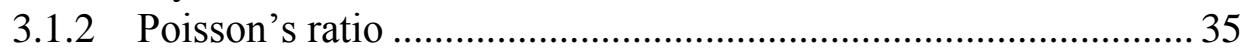

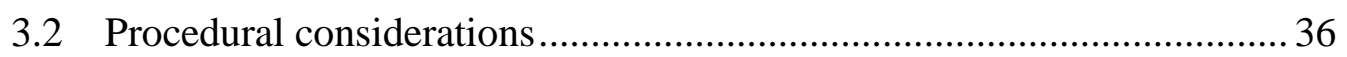

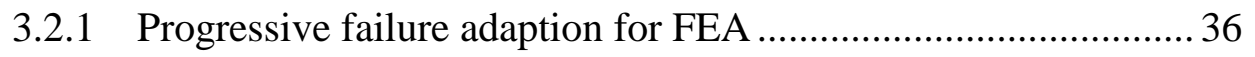

3.2.2 Tracking progressive failure ..................................................... 41

3.2.3 Selection of elements............................................................... 42

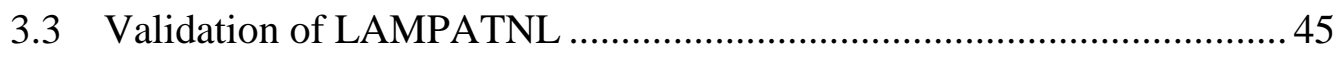

3.3.1 Validation of LAMPATNL for linear materials ........................... 47

3.3.2 Validation of LAMPATNL for nonlinear materials..................... 50

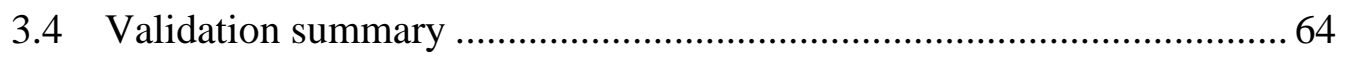

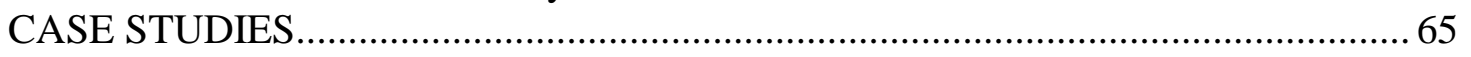

4.1 LAMPATNL output parameters .......................................................... 65

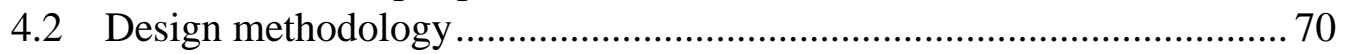

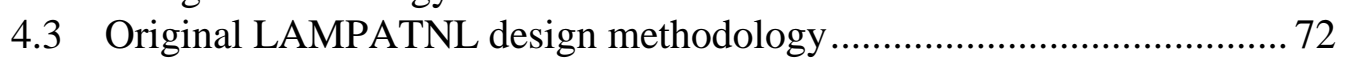

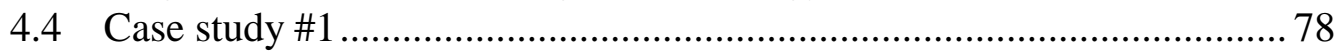

4.4.1 Description .................................................................... 78 


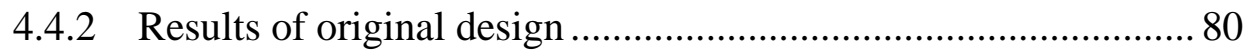

4.4.3 Design iteration \#1 .......................................................... 93

4.4.4 Design iteration \#2 ............................................................... 100

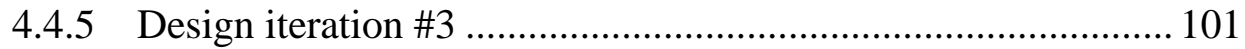

4.5 Case study \#2 ......................................................................... 108

4.5.1 Description ................................................................... 108

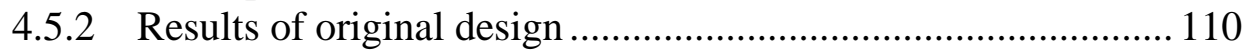

4.5.3 Design iteration \#1 ........................................................... 123

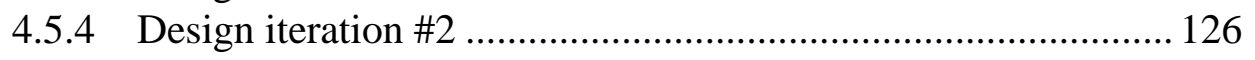

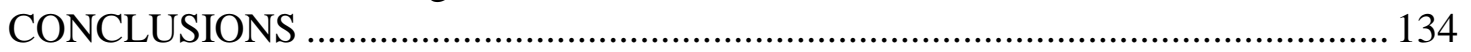

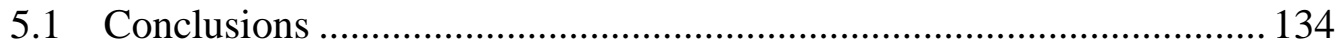

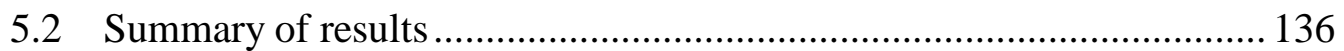

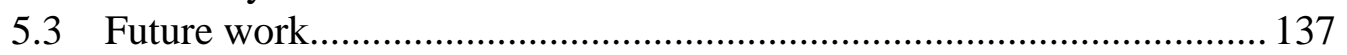

REFERENCES .............................................................................................. 140

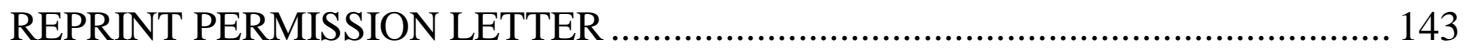




\section{LIST OF TABLES}

Table 1.1 Percentage of keyword papers containing FEA software ....................... 10

Table $2.1 \quad$ Failure mode and property modification .......................................... 26

Table 3.1 Examples provided for LAMPATNL validation ............................... 47

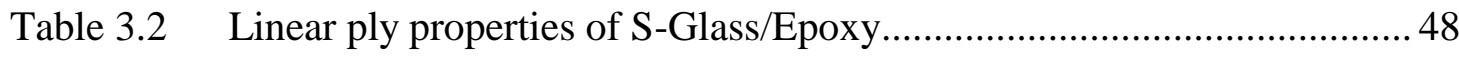

Table 3.3 Ply properties for linear S-Glass/Epoxy …........................................ 48

Table 3.4 Ply properties for linear T300/PR-319 .......................................... 50

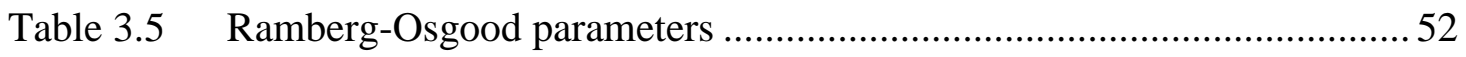

Table 3.6 Maximum strain failure allowables ..................................................... 52

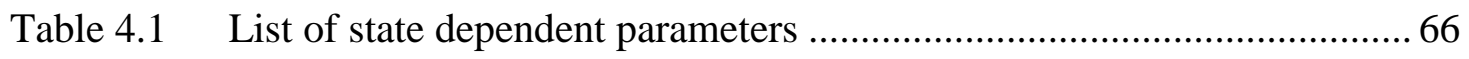




\section{LIST OF FIGURES}

Figure 2.1 LAMPAT process methodology ........................................................ 15

Figure 2.2 Laminate configuration [1] ........................................................... 16

Figure 2.3 Relation of global coordinates to laminate and ply coordinates............. 18

Figure 2.4 Nonlinear stress-strain response ........................................................... 21

Figure 2.5 Incremental laminate loading methodology [2] [..................................22

Figure 2.6 Effect of increment size on nonlinear stress-strain response...................2 24

Figure 3.1 Ply stress and strain calculation procedure for LAM3DNLP .................. 31

Figure 3.2 Ply stress and strain calculation procedure for LAMPATNL ………..... 34

Figure 3.3 LAM3DNLP progressive failure procedure .......................................... 37

Figure 3.4 Stress-strain curves of $\left[0^{\circ} / 90^{\circ} / \pm 45^{\circ}\right]_{\mathrm{S}}$ S2 Glass/Epoxy laminate ............ 38

Figure 3.5 LAMPATNL progressive failure procedure.........................................39

Figure 3.6 Stress-strain curves of $\left[0^{\circ} / 90^{\circ} / \pm 45^{\circ}\right]_{\mathrm{S}}$ S2-Epoxy laminate LAM3DNLP output and ABAQUS UMAT output ................................ 40

Figure 3.7 Tracking failure history is mode, ply, integration point, and

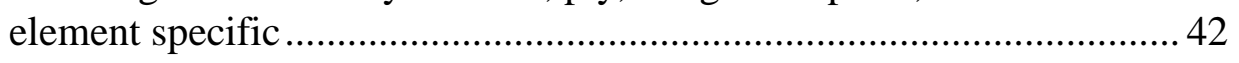

Figure 3.8 Comparison of visualization of full integration (left) and reduced integration (right) elements .

Figure 3.9 Stress vs. strain curves in the X-direction for $\left[0^{\circ} / 90^{\circ} / \pm 45^{\circ}\right]_{\mathrm{s}} \mathrm{S}$ Glass/Epoxy comparing the LAM3D and LAMPATNL codes.

Figure 3.10 Stress vs. strain curves in the Y-direction for $\left[ \pm 30^{\circ}\right]_{\mathrm{s}} \mathrm{T} 300 / \mathrm{PR}-$ 319 comparing the LAM3D and LAMPATNL codes 50 
Figure 3.11 Stress vs. strain curves in the 1-direction for $\left[0^{\circ}\right] \mathrm{S}-\mathrm{Glass} / \mathrm{Epoxy}$ comparing the UMAT and LAM3DNLP codes

Figure 3.12 Stress vs. strain curves in the 2-direction for $\left[0^{\circ}\right] \mathrm{S}-\mathrm{Glass} / \mathrm{Epoxy}$ comparing the UMAT and LAM3DNLP codes 55

Figure 3.13 Stress vs. strain curves in the 3-direction for $\left[0^{\circ}\right] \mathrm{S}-$ Glass/Epoxy comparing the UMAT and LAM3DNLP codes 56

Figure 3.14 Stress vs. strain curves in the X-direction for $\left[0^{\circ} / 90^{\circ} / \pm 45^{\circ}\right]_{\mathrm{S}} \mathrm{S}$ Glass/Epoxy comparing the UMAT and LAM3DNLP codes 57

Figure 3.15 Stress vs. strain curves in the X-direction for $\left[ \pm 35^{\circ}\right]_{\mathrm{s}}$ IM7/8551-7 comparing the UMAT and LAM3DNLP codes 58

Figure 3.16 Stress vs. strain curves in the Y-direction for $\left[ \pm 35^{\circ}\right]_{\mathrm{S}} \mathrm{IM} 7 / 8551-7$ comparing the UMAT and LAM3DNLP codes 59

Figure 3.17 Stress vs. strain curves in the Z-direction for $\left[ \pm 35^{\circ}\right]_{\mathrm{S}} \mathrm{IM} 7 / 8551-7$ comparing the UMAT and LAM3DNLP codes

Figure 3.18 Stress vs. strain curves in X-direction tension for $\left[ \pm 55^{\circ}\right]_{\mathrm{S}} \mathrm{E}$ Glass/MY750 comparing the UMAT and LAM3DNLP codes. 61

Figure 3.19 Stress vs. strain curves in X-direction compression for $\left[ \pm 55^{\circ}\right]_{\mathrm{s}}$ E-Glass/MY750 comparing the UMAT and LAM3DNLP codes 62

Figure 3.20 Stress vs. strain curves in Y-direction tension for $\left[ \pm 55^{\circ}\right]_{\mathrm{S}}$ EGlass/MY750 comparing the UMAT and LAM3DNLP codes. 63

Figure 3.21 Stress vs. strain curves in Y-direction compression for $\left[ \pm 55^{\circ}\right]_{\mathrm{s}}$ E-Glass/MY750 comparing the UMAT and LAM3DNLP codes 64

Figure 4.1 Relation of global coordinates to laminate and ply coordinates............ 69

Figure 4.2 Design methodology flowchart ............................................. 71

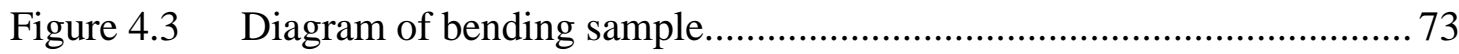

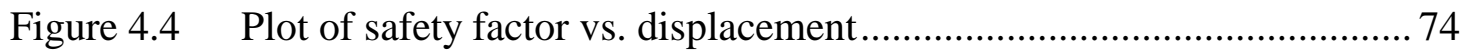

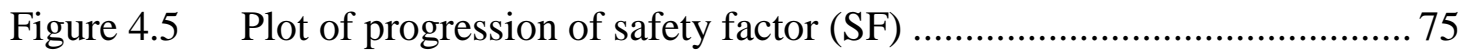

Figure 4.6 Plot of minimum stiffness ratio (MINCIJ) vs. displacement ............... 76 
Figure 4.7 Plot of progression of minimum stiffness ratio (MINCIJ) ................... 77

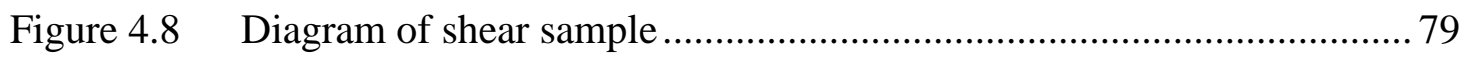

Figure 4.9 Contour plot of minimum $\mathrm{C}_{\mathrm{ij}}$ stiffness ratio, MINCIJ....................... 81

Figure 4.10 Contour plot of the direction of minimum $C_{i j}$ ratio, MINCIJN............. 82

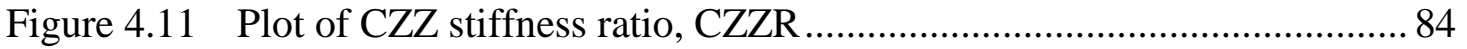

Figure 4.12 Plot of CXY stiffness ratio, CXYR ................................................ 85

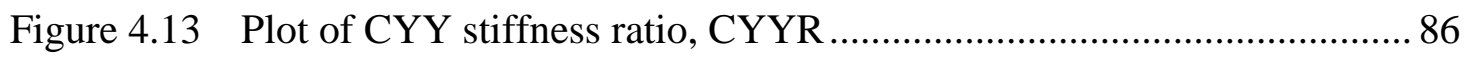

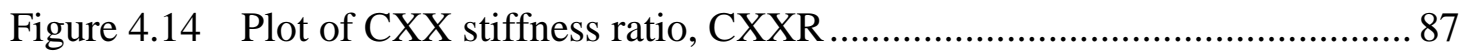

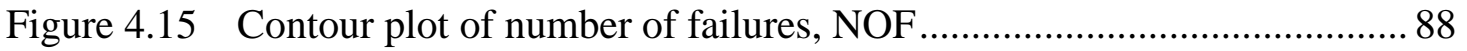

Figure 4.16 Plot of progression of last failed mode, FMODE ................................. 90

Figure 4.17 Plot of progression of last failed ply, FPLY .................................. 91

Figure 4.18 Diagram of regions .................................................................... 92

Figure 4.19 Comparison of minimum stiffness ratio MINCIJ $\left[0^{\circ} / 90^{\circ}\right]_{\mathrm{s}}$ (left)

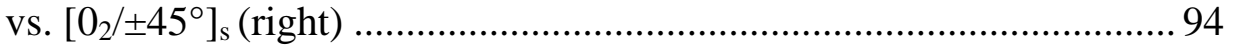

Figure 4.20 Plot of the direction of minimum $\mathrm{C}_{\mathrm{ij}}$ ratio MINCIJN for $\left[\mathrm{O}_{2} / \pm 45\right]_{\mathrm{s}}$

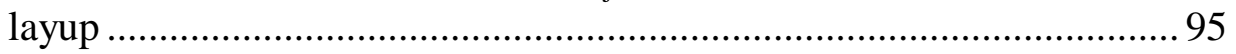

Figure 4.21 Plot of $\mathrm{C}_{\mathrm{XX}}$ stiffness ratio $\mathrm{CXXR}$ comparing $\left[0^{\circ} / 90^{\circ}\right]_{\mathrm{s}}(\mathrm{left})$ to

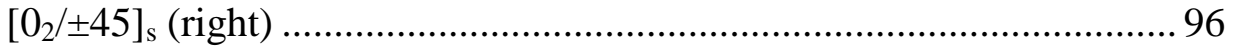

Figure 4.22 Plot of $\mathrm{C}_{\mathrm{YY}}$ stiffness ratio (CYYR) comparing $\left[0^{\circ} / 90^{\circ}\right]_{\mathrm{s}}$ (left) to $\left[0_{2} / \pm 45\right]_{\text {s }}$ (right)

Figure 4.23 Plot of $\mathrm{C}_{\mathrm{ZZ}}$ stiffness ratio $(\mathrm{CZZR})$ comparing $\left[0^{\circ} / 90^{\circ}\right]_{\mathrm{s}}$ (left) to $\left[0_{2} / \pm 45\right]_{\mathrm{s}}$ (right) 98

Figure 4.24 Plot of $\mathrm{C}_{\mathrm{XY}}$ stiffness ratio (CXYR) comparing $\left[0^{\circ} / 90^{\circ}\right]_{\mathrm{s}}(\mathrm{left})$ to $\left[0_{2} / \pm 45\right]_{\mathrm{s}}$ (right) 99

Figure 4.25 Comparison of minimum stiffness ratio MINCIJ, $\left[0^{\circ} / 90^{\circ}\right]_{\mathrm{s}}(\mathrm{left})$ vs. $\left[0_{2} / \pm 25^{\circ}\right]_{\mathrm{s}}$ (right) 102 
Figure 4.26 Plot of the direction of minimum $\mathrm{C}_{\mathrm{ij}}$ ratio MINCIJN for $\left[0_{2} / \pm 25\right]_{\mathrm{s}}$ layup 103

Figure 4.27 Plot of $\mathrm{C}_{\mathrm{XX}}$ stiffness ratio $(\mathrm{CXXR})$ comparing $\left[0^{\circ} / 90^{\circ}\right]_{\mathrm{s}}(\mathrm{left})$ to $\left[0_{2} / \pm 25\right]_{\mathrm{s}}$ (right) 104

Figure 4.28 Plot of $\mathrm{C}_{\mathrm{YY}}$ stiffness ratio (CYYR) comparing $\left[0^{\circ} / 90^{\circ}\right]_{\mathrm{s}}$ (left) to $\left[0_{2} / \pm 25\right]_{\mathrm{s}}$ (right) 105

Figure 4.29 Plot of $\mathrm{C}_{\mathrm{ZZ}}$ stiffness ratio $(\mathrm{CZZR})$ comparing $\left[0^{\circ} / 90^{\circ}\right]_{\mathrm{s}}$ (left) to $\left[0_{2} / \pm 25\right]_{\mathrm{s}}$ (right) 106

Figure 4.30 Plot of $\mathrm{C}_{\mathrm{XY}}$ stiffness ratio (CXYR) comparing $\left[0^{\circ} / 90^{\circ}\right]_{\mathrm{s}}(\mathrm{left})$ to $\left[0_{2} / \pm 25\right]_{\mathrm{s}}$ (right) 107

Figure 4.31 Diagram of open hole sample 109

Figure 4.32 Contour plot of minimum $\mathrm{C}_{\mathrm{ij}}$ stiffness ratio MINCIJ 111

Figure 4.33 Contour plot of the direction of minimum $\mathrm{C}_{\mathrm{ij}}$ ratio MINCIJN 112

Figure 4.34 Contour plot of number of failures, NOF. 113

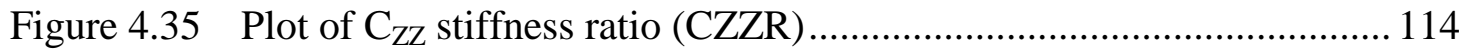

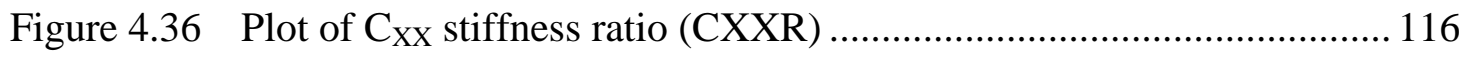

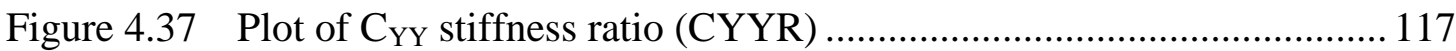

Figure 4.38 Plot of $\mathrm{C}_{\mathrm{XY}}$ stiffness ratio (CXYR) ............................................... 118

Figure 4.39 Plot of progression of last failed mode FMODE ............................... 120

Figure $4.40 \quad$ Plot of progression of last failed ply FPLY .................................. 121

Figure 4.41 Diagram of regions ................................................................... 122

Figure 4.42 Plot of $\mathrm{C}_{Y Y}$ stiffness ratio (CYYR) comparing $\left[0^{\circ} / 90^{\circ} / \pm 45^{\circ}\right]_{\mathrm{s}}$ (left) to $\left[0^{\circ} / 90^{\circ} / \pm 30^{\circ}\right]_{\mathrm{s}}$ (right)

Figure 4.43 Plot of last failed ply (FPLY) comparing $\left[0^{\circ} / 90^{\circ} / \pm 45^{\circ}\right]_{\mathrm{s}}$ (left) to $\left[0^{\circ} / 90^{\circ} / \pm 30^{\circ}\right]_{\mathrm{s}}$ (right)

Figure 4.44 Comparison of minimum stiffness ratio (MINCIJ), $\left[0^{\circ} / 90^{\circ} / \pm 45^{\circ}\right]_{\mathrm{s}}$ (left) to $\left[0^{\circ} / 90^{\circ} / \pm 20^{\circ}\right]_{\mathrm{s}}$ (right) 
Figure 4.45 Plot of the direction of minimum $\mathrm{C}_{\mathrm{ij}}$ ratio MINCIJN for $\left[0^{\circ} / 90^{\circ} \% 20^{\circ}\right]_{\mathrm{s}}$ layup

Figure 4.46 Plot of $\mathrm{C}_{\mathrm{XX}}$ stiffness ratio (CXXR) comparing $\left[0^{\circ} / 90^{\circ} / \pm 45^{\circ}\right]_{\mathrm{s}}$ (left) to $\left[0^{\circ} / 90^{\circ} / \pm 20^{\circ}\right]_{\mathrm{s}}$ (right)

Figure 4.47 Plot of $\mathrm{C}_{\mathrm{YY}}$ stiffness ratio (CYYR) comparing $\left[0^{\circ} / 90^{\circ} / \pm 45^{\circ}\right]_{\mathrm{s}}$ (left) to $\left[0^{\circ} / 90^{\circ} / \pm 20^{\circ}\right]_{\mathrm{s}}$ (right)

Figure 4.48 Plot of $\mathrm{C}_{\mathrm{ZZ}}$ stiffness ratio (CZZR) comparing $\left[0^{\circ} / 90^{\circ} / \pm 45^{\circ}\right]_{\mathrm{s}}$ (left) to $\left[0^{\circ} / 90^{\circ} / \pm 20^{\circ}\right]_{\mathrm{S}}$ (right)...

Figure 4.49 Plot of $\mathrm{C}_{\mathrm{XY}}$ stiffness ratio (CXYR) comparing $\left[0^{\circ} / 90^{\circ} \% 45^{\circ}\right]_{\mathrm{s}}$ (left) to $\left[0^{\circ} / 90^{\circ} \% 20^{\circ}\right]_{\mathrm{s}}$ (right) 


\begin{abstract}
Material nonlinearity and progressive ply failure are important considerations in the finite element modeling of thick section composite structures. Ply-level anisotropic nonlinearity and ply-based failure criteria require ply-level stresses and strains, but discretely modeling individual plies in a large scale, thick section composite structure with hundreds of plies is not computationally feasible. A method was developed [1-4] to model the material nonlinearity and progressive ply failure of composite laminates using finite element software without explicitly simulating individual plies. In this method, the multiple plies of a laminate are treated as a homogenous, or smeared, material with equivalent material properties. Ply-level material nonlinearity and progressive failure analysis are incorporated by dehomogenizing, or unsmearing, the laminate. The LAMPATNL program integrated this method into a finite element environment [4]. Improvements to this program are documented and discussed in this work. Also, the LAMPATNL user material is validated against both the linear and nonlinear material point models.

In this work, a standardized process for designing composite structures with the LAMPATNL user material is developed. The design methodology uses newly formulated output parameters, stiffness ratios, to analyze the nonlinear response and progressive failure of the composite structure. These new parameters greatly improve the visualization of critical design information of the structure. An example comparing the original outputs of LAMPATNL to the new outputs is provided to illustrate the contributions of the stiffness ratio parameters. Two case studies, an open-
\end{abstract}


hole sample under multi-axial loading and a compressive shear sample, are evaluated using the design methodology. Changes to the layups of the laminates in these cases are made using the insights gained from the design methodology. Coupling LAMPATNL with a design methodology and new stiffness ratio parameters demonstrates the utility of progressive failure and nonlinear analysis when applied to composite structures. The straightforward visualization of critical design information creates a unique approach to analyzing the design of thick section composites. This methodology represents a unique contribution to the modeling of composite structures that is not matched by any current composite model. 


\section{Chapter 1}

\section{INTRODUCTION}

As the use of composite materials expands, the demand for an accurate model of the response and failure of these materials has increased. The adoption of the finite element (FE) method as a tool to analyze the response of complex structures under load has greatly improved the understanding and design of these structures. Linear, elastic materials that are used in many applications are easily handled by any well developed FE software, but the unique nature of laminated composite materials have not been fully addressed in commercially available software. Composite materials are unique due to their ply-level, anisotropic, nonlinear stress-strain response. It is possible through the load-displacement history of a composite structure for a ply or plies to fail while the overall structure does not fail. Accounting for firstply failure and any subsequent failures, know as progressive failure analysis, is therefore important in accurately simulating the response of composites. The incorporation of progressive failure for composite materials in commercial software has been limited [5]. In this chapter, a review of the state-of-the-art composite modeling features offered by the most widely available finite element software and specialized composite-oriented supplemental software is presented. A literature review on topics related to the progressive damage and failure analysis of composite structures is also discussed. 


\subsection{Problem statement}

Large scale, thick section composite structures cannot be modeled efficiently using a discrete ply-by-ply approach. For structures with hundreds of layers, the number of elements through the thickness would be too large to be computationally efficient. Creating the model and interpreting the ply-by-ply stresses and strains would be very time consuming and prone to errors. To address the issues of ply-by-ply analysis, a multi-scale approach is taken to account for the ply-level response and failure of the composite structure while not explicitly modeling the plies. To achieve this, multilayered laminates are treated as a homogenous, or smeared, material with equivalent material properties. Ply-level material nonlinearity and progressive failure analysis using ply-based failure criteria are incorporated into the multi-scale approach by dehomogenizing, or unsmearing, the laminate.

An investigation of three commercially available finite element programs, state-of-the-art composite modeling software products, and recent publications is presented in this chapter. All these works contain either anisotropic material nonlinearity, or progressive failure analysis, or the multi-scale "smearing-unsmearing" approach, but it is shown that none contain all three. The combination of these three aspects is what makes the modeling approach presented in this work unique. The objective of this research is to develop a methodology that uses this unique multi-scale approach in conjunction with finite element analysis to design and analyze thicksection composite structures. 


\subsection{Benchmarking}

\subsubsection{State-of-the-art commercial composite models}

The most advanced composite modeling capabilities of current, commercially available, FE software are investigated in this section. ABAQUS, ANSYS, and MSC.Nastran are three major finite element programs that have composite modeling capabilities. All three programs have specialized features that enable the user to construct and analyze composite materials. For the purpose of this research, the features investigated in these programs include: the ability to have plylevel nonlinearity in the principle and shear directions, progressive ply failure capabilities, support for a wide variety of failure criteria, the ability to efficiently model the layup by homogenizing properties to get an equivalent response, and an effective way of visualizing this data.

In recent software updates, ABAQUS has incorporated the ability to model composite layups through the use of conventional or continuum shell layup sections for shell elements and solid layup sections for solid elements [6]. These sections are able to analyze composite materials by modeling each ply discretely. The layup can be comprised of isotropic nonlinear materials, but nonlinear anisotropic materials are not supported [7]. There is support for progressive failure and damage evolution laws in ABAQUS, but it is restricted to linear, elastic materials, which can be anisotropic [8]. Furthermore, progressive failure behavior is restricted to shell elements and the only damage initiation criterion that can be used is the Hashin criteria [8]. ABAQUS is able to visualize the damage initiation criteria (tensile and compressive damage index for both fiber and matrix) and has the ability to label these 
values by ply. Although limited in scope and restricted to specific element types, ABAQUS provides a few important modeling features for composite materials.

ANSYS uses both shell (SHELL99, 91, and 181) and solid (SOLID186, 46, 191, and 95) elements to model composite layups [9]. Each shell and solid element listed has distinct advantages and disadvantages, as well as specific applications in which they are used. Several of these elements are able to handle nonlinear material properties [9], with extensive options for different types of anisotropic nonlinear behavior. The three basic failure criteria that are supported by default are maximum stress, maximum strain, and Tsai-Wu [10], with the option of expanding the criteria through user written code. These failure criteria are used to determine whether the material would have failed and are not coupled to the overall structural response. ANSYS does contain capabilities for delamination and crack growth and propagation, but progressive failure for composites in ANSYS is not possible. Similar to ABAQUS, ply based results are available for viewing in ANSYS, but there is limited support for critical mode and ply display options.

The programs developed under MSC Software, including Patran, Nastran, Marc, and several others, have recently begun to add progressive failure capabilities to their existing composite modeling abilities. In Nastran, a total of seven failure criteria, including Puck and Hashin, can be used in conjunction with progressive failure [11]. A variety of elements are available for modeling composites, including 2D and 3D layered shell, solid, and solid shell elements. Material options can be used to create anisotropic, nonlinear material response. Like other FE software, there are few options for visualizing and analyzing composite-specific design data that is produced from progressive failure analysis. The majority of MSC Software's progressive failure 
features are included in a separate product, developed in part by NASA, called GENOA. This product and other notable composite design oriented products are discussed in the next section.

\subsubsection{State-of-the-art for other software products}

Before the most recent releases of major FEA programs, there was little support and options for modeling composite materials. A demand for the accurate characterization of composite structures spurred the development of several products that went beyond the available capabilities of these programs. Developed either as an add-on to software such as ABAQUS, ANSYS, Nastran, and other programs or as a standalone pre- or post-processing product, features such as progressive damage, nonlinear material properties, and advanced composite design visualization were able to be incorporated into the FEA design cycle. While the built-in capabilities of current FEA programs are catching up, these products still offer some of the most advanced composite modeling features available.

As mentioned before, GENOA is standalone pre- and post-processing software that is compatible with Nastran, MSC MARC, LS-DYNA, ANSYS, and ABAQUS [12]. Offering a multitude of features, GENOA includes multi-scale progressive failure analysis, the ability to handle nonlinear stress-strain response, and advanced visualization options. In GENOA, the plies that make up the composite structures are modeled and displayed separately. In the simulation of structures that are hundreds of layers thick, the homogenization of composite laminates can improve the computational efficiency of the model. A homogenizing feature is something that is missing from this software. 
Another product that is specifically tailored to simulate composite materials is Helius:MCT created by Firehole Technologies. Helius was developed as a user material subroutine for ABAQUS and ANSYS [13]. Through an ABAQUS plugin and graphical interface, a composite material that is selected from a database is turned into a user material (UMAT). This UMAT allows for coupled, progressive failure of the composite part based on a multi-continuum theory. Nonlinear material response is limited to the in-plane and out-of-plane shear stiffness [14]. Much like modeling a composite in ABAQUS, a layered composite section is created using the UMAT as the constitutive material. The main drawback to this approach is that each ply is modeled separately, decreasing the computational efficiency when compared to a homogenized, equivalent composite material. In Helius, the progressive failure analysis provides visualization of matrix and fiber failure of the structure, but does not provide indication of whether it is tensile or compressive and there is no shear failure support. Directionally dependent material nonlinearity and a homogenization approach are aspects of composites modeling that are not currently available in Helius:MCT.

There are several additional standalone and integrated products that have been developed to tackle a range of composite modeling problems. ESAComp, offering integration with ABAQUS, ANSYS, LS-DYNA, Nastran, NISA, and IDEAS, is capable of evaluating several different failure theories of nonlinear composites and provides informative plots of analysis results through a graphical interface [15]. NEi Nastran [16] has unique composite analysis features such as the visualization of critical mode and ply data, progressive ply failure analysis, support for the latest failure criteria, and nonlinear material models. NISA/Composite [17] is able 
to display specialized composite analysis parameters and model nonlinear materials using several available 3D layered elements. The main drawback of all these programs is the reliance on individual ply modeling and subsequent lack of support for the homogenizing of properties, which improves the computational efficiency of modeling of large-scale, thick section, composite structures.

\subsubsection{Literature review}

A review of recent publications relating to progressive damage and failure modeling, as well as nonlinear composite material modeling, was conducted to determine the current state of research in these areas. Many papers deal with both of these areas and provide innovative ways to utilize them. The search was focused on trying to find other research that contained a part or all of the key features that have been determined to effectively model large laminated structures. The key aspects of the proposed modeling solution are nonlinear material responses that are directionally dependent, progressive ply failure, and the ability to efficiently model the composite through homogenized, effective properties.

Numerous researchers have conducted progressive failure analyses using linear, orthotropic material properties. Using a newly developed damage evolution criteria, Lapczyk and Hurtado [18] use the progressive damage features within ABAQUS to model open-hole tension tests of aluminum/composite sandwich structures. Zhang et al. [19] create a finite element model of grid stiffened plates subjected to damage based on a modified Hashin criterion. Progressive damage and delamination are investigated on open-hole samples subjected to tension, compression, and interlaminar shear. Spottswood and Palazotto [20] use simplified large displacement and rotation theory to look at the progressive failure of curved composite 
shells up to and through their snapping point. The effect of two material degradation models on the response of composite bolted joints is investigated by Huhne et al [21]. Both a constant and continuous degradation approach are incorporated into an ABAQUS subroutine and compared to experimental data. Xie and Biggers [22] look at the effect width-to-hole-diameter ratio on open-hole tensile response by using a progressive damage model that discounts plies instantaneously after failure. This behavior is programmed into an ABAQUS user material and the ability to tailor the composite using the results is demonstrated. Buckling and progressive damage of an open-hole compression sample is simulated by Labeas et al [23]. Using ANSYS, two different failure theories and two degradation models are compared with experimental results to determine the best combination. Tserpes et al. [24, 25] created a user material for ANSYS that uses the Hashin criteria and the ply discount method to model progressive failure. Variations on this approach were used to parametrically study laminate-bolt interactions to close agreement.

Nonlinear stress-strain response, especially in the transverse and throughthickness directions, is an important aspect of composites. There are a number of papers that incorporate progressive failure with nonlinear response. Schuecker and Pettermann [26] create a continuum damage model that they compare to results from the World Wide Failure Exercise (WWFE). Hochard et al. [27] develop an ABAQUS user material using shear damage and inelastic strain evolution laws. Both static and fatigue loads are applied to open-hole samples and strain fields are compared to data obtained from digital image correlation. The progression of failure and post-buckling response of tapered composites, especially those with ply drop-offs, is studied by Ganesan and Liu [28]. Using nonlinear ply properties and the maximum stress failure 
criteria, multiple layups are evaluated against one another. Kilic and Haj-Ali [29] developed an ABAQUS user material that utilizes Ramberg-Osgood based nonlinear behavior and Tsai-Wu failure criteria to model variations of both single bolt and openhole tension tests. Open-hole and double notched compression samples are modeled by Basu et al. [30] using layered shell element and a user material in ABAQUS. Nonlinear material properties are simulated using Schapery theory and fiber rotation under axial compression. Antoniou et al. [31] simulated thick cylindrical composite shells under compressive, tensile, and torsion loading in ANSYS. A user material that had linear, elastic fiber direction response and nonlinear transverse and shear response was used to create failure envelopes of first and last ply failure for comparisons with experimental data. Huang [32] developed an ABAQUS user shell section that uses the Bridging model to degrade the nonlinear fiber and matrix properties upon failure. The effect of mesh size, element type, and load application are investigated and compared to experimental results. A unique aspect of this failure analysis is that if a ply associated with an element fails, that ply is discounted throughout the entire structure. While there are several examples of both linear and nonlinear behavior coupled with progressive failure analysis, none of these papers have the ability to simulate effective properties by homogenizing the laminate into one material. An important part of modeling is the computational efficiency of the code, so the designer can quickly analyze many design iterations. This aspect of progressive failure and composites simulation has not been addressed in previous work and is important when creating an effective design tool. 


\subsubsection{Selection of FEA software}

An investigation of the phrases composite, nonlinear, nonlinear composite, composite progressive failure, and nonlinear composite progressive failure was conducted using publications from January 2000 to January 2010. The most widely mentioned codes in publications containing the key phrases were ABAQUS, ANSYS, and, to a lesser extent, MSC.Nastran. Table 1.1 shows the percentage of papers with the phrases that also mention ABAQUS, ANSYS, or Nastran. Throughout all of these papers, the most widely used program is ABAQUS, ranging from $1 \%$ of all papers with the keyword composite to $17.6 \%$ of all papers with the keywords nonlinear composite progressive failure.

Table 1.1 Percentage of keyword papers containing FEA software

\begin{tabular}{|l|r|r|r|}
\hline \multicolumn{1}{|c|}{ Keywords } & Abaqus & ANSYS & Nastran \\
\hline Composite & $1.1 \%$ & $0.8 \%$ & $0.2 \%$ \\
\hline Nonlinear & $1.3 \%$ & $0.8 \%$ & $0.1 \%$ \\
\hline Nonlinear Composite & $4.7 \%$ & $3.0 \%$ & $0.5 \%$ \\
\hline Composite Progressive Failure & $5.6 \%$ & $2.5 \%$ & $0.4 \%$ \\
\hline Nonlinear Composite Progressive Failure & $17.6 \%$ & $6.8 \%$ & $1.3 \%$ \\
\hline
\end{tabular}

Due to its wide use in modeling the progressive damage and failure of nonlinear composite materials, ABAQUS was selected as the software in which the homogenization approach and progressive ply failure technique will be implemented. 


\section{Chapter 2}

\section{SOLID MECHANICS APPROACH}

The solid mechanics based "LAM" codes were developed for the design and failure analysis of thick section composite structures. Both linear and nonlinear, these codes use a multi-scale "smearing-unsmearing" approach and progressive ply failure to analyze multilayered composite laminates. A background on the development of these programs and discussion on the key assumptions and procedures, particularly for the nonlinear codes, are given in this chapter.

\subsection{Smearing-unsmearing approach}

The analysis of composite structures using finite element techniques is complicated by the nonlinear, anisotropic ply-level response of these materials. Furthermore, the failure analysis of a ply or lamina depends upon the stress and strain state within individual plies. It is therefore important to track the individual ply stresses and strains in order to accurately model the nonlinear material response and to be able to apply failure predictions.

One way to accurately calculate the ply-level stresses and strains would be to model each ply discretely. Using several elements through the thickness of the ply, a mesh containing all the plies of the structure could be created. While this approach would most accurately capture the ply-level response, there would be several disadvantages. A model that is both large in scale and in number of plies would prove very time consuming to create, run, and analyze. In addition, the vast amount of data 
produced by a large, complex model would be difficult to interpret. There would also be a greater chance for errors when creating the model when compared to a homogenized structure.

A way to address the computational and logistical disadvantages of discretely modeling each ply is by homogenizing the laminate. Complications arise when the application of ply-based failure criteria are considered for a homogeneous material. Ply-level stresses and strains must be extracted from structural stress and strain profile in order to conduct failure analysis. To deal with these issues, Bogetti et al. implemented the well established "smearing/unsmearing" approach [1-3]. Equivalent laminate properties are generated by "smearing" the ply-level nonlinear, anisotropic material behavior of the layup and ply-level stress state needed for failure analysis is generated by "unsmearing" the elemental stresses and strains.

\subsection{Background of the "LAM" codes}

The programs LAM3D, LAM3DNLP, LAMPAT, and LAMPATNL are the four codes in the "LAM" series. The programs use the "smearing-unsmearing" approach and progressive ply failure analysis to model multilayered composite laminates on two scales. LAM3D and its nonlinear version LAM3DNLP are codes that use analytical models to simulate the material point response of laminates. LAMPAT and LAMPATNL scale up the LAM3D and LAM3DNLP approaches for use in finite element analysis to evaluate composite structures. A discussion of each code is provided in this section.

LAM3D was created by Bogetti et al. [1] and uses orthotropic, linear ply properties and progressive ply failure to simulate the material point response of a laminate. The code determines the three dimensional effective properties, ultimate 
strength predictions under mechanical and thermal loading, and effective stress-strain response due to progressive ply failure under mechanical loading of thick section composites. Using a specified mechanical load, LAM3D simulates first ply to last ply failure, calculates effective laminate properties and ply-level stresses and strains after each failure, and determines the safety factor, critical mode, and critical ply of the laminate.

The effective property and strength predictions of the LAM3D code for many composite laminates were validated against theoretical predictions and experimental results. While LAM3D provided valuable insight into laminate response due to progressive failure, the code did not support nonlinear ply properties. Nonlinear material response is more accurate than linear for the transverse and shear directions of composite materials. In order to address this issue, Bogetti et al. [2] created the nonlinear, progressive failure code LAM3DNLP. In this code, nonlinear constitutive relationships for all six principle directions were modeled using RambergOsgood parameters. Similar to LAM3D, the "smearing-unsmearing" approach and progressive ply failure methodology are used by LAM3DNLP to simulate the material point response of a laminate. Both LAM3D and LAM3DNLP were independent analytical programs developed using FORTRAN and were not coupled to finite element analysis. The desire to use these material point models in the design of large composite structures led to the development of LAMPAT and LAMPATNL.

The LAM3DNLP analytical code was ranked third out of 19 participants in the first World Wide Failure Exercise (WWFE-I) [33]. This exercise was an assessment of the state-of-the-art of composite failure predictions. LAM3DNLP was used to predict progressive ply failure in composite laminates for 14 loading cases. 
These failure predictions were compared to experimental results and rated against the failure predictions of the other participants [33-35]. The 14 loading cases provided an experimental validation of the LAM3DNLP failure predictions. The first exercise focused on failure response of laminates subjected to in-plane loading. The second exercise (WWFE-II) is currently in progress [36]. This exercise focuses on out-ofplane failure predictions and, similar to the first exercise, will provide additional validation for LAM3DNLP.

LAMPAT was created by Bogetti et al. [4] as a way of using the "smearing-unsmearing" approach and progressive failure analysis of LAM3D with finite element software packages. LAMPAT was designed as a pre- and postprocessor that created effective composite laminate properties and evaluated the failure of laminates based on element stress and strain. Originally developed to interface with PATRAN, it was later expanded to accommodate ANSYS, ABAQUS, DYNA3D, and NIKE3D. As a preprocessor, LAMPAT uses the orthotropic, linear lamina properties and the architecture of the laminate to create a set of "smeared" material properties that represent the effective response of the laminate. Once the composite structure with effective properties is evaluated, the postprocessor takes global stresses and strains and creates "unsmeared" ply stresses and strains. The stress and strain allowables of the lamina are then used to analyze failures within the composite to provide safety factor, critical mode, and critical ply data. This process is shown in Figure 2.1. 


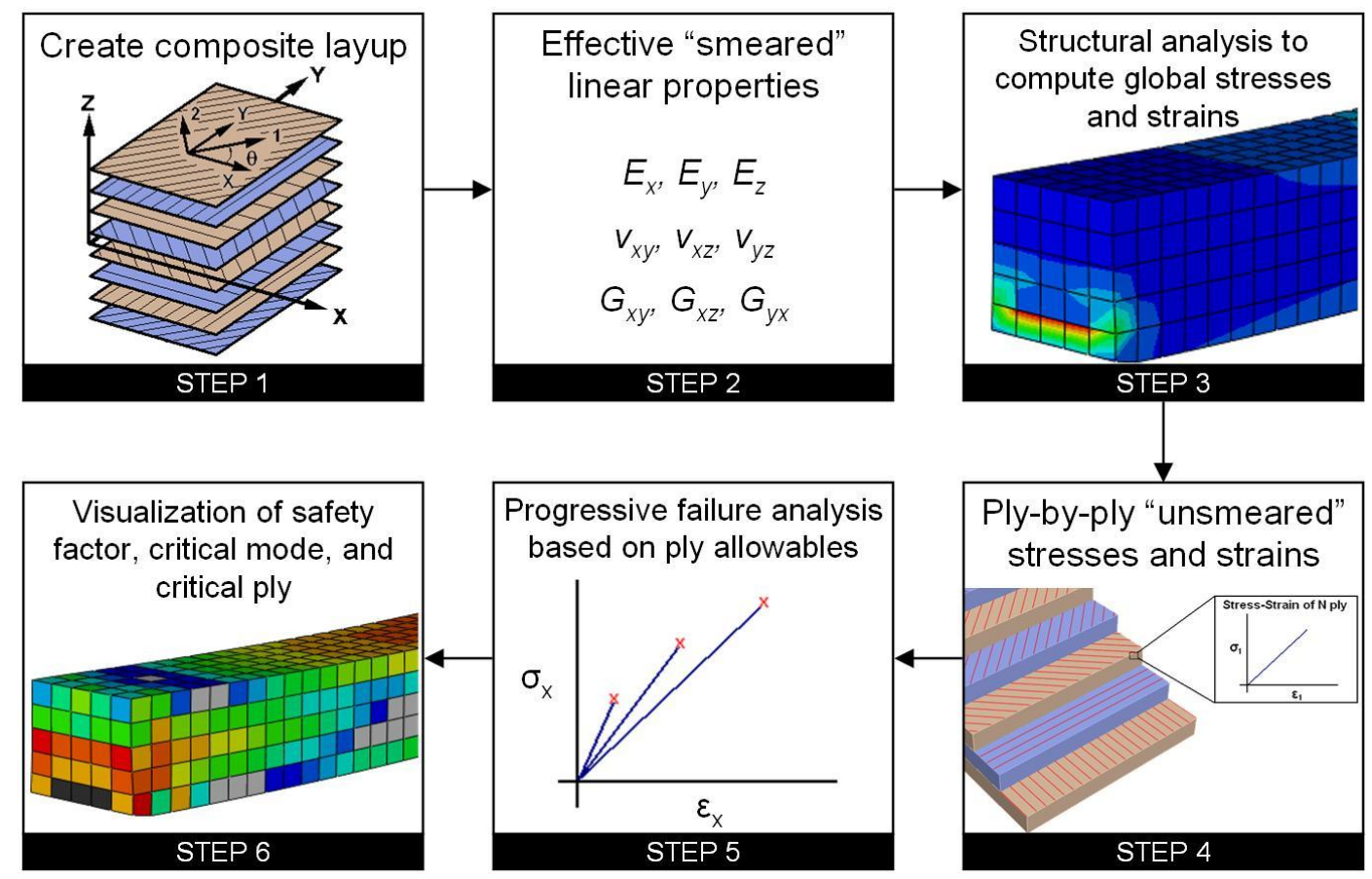

\section{Figure 2.1 LAMPAT process methodology}

Implementing LAM3D into finite element software using LAMPAT demonstrated the power of this approach when designing large scale, thick section composite structures. To more accurately capture the response of composite materials, the material nonlinearity features of LAM3DNLP were needed. In LAMPAT, failure analysis occurred after the stress and strain profile of the structure was complete. This did not allow for the redistribution of load through the structure after ply failure had occurred. In order to address this issue, Powers et al. [4] developed the nonlinear, progressive failure code LAMPATNL. While LAMPAT was developed as a pre- and post-processing tool, the nonlinear material behavior and progressive failure analysis of LAMPATNL required closer integration to the finite element package. This was accomplished by creating a coupled analysis using a user-defined material in 
ABAQUS. Limited validation and demonstration of the LAMPATNL code was provided by Powers in [4]. A full validation and development of a design methodology using LAMPATNL is documented in Chapters 3 and 4.

\subsection{Laminated media methodology}

The three dimensional laminated media model that is the basis of all the "LAM" codes was created from an analytical model developed by Chou et al. [37]. The model is used to determine the homogenized, or "smeared", engineering constants of a multilayered laminate (see Figure 2.2). Significant features of the theory are discussed by Bogetti et al. in [1-3] and an overview is given in this section.

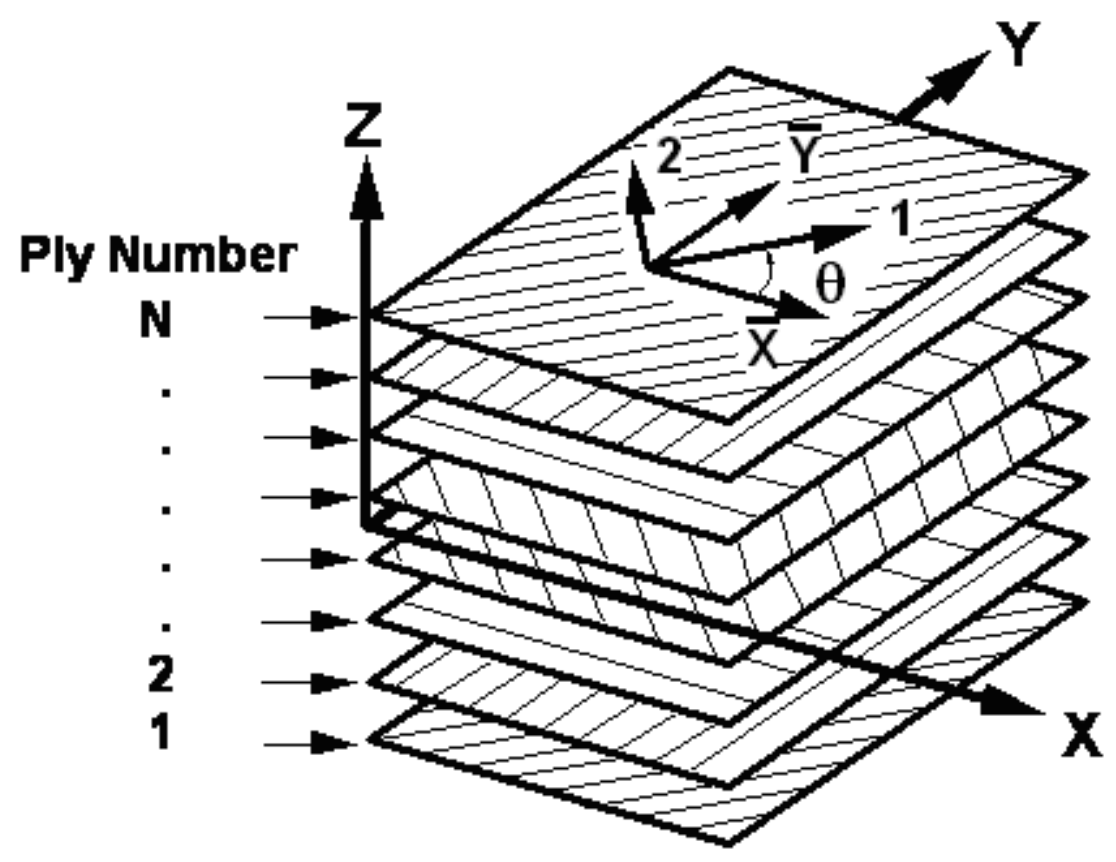

Figure 2.2 Laminate configuration [1] 
Equation 2.1 represents the effective stress/strain constitutive relationship for the laminate:

$$
\begin{gathered}
\left.\left\lfloor\bar{\sigma}^{*}\right]=\left[\bar{C}_{i j}^{*}\right\rfloor \bar{\varepsilon}^{*}\right\rfloor \\
\text { where }\left[\bar{\sigma}^{*}\right]=\left[\bar{\sigma}_{1}^{*} \bar{\sigma}_{2}^{*} \bar{\sigma}_{3}^{*} \bar{\sigma}_{4}^{*} \bar{\sigma}_{5}^{*} \bar{\sigma}_{6}^{*}\right]^{T} \\
{\left[\bar{\varepsilon}^{*}\right]=\left[\bar{\varepsilon}_{1}^{*} \bar{\varepsilon}_{2}^{*} \bar{\varepsilon}_{3}^{*} \bar{\varepsilon}_{4}^{*} \bar{\varepsilon}_{5}^{*} \bar{\varepsilon}_{6}^{*}\right]^{T}} \\
{\left[\bar{C}_{i j}^{*}\right]=\left[\begin{array}{llllll}
\bar{C}_{11}^{*} & \bar{C}_{12}^{*} & \bar{C}_{13}^{*} & \bar{C}_{14}^{*} & \bar{C}_{15}^{*} & \bar{C}_{16}^{*} \\
\bar{C}_{21}^{*} & \bar{C}_{22}^{*} & \bar{C}_{23}^{*} & \bar{C}_{24}^{*} & \bar{C}_{25}^{*} & \bar{C}_{26}^{*} \\
\bar{C}_{31}^{*} & \bar{C}_{32}^{*} & \bar{C}_{33}^{*} & \bar{C}_{34}^{*} & \bar{C}_{35}^{*} & \bar{C}_{36}^{*} \\
\bar{C}_{41}^{*} & \bar{C}_{42}^{*} & \bar{C}_{43}^{*} & \bar{C}_{44}^{*} & \bar{C}_{45}^{*} & \bar{C}_{46}^{*} \\
\bar{C}_{51}^{*} & \bar{C}_{52}^{*} & \bar{C}_{53}^{*} & \bar{C}_{54}^{*} & \bar{C}_{55}^{*} & \bar{C}_{56}^{*} \\
\bar{C}_{61}^{*} & \bar{C}_{62}^{*} & \bar{C}_{63}^{*} & \bar{C}_{64}^{*} & \bar{C}_{65}^{*} & \bar{C}_{66}^{*}
\end{array}\right]}
\end{gathered}
$$

The barred notation is used to identify that it is in the coordinate system of the laminate and the star $\left(^{*}\right)$ signifies that it is an average value. The relationship between the global coordinates (X, Y, Z), laminate coordinates $(\bar{X}, \bar{Y}, \bar{Z})$, and ply coordinates $(1,2,3)$ is shown in Figure 2.3. 

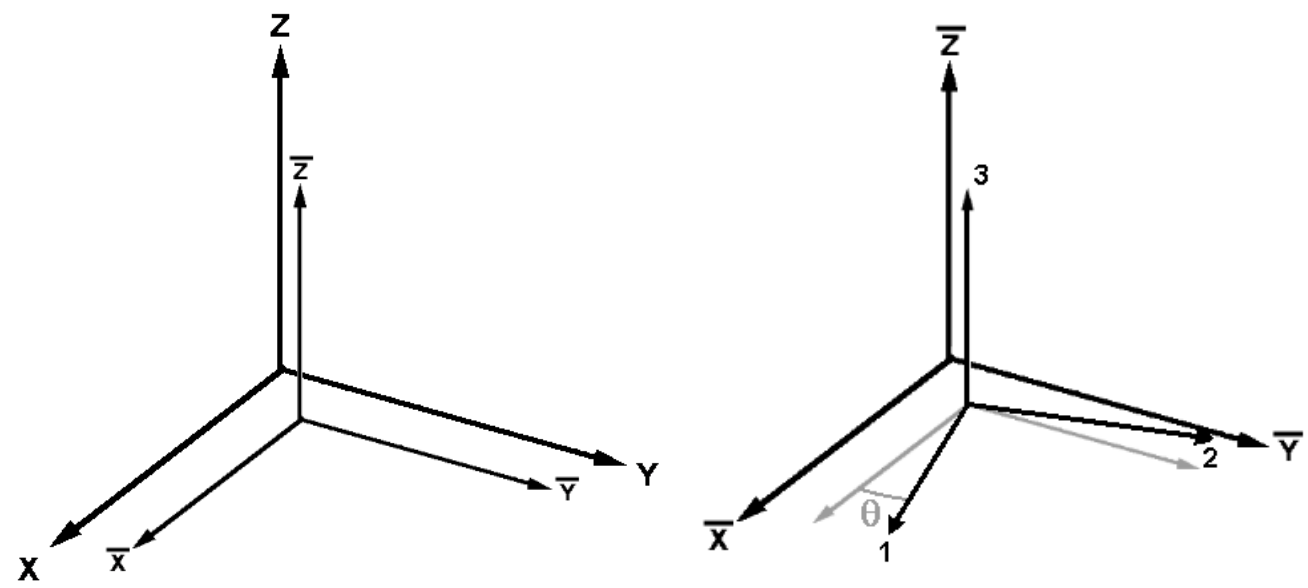

Figure 2.3 Relation of global coordinates to laminate and ply coordinates

Chou et al. [37] derived a homogeneous representation for the laminate.

The coefficients of the laminate stiffness matrix, $\bar{C}_{i j}^{*}$, are given in Equations 2.5 to 2.7.

$$
\begin{gathered}
\overline{C_{i j}^{*}}=\sum_{k=1}^{N} V^{k}\left\lfloor\overline{C_{i j}^{k}}-\frac{\overline{C_{13}^{k}} \overline{C_{3 j}^{k}}}{\overline{C_{33}^{k}}}+\frac{\overline{C_{i 3}^{k}} \sum_{\ell=1}^{N} \frac{V^{\ell} \overline{C_{3 j}^{k}}}{\overline{C_{33}^{k}}}}{\left.\overline{C_{33}^{k}} \sum_{\ell=1}^{N} \frac{V^{\ell} \overline{C_{i j}^{k}}}{\overline{C_{33}^{k}}}\right\rfloor \text { for }(\mathrm{i}, \mathrm{j}=1,2,3,6)}\right. \\
\overline{C_{i j}^{*}}=0 \text { and } \overline{C_{j i}^{*}}=0 \text { for }(\mathrm{i}=1,2,3,6 ; \mathrm{j}=4,5) \\
\overline{C_{i j}^{*}}=\left\lfloor\frac{\sum_{k=1}^{N} \frac{V^{k}}{\Delta_{k}} \overline{C_{i j}^{k}}}{\sum_{k=1}^{N} \sum_{\ell=1}^{N} \frac{V^{k} V^{\ell}}{\Delta_{k} \Delta_{\ell}}\left(\overline{C_{44}^{k}} \overline{C_{55}^{k}}-\overline{C_{45}^{k}} \overline{C_{54}^{k}}\right)}\right\rfloor \text { for }(\mathrm{i}, \mathrm{j}=4,5)
\end{gathered}
$$

Where the $k$ term refers to the $k^{\text {th }}$ ply of the laminate, $V^{k}$ is the ratio of the original thickness of the $k^{\text {th }}$ ply over the original thickness of the entire laminate, and:

$$
\Delta_{k}=\left|\begin{array}{l}
\overline{C_{44}^{k}} \overline{C_{45}^{k}} \\
\overline{C_{54}^{k}} \\
\overline{C_{55}^{k}}
\end{array}\right|=\overline{C_{44}^{k}} \overline{C_{55}^{k}}-\overline{C_{45}^{k}} \overline{C_{54}^{k}}
$$


The assumption is made that the applied mechanical loading acting on the laminate $\left[\bar{\sigma}^{*}\right]$ is known, not varying through the thickness, and represents the "average" or "effective" stress. The associated "effective" or "smeared" laminate strains $\left[\bar{\varepsilon}^{*}\right]$ can be obtained directly from the inversion of Equation 2.1.

In determining the individual ply-level stresses and strains, two major assumptions are used. These assumptions are that the in-plane ply strains are equal to the effective strains of the laminate and that the out-of-plane ply stresses are uniform through the thickness and equal to the effective stresses in the laminate. The assumptions are shown in Equations 2.9 and 2.10, respectively.

$$
\begin{aligned}
& \overline{\varepsilon_{i}^{k}}=\overline{\varepsilon_{i}^{*}} \text { for }(\mathrm{i}=1,2,6 \text { and } \mathrm{k}=1,2, \ldots, \mathrm{N}) \\
& \overline{\sigma_{i}^{k}}=\overline{\sigma_{i}^{*}} \text { for }(\mathrm{i}=3,4,5 \text { and } \mathrm{k}=1,2, \ldots, \mathrm{N})
\end{aligned}
$$

The expression derived by Sun and Liao [38] is used to determine the remaining strain components and is given in Equation 2.11.

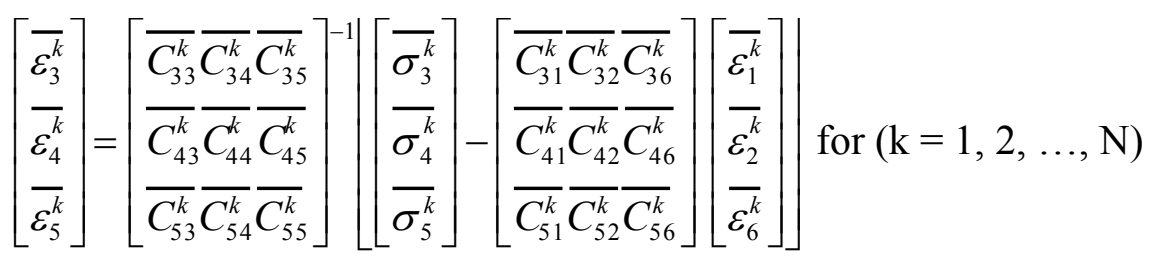

The remaining stress components are easily calculated using the relation in Equation 2.12. 


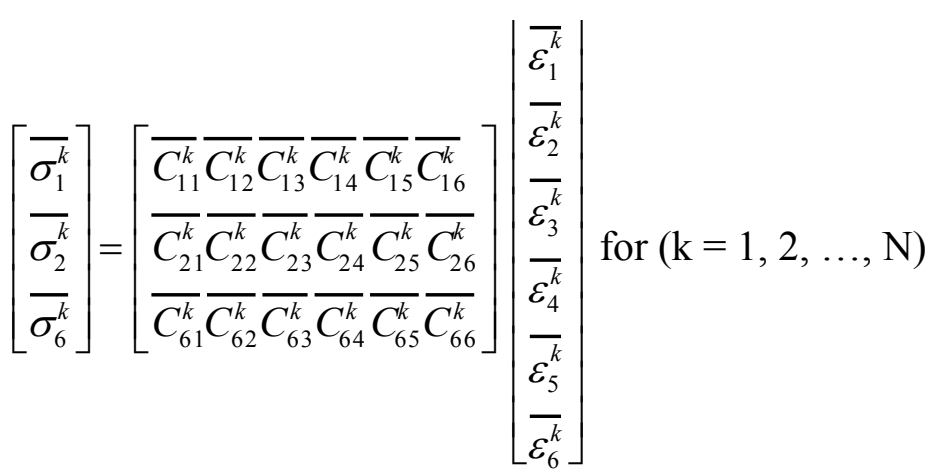

\subsection{Nonlinear constitutive relationships}

Ply-level material nonlinearity is represented by using the RambergOsgood equation. Three dimensional nonlinearity is accommodated in all principal material directions. The longitudinal, transverse, through thickness, out-of-plane shear, and in-plane shear directions can all have distinct nonlinear behavior. The Ramberg-Osgood equation, shown below, defines stress as a function of strain and three parameters.

$$
\sigma=\frac{E_{0} \varepsilon}{\left(1+\left(\frac{E_{0} \varepsilon}{\sigma_{0}}\right)^{n}\right)^{\frac{1}{n}}}
$$

where $\mathrm{E}_{0}$ is the initial modulus, $\sigma_{0}$ is the stress asymptote, and $n$ is the shape factor of the nonlinear stress-strain curve. The effect that these parameters have on the stressstrain response is shown in Figure 2.4. 


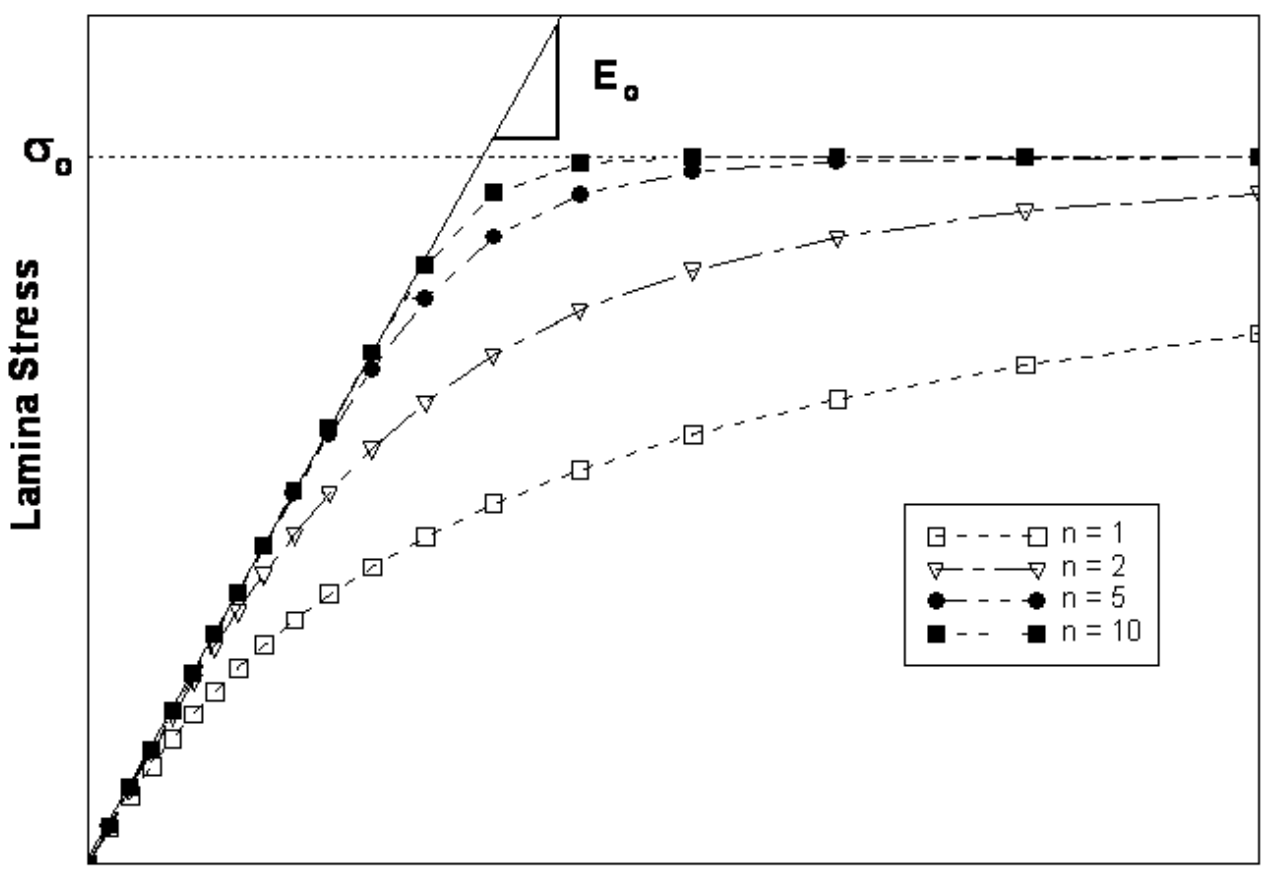

Lamina Strain

Figure 2.4 Nonlinear stress-strain response

For computational considerations, it is desired to define the instantaneous or tangent lamina stiffness as a continuous function of strain. Taking the derivative of Equation 2.13 with respect to strain, the following expression is obtained:

$$
E_{t}=\frac{d \sigma}{d \varepsilon}=\frac{E_{o}}{\left(1+\left(\frac{E_{o} \varepsilon}{\sigma_{o}}\right)^{n}\right)^{1+\frac{1}{n}}}
$$

where $E_{t}$ is the instantaneous or tangent lamina stiffness modulus expressed explicitly in terms of strain and the three Ramberg-Osgood parameters. 


\subsection{Incremental approach to predicting nonlinear laminate response}

The analytical code LAM3DNLP models the nonlinear laminate response as a set of piecewise linear increments. It predicts laminate stress-strain response using a specified load increment up until failure. The incremental approach starts with the initial stiffness as determined by the smeared properties of the laminate. At the end of each load increment, the stress state from the laminate is unsmeared for plylevel stresses and strains, failure analysis occurs, the nonlinear constitutive relationships are updated to determine the stiffness in each principal ply direction, and effective properties used for the application of the next load increment are obtained by smearing the laminate. Figure 2.5 provides a representation of the incremental loading strategy for an arbitrary laminate.

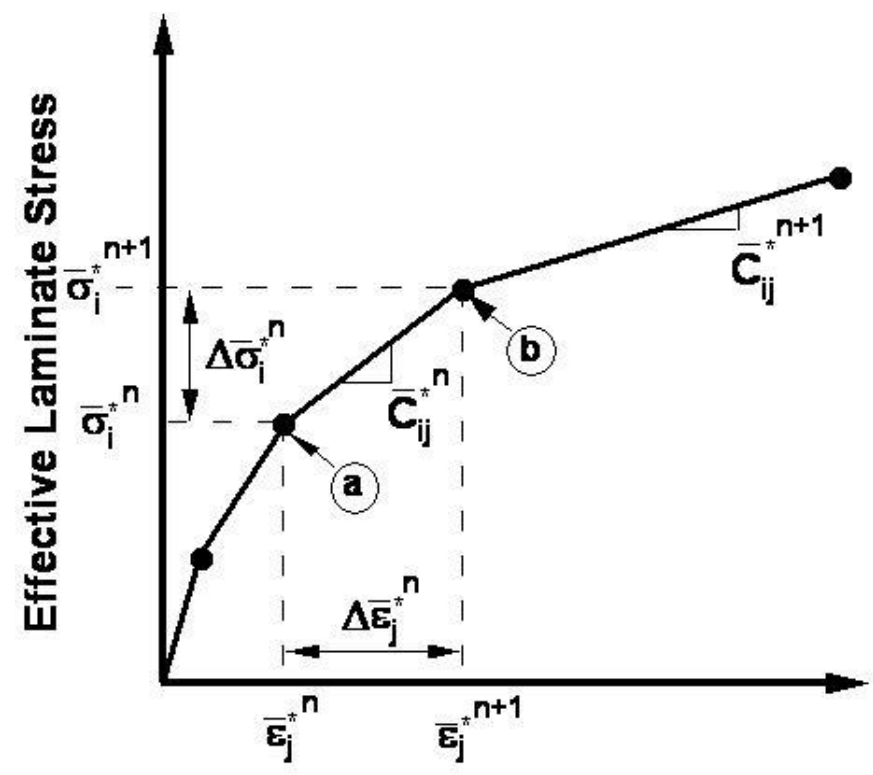

Effective Laminate Strain

Figure 2.5 Incremental laminate loading methodology [2] 
Assume that at point (a), corresponding to the end of the $n^{\text {th }}$ stress increment, the strain and stress state of the laminate is known $\left(\left[\bar{\varepsilon}_{j}^{*_{n}}\right],\left[\bar{\sigma}_{i}^{*_{n}}\right]\right)$. From this point, the objective is to determine the strain and stress state at point ( $b$ ) or $\left(\left[\bar{\varepsilon}_{j}^{* n+1}\right],\left[\bar{\sigma}_{i}^{* n+1}\right]\right)$. The effective laminate stiffness matrix at the end of stress increment $n,\left[\bar{C}_{i j}^{* n}\right]$, is computed from an incremental form of the laminated media model constitutive relation, Equation 2.1. With the increment in load defined, $\left[\Delta \bar{\sigma}_{i}^{*_{n}}\right]$, the corresponding increment in laminate strain, $\left[\Delta \bar{\varepsilon}_{j}^{*_{n}}\right]$, is calculated from an inverse form of Equation 2.1:

$$
\left[\Delta \bar{\varepsilon}_{j}^{*_{n}}\right]=\left[\bar{C}_{i j}^{*_{n}}\right]^{-1}\left[\Delta \bar{\sigma}_{i}^{*_{n}}\right]
$$

Individual ply stress and strain increments are calculated according to the equations presented previously. A cumulative summation is maintained to track the total stress-and-strain levels in each ply of the laminate. The tangent modulus values for each ply and material direction are calculated according to Equation 2.14 and used in the determination of the laminate stiffness matrix for the next laminate stress increment calculation. The entire nonlinear response for the laminate is obtained by the cumulative sum of all stress and strain increments throughout the entire stress loading history.

Figure 2.6 illustrates the importance of the incremental approach when modeling nonlinear material behavior. This figure shows the modeled lamina stressstrain response with three different load increments applied. The solid line represents the exact response that is the analytical solution of the Ramberg-Osgood equation. The larger load increment results in a response that is stiffer than the desired nonlinear response. As the increment size decreases, the model converges towards the exact 
response. It is therefore important to select a sufficiently small load increment when simulating material nonlinearity.

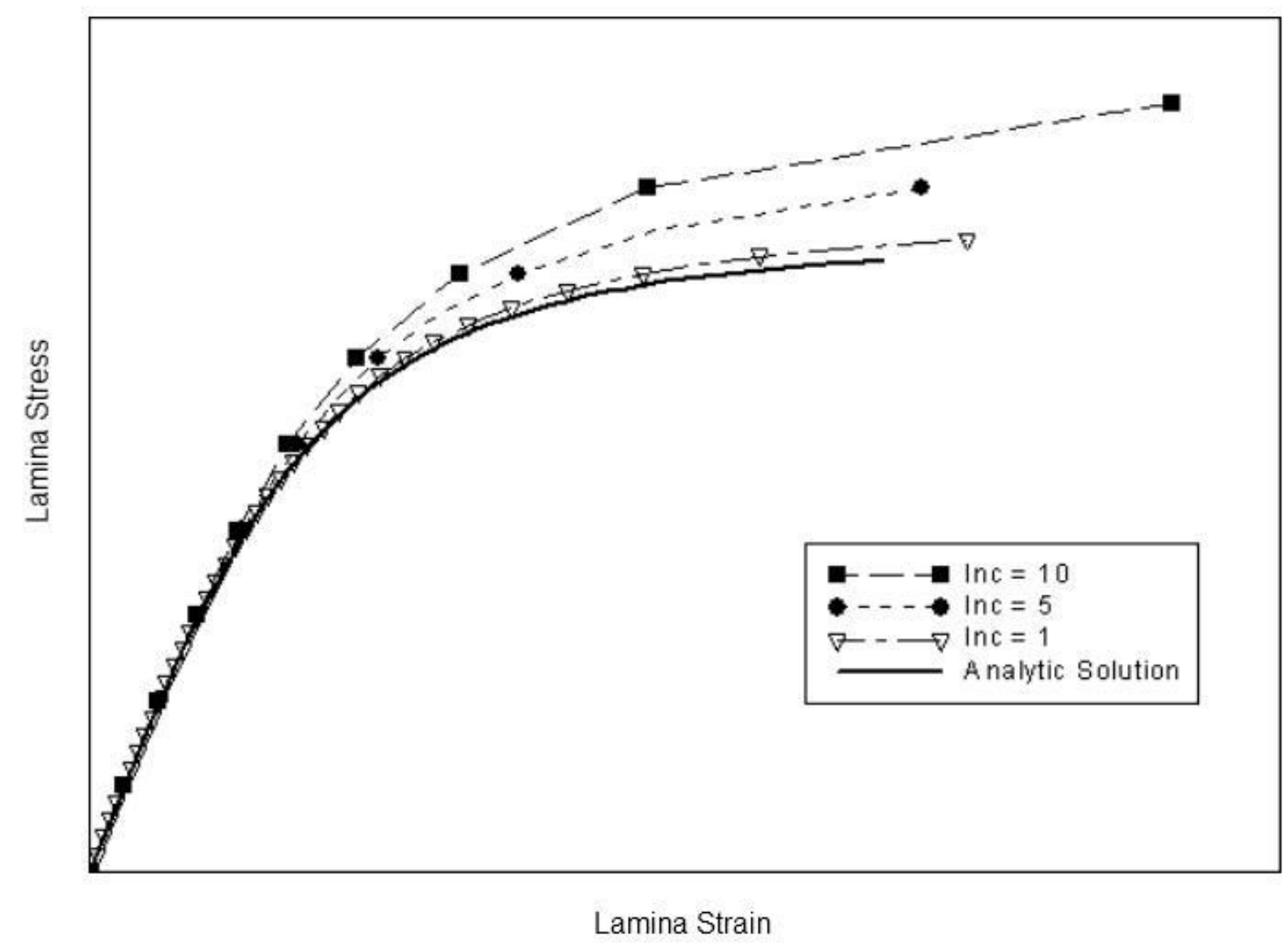

Figure 2.6 Effect of increment size on nonlinear stress-strain response

\subsection{Progressive ply failure methodology}

Along with ply-level nonlinearity, progressive ply failure will also influence the effective laminate response to load. Using the stresses and strains of individual plies, failure predictions and post-failure behavior are modeled for the 
laminate. Failure criteria that have been incorporated into the "LAM" codes include Maximum Strain, Maximum Stress, Hydrostatic Pressure Adjusted Maximum Stress, Tsai-Wu, Christensen, Feng, Hashin, and Von Mises.

The maximum strain failure criterion is commonly used for analysis using the "LAM" codes $[35,4]$. This criterion compares the current strains of each ply $\left(\varepsilon_{1}\right.$, $\left.\varepsilon_{2}, \varepsilon_{3}, \varepsilon_{4}, \varepsilon_{5}, \varepsilon_{6}\right)$ to the maximum strain allowables (Y1T, Y1C, Y2T, Y2C, Y3T, Y3C, Y23, Y13, Y12) in each principal direction and assumes a ply fails if these strain allowables are exceeded. The relations of the strains to allowables are documented in Equations 2.16 through 2.24 .

If $\varepsilon_{1}>0$ and if $\varepsilon_{1}>\mathrm{Y} 1 \mathrm{~T}$, then the failure mode is fiber tension 2.16

If $\varepsilon_{1}<0$ and if $\left|\varepsilon_{1}\right|>Y 1 C$, then the failure mode is fiber compression

If $\varepsilon_{2}>0$ and if $\varepsilon_{2}>\mathrm{Y} 2 \mathrm{~T}$, then the failure mode is matrix tension

If $\varepsilon_{2}<0$ and if $\left|\varepsilon_{2}\right|>\mathrm{Y} 2 \mathrm{C}$, then the failure mode is matrix compression

If $\varepsilon_{3}>0$ and if $\varepsilon_{3}>Y 3 T$, then the failure mode is matrix tension

If $\varepsilon_{3}<0$ and if $\left|\varepsilon_{3}\right|>Y 3 C$, then the failure mode is matrix compression

If $\left|\varepsilon_{4}\right|>Y 23$, then the failure mode is interlaminar shear

If $\left|\varepsilon_{5}\right|>Y 13$, then the failure mode is interlaminar shear

If $\left|\varepsilon_{6}\right|>Y 12$, then the failure mode is in-plane shear

The ply discount method is used by the "LAM" codes to reduce the material properties of failed plies. In this method, the material stiffness in the direction of failure is discounted and the Poisson's ratios associated with that direction are adjusted. For example, if a ply fails in the 2 direction, the elastic modulus of that ply in the 2 direction is set to $1 \%$ of the current value and this direction is decoupled 
by setting $v_{12}$ and $v_{23}$ to zero. Decoupling the ply by zeroing the Poisson's ratios prevents unrealistic ply strains caused by Poisson's effect in the failed ply. Table 2.1 lists which properties are modified for the six different modes of failure.

Table 2.1 Failure mode and property modification

\begin{tabular}{|c|c|}
\hline Failure Mode & Property Modification \\
\hline 1 & $\mathrm{E}_{1}=0.01^{\star} \mathrm{E}_{1}, v_{12}=v_{13}=0$ \\
\hline 2 & $\mathrm{E}_{2}=0.01^{\star} \mathrm{E}_{2}, v_{12}=v_{23}=0$ \\
\hline 3 & $\mathrm{E}_{3}=0.01^{\star} \mathrm{E}_{3}, v_{13}=v_{23}=0$ \\
\hline 12 & $\mathrm{G}_{12}=0.01^{*} \mathrm{G}_{12}$ \\
\hline 13 & $\mathrm{G}_{13}=0.01^{*} \mathrm{G}_{13}$ \\
\hline 23 & $\mathrm{G}_{23}=0.01^{*} \mathrm{G}_{23}$ \\
\hline
\end{tabular}

Bogetti describes the progressive failure procedure of the analytical model in [2]. As the laminate is loaded and laminate strains develop, the individual ply strains are monitored. When ply failure is predicted in any ply, according to the maximum strain failure criteria, the incremental loading to that point is stopped and the entire laminate stress vs. strain response is recorded. The modulus associated with the particular mode of failure in the failed ply is then reduced according to property modifications in Table 2.1 and the incremental loading strategy is repeated from the beginning (all stresses and strains are set to zero). The loading procedure is continued until the next failure in a ply is detected. The corresponding modulus value is again discounted, the laminate response is recorded, and the procedure is repeated. This progressive ply failure response is repeated until final failure is determined, which is assumed when the laminate looses sufficient stiffness such that it cannot carry any load 
without undergoing an arbitrarily excessive amount of deformation (greater than 10\% strain).

This progressive failure procedure is effective in capturing the nonlinear stress-strain response of the laminate, but modifications to this approach are needed for successful implementation into FEA software. These modifications will be discussed in the next chapter. 


\section{Chapter 3}

\section{IMPLEMENTATION}

LAM3DNLP was implemented into finite element software by Powers et al. with the creation of LAMPATNL [4]. LAMPATNL is a user material subroutine (UMAT) used to incorporate the "smearing-unsmearing" approach, nonlinear anisotropy, and progressive failure analysis into ABAQUS. The subroutine UMAT is used to define the mechanical constitutive behavior of a material and is called at all material calculation points of the element. LAMPATNL treats each material calculation point within the finite element model as though it was a laminate in

\section{LAM3DNLP.}

Several implications arise when converting the analytical code into a user material subroutine. The analytical code was designed to simulate a laminate as a material point under a prescribed load increment. While it is relatively straightforward to keep track of the nonlinear response and failure history of a single point, mapping this procedure for thousands of elements and material points can be complicated. In addition, there are certain constraints imposed by the finite element method to insure stability. The constraints are based on thermodynamic stability conditions. Changes to the material response and the key assumptions of the laminated media methodology are required. Powers [4] briefly describes these implications and changes, but an investigation into these issues is discussed below. 


\subsection{Theoretical consideration}

\subsubsection{Ply-level stress and strain calculations}

The two major assumptions of the theory used in the "LAM" codes are stated in Chapter 2. The first assumption is that the in-plane ply strains are equal to the effective strains of the laminate and is shown in Equation 3.1. The second assumption is that the out-of-plane stresses are uniform and equal to the effective stresses in the laminate and is expressed in Equation 3.2. In these equations, the $k$ term refers to the $k^{\text {th }}$ ply of the laminate.

$$
\begin{aligned}
& \overline{\varepsilon_{i}^{k}}=\overline{\varepsilon_{i}^{*}} \text { for }(\mathrm{i}=1,2,6 \text { and } \mathrm{k}=1,2, \ldots, \mathrm{N}) \\
& \overline{\sigma_{i}^{k}}=\overline{\sigma_{i}^{*}} \text { for }(\mathrm{i}=3,4,5 \text { and } \mathrm{k}=1,2, \ldots, \mathrm{N})
\end{aligned}
$$

All the remaining ply strains $(3,4$, and 5$)$ and ply stresses $(1,2$, and 6$)$ are determined by the expressions given by Sun and Liao [38], shown in Equations 3.3 and 3.4 , respectively.

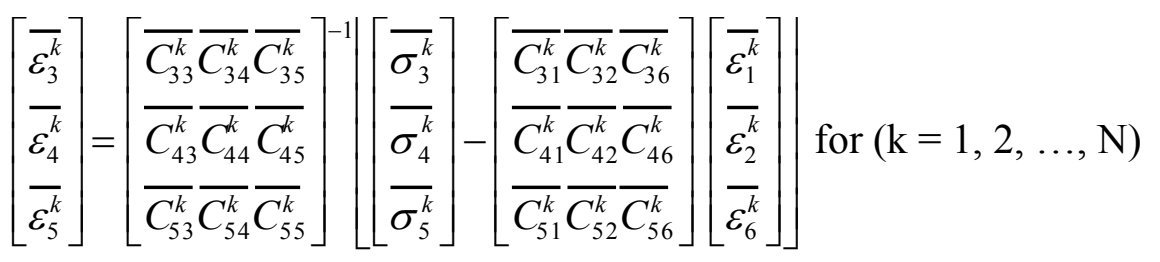

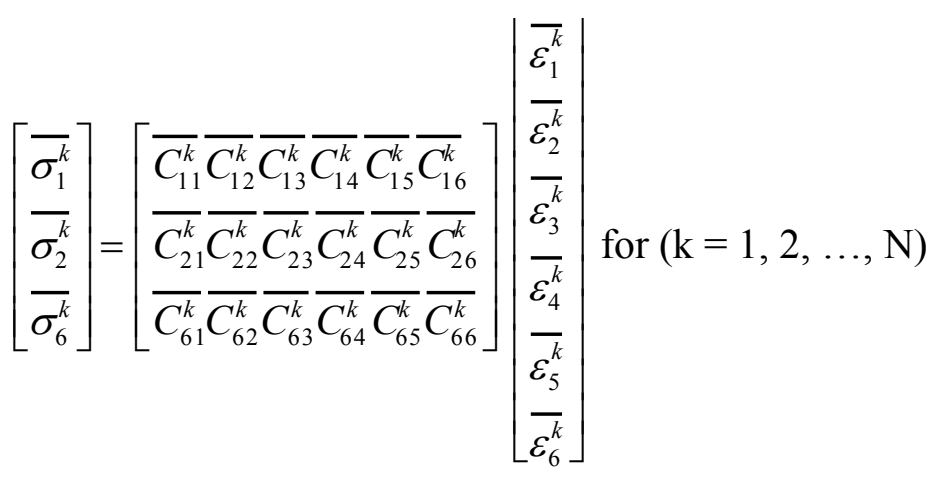


The ply stresses and strains are used to calculate the tangential stiffness properties for each ply. These ply-level properties are "smeared" to determine the effective stiffness of the laminate for that increment. Ply stresses and strains are also needed to apply ply-based failure criteria for progressive failure in the structure.

The procedure for calculating the ply-level stresses and strains for the nonlinear analytical code is outlined in Figure 3.1. In LAM3DNLP, the three dimensional load increment for the laminate, in the form $\left(\sigma_{x}, \sigma_{y}, \sigma_{z}, \sigma_{x y}, \sigma_{x z}, \sigma_{y z}\right)$, is input into the program. After initializing laminate strain, ply strains, and ply stresses, the program calculates the ply-level tangential stiffness properties, laminate stiffness matrix, and ply-level stiffness matrices based upon the current ply strains. The laminate stiffness matrix and laminate load increment are then used to calculate the laminate strain increment. Using the assumption in Equation 3.1, the in-plane ply strain increment is set equal to the in-plane laminate strain increment. Similarly for the assumption in Equation 3.2, the out-of-plane ply stress increment is set equal to the out-of-plane laminate stress increment. The out-of-plane ply strain increment is calculated using the ply-level stiffness matrices, the in-plane laminate strain increment, and the out-of-plane laminate stress increment using Equation 3.3. The in-plane ply stress increment is calculated similarly using Equation 3.4. The increments for ply stress, ply strain, and laminate strain are used to update their respective values and the procedure is continued for the next load increment. This procedure demonstrates the direct implementation of the assumptions of Chou's theory when calculating the plylevel stress and strain components in LAM3DNLP. 


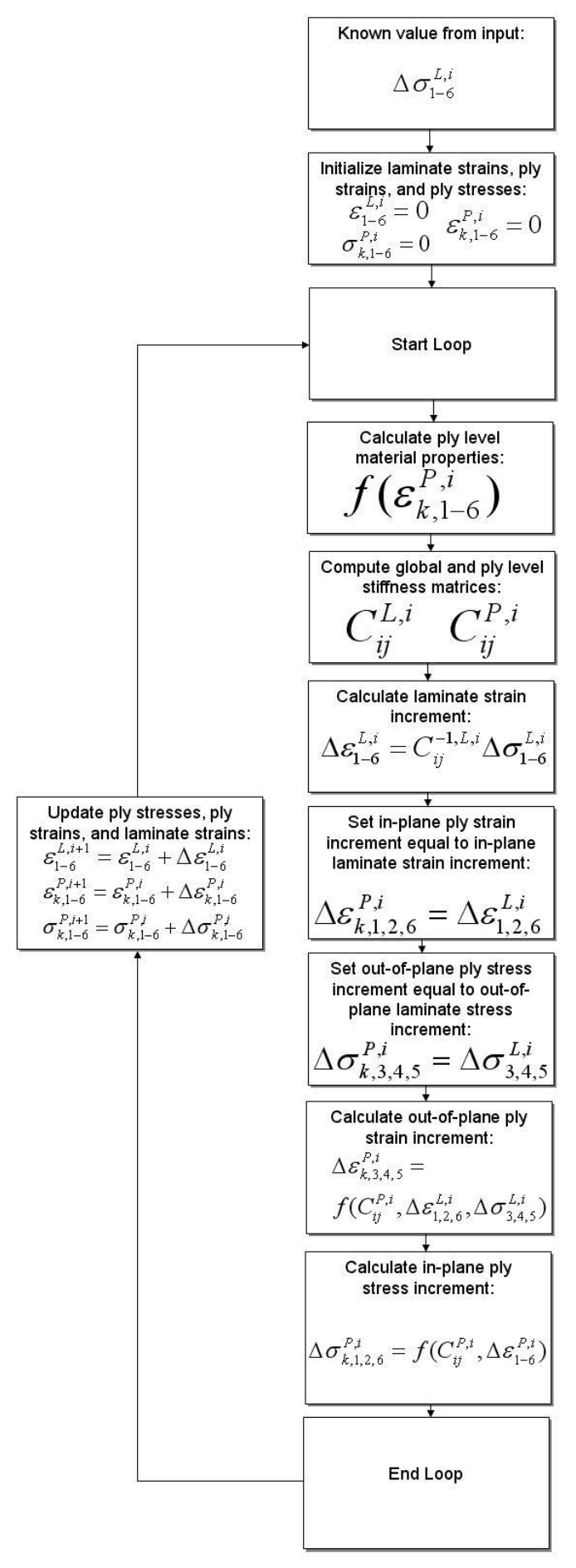

Figure 3.1 Ply stress and strain calculation procedure for LAM3DNLP 
Implementing LAM3DNLP into the LAMPATNL UMAT requires modifications to the procedure shown in Figure 3.1. In ABAQUS, the user material is required to output the stiffness matrix and update the stress tensor at the material calculation point at the end of the increment. These values must be determined from the current laminate stress, the current laminate strain, and the laminate strain increment. The procedure for calculating the stiffness matrix and stress tensor using ply-level stresses and strains in LAMPATNL is outlined in Figure 3.2.

The major difference between the LAMPATNL procedure and the LAM3DNLP procedure occurs when determining the tangential stiffness properties of the plies. In LAM3DNLP, the ply strains that are initially zero are recorded and updated throughout the procedure. These strains are used to calculate ply-level material properties and ply and laminate stiffness matrices. The LAMPATNL user material subroutine does not record the ply-level strain data from increment to increment due to the "smearing" approach in the code. LAMPATNL must calculate the ply-level material properties and ply and laminate stiffness matrices at the beginning of the increment without the ply-level strains. To accomplish this, the ply strains are set equal to the laminate strains as shown in Equation 3.5.

$$
\overline{\varepsilon_{i}^{k}}=\overline{\varepsilon_{i}^{*}} \text { for }(\mathrm{i}=1,2,3,4,5,6 \text { and } \mathrm{k}=1,2, \ldots, \mathrm{N})
$$

This enables LAMPATNL to calculate the ply and laminate stiffness matrices at the beginning of the increment, update the stress tensor for the increment, and determine the laminate stiffness matrix at the end of the increment. Ply stresses used for stress based failure criteria are determined analytically using the ply strains and Ramberg-Osgood relationship. 
The out-of-plane ply strains are taken directly from the laminate strains in LAMPATNL while the out-of-plane strains in LAM3DNLP are calculated using the stiffness matrix, out-of-plane laminate stresses, and in-plane laminate strains. These changes do not affect the calculated stress-strain response of laminate made of one material through the thickness or a laminate subjected to in-plane loading. The implication of this change for hybrid composites, with different material through the thickness, is a subject for future work. 


$$
\begin{aligned}
& \text { Known values from Abaqus: } \\
& \mathcal{E}_{1-6}^{L, i} \Delta \mathcal{E}_{1-6}^{L, i} \quad \sigma_{1-6}^{L, i}
\end{aligned}
$$

$$
\begin{aligned}
& \text { Set ply strains equal to } \\
& \text { laminate strains: } \\
& \mathcal{E}_{k, 1-6}^{P, i}=\varepsilon_{1-6}^{L, i}
\end{aligned}
$$

Calculate ply leve material properties:

$\boldsymbol{f}\left(\boldsymbol{\varepsilon}_{k, 1-6}^{P, i}\right)$

Compute global and ply level stiffness matrices:

$C_{i j}^{L, i} C_{i j}^{P, i}$

$\begin{gathered}\text { Calculate laminate } \\ \text { stress increment: }\end{gathered}$
$\Delta \sigma_{1-6}^{L, i}=C_{i j}^{L, i} \Delta \varepsilon_{1-6}^{L, i}$

Update laminate stress: $\sigma_{1-6}^{L, i+1}=\sigma_{1-6}^{L, i}+\Delta \sigma_{1-6}^{L, i}$

Update laminate strain

$\varepsilon_{1-6}^{L, i+1}=\varepsilon_{1-6}^{L, i}+\Delta \varepsilon_{1-6}^{L, i}$

Set ply strains equal to laminate strains:

$\varepsilon^{P, i+1}=\varepsilon_{1-6}^{L, i+1}$

$\mathcal{E}_{k, 1-6}=\mathcal{E}_{1-6}^{L, i+1}$

Calculate ply level

material properties:

$f\left(\varepsilon_{k, 1-6}^{P, i+1}\right)$

Compute global and ply level stiffness matrices:

$C_{i j}^{L, i+1} C_{i j}^{P, i+1}$

Output laminate stiffness matrix:

$C L, i+1$

ij

Calculate ply level stresses:

$\sigma_{k, 1-6}^{P, i+1}=f\left(\varepsilon_{k, 1-6}^{P, i+1}\right)$

Figure 3.2 Ply stress and strain calculation procedure for LAMPATNL 


\subsubsection{Poisson's ratio}

The response of the composite laminate is modeled using the RambergOsgood equation given in Equation 2.13. This stress-strain response is nonlinear and, when coupled with the incremental approach, becomes a piecewise linear response. At each load step, the instantaneous tangent moduli for the extensional and shear directions are calculated using Equation 2.14. Over each load step, the material is considered to be a linear, elastic material.

The numerical stability for calculations of a linear, elastic, orthotropic material requires the following five conditions to be met [39]:

$$
\begin{aligned}
E_{1}, E_{2}, E_{3}, G_{12}, G_{13}, G_{23}>0 \\
\left|v_{12}\right|<\left(\frac{E_{1}}{E_{2}}\right)^{1 / 2} \\
\left|v_{13}\right|<\left(\frac{E_{1}}{E_{3}}\right)^{1 / 2} \\
\left|v_{23}\right|<\left(\frac{E_{2}}{E_{3}}\right)^{1 / 2} \\
1-v_{12} v_{21}-v_{23} v_{32}-v_{13} v_{31}-2 v_{21} v_{32} v_{13}>0
\end{aligned}
$$

At the start of the analysis, these conditions are satisfied, but the incorporation of ply-level progressive failure can cause conditions 3.7, 3.8, and 3.9 to become unsatisfied. To correct this problem, the Poisson's ratio for each ply is continuously updated throughout the simulation. The current moduli are used in conjunction with the original minor Poisson's ratios $\left(v_{21}, v_{31}, v_{32}\right)$, which are stored at 
the beginning of the analysis, to calculate the updated Poisson's ratios and ensure stability. The reciprocity relationships used for this are:

$$
\begin{aligned}
& v_{23}^{c}=v_{32}^{i} \frac{E_{2}^{T}}{E_{3}^{T}} \\
& v_{13}^{c}=v_{31}^{i} \frac{E_{1}^{T}}{E_{3}^{T}} \\
& v_{12}^{c}=v_{21}^{i} \frac{E_{1}^{T}}{E_{2}^{T}}
\end{aligned}
$$

where $v^{c}$ is the current Poisson's ratio, $v^{i}$ is the initial Poisson's ratio, and $E^{T}$ is the tangential, or instantaneous, elastic modulus at the load increment. These adjustments ensure that the material stability of the UMAT is satisfied through the entire simulation. The LAMPATNL work of Powers et al. [4] contains these adjustments but does not specifically document them.

\subsection{Procedural considerations}

\subsubsection{Progressive failure adaption for FEA}

The LAM3DNLP approach was developed to analyze the material point response of a laminate. Modifications to the post failure behavior of the analysis are made when implementing the code in LAMPATNL. In LAM3DNLP, a specified load increment is applied to the laminate up until failure. Once failure occurs, the necessary adjustments to the failed plies, such as elastic modulus reduction and Poisson's ratio adjustment, are made and the analysis of the modified material point restarts from the first load increment. This process is illustrated in the flowchart shown in Figure 3.3. 


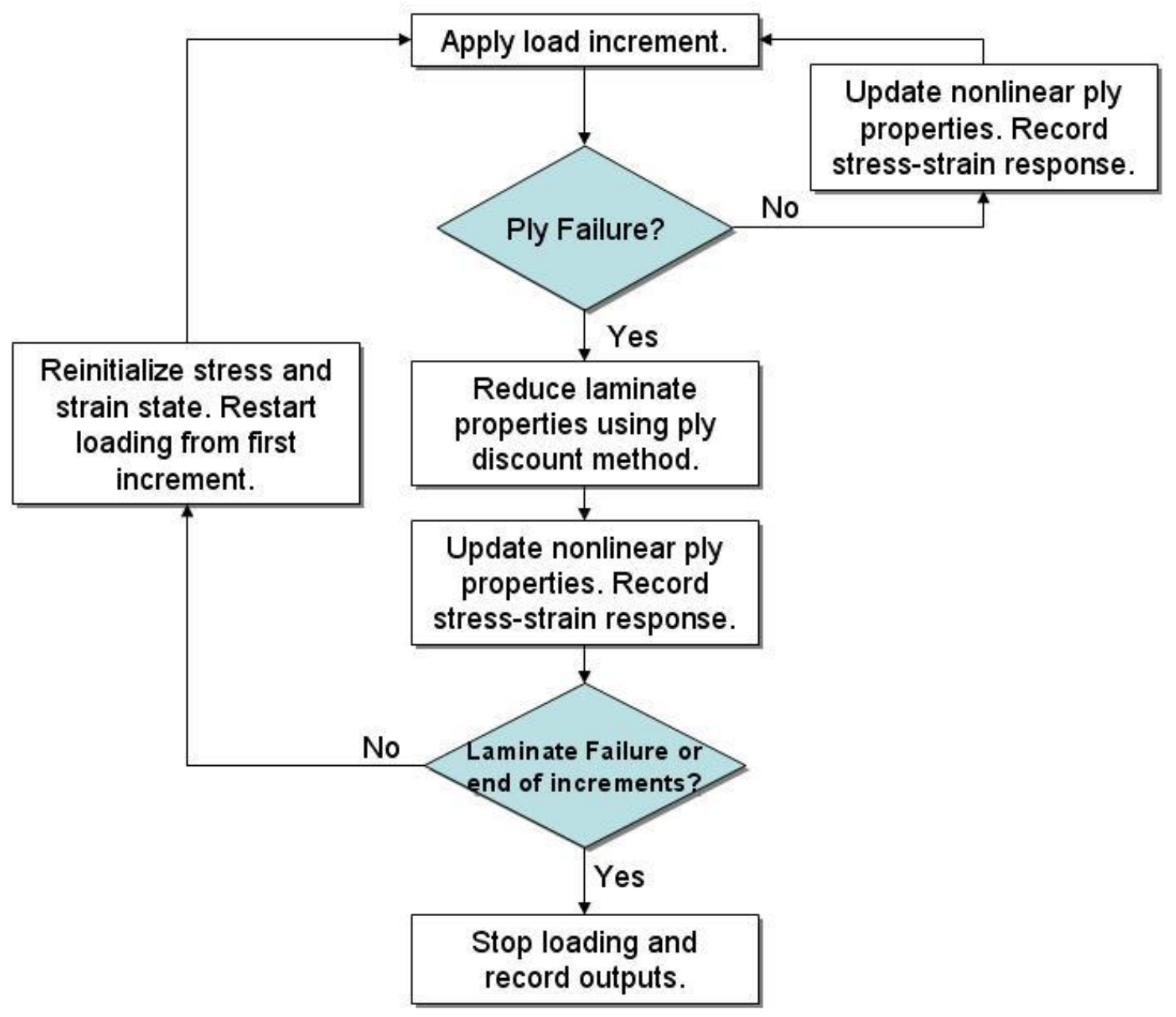

Figure 3.3 LAM3DNLP progressive failure procedure

The procedure creates multiple stress-strain curves and load "drops" between them, as shown in of Figure 3.4. This figure shows the stress-strain response and progressive failure for this quasi-isotropic layup of S2 Glass/Epoxy. First ply failure is represented in the first iteration. Ultimate or last ply failure is defined as the failure that occurs at the highest stress state. In this case, the third iteration is determined to be representative of last ply failure. 


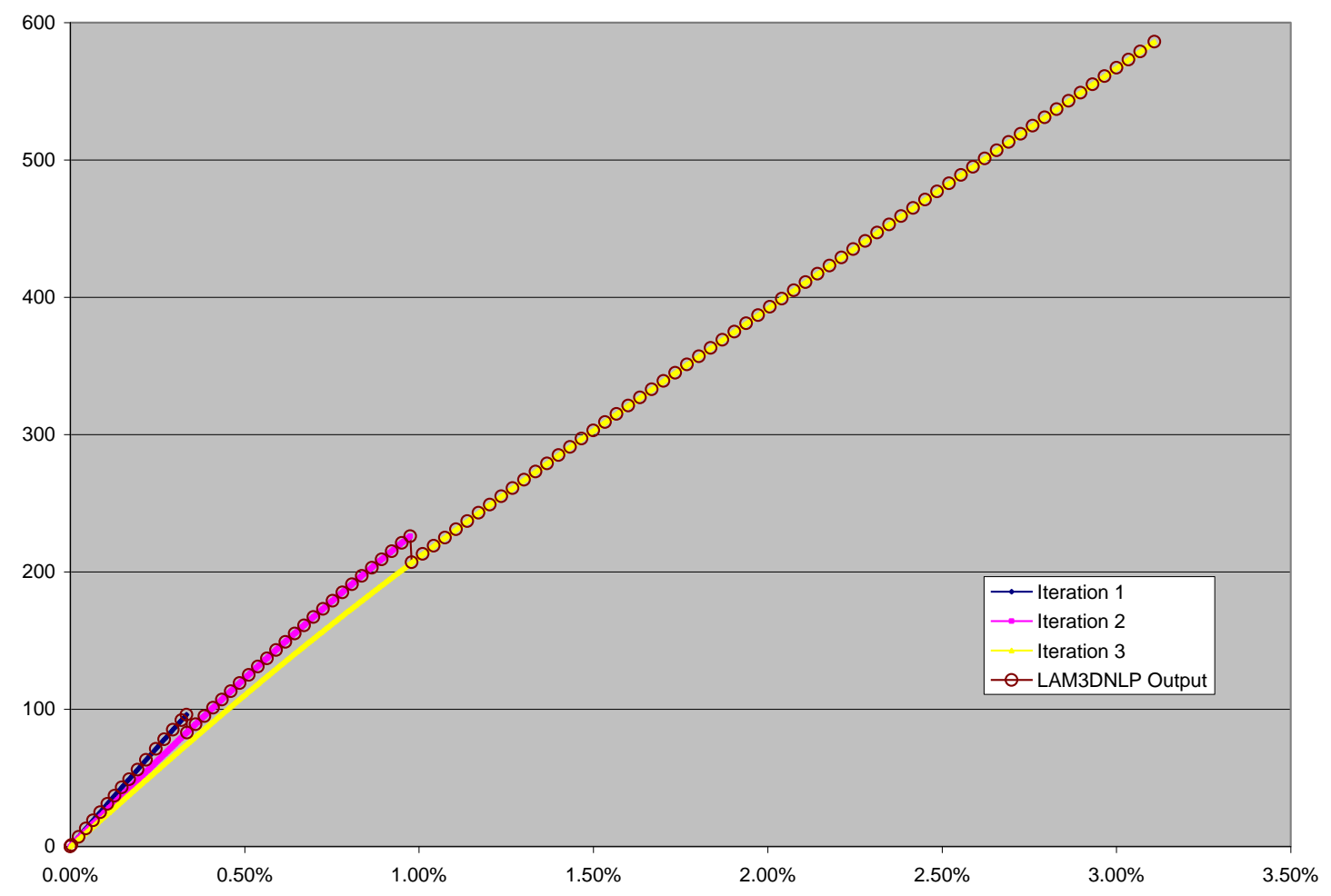

Figure 3.4 Stress-strain curves of $\left[0^{\circ} / 90^{\circ} \% 45^{\circ}\right]_{\mathrm{s}} \mathrm{S} 2$ Glass/Epoxy laminate

The effective stress-strain response of the laminate is the combination of the first three iterations. This output is represented as the circled LAM3DNLP stressstrain response in Figure 3.4. This iterative procedure is effective in capturing the immediate loss of load carrying capability that is seen in experimental stress-strain curves, but the process of restarting the analysis from the first increment is not practical for finite element applications.

Changing this approach when implementing LAMPATNL was done simply by continuing the analysis with reduced material properties at the current stress-strain state after failure has occurred. This change is reflected in the LAMPATNL flowchart of Figure 3.5. Comparing this procedure to LAM3DNLP 
procedure in Figure 3.3, the stress and strain state of the laminate is no longer reinitialized and laminate is not restarted from the first increment.

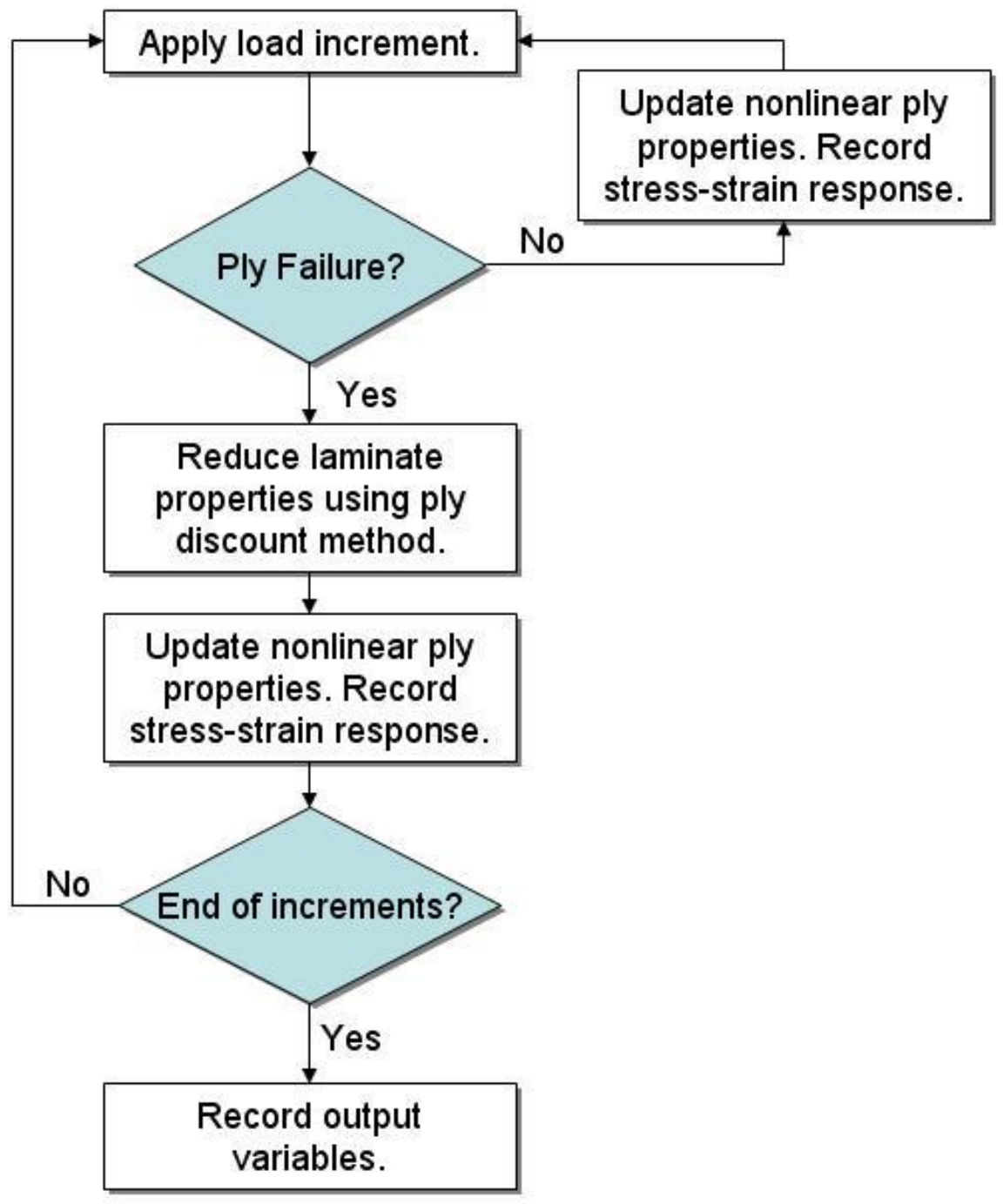

Figure 3.5 LAMPATNL progressive failure procedure 
The process changes the predicted stress-strain response to that shown as the UMAT curve of Figure 3.6. Instead of abrupt drops in load, ply failure causes a reduction in the overall modulus of the material. This can be seen in the slight deflection of the curve at $0.35 \%$ and $1 \%$ strain and the noticeable deflection at $3.2 \%$ strain. To facilitate a one-to-one validation of the UMAT and the analytical code, simple modifications to the underlying FORTRAN code of the original LAM3DNLP were made to incorporate this procedure.

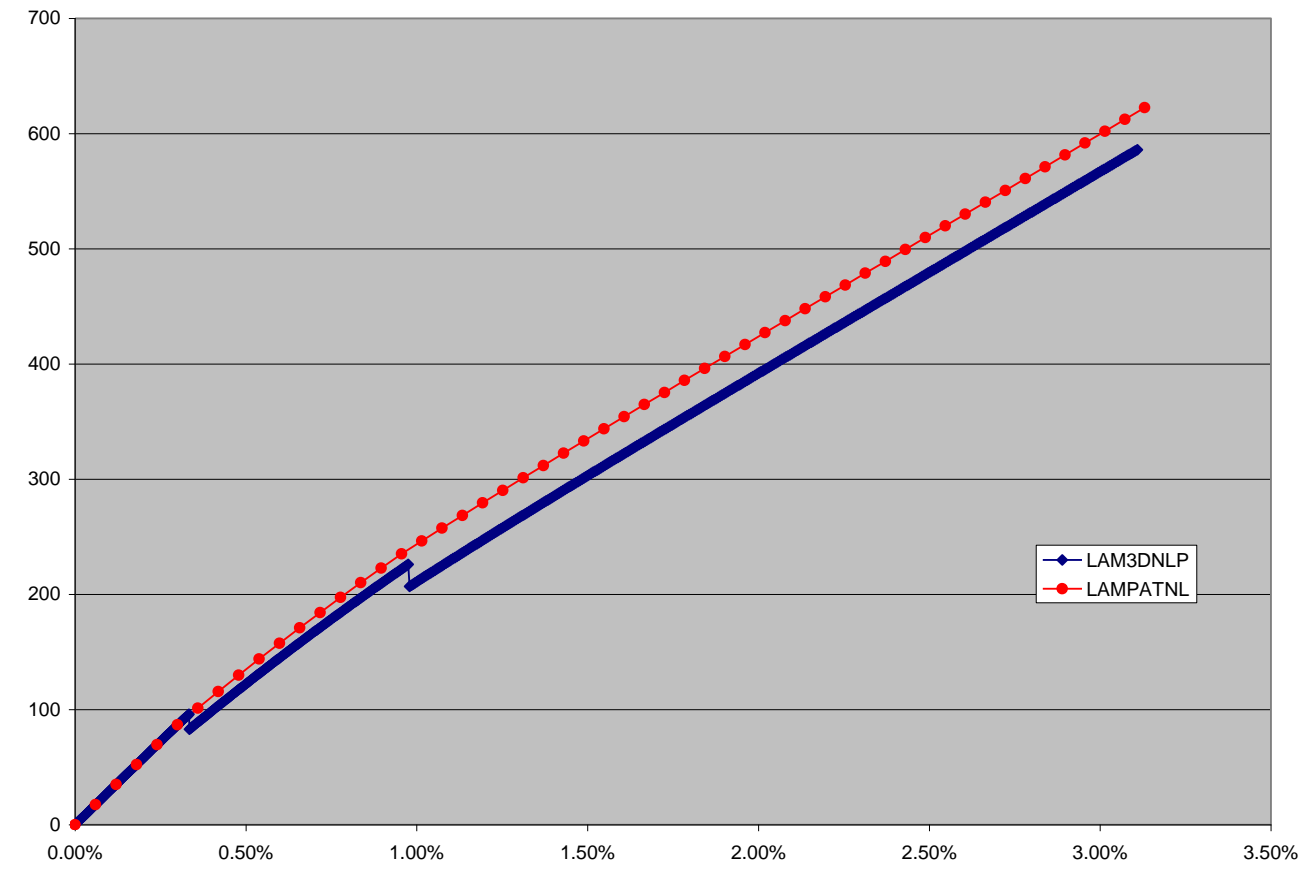

Figure 3.6 Stress-strain curves of $\left[0^{\circ} / 90^{\circ} / \pm 45^{\circ}\right]_{s}$ S2-Epoxy laminate LAM3DNLP output and ABAQUS UMAT output 


\subsubsection{Tracking progressive failure}

Improvements to the tracking of failure progression were added to the LAMPATNL user material subroutine developed by Powers et al. In LAM3DNLP, one material point is simulated, but LAMPATNL must account for upwards of several thousand elements with multiple integration points. The user material subroutine is called at every integration point during each load increment within the analysis. During each call, the UMAT receives the strain state of that integration point and determines the stiffness matrix of the material in order for the program to calculate the stress. To accomplish this, the UMAT must know the failure history of the laminate at that integration point.

The failure history tracks which ply and in which direction failure has occurred. This requires the failure history to be element, integration point, ply, and direction specific (Figure 3.7). With a model containing hundreds of plies each with six moduli $\left(E_{1}, E_{2}, E_{3}, G_{12}, G_{13}, G_{23}\right)$ and thousands of elements each with multiple integration points, tracking all of this necessary information can be difficult and memory intensive. It is accomplished by saving a large array that holds the failure history and is sorted by ply number, element number, and integration point number. 


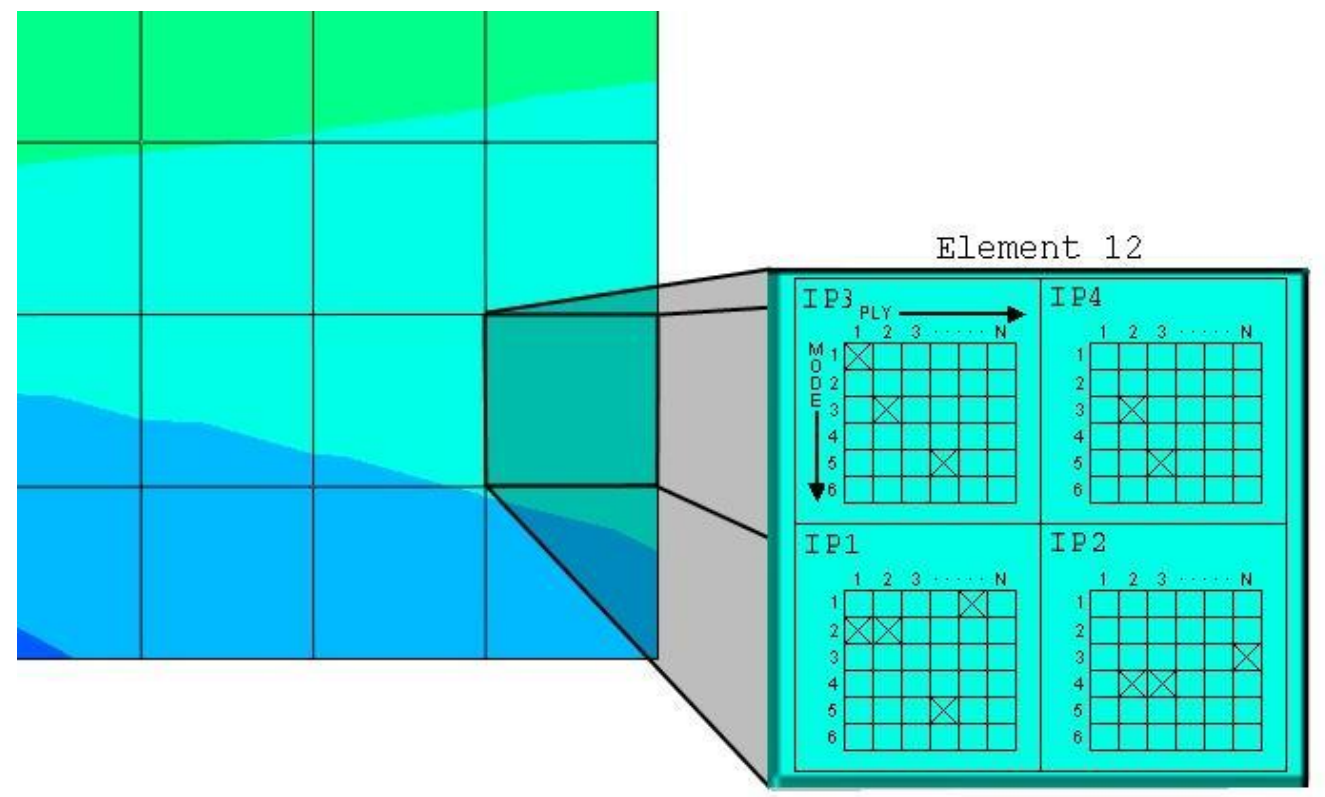

Figure 3.7 Tracking failure history is mode, ply, integration point, and element specific

\subsubsection{Selection of elements}

Selecting the correct element is important when simulating the behavior of complex structures. The "LAM" codes were developed to analyze thick section composite structures. To match the analysis capability of these programs, it is important for LAMPATNL to be able to interface with three-dimensional elements. LAMPATNL was developed by Powers et al. to support the use of two dimensional, solid (continuum), axisymmetrical 4-node bilinear (CAX4) elements. These elements were first supported because of the need for simulating cylinders and other axisymmetric structures. The user material was also able to interface with elements with four term stress and strain tensors of the form $\left(\sigma_{x}, \sigma_{y}, \sigma_{z}, \sigma_{x y}\right)$ and $\left(\varepsilon_{x}, \varepsilon_{y}, \varepsilon_{z}, \varepsilon_{x y}\right)$. To improve the three dimensional modeling capabilities of 
LAMPATNL, support of 8-node linear brick elements (C3D8 in ABAQUS) was added. This support extends to any element that has six term stress and strain tensors in the forms $\left(\sigma_{x}, \sigma_{y}, \sigma_{z}, \sigma_{x y}, \sigma_{x z}, \sigma_{y z}\right)$ and $\left(\varepsilon_{x}, \varepsilon_{y}, \varepsilon_{z}, \varepsilon_{x y}, \varepsilon_{x z}, \varepsilon_{y z}\right)$.

It is important to investigate which of these supported elements are best for the accurate simulation of thick-section composite structures and which provide easily interpreted visualizations of key outputs. Modeling non-axisymmetric structures leads to the use of the three-dimensional 8-node linear brick elements. There are several options available for this node type, including hybrid with both linear and constant pressure, the support of incompatible modes, and reduced integration.

The reduced integration option for this element has several advantages and disadvantages. Fully integrated C3D8 elements contain 8 integration points per element and reduced integration C3D8R elements contain only 1 integration point. Using reduced integration elements would result in one eighth of the number of calculations for the same amount of elements. The resulting simulation would be less accurate, especially in cases where reduced integration elements have historically exhibited problems, such as bending. Elements with reduced integration are also prone to hourglassing and controls must be used to prevent undesirable distortions.

The drawbacks of reduced integration elements are balanced by less computational cost and simplified visualizations. Figure 3.8 shows visualization of a model using fully integrated elements on the left and reduced integration elements on the right. For this case, the output is direction of the minimum $\mathrm{C}_{\mathrm{ij}}$ ratio, MINCIJN, which can be integer values between zero and six. Non-integers, negative numbers represented as black areas, and number greater than six (grey areas) do not reflect 
correct values. These incorrect values are a product of displaying extrapolated values, derived from integration points, at the nodes of full integration elements. For this output, the values can be discontinuous from one element to the next, yet the nodal extrapolation assumes these values to be continuous. Using reduced integration elements avoids problems associated with the visualization of extrapolated nodal values.
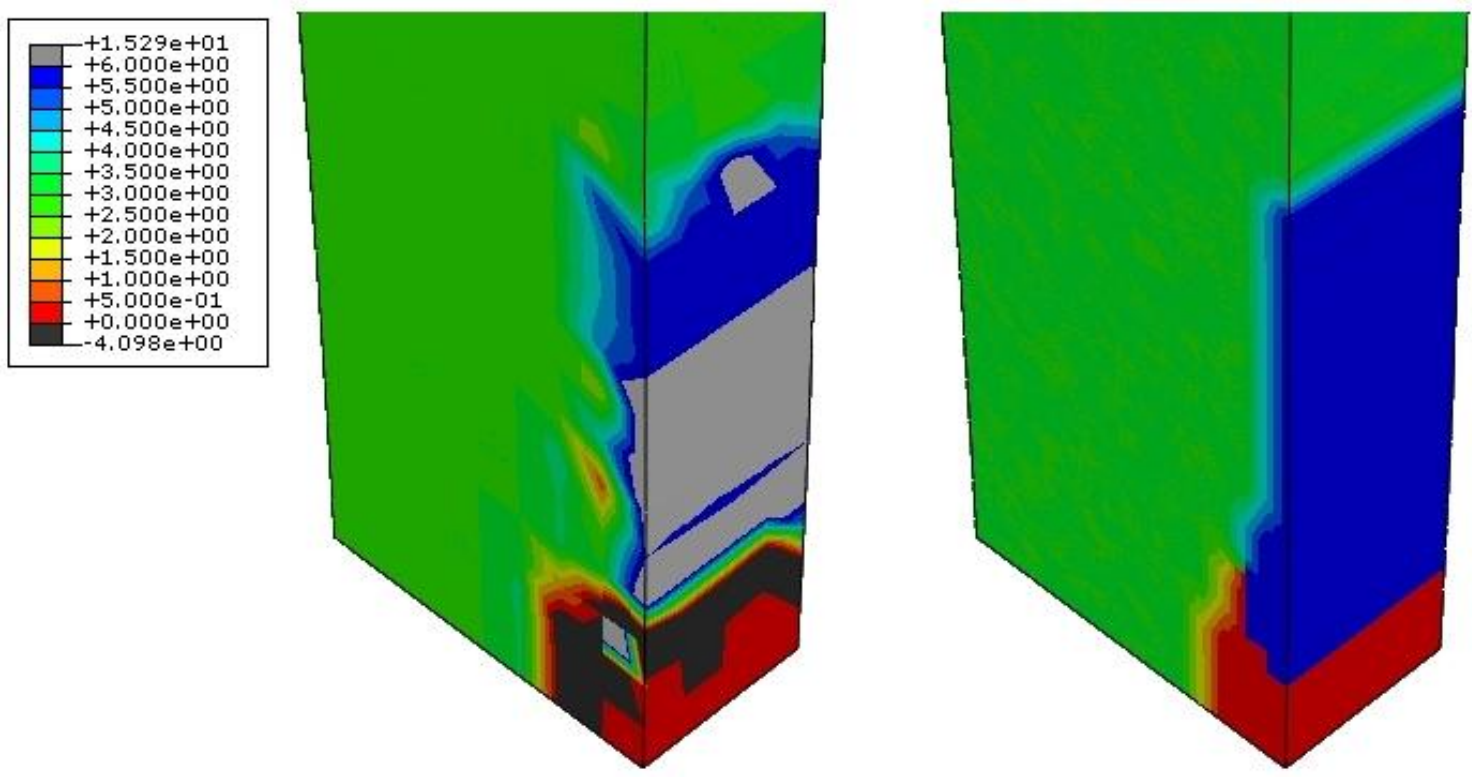

\section{Figure 3.8 Comparison of visualization of full integration (left) and reduced integration (right) elements}

Careful consideration was taken to ensure all the concerns associated with reduced integration elements are addressed and the implementation of LAMPATNL in conjunction with these elements was correct. Using a user material with reduced integration elements required hourglass stiffness controls. To ensure the hourglass 
stiffness of the model was set to an appropriate value, the elastic strain energy was compared to the hourglass energy calculated by the finite element program. The hourglass energy should be less than $10 \%$ of the elastic strain energy to ensure no hourglassing had occurred. The calculation of elastic strain energy was added to LAMPATNL to make this comparison.

\subsection{Validation of LAMPATNL}

Validating the LAMPATNL user material subroutine begins with modeling simple composite layups using linear ply properties and no progressive failure. These single element models are validated with comparisons to the material point response calculated by LAM3D. Matching the stress-strain curve produced by the UMAT using linear ply properties to that created by LAM3D ensures that the user material "smears" the ply properties of the laminate correctly. While the stress-strain curve comparison is straightforward, comparing the output parameters created by each program is more complex. The parameters calculated by LAM3D are the safety factor, critical mode, and critical ply. LAMPATNL also produces these parameters and 13 additional parameters, but there are major differences in the meaning of the parameters between the two.

For the linear case, safety factor is defined as the ultimate load that a laminate could sustain, based on the allowable amount of progressive failure, divided by the applied loading on the laminate. The safety factor is therefore a scalar multiple of the applied loading. The process of determining this value starts by calculating the ratio of the strain allowable to ply strain for each ply and each direction. The lowest ratio is called the safety factor for that iteration and the ply and direction in which the lowest ratio occurs is called the critical ply and critical mode respectively. The ply and 
direction are next flagged for failure and the stiffness in the critical direction of that ply is discounted. New linear "smeared" properties for the laminate are then calculated and the process repeats. A new safety factor, critical mode, and critical ply are calculated and recorded for the next iteration, the plies are discounted, and "smeared" properties are updated. Iterations continue until the structural integrity of the laminate has been compromised. At the end of the analysis, the highest safety factor of all the iterations is determined to be last ply failure and the mode and ply of that highest safety factor are reported as critical mode and ply for the element.

The process for determining the safety factor in nonlinear, progressive failure analysis is not as straightforward. First, stress and strains in nonlinear analysis cannot be linearly scaled to larger values because this analysis uses the incremental approach for determining stress from strain. Secondly, the progressive nature of the analysis requires that plies must exceed their strain allowable to be flagged for failure. In the linear analysis, the lowest ratio of the strain failure allowable to the ply strain is designated for failure and the ply is discounted. In nonlinear, progressive failure analysis, the safety factor is defined as the lowest ratio of failure allowable to ply strain at the current level and the critical ply and mode are the ply and direction of this lowest ratio. This determines which ply and direction are closest to failure, not which ply and direction would cause last ply failure. Because of these differences, it is not appropriate to directly compare values of the variables calculated in LAMPATNL to those calculated in the LAM3D.

An outline of the examples used to validate the LAMPATNL user material subroutine is shown in Table 3.1. Using linear ply properties and no progressive failure, two laminates are analyzed with LAMPATNL and compared to LAM3D 
analysis. With nonlinear ply properties and progressive failure, LAMPATNL is validated against LAM3DNLP for several materials and layups. For all of these examples, laminate stress-strain response is compared between the UMAT and analytical models. Because of the differences in safety factor calculations, this value cannot be directly compared.

Table 3.1 Examples provided for LAMPATNL validation

\begin{tabular}{|c|c|c|c|c|c|}
\hline Layup & Material & Load (MPa) & Load Direction & Linear/Nonlinear & Progressive Failure \\
\hline$[0 / 90 / \pm 45]$ & S-Glass Epoxy & 100 & X Tension & Linear & No \\
\hline$[ \pm 30]$ & T300/PR-319 & 150 & Y Tension & Linear & No \\
\hline$[0]$ & S-Glass Epoxy & 1700 & 1 Tension & Nonlinear & Yes \\
\hline$[0]$ & S-Glass Epoxy & 65 & 2 Tension & Nonlinear & Yes \\
\hline$[0]$ & S-Glass Epoxy & 50 & 3 Tension & Nonlinear & Yes \\
\hline$[0 / 90 / \pm 45]$ & S-Glass Epoxy & 800 & X Tension & Nonlinear & Yes \\
\hline$[ \pm 35]$ & IM7/8551-7 & 425 & X Tension & Nonlinear & Yes \\
\hline$[ \pm 35]$ & IM7/8551-8 & 160 & Y Tension & Nonlinear & Yes \\
\hline$[ \pm 35]$ & IM7/8551-9 & 85 & Z Tension & Nonlinear & Yes \\
\hline$[ \pm 55]$ & E-Glass/MY750 & 125 & X Tension & Nonlinear & Yes \\
\hline$[ \pm 55]$ & E-Glass/MY750 & -200 & X Compression & Nonlinear & Yes \\
\hline$[ \pm 55]$ & E-Glass/MY750 & 350 & Y Tension & Nonlinear & Yes \\
\hline$[ \pm 55]$ & E-Glass/MY750 & -225 & Y Compression & Nonlinear & Yes \\
\hline
\end{tabular}

\subsubsection{Validation of LAMPATNL for linear materials}

In the first example, an S-Glass/Epoxy laminate with a $\left[0^{\circ} / 90^{\circ} / \pm 45^{\circ}\right]_{\mathrm{s}}$ layup is evaluated in simple tension load of $100 \mathrm{MPa}$ in the X-direction. The linear ply level properties of this material for LAM3D are shown in Table 3.2. Maximum strain is the failure criteria that is used for this example and the failure allowables are also shown in Table 3.2. 
Table 3.2 Linear ply properties of S-Glass/Epoxy

\begin{tabular}{|c|c|c|c|}
\hline \multicolumn{2}{|c|}{ Ply Properties } & \multicolumn{2}{|c|}{ Strain Allowables } \\
\hline$E_{1}$ & 52000 & $\varepsilon_{1}^{\top}$ & $3.270 \%$ \\
\hline$E_{2}$ & 19000 & $\varepsilon_{1}{ }^{\mathrm{C}}$ & $2.210 \%$ \\
\hline$E_{3}$ & 19000 & $\varepsilon_{2}^{\top}$ & $0.263 \%$ \\
\hline $\mathrm{G}_{12}$ & 6700 & $\varepsilon_{2}^{C}$ & $1.500 \%$ \\
\hline $\mathrm{G}_{13}$ & 6700 & $\varepsilon_{3}^{\top}$ & $0.263 \%$ \\
\hline $\mathrm{G}_{23}$ & 6700 & $\varepsilon_{3}{ }^{C}$ & $1.500 \%$ \\
\hline$v_{12}$ & 0.30 & $Y_{12}$ & $4.000 \%$ \\
\hline$v_{13}$ & 0.30 & $Y_{13}$ & $4.000 \%$ \\
\hline$v_{23}$ & 0.42 & $Y_{23}$ & $0.590 \%$ \\
\hline
\end{tabular}

The ply properties input into the nonlinear user material must be linearized, which is achieved by setting the stress asymptote and shape factor Ramberg-Osgood parameters to large values. Table 3.3 contains the LAMPATNL input values for the linearized material properties. Additionally, to disable the progressive failure capabilities of the code, maximum strain allowables are set to $10 \%$.

\section{Table 3.3 Ply properties for linear S-Glass/Epoxy}

\begin{tabular}{|c|c|c|c|c|c|c|}
\hline S-Glass/Epoxy & $\mathbf{1}$ & $\mathbf{2}$ & $\mathbf{3}$ & $\mathbf{1 2}$ & $\mathbf{1 3}$ & $\mathbf{2 3}$ \\
\hline $\mathbf{E}_{\mathbf{0}}(\mathbf{G P a})$ & 52 & 19 & 19 & 6.7 & 6.7 & 6.7 \\
\hline $\boldsymbol{\sigma}_{\mathbf{0}} \mathbf{( G P a )}$ & 100 & 100 & 100 & 100 & 100 & 100 \\
\hline $\mathbf{n}$ & 10 & 10 & 10 & 10 & 10 & 10 \\
\hline $\boldsymbol{v}$ & - & - & - & 0.3 & 0.3 & 0.42 \\
\hline
\end{tabular}

The linear stress-strain curves of both LAMPATNL and the LAM3D results are shown in Figure 3.9. The calculated stress-strain responses from these 
codes are coincident as expected. Because of the reasons stated in the previous section, the direct comparison of safety factor, critical mode, and critical ply are not performed.

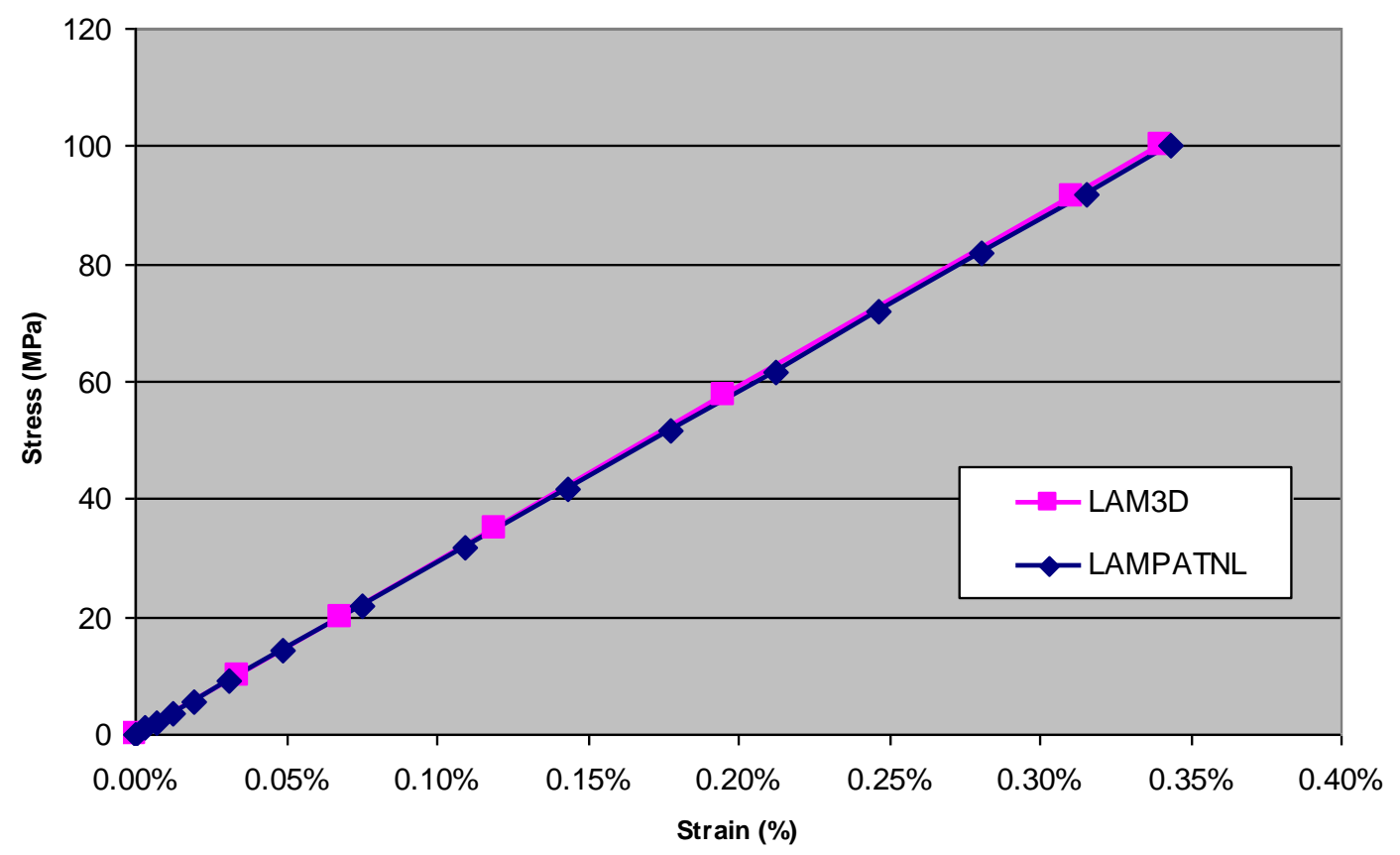

Figure 3.9 Stress vs. strain curves in the X-direction for $\left[0^{\circ} / 90^{\circ} / \pm 45^{\circ}\right]_{\mathrm{S}} \mathrm{S}$ Glass/Epoxy comparing the LAM3D and LAMPATNL codes

For the next example, T300/PR-319 in a $\left[ \pm 30^{\circ}\right]_{\mathrm{s}}$ layup is subjected to a tensile load of $150 \mathrm{MPa}$ in the $\mathrm{Y}$-direction. The ply properties used for the material are listed in Table 3.4 below, with the $\sigma_{0}$ and $n$ values not used for input into LAM3D. The resulting linear stress-strain curves are shown in Figure 3.10 and are again coincident. 
Table 3.4 Ply properties for linear T300/PR-319

\begin{tabular}{|c|c|c|c|c|c|c|}
\hline T300/PR319 & $\mathbf{1}$ & $\mathbf{2}$ & $\mathbf{3}$ & $\mathbf{1 2}$ & $\mathbf{1 3}$ & $\mathbf{2 3}$ \\
\hline $\mathbf{E}_{\mathbf{0}} \mathbf{( G P a )}$ & 129 & 5.6 & 5.6 & 1.33 & 1.33 & 1.86 \\
\hline $\boldsymbol{\sigma}_{\mathbf{0}} \mathbf{( G P a )}$ & 100 & 100 & 100 & 100 & 100 & 100 \\
\hline $\mathbf{n}$ & 10 & 10 & 10 & 10 & 10 & 10 \\
\hline $\boldsymbol{v}$ & - & - & - & 0.318 & 0.318 & 0.5 \\
\hline
\end{tabular}

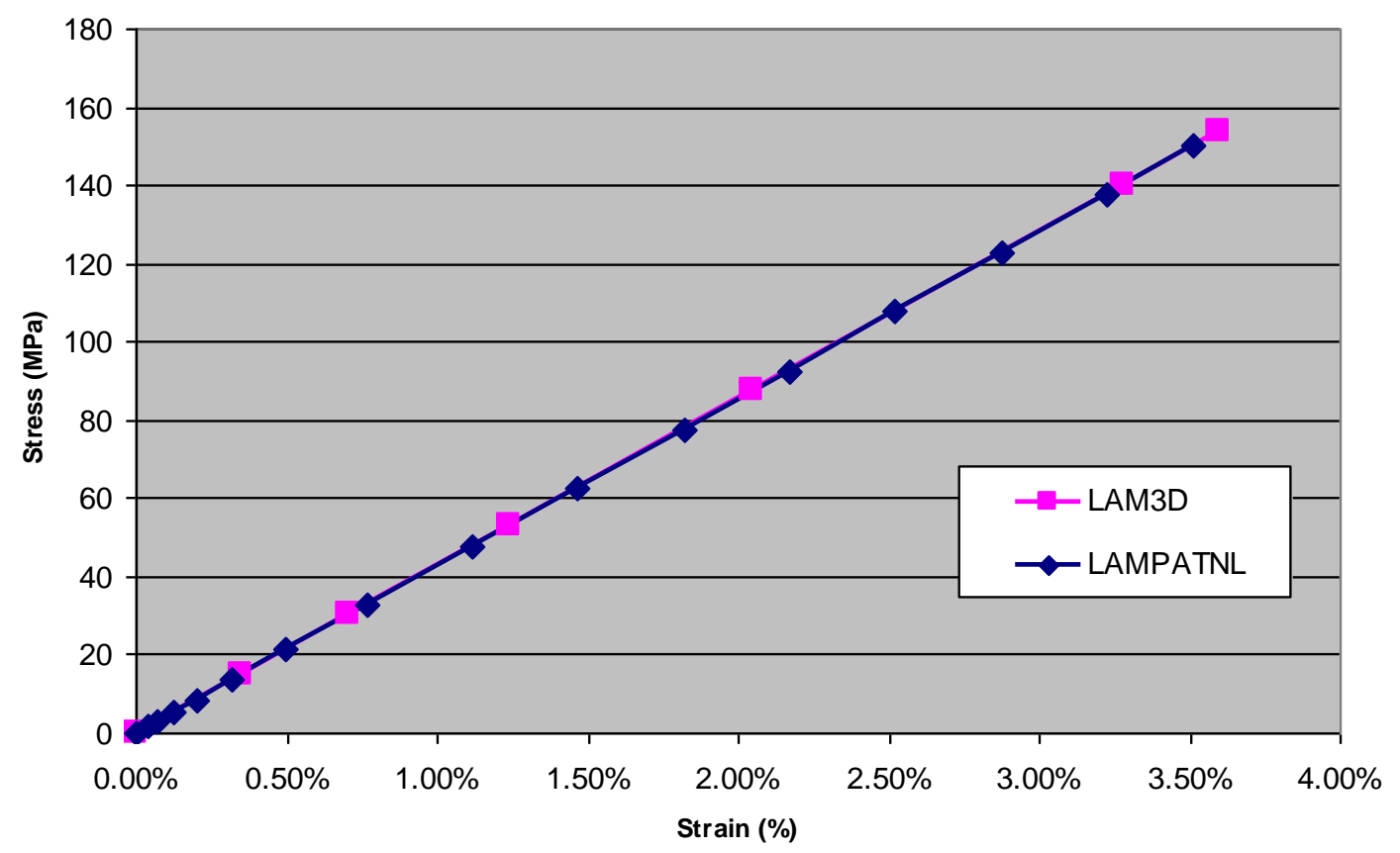

Figure 3.10 Stress vs. strain curves in the Y-direction for $\left[ \pm 3^{\circ}\right]_{S}$ T300/PR-319 comparing the LAMBD and LAMPATNL codes

\subsubsection{Validation of LAMPATNL for nonlinear materials}

Comparisons between the LAMPATNL user material and LAM3D were made by suppressing the nonlinear and progressive failure features of the user material. In order to completely validate its proper function, the user material model 
must include these features. The next step in validating the UMAT is to match results using a single element model with those that are output by the analytical code LAM3DNLP. Changes to the post-failure loading procedure for the analytical code were detailed in the Procedural considerations sections of this chapter. These changes facilitate a one-to-one comparison of stress-strain curves, critical modes, and critical plies between the user material and LAM3DNLP.

The Ramberg-Osgood parameters that are used to model the nonlinear properties for each material used in the examples are provided in Table $3.5[2,36]$. The maximum strain failure criterion is used for every example and the strain allowables are shown in Table $3.6[2,36]$. 
Table 3.5 Ramberg-Osgood parameters

\begin{tabular}{|c|c|c|c|c|c|c|}
\hline \multirow{2}{*}{$\begin{array}{c}\text { Material \& } \\
\text { Its Parameters } \\
\text { S-Glass/Epoxy }\end{array}$} & \multicolumn{6}{|c|}{$\begin{array}{c}\text { Spatial Directions } \\
\text { for Constitutive Modeling }\end{array}$} \\
\hline & 1 & 2 & 3 & 12 & 13 & 23 \\
\hline$E_{0}(G P a)$ & 52 & 19 & 19 & 6.7 & 6.7 & 6.7 \\
\hline$\sigma_{0}(\mathrm{GPa})$ & 100 & 0.189 & 0.189 & 0.071 & 0.071 & 100 \\
\hline $\mathbf{n}$ & 10 & 3.601 & 3.601 & 2.365 & 2.365 & 10 \\
\hline$v$ & - & - & - & 0.3 & 0.3 & 0.42 \\
\hline T300/PR319 & 1 & 2 & 3 & 12 & 13 & 23 \\
\hline $\mathrm{E}_{0}(\mathrm{GPa})$ & 129 & 5.6 & 5.6 & 1.33 & 1.33 & 1.86 \\
\hline$\sigma_{0}(\mathrm{GPa})$ & 100 & 0.135 & 0.135 & 0.108 & 0.108 & 100 \\
\hline $\mathbf{n}$ & 10 & 4.728 & 4.728 & 4.872 & 4.872 & 10 \\
\hline $\mathbf{v}$ & - & - & - & 0.318 & 0.318 & 0.5 \\
\hline IM7/8551-7 & 1 & 2 & 3 & 12 & 13 & 23 \\
\hline $\mathrm{E}_{0}(\mathrm{GPa})$ & 165 & 9.01 & 9.01 & 5.6 & 5.6 & 2.8 \\
\hline$\sigma_{0}(\mathrm{GPa})$ & 100 & 0.193 & 0.193 & 0.089 & 0.089 & 100 \\
\hline $\mathbf{n}$ & 10 & 3.604 & 3.604 & 2.018 & 2.018 & 10 \\
\hline $\mathbf{v}$ & - & - & - & 0.34 & 0.34 & 0.5 \\
\hline E-Glass/MY750 & 1 & 2 & 3 & 12 & 13 & 23 \\
\hline$E_{0}(G P a)$ & 45.6 & 16.2 & 16.2 & 6.42 & 6.42 & 5.79 \\
\hline$\sigma_{0}(\mathrm{GPa})$ & 100 & 100 & 100 & 0.077 & 0.077 & 100 \\
\hline $\mathbf{n}$ & 10 & 10 & 10 & 1.8 & 1.8 & 10 \\
\hline $\mathbf{v}$ & - & - & - & 0.278 & 0.278 & 0.4 \\
\hline E-Glass/LY556 & 1 & 2 & 3 & 12 & 13 & 23 \\
\hline $\mathrm{E}_{0}(\mathrm{GPa})$ & 53.5 & 17.7 & 17.7 & 6.36 & 6.36 & 6.32 \\
\hline$\sigma_{0}(\mathrm{GPa})$ & 100 & 100 & 100 & 0.076 & 0.076 & 100 \\
\hline $\mathbf{n}$ & 10 & 10 & 10 & 1.85 & 1.85 & 10 \\
\hline $\mathbf{v}$ & - & - & - & 0.278 & 0.278 & 0.4 \\
\hline AS4/3501-6 & 1 & 2 & 3 & 12 & 13 & 23 \\
\hline $\mathrm{E}_{0}(\mathrm{GPa})$ & 126 & 11 & 11 & 6.8 & 6.8 & 3.93 \\
\hline$\sigma_{0}(\mathrm{GPa})$ & 100 & 100 & 100 & 0.097 & 0.097 & 100 \\
\hline $\mathbf{n}$ & 10 & 10 & 10 & 1.96 & 1.96 & 10 \\
\hline $\mathrm{v}$ & - & - & - & 0.28 & 0.28 & 0.4 \\
\hline
\end{tabular}

\section{Table 3.6 Maximum strain failure allowables}

\begin{tabular}{|c|c|c|c|c|c|c|c|c|c|}
\hline Material & Y1T (\%) & Y1C (\%) & Y2T (\%) & Y2C (\%) & Y3T (\%) & Y3C (\%) & Y23 (\%) & Y13 (\%) & Y12 (\%) \\
\hline S-Glass/Epoxy & 3.27 & -2.21 & 0.33 & -1.5 & 0.263 & -1.5 & 0.59 & 4 & 4 \\
\hline T300/PR319 & 1.07 & -0.74 & 0.43 & -2.8 & 0.43 & -2.8 & 1.5 & 8.6 & 8.6 \\
\hline IM7/8551-7 & 1.551 & -0.96 & 0.87 & -3.2 & 0.755 & -3.2 & 2.1 & 5 & 5 \\
\hline E-glass/MY750 & 2.81 & -1.75 & 0.25 & -1.2 & 0.25 & -1.2 & 4 & 4 & 4 \\
\hline E-glass/LY556 & 2.13 & -1.07 & 0.2 & -0.64 & 0.2 & -0.64 & 3.8 & 3.8 & 3.8 \\
\hline AS4/3501-6 & 1.38 & -1.18 & 0.44 & -2 & 0.44 & -2 & 2 & 2 & 2 \\
\hline
\end{tabular}


Using a single element model for each example, the laminate is loaded in the $\mathrm{X}$-direction until failure has occurred. This process is similarly repeated for the $\mathrm{Y}$ and Z-directions. The first comparison between the LAMPATNL user material and LAM3DNLP is a simple unidirectional layup of S-Glass/Epoxy. As with all of the materials tested, this material is linear in the fiber direction. The tensile failure strains in the 2- and 3-directions for this material are relatively small, which results in the nonlinear responses of the material in those directions appearing to be linear. Figure 3.11 shows the stress-strain response of the unidirectional material in the 1 direction. As expected, the UMAT curve is coincident with the analytical model and both reach failure at $3.27 \%$ strain. 


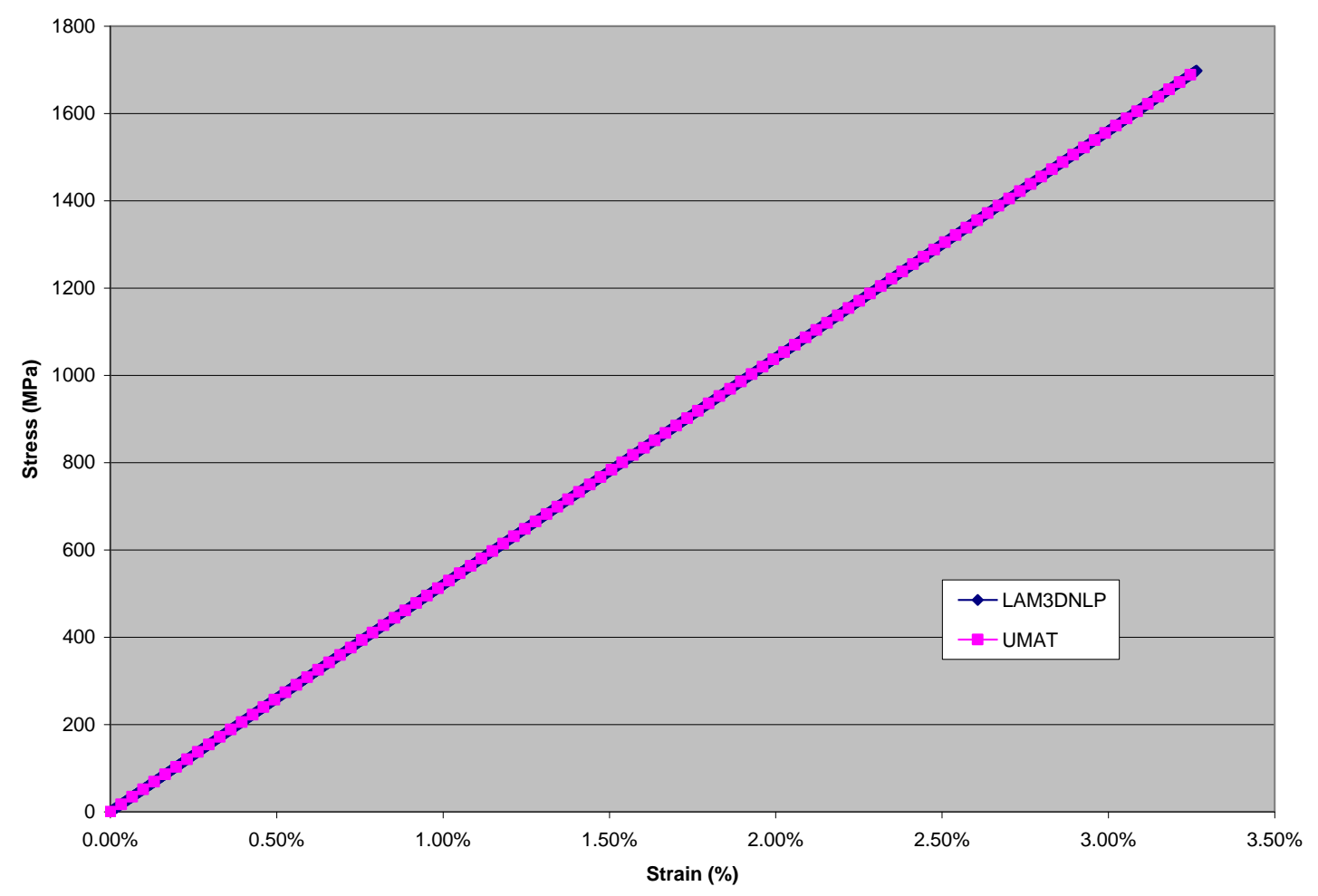

Figure 3.11 Stress vs. strain curves in the 1-direction for $\left[0^{\circ}\right]$ S-Glass/Epoxy comparing the UMAT and LAMBDNLP codes

The stress-strain response in the 2-direction is shown in Figure 3.12.

Failure in this direction occurs at $0.33 \%$ strain and this is reflected in the results.

Figure 3.13 shows the response of this material in the 3 -direction, with failure occurring at $0.26 \%$ strain in both the LAMPATNL and LAM3DNLP. 


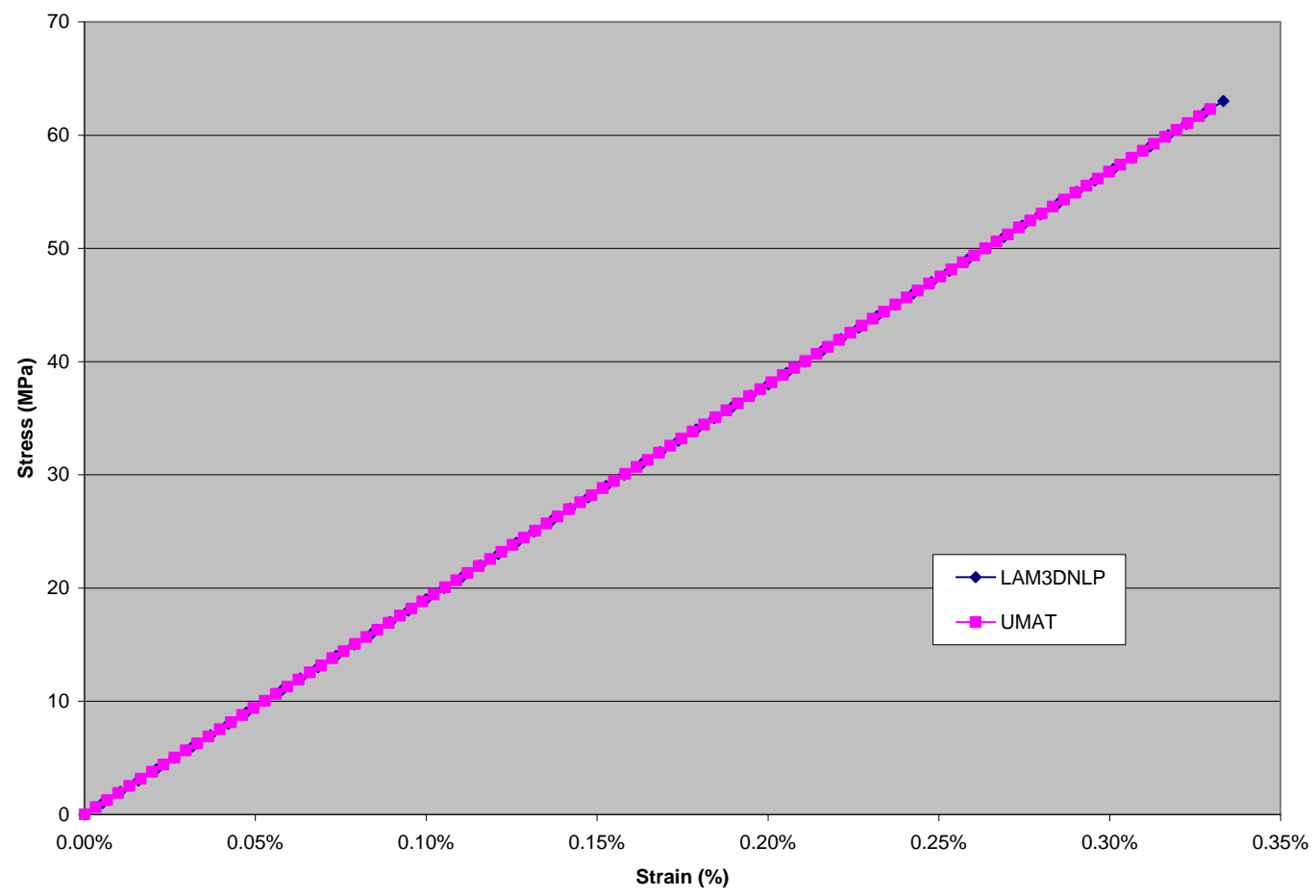

Figure 3.12 Stress vs. strain curves in the 2-direction for $\left[0^{\circ}\right] \mathrm{S}-\mathrm{Glass} / \mathrm{Epoxy}$ comparing the UMAT and LAM3DNLP codes 


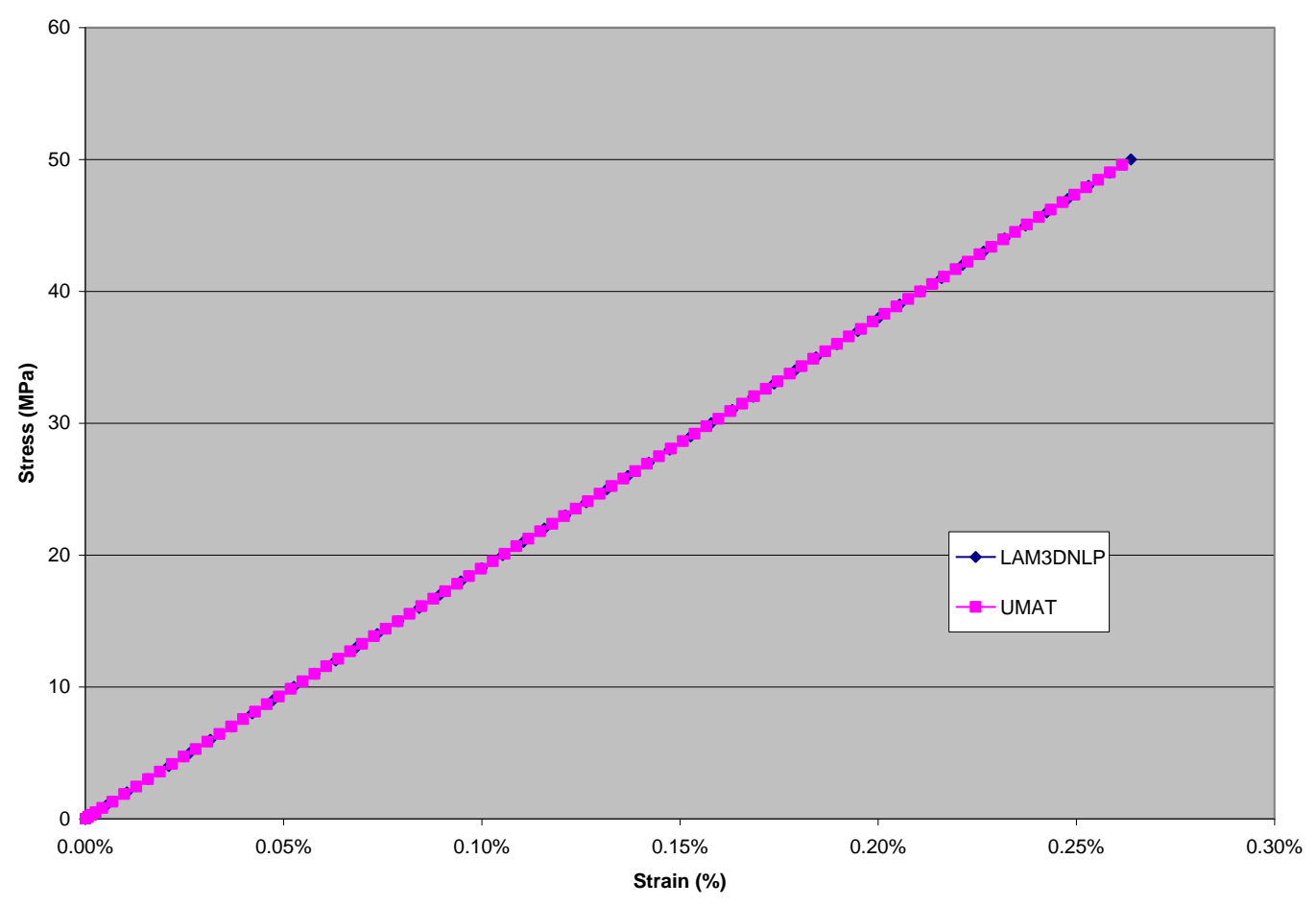

\section{Figure 3.13 Stress vs. strain curves in the 3-direction for [ $\left.0^{\circ}\right]$ S-Glass/Epoxy comparing the UMAT and LAM3DNLP codes}

The next example is an S-Glass/Epoxy laminate in a $\left[0^{\circ} / 90^{\circ} / \pm 45^{\circ}\right]_{\mathrm{s}}$, or quasi-isotropic, layup. In this example, the response to load applied in the X-direction is the same as response to load applied in the Y-direction, so only one plot is shown for these two load cases. The nonlinear material response and progressive failure of the laminate is shown in Figure 3.14. Transverse tensile failure in the $90^{\circ}$ plies occurs in the laminate at $0.35 \%$ strain and in the $\pm 45^{\circ}$ plies at $1 \%$ strain. These failures produce slight deflections in the stress-strain response. Some additional failure has little effect on the overall stiffness of the laminate in this direction. Longitudinal tensile failure in the $0^{\circ}$ plies occurred at $3.3 \%$ strain that caused a dramatic decrease in the stiffness of the laminate. The final failure recorded for this case is longitudinal 
compressive failure in the $90^{\circ}$ plies. Both the analytical code and the user material yield the same results for this test case, continuing to validate the correct function of the user material.

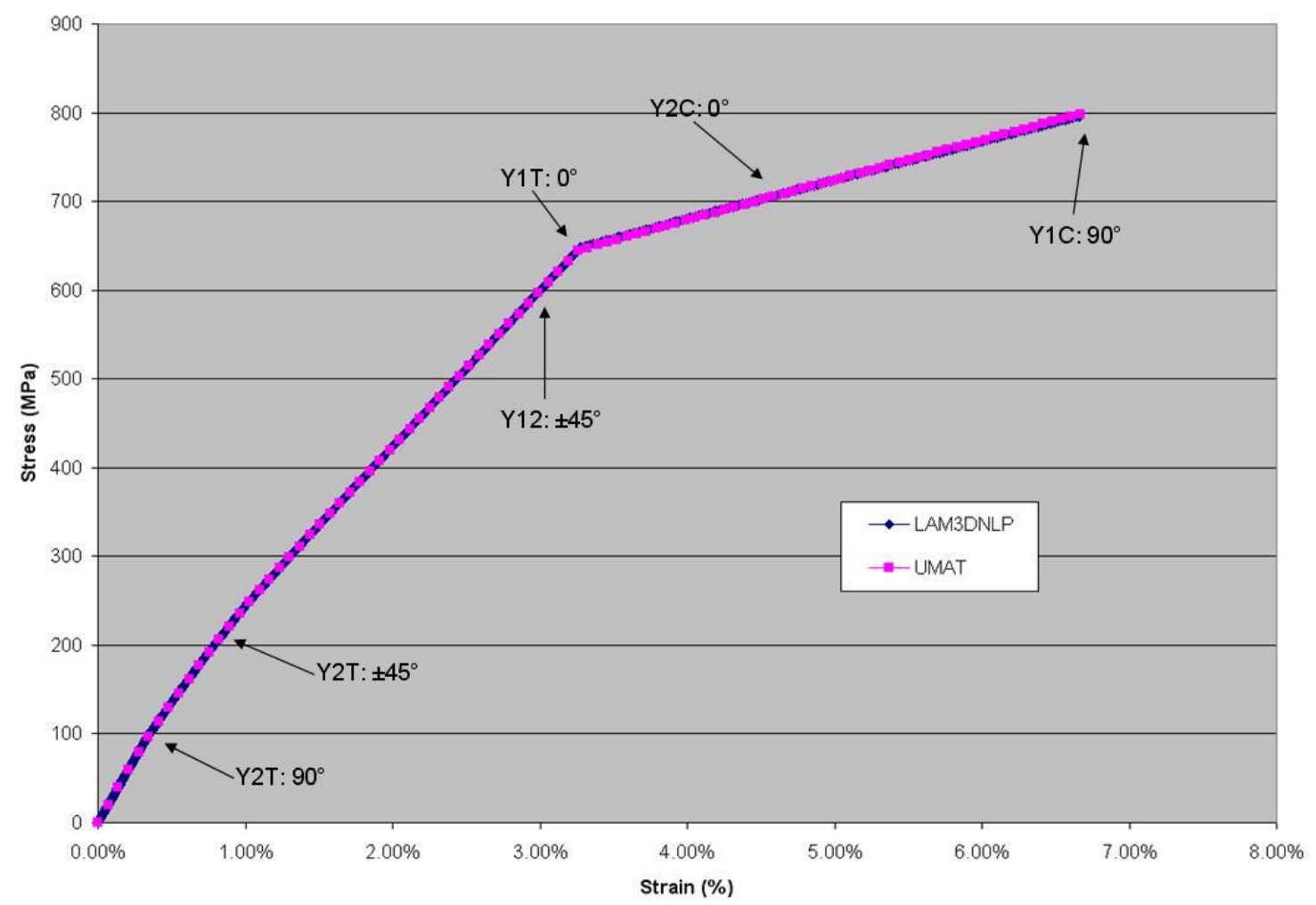

Figure 3.14 Stress vs. strain curves in the X-direction for $\left[0^{\circ} / 90^{\circ} / \pm 45^{\circ}\right]_{\mathrm{s}} \mathrm{S}$ Glass/Epoxy comparing the UMAT and LAM3DNLP codes

The out-of-plane stiffness of the laminate is not significantly affected by its layup and there is no progressive failure in this direction because first ply failure is catastrophic. The stress-strain response in the Z-direction is the same as that shown in 
Figure 3.13 because the material used for this laminate is the same used in the first example.

A laminate comprised of IM7/8551-7 in a $\left[ \pm 35^{\circ}\right]_{\mathrm{s}}$ layup is used in the next validation test case. In this composite layup, the nonlinear transverse and shearing directions are a contributing factor to the response in X-direction loading. The stressstrain curves in Figure 3.15 do not show abrupt discontinuities or changes in stiffness outside those normally associated with nonlinear materials, suggesting that the failures did not significantly affect the response of the laminate in this direction.

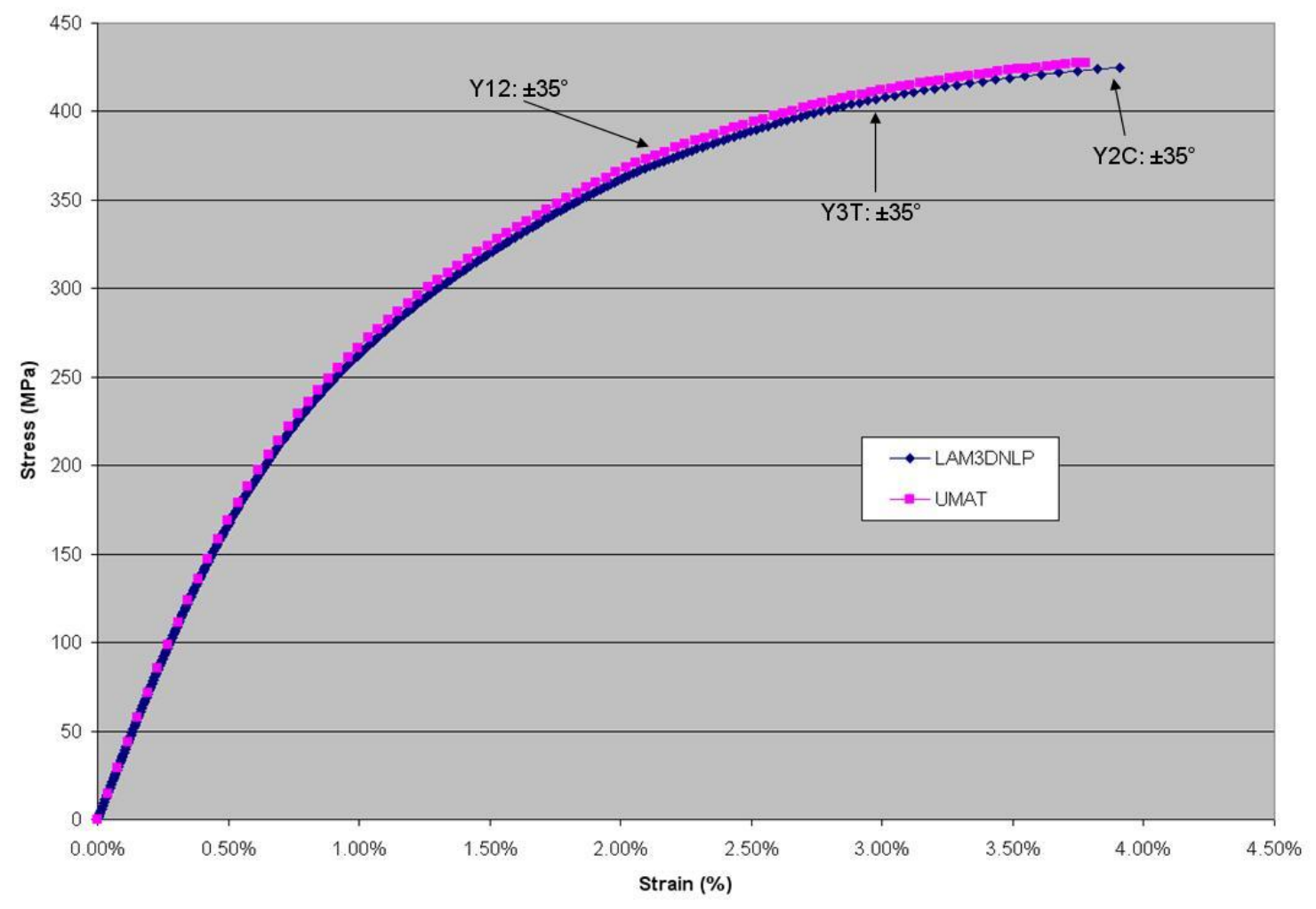

Figure 3.15 Stress vs. strain curves in the X-direction for $\left[ \pm 35^{\circ}\right]_{\mathrm{S}} \mathrm{IM7/8551-7}$ comparing the UMAT and LAM3DNLP codes 
Subjecting the same laminate to a load in the Y-direction yields a response that is both highly nonlinear and significantly effected by progressive ply failure. In Figure 3.16, the stress-strain response deviates from the nonlinear behavior to a more compliant response at approximately $1.7 \%$ strain. This failure corresponds to transverse tensile failure in the $\pm 35^{\circ}$ plies. Ultimate failure in this laminate is in-plane shearing in all the plies. The results from the user material once again mirror the results obtained by LAM3DNLP.

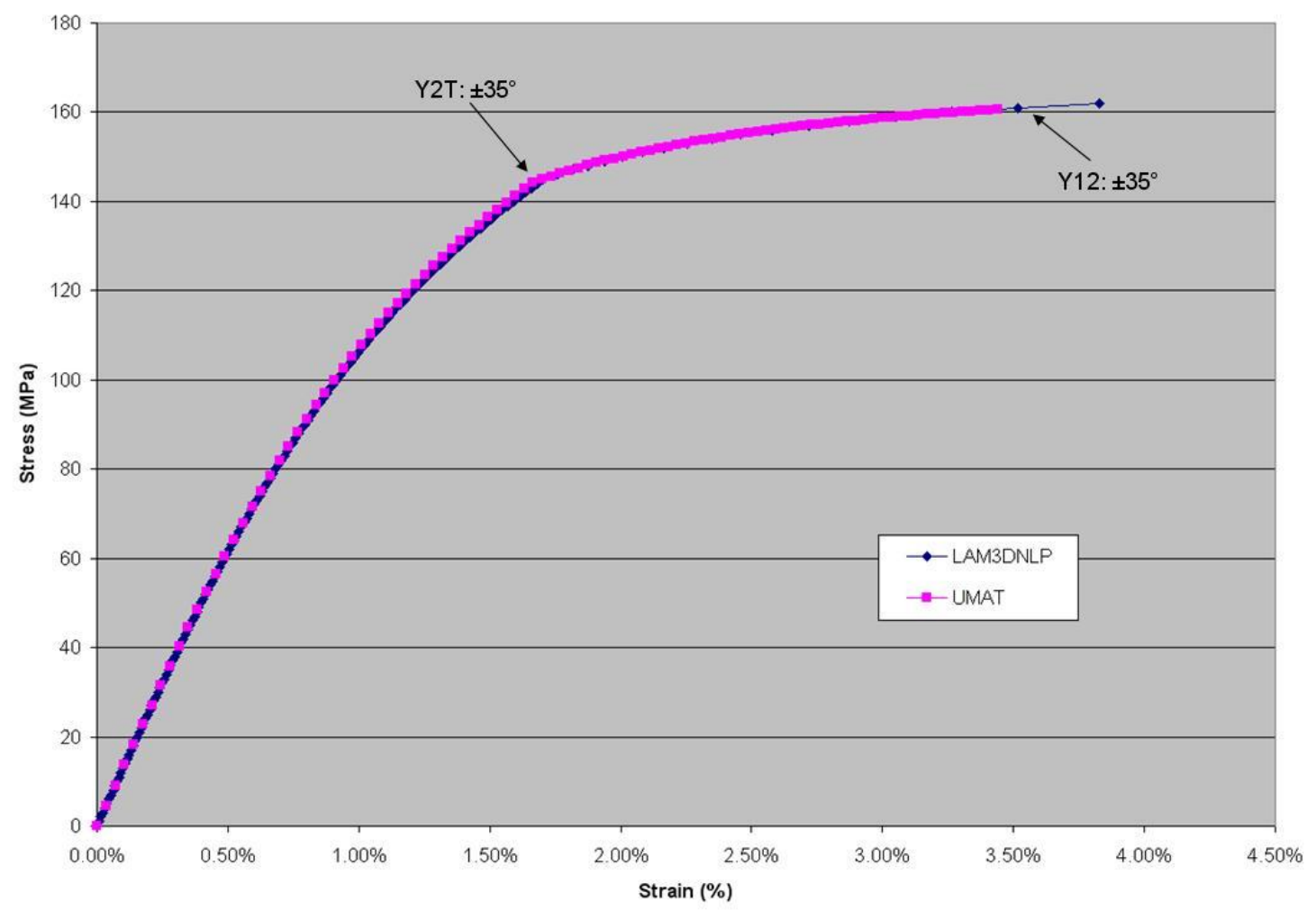

Figure 3.16 Stress vs. strain curves in the Y-direction for $\left[ \pm 35^{\circ}\right]_{\mathrm{S}} \mathrm{IM7/8551-7}$ comparing the UMAT and LAMBDNLP codes 
The response of this laminate in the Z-direction (Figure 3.17) is linear until failure. Once again, the small tensile failure strain of the material limits its response to the linear regime of the nonlinear curve. Both the user material and LAM3DNLP responses continue to match.

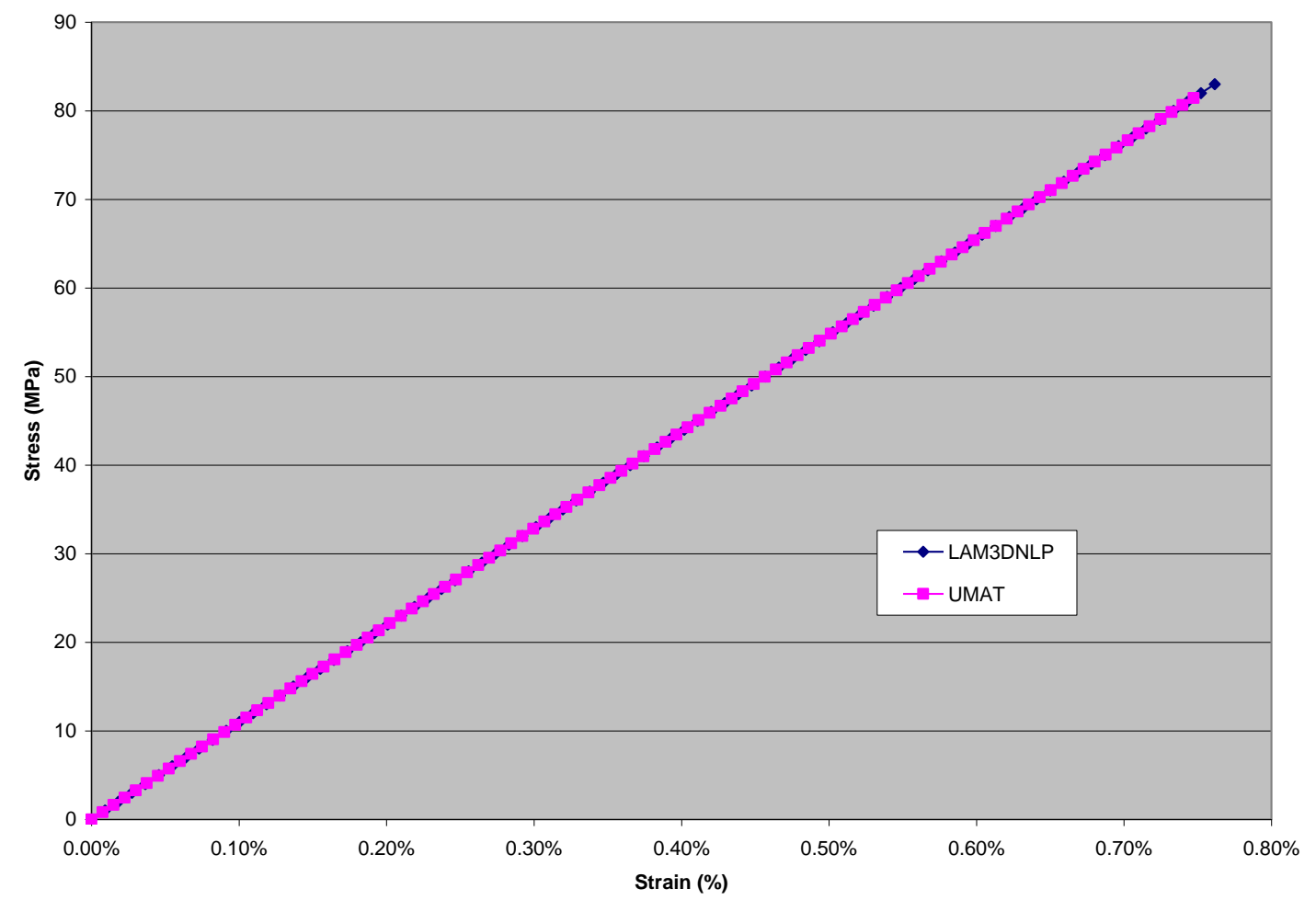

Figure 3.17 Stress vs. strain curves in the Z-direction for $\left[ \pm 35^{\circ}\right]_{\mathrm{s}} \mathrm{IM} 7 / 8551-7$ comparing the UMAT and LAM3DNLP codes

The final example for validation is an E-Glass/MY750 composite in a $\left[ \pm 55^{\circ}\right]_{\mathrm{S}}$ layup. This example tests the $\mathrm{X}$ - and Y-direction response of the laminate in both tension and compression. The material properties, layup, and load scenario are 
the same as those studied in the first World Wide Failure Exercise (WWFE-I) (see test case 9) [2]. The details of this exercise are discussed in the Background of the "LAM" codes section of Chapter 2 .

The first validation for this laminate is tension in the X-direction. In Figure 3.18, the laminate has an almost purely linear response up to around $0.5 \%$ strain then a noticeable shift to nonlinear response after. This shift is caused by transverse tensile failure in all the plies of the laminate. The coincidence of the curves further validates the results of the UMAT.

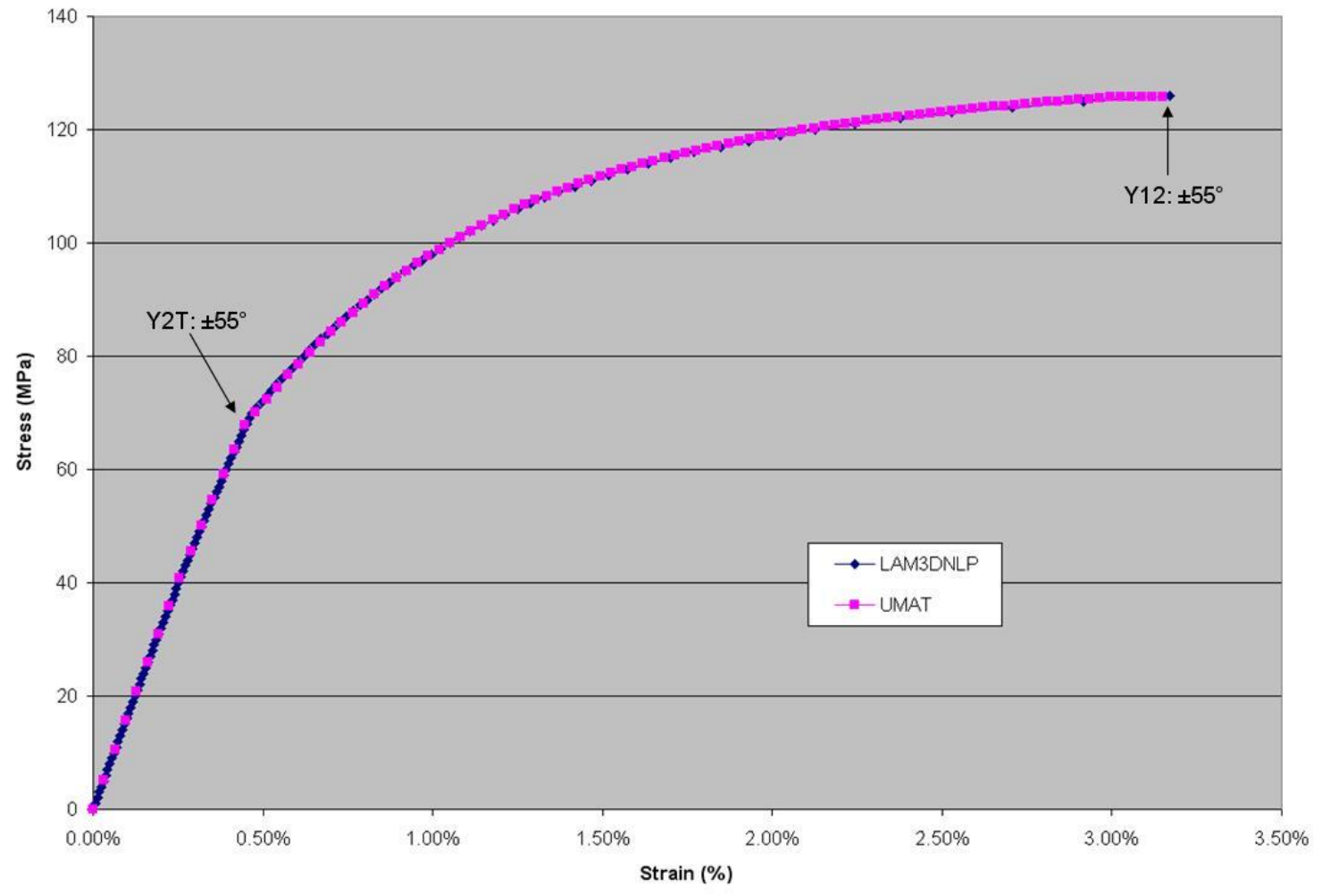

Figure 3.18 Stress vs. strain curves in X-direction tension for $\left[ \pm 55^{\circ}\right]_{\mathrm{s}} \mathrm{E}$ Glass/MY750 comparing the UMAT and LAM3DNLP codes 
The second validation is compression in the X-direction, shown in Figure 3.19. Like previous examples, the LAM3DNLP results and the user material results match. Transverse compressive failure in the plies around $2.5 \%$ strain causes the laminate to become compliant. Ultimate failure in this test case is a result of shear failure in the plies.

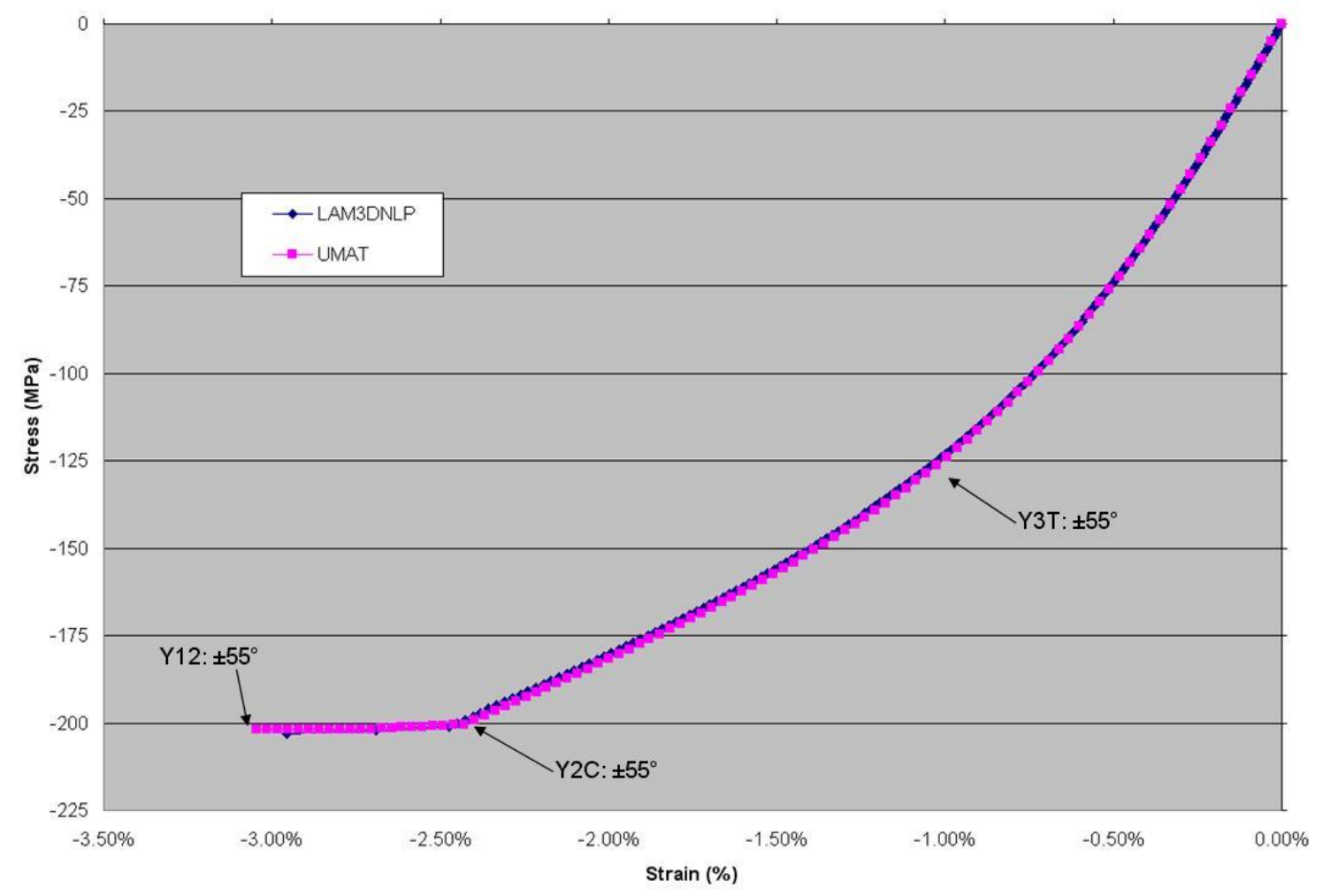

Figure 3.19 Stress vs. strain curves in X-direction compression for $\left[ \pm 55^{\circ}\right]_{\mathrm{s}}$ E-Glass/MY750 comparing the UMAT and LAM3DNLP codes

Tension in the Y-direction is next investigated for validation and shown in Figure 3.20. The response of the laminate is nonlinear with no noticeable stiffness 
changes that can be attributed to progressive failure. In-plane shear failure in this laminate around $2.25 \%$ strain does not significantly affect the response in this direction. Ultimate failure in this test case is a result of transverse compressive failure. The final example in Figure 3.21 is compression in the Y-direction. A change in stiffness around $1.25 \%$ strain is a result of transverse tensile failure in the plies. This failure has a small effect on the response of the laminate in this direction. In-plane shear failure in all plies is the ultimate failure in this case. Similar to all other validation examples, the UMAT stress-strain curves match those produced by the analytical LAM3DNLP code.

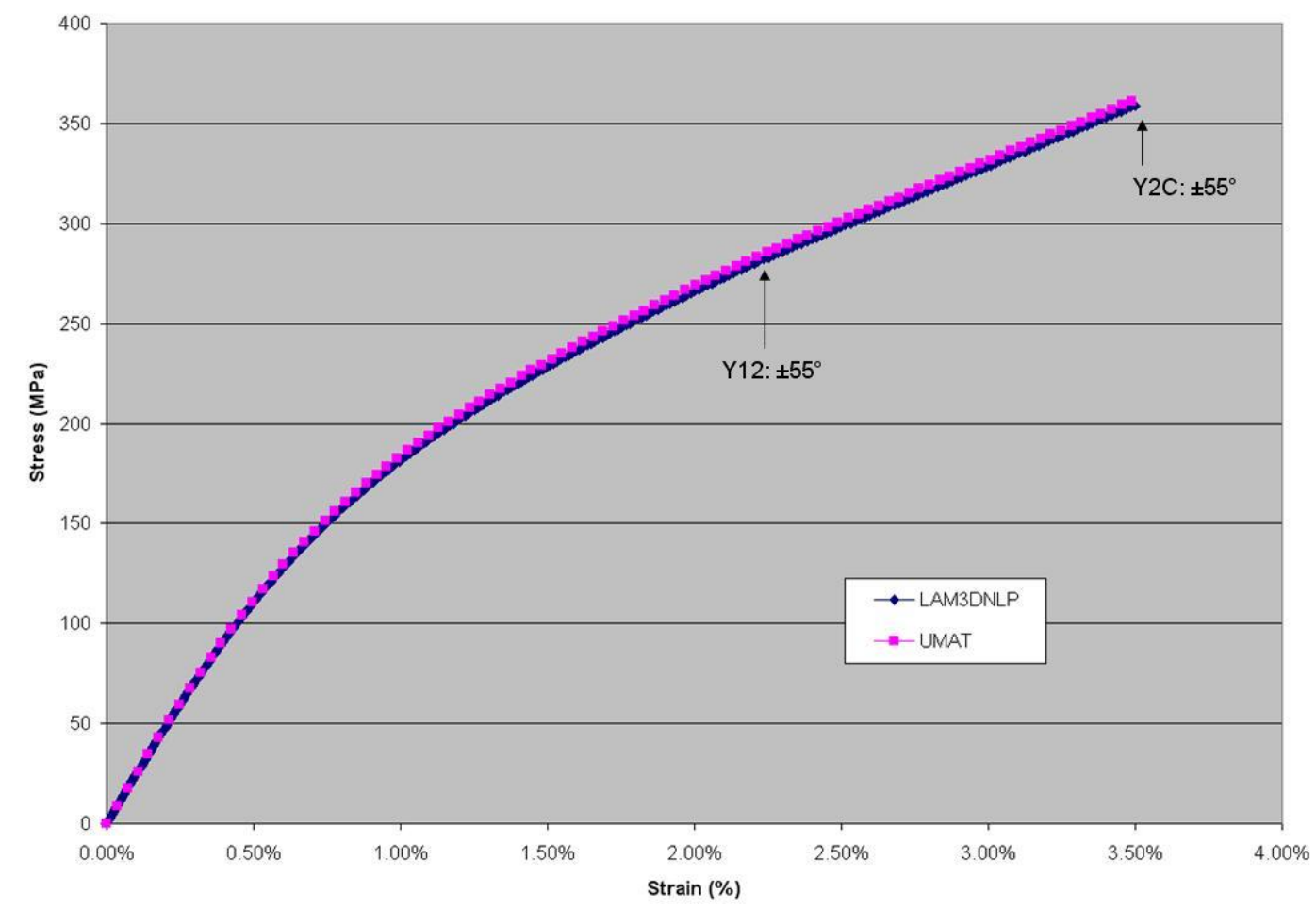

Figure 3.20 Stress vs. strain curves in Y-direction tension for $\left[ \pm 55^{\circ}\right]_{\mathrm{s}} \mathbf{E}$ Glass/MY750 comparing the UMAT and LAM3DNLP codes 


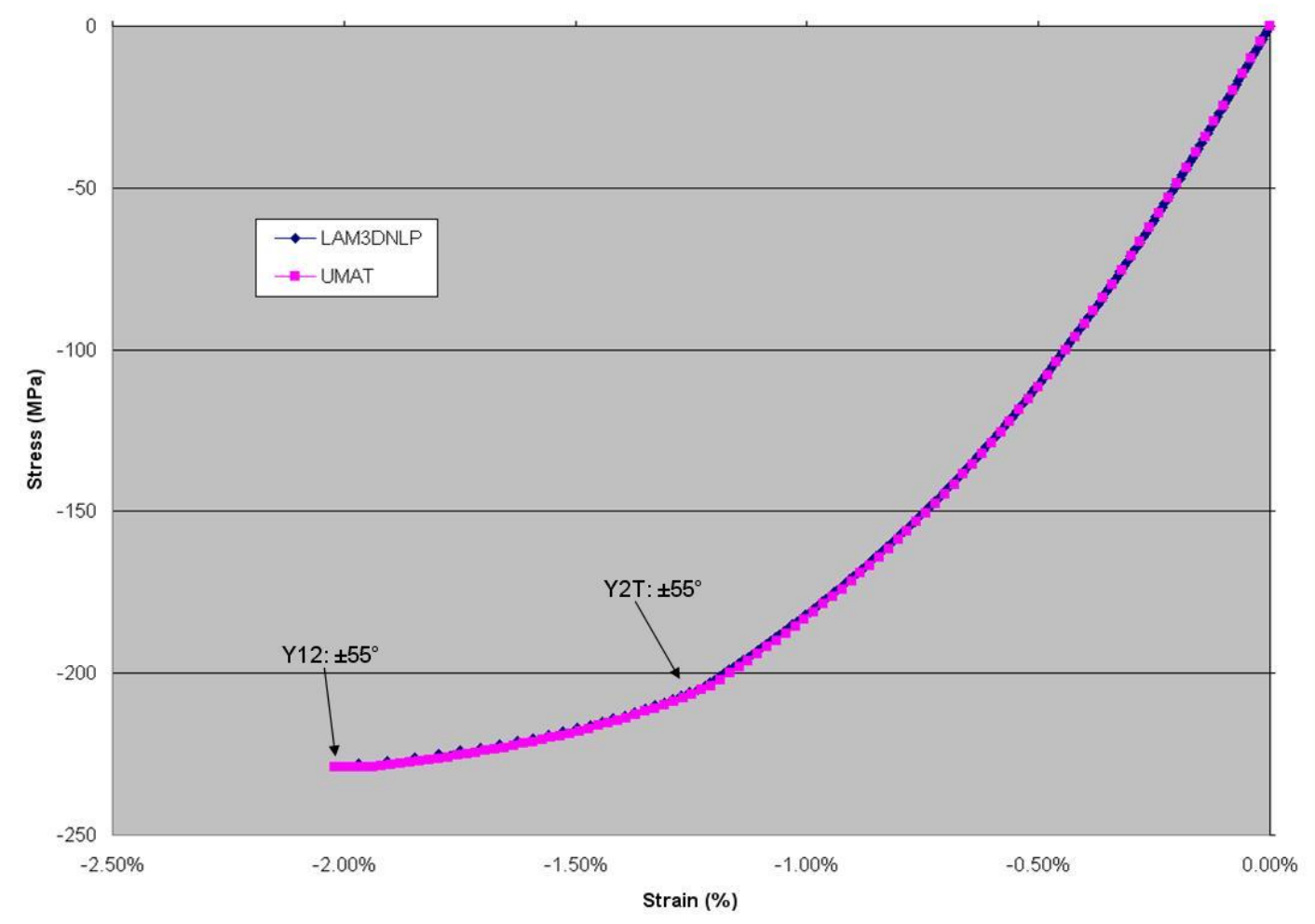

Figure 3.21 Stress vs. strain curves in Y-direction compression for $\left[ \pm 55^{\circ}\right]_{s}$ E-Glass/MY750 comparing the UMAT and LAM3DNLP codes

\subsection{Validation summary}

The comparison of the LAMPATNL user material output using a single element model to LAM3D for linear properties provided the first step towards validating the proper function of the subroutine. Four example cases were shown to validate the nonlinear and progressive failure aspects of the user material function correctly by generating the same output as LAM3DNLP. The validated LAMPATNL user material can now be utilized in the design of composite structures. The procedure of incorporating the user material into the design process of thick section composites is documented in the next chapter. 


\section{Chapter 4}

\section{CASE STUDIES}

LAM3DNLP and LAMPATNL were developed to analyze symmetric, thick section composite laminates and structures with ply level material nonlinearity and failure. In this chapter, two case studies are presented and examined with the LAMPATNL user material. The first case study is a simple block in compression that is partially fixed on one edge, inducing in-plane shear stresses. The second case study is an open hole sample subjected to simultaneous loading in the X-and Y-directions. The open hole sample is commonly used to check the effectiveness of composite failure models $[18,19,21-25,27,29,30]$. An example illustrating the improvements and contributions to the LAMPATNL design method over its original version is also provided.

\subsection{LAMPATNL output parameters}

A total of 16 parameters are output by the UMAT, so filtering and processing this data is an important part of the design process. Several useful output parameters are calculated for each element in the model in addition to the safety factor, critical mode, and critical ply parameters produced by the original LAMPATNL user material [4]. A full list and brief description of each parameter is provided in Table 4.1. These history dependent parameters are calculated and stored throughout the incremental solution. 
Table 4.1 List of state dependent parameters

\begin{tabular}{|c|c|l|}
\hline $\begin{array}{c}\text { Abaqus } \\
\text { Designation }\end{array}$ & Parameter Name & \multicolumn{1}{|c|}{ Description } \\
\hline SDV1 & CXXR & $\mathrm{C}_{X X}$ Ratio, X Stiffness \\
\hline SDV2 & CYYR & $\mathrm{C}_{Y Y}$ Ratio, Y Stiffness \\
\hline SDV3 & CZZR & $\mathrm{C}_{Z Z}$ Ratio, Z Stiffness \\
\hline SDV4 & CYZR & $\mathrm{C}_{Y Z}$ Ratio, YZ Stiffness \\
\hline SDV5 & CXZR & $\mathrm{C}_{X Z}$ Ratio, XZ Stiffness \\
\hline SDV6 & CXYR & $\mathrm{C}_{X Y}$ Ratio, XY Stiffness \\
\hline SDV7 & NOF & Number of Failures \\
\hline SDV8 & CMODE & Current Critical Failure Mode \\
\hline SDV9 & FMODE & Previous Failed Mode \\
\hline SDV10 & CPLY & Current Critical Ply Number \\
\hline SDV11 & FPLY & Previous Failed Ply Number \\
\hline SDV12 & SF & Safety Factor \\
\hline SDV13 & SUMCIJ & Sum of SDV1 through SDV6 \\
\hline SDV14 & PRODCIJ & Product of SDV1 through SDV6 \\
\hline SDV15 & MINCIJ & Minimum value of SDV1 through SDV6 \\
\hline SDV16 & MINCIJN & $C_{\text {ij }}$ number (1 to 6) of SDV15 \\
\hline
\end{tabular}

The first six parameters are stiffness ratios evaluated directly from the elemental (global) stiffness matrix. At the beginning of the finite element analysis, the values on the diagonal of the stiffness matrix, $\mathrm{C}_{\mathrm{ij}}$, are stored. These values change throughout the analysis due to material nonlinearity and progressive ply failure. The stiffness matrix is updated and the current values occupying the diagonal are divided by the original values to determine the stiffness ratio for that direction. Equation 4.1 shows the calculation of the $\mathrm{C}_{\mathrm{XX}}$ stiffness ratio $\mathrm{CXXR}$, with the calculation of the five other ratios following similarly.

$$
C X X R=\frac{C_{X X}^{c}}{C_{X X}^{i}}
$$


In Equation 4.1, the $c$ term is the current value and the $i$ term is the initial value. For this analysis, $\mathrm{C}_{\mathrm{XX}}$ refers to value in the $(1,1)$ position of the global $\mathrm{C}_{\mathrm{ij}}$ stiffness matrix, $\mathrm{C}_{\mathrm{YY}}$ in the $(2,2), \mathrm{C}_{\mathrm{ZZ}}$ in the $(3,3), \mathrm{C}_{\mathrm{YZ}}$ in the $(4,4), \mathrm{C}_{\mathrm{XZ}}$ in the $(5,5)$, and $\mathrm{C}_{\mathrm{XY}}$ in the $(6,6)$. The values of the stiffness ratios range from 1 to 0 , where a value of 1 indicates no stiffness loss from the original stiffness and 0 indicates complete loss of stiffness of the element in the direction.

The parameter for the number of failures, NOF or SDV7, records the number of ply failures that have occurred in the element. For example, if a $\left[0^{\circ} / 90^{\circ}\right]_{\mathrm{s}}$ laminate had transverse tensile failure in the $90^{\circ}$ plies and longitudinal tensile failure in the $0^{\circ}$ plies the number of failures would be 4 . This value is a result of symmetry with a single failure recorded in the two $90^{\circ}$ plies and another single failure recorded in the two $0^{\circ}$ plies. If failure has not occurred in the element, NOF will be at zero. This parameter does not indicate the effect of ply failure on the stiffness of the sample but is a count of the number of failure allowables exceeded in the element up to this point.

The critical mode CMODE, previous failed mode FMODE, critical ply CPLY, previous failed ply FPLY, and safety factor SF are important parameters used to determine the progressive ply failure history in LAMPATNL. The safety factor is defined as the ratio of the principle material direction strain allowable to the current ply level strain, as shown below:

$$
\begin{gathered}
S F_{1}=\frac{Y 1 T}{\varepsilon_{1}} \text { if } \varepsilon_{1}>0 \\
S F_{2}=\left|\frac{Y 1 C}{\varepsilon_{1}}\right| \text { if } \varepsilon_{1}<0
\end{gathered}
$$




$$
\begin{gathered}
S F_{3}=\frac{Y 2 T}{\varepsilon_{2}} \text { if } \varepsilon_{2}>0 \\
S F_{4}=\left|\frac{Y 2 C}{\varepsilon_{2}}\right| \text { if } \varepsilon_{2}<0 \\
S F_{5}=\frac{Y 3 T}{\varepsilon_{3}} \text { if } \varepsilon_{3}>0 \\
S F_{6}=\left|\frac{Y 3 C}{\varepsilon_{3}}\right| \text { if } \varepsilon_{3}<0 \\
S F_{7}=\left|\frac{Y 23}{\varepsilon_{4}}\right| \\
S F_{8}=\left|\frac{Y 13}{\varepsilon_{5}}\right| \\
S F_{9}=\left|\frac{Y 12}{\varepsilon_{6}}\right|
\end{gathered}
$$

where Y1T, Y1C, Y2T, Y2C, Y3T, Y3C, Y23, Y13, and Y12 are the maximum strain allowables. These calculations are done for all $\mathrm{N}$ plies in the laminate. The lowest value out of the $9 \mathrm{~N}$ safety factors is recorded and displayed as the SF output parameter. The ply with the lowest safety factor becomes the critical ply CPLY and the mode in which this safety factor has occurred is recorded as the critical mode CMODE. The values of CPLY range from 1 to $\mathrm{N}$. The values of CMODE correspond to the number of the lowest safety factor, as defined in Equations 4.2 to 4.10 , and range from 1 to 9 . Critical or failure mode 1 refers to 1-direction fiber tension, mode 2 is 1-direction fiber compression, mode 3 is 2-direction matrix tension, mode 4 is 2 direction matrix compression, mode 5 is 3 -direction matrix tension, mode 6 is 3 direction matrix compression, mode 7 is interlaminar (23) shear, mode 8 is 
interlaminar (13) shear, and mode 9 is in-plane (12) shear. The failure modes refer to the ply-level coordinate system that is related to the laminate and global systems as shown in Figure 4.1.
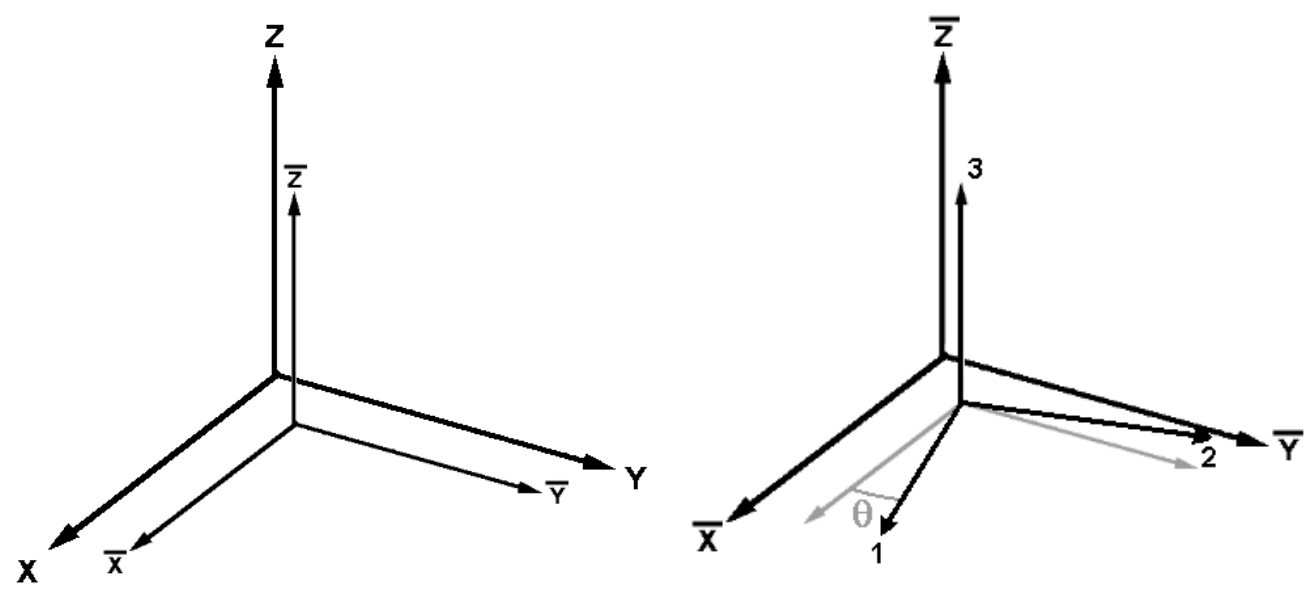

Figure 4.1 Relation of global coordinates to laminate and ply coordinates

When a strain in a ply has reached its allowable (safety factor=1), the failed ply and direction are discounted and excluded from the safety factor calculation. The critical ply at this point is recorded as the previous failed ply number FPLY and the critical mode becomes the previous failed mode FMODE. These values are initially at zero and will take on the range of values of CPLY and CMODE if ply failure occurs in the element. If failure is recorded, the FPLY and FMODE parameters will portray the progression of failure in the analysis.

The SUMCIJ parameter is simply the sum of the CXXR, CYYR, CZZR, CYZR, CXZR, and CXYR stiffness ratio parameters and can range from 6 to 0 . The PRODCIJ parameter is the product of these stiffness ratios and ranges from 1 to 0. 
The MINCIJ parameter records the minimum value of the six stiffness ratios and also ranges from 1 to 0 . The MINCIJN parameter indicates which stiffness ratio is recorded as the minimum for the element. If CXXR is the minimum stiffness ratio, MINCIJN is 1 , for CYYR it is 2, for CZZR it is 3, for CYZR it is 4, for CXZR it is 5, and for CXYR it is 6. If the minimum stiffness ratio for the element is greater than $80 \%$, no value for MINCIJN is recorded and this parameter is set to zero. Some output parameters are not used in the following case studies but may have more important uses in different analyses.

\subsection{Design methodology}

A standardized process for designing composite structures with the LAMPATNL user material has been developed. The output parameters produced by the user material are subsequently used to analyze the nonlinear response and progressive failure of the composite structure. The methodology for designing a structure using LAMPATNL is outlined in Figure 4.2. 


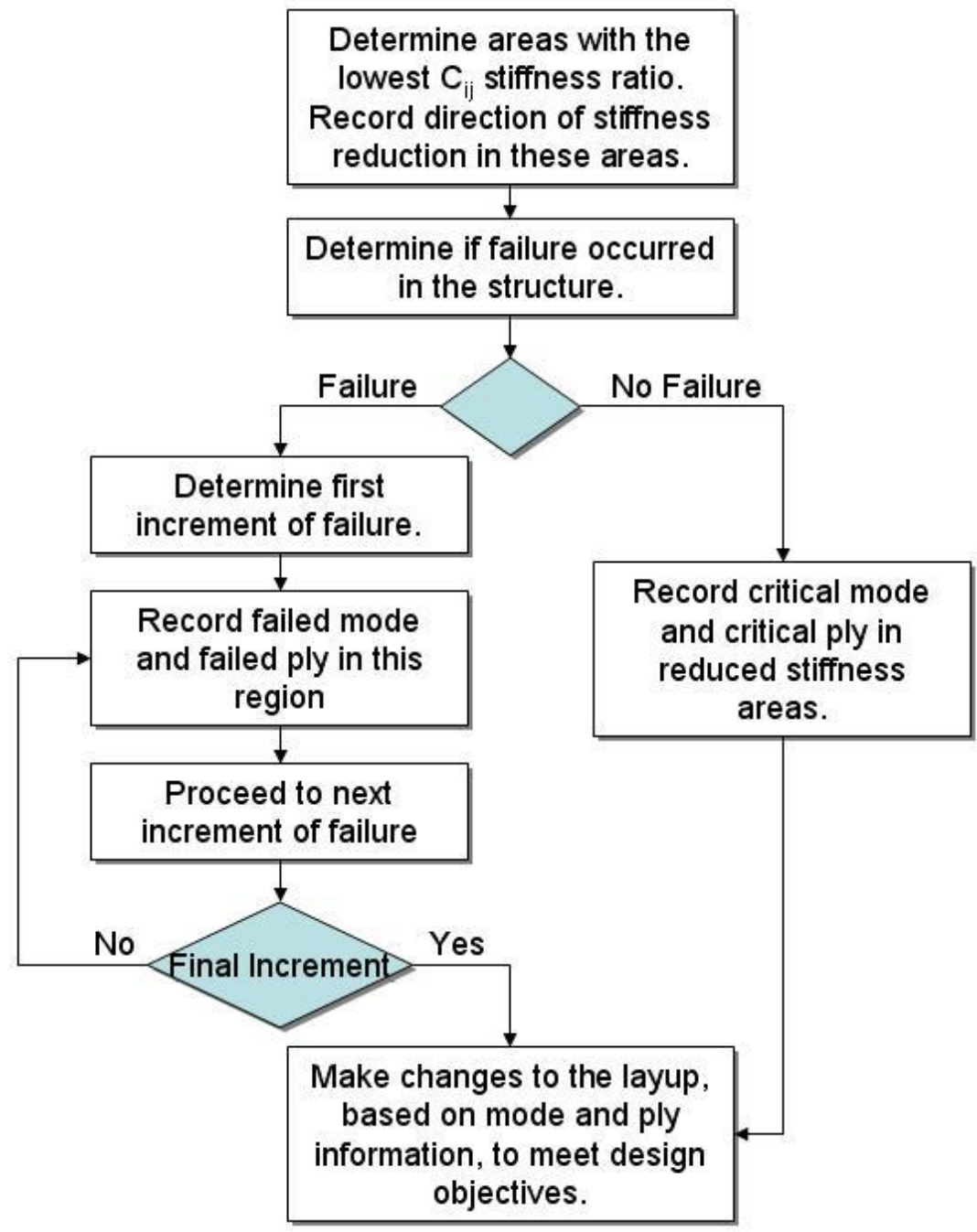

Figure 4.2 Design methodology flowchart

The largest reduction in original stiffness, identified by the lowest $\mathrm{C}_{\mathrm{ij}}$ ratio MINCIJ at the end of analysis, and its corresponding direction MINCIJN are examined first. The next step is to determine from the NOF parameter, which records the number of failures, whether the reduction in stiffness has been caused by material nonlinearity or ply failures. If there are ply failures in the areas of concern, the complete failure progression of the structure is constructed using the failed mode 
FMODE and failed ply FPLY. If the areas of low stiffness ratio are caused by nonlinear effects, the critical ply CPLY and mode CMODE at the final increment become the basis for changes to the layup. The designer would use this information, critical ply and mode or failure progression, to make changes to the design of the structure to achieve the objectives of the analysis. Multiple iterations of this design methodology may be needed in order to achieve these objectives. The following case studies help to demonstrate this design methodology.

\subsection{Original LAMPATNL design methodology}

An example comparing the original outputs of LAMPATNL (safety factor, critical mode, and critical ply) to the new stiffness ratios outputs is provided in this section. This example illustrates new contributions that the stiffness ratio parameters bring to visualizing the critical design information of the structure.

In this example, a laminate of a $\left[0^{\circ} / 90^{\circ}\right]_{\mathrm{S}}$ layup of IM7/8551-7 is tested as a beam in bending. The Ramberg-Osgood parameters and maximum strain allowables for this material are shown in Tables 3.4 and 3.5 respectively. The sample is constrained in $\mathrm{X}$ - and Z-directions along the bottom right edge and the Z-direction along the bottom left edge as shown in Figure 4.3. Also in Figure 4.3, a displacement in the Z-direction along a portion of the top face is applied to introduce a bending load into the sample. 


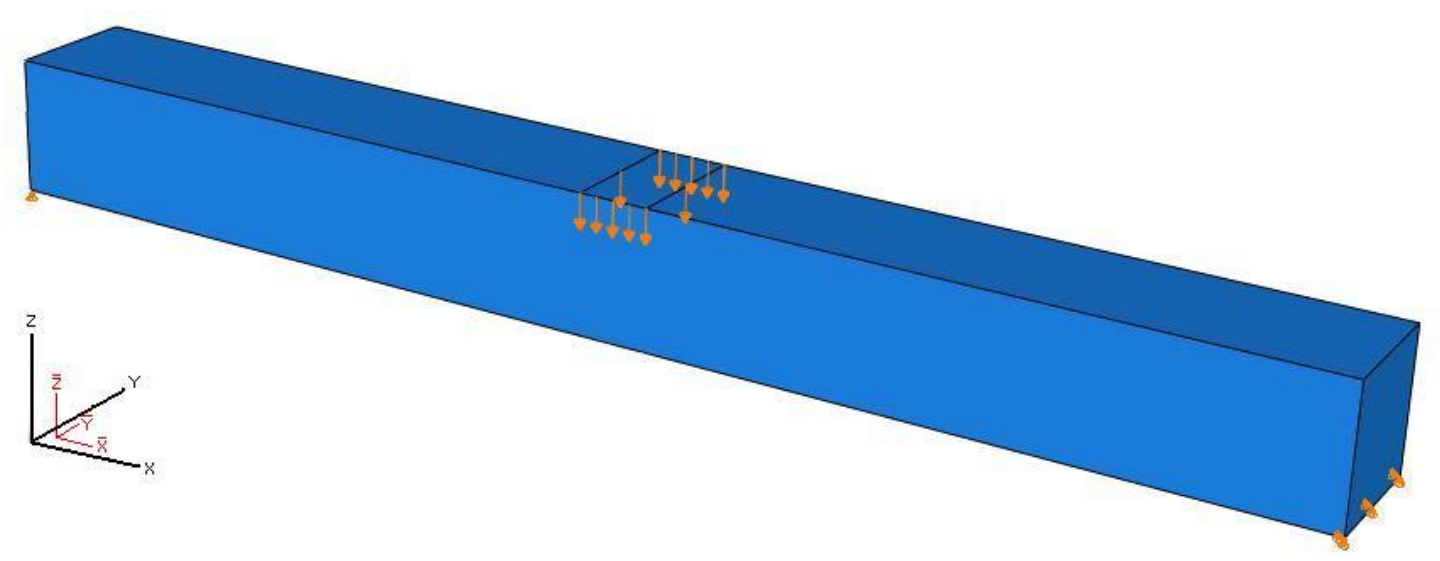

Figure 4.3 Diagram of bending sample

The outputs that were originally available in LAMPATNL analysis were the safety factor SF, critical mode CMODE, and critical ply CPLY. When a strain in a ply has reached its allowable, the ply fails. This ply and direction are discounted and excluded from the safety factor calculation. The recorded value of the safety factor therefore decreases to one before jumping to a different value, as shown for the loading of an arbitrary element in Figure 4.4. 


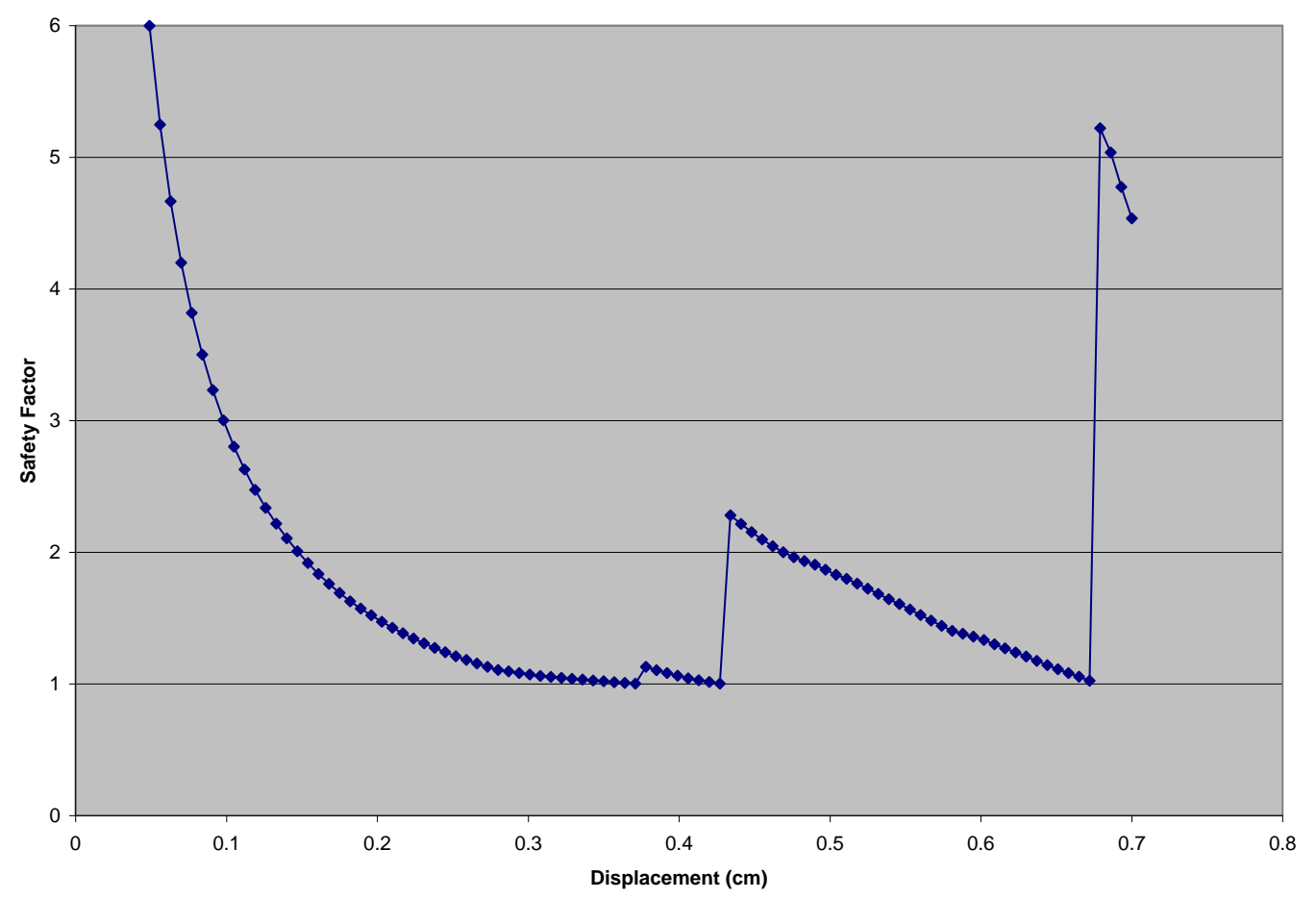

\section{Figure 4.4 Plot of safety factor vs. displacement}

At the end of the simulation for this example, the element shown in Figure 4.4 displays a safety factor of 4.53 yet there have been at least three ply failures in this element. Information on the failure history of the laminate in this element cannot be determined from this final value of safety factor.

Figure 4.5 shows the contour plots of safety factor from the beginning to the end of the analysis. In these plots, blue areas have a safety factor close to 1 , red areas indicate a safety factor of 5, and grey areas are anything greater than 5. From the plot of the final increment (last plot in the series), it can be determined that the blue areas are close to failure, but there is no information on which areas and plies have failed nor is there information about how these failures have affected the stiffness of 
the structure. The complex and abrupt fluctuations in the safety factor and the inability to determine the failure history prevent the original outputs of LAMPATNL from effectively providing the information necessary to make changes to the composite design.
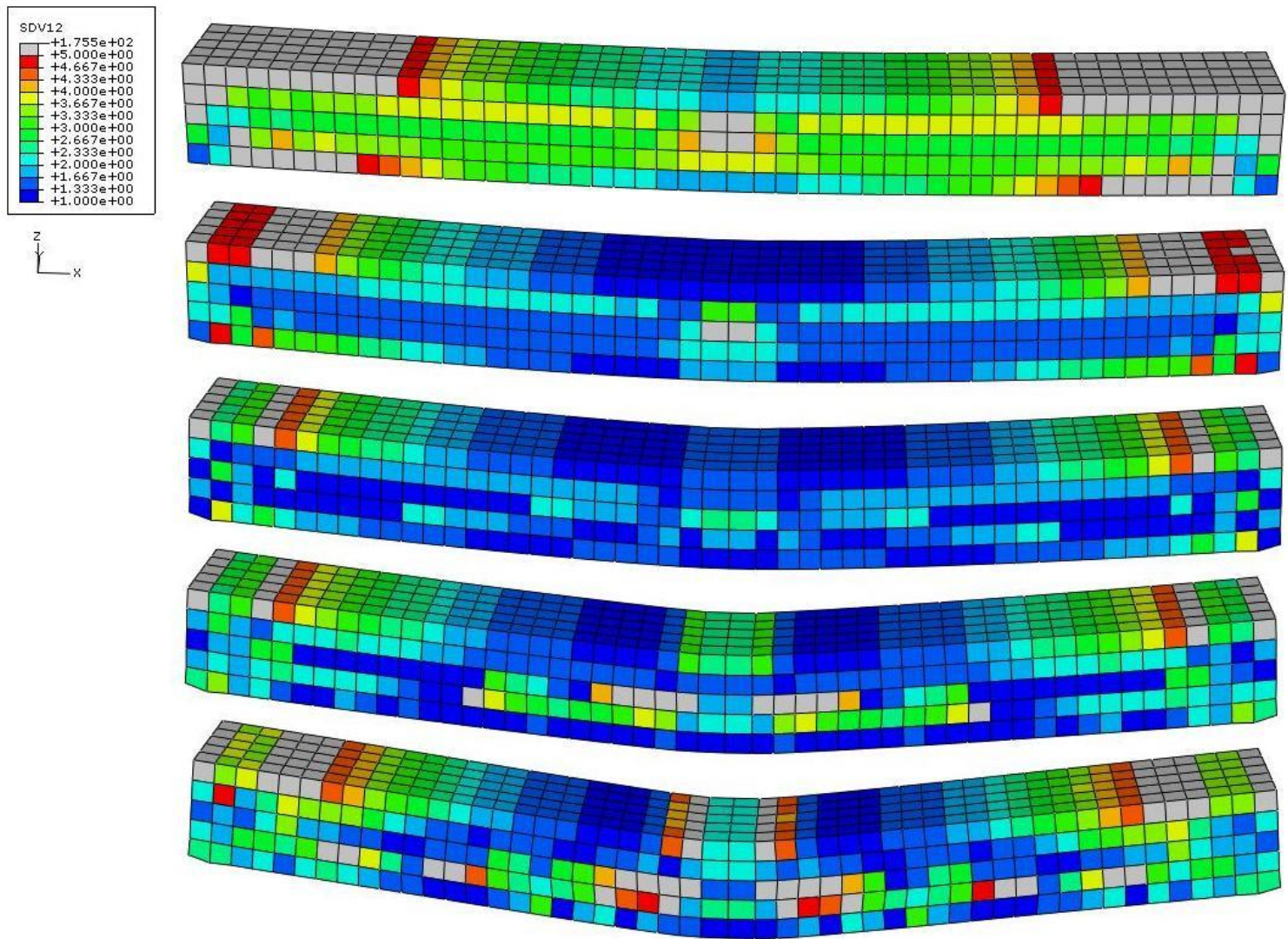

Figure 4.5 Plot of progression of safety factor (SF)

In this work, new output parameters from LAMPATNL are proposed that include the structural stiffness ratios of the laminate. These parameters are detailed in the LAMPATNL output parameters section of this chapter. Figure 4.6 shows the 
results of the MINCIJ parameter in the same arbitrary element documented in Figure 4.4. This plot shows that there was catastrophic stiffness loss in at least one direction for this element. At the end of the analysis, the value of this parameter is 0.007 , indicating that complete stiffness loss has occurred in at least one direction in this element.

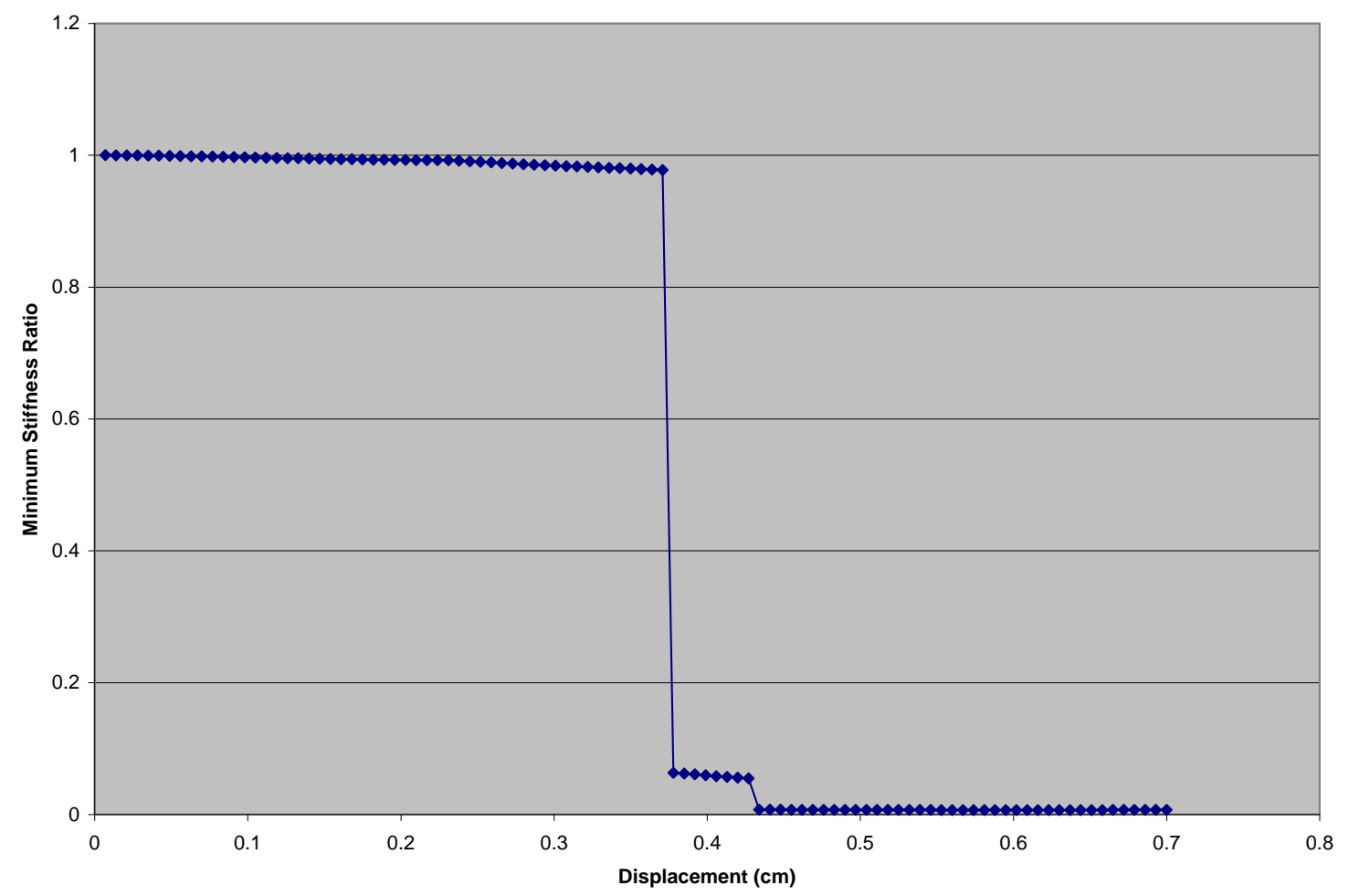

Figure 4.6 Plot of minimum stiffness ratio (MINCIJ) vs. displacement

A progression plot of the MINCIJ parameter is shown in Figure 4.7. In this plot, areas that are blue correspond to a zero stiffness ratio (complete stiffness loss) and areas that are red correspond to no stiffness loss. By examining the contour 
plot of the last increment, it is easy to determine which areas have severe stiffness loss and which areas do not. Because of the simple nature of the stiffness ratio measure, it is easy to determine from the progression which areas have failed and in which order they have failed. This contrasts from the safety factor plots shown in Figure 4.5, which do not efficiently visualize the failure history of the part.
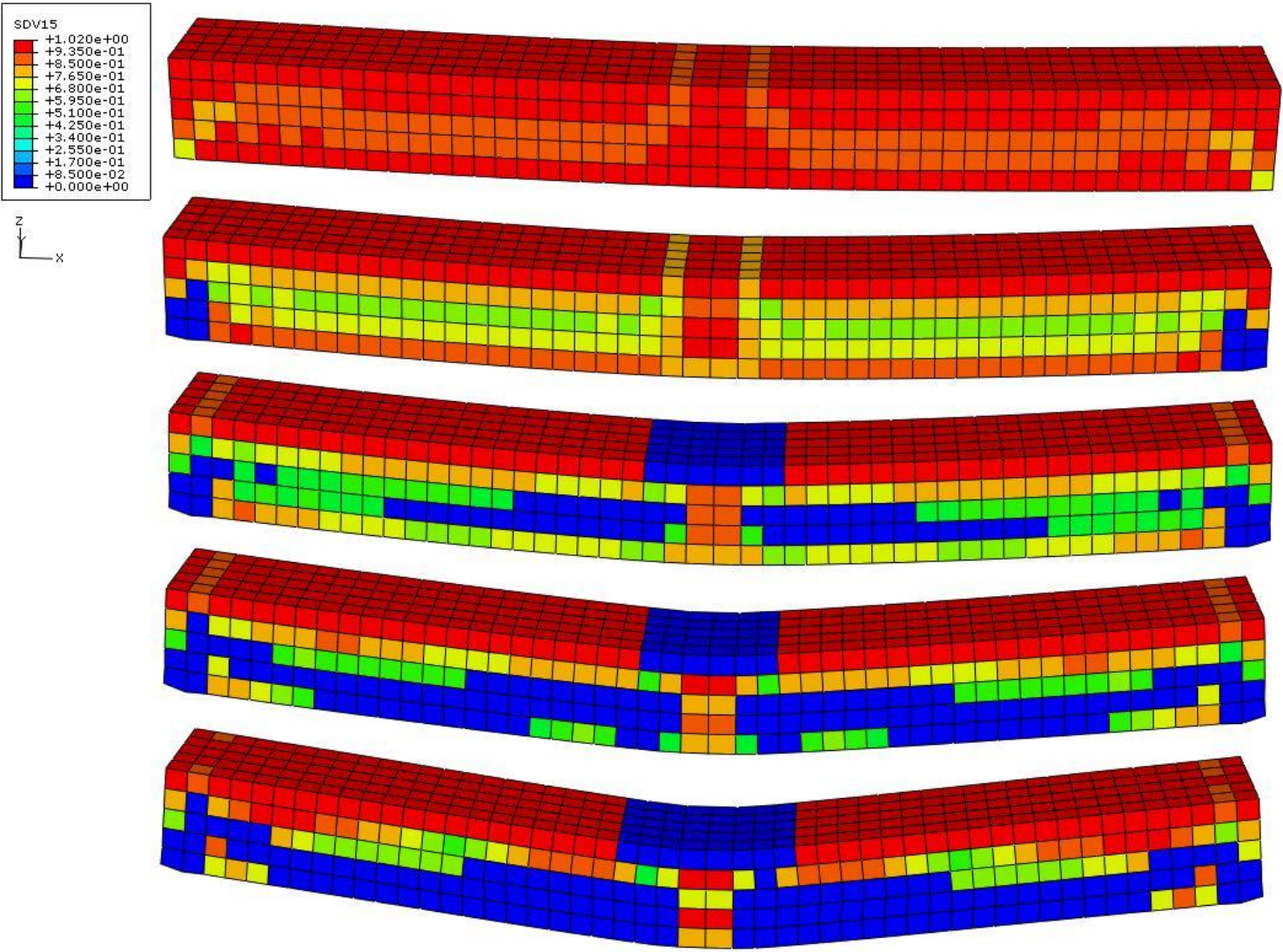

Figure 4.7 Plot of progression of minimum stiffness ratio (MINCIJ) 


\subsection{Case study \#1}

\subsubsection{Description}

The first case study that is examined with the LAMPATNL is a compressive shear sample. This sample was created to represent a composite material that is bonded to a much stiffer material. The sample, shown in Figure 4.8, is rectangular with an aspect ratio of 2.5 that is fixed on one half of one side. A compressive load in the $\mathrm{X}$-direction is applied to one end of the sample and a boundary condition on the opposing end prevents the sample from moving in the $\mathrm{X}$ direction. 


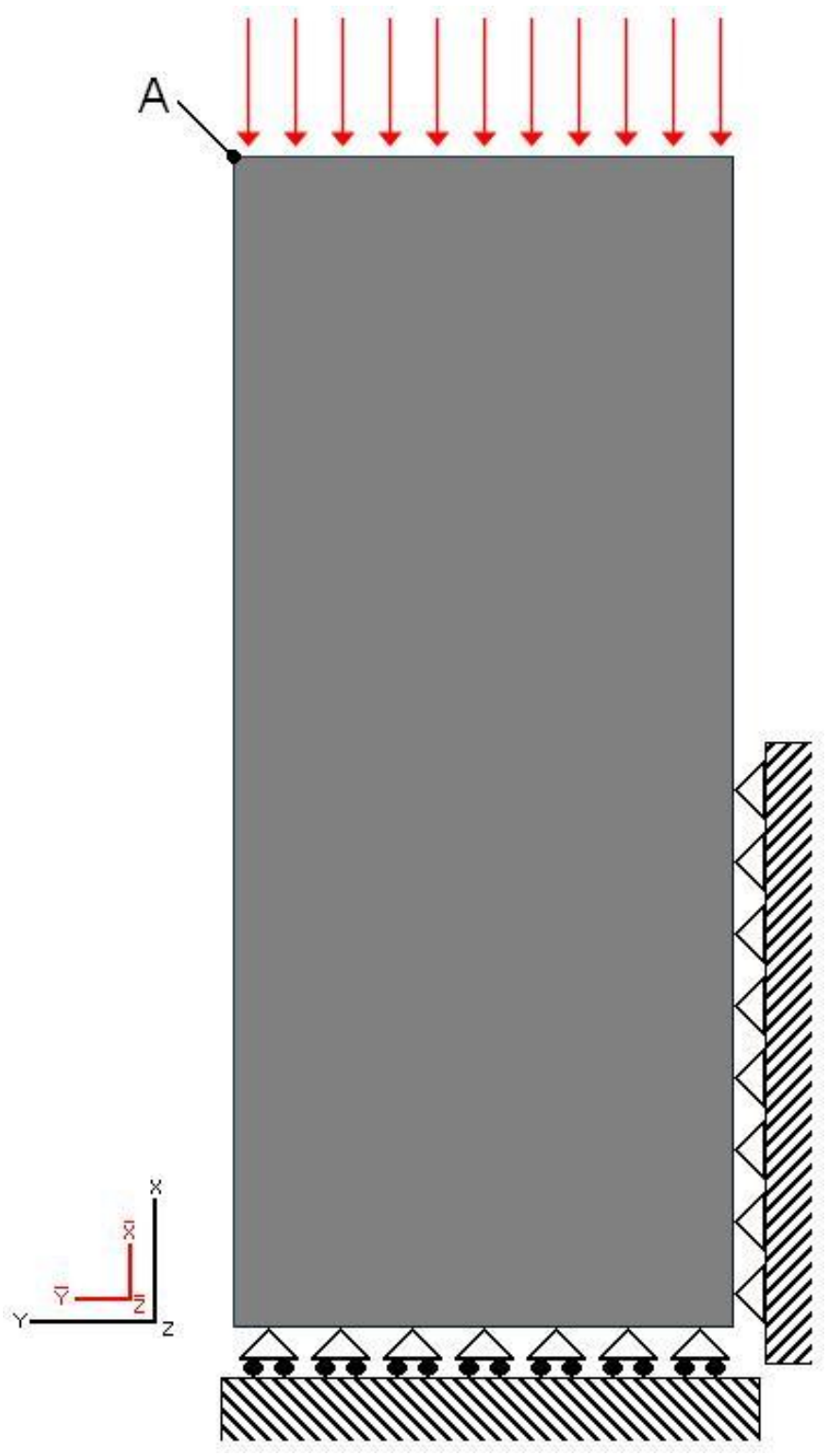

Figure 4.8 Diagram of shear sample

The first design tested is a $\left[0^{\circ} / 90^{\circ}\right]_{\mathrm{S}}$ layup of AS4/3501-6. The RambergOsgood parameters and maximum strain allowables for this material are shown in Tables 3.4 and 3.5, respectively. A uniform pressure of $800 \mathrm{MPa}$ is applied to the top 
end of the sample, causing compressive stresses and a shear stress concentration close to the right fixed boundary condition.

The sample is modeled using a mesh of 6448 three-dimensional 8-node linear brick elements with reduced integration, type C3D8R in ABAQUS. The mesh contains 8505 nodes each with three degrees of freedom, resulting in 25515 total degrees of freedom. For each case study, the mesh was varied in both density and structure to ensure the results of the simulation did not change dramatically.

The objective of this case study is to limit the displacement of point A (see Figure 4.8) in the X-direction to $0.05 \mathrm{~m}$. Limiting the shear and longitudinal failure is important to the performance of this sample, so reducing areas of stiffness loss in these directions is also an objective. Based upon the performance of the first layup, modifications to the laminate may be needed to achieve the objective. Any change to the laminate must maintain the same material, weight, and thickness from the original layup. These changes are made based on information gained from the process outlined in the design methodology.

\subsubsection{Results of original design}

Following the procedure outlined in the design methodology, the first step is to investigate the lowest ratio of current stiffness to original stiffness at the end of the analysis. The contour plot of the LAMPATNL output parameter MINCIJ is shown in Figure 4.9. In this plot, areas of concern are those that are blue, corresponding to a zero stiffness ratio, and areas of least concern are red, corresponding to no stiffness loss. This color scale holds for all plots of the MINCIJ, CXXR, CYYR, CZZR, and CXYR shown in this case study. 


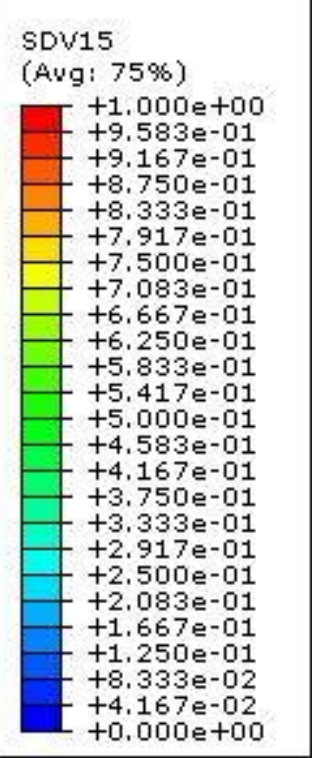

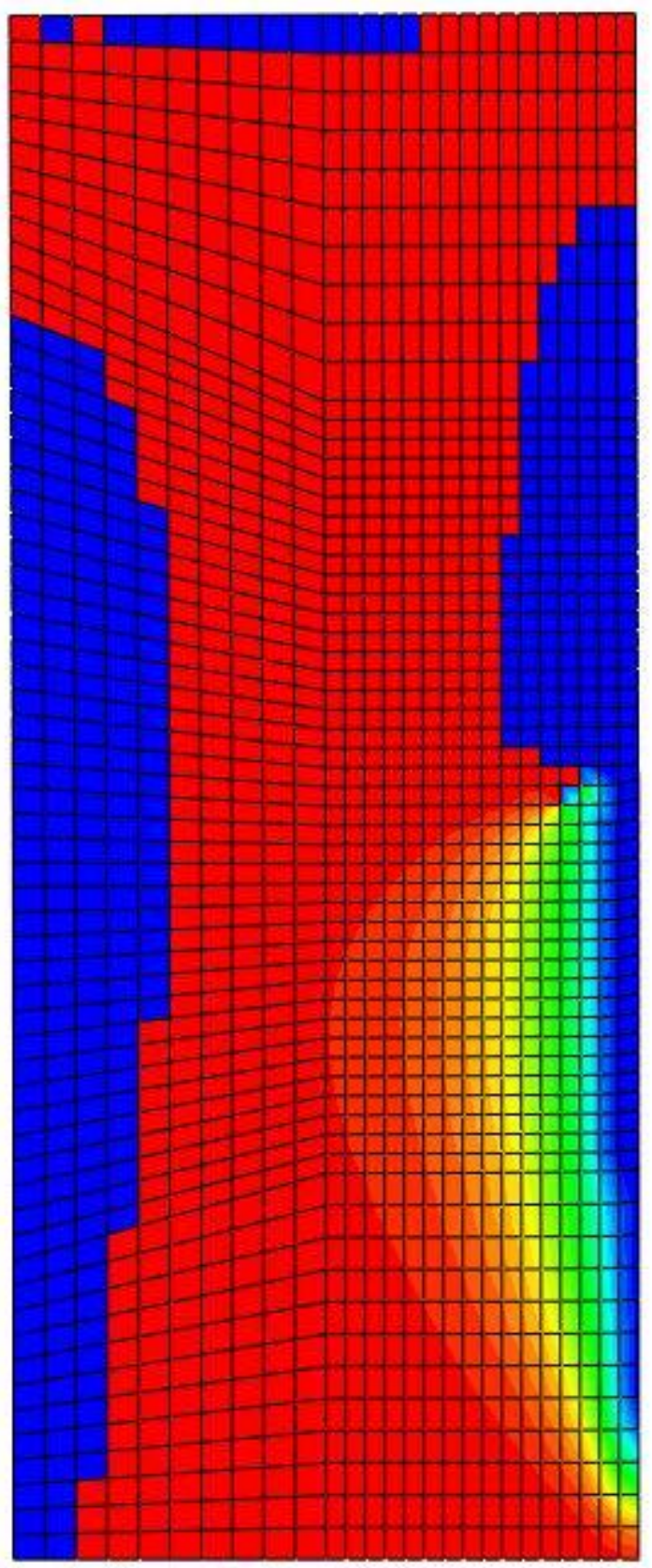

Figure 4.9 Contour plot of minimum $C_{i j}$ stiffness ratio, MINCIJ 
A significant area of the structure has at least one of its stiffness ratios near zero. The next step in this methodology is to determine which direction the stiffness ratios are at or near zero. A plot of the $C_{i j}$ number (1-6), MINCIJN, indicates the critical direction of the lowest stiffness ratio and is shown in Figure 4.10.
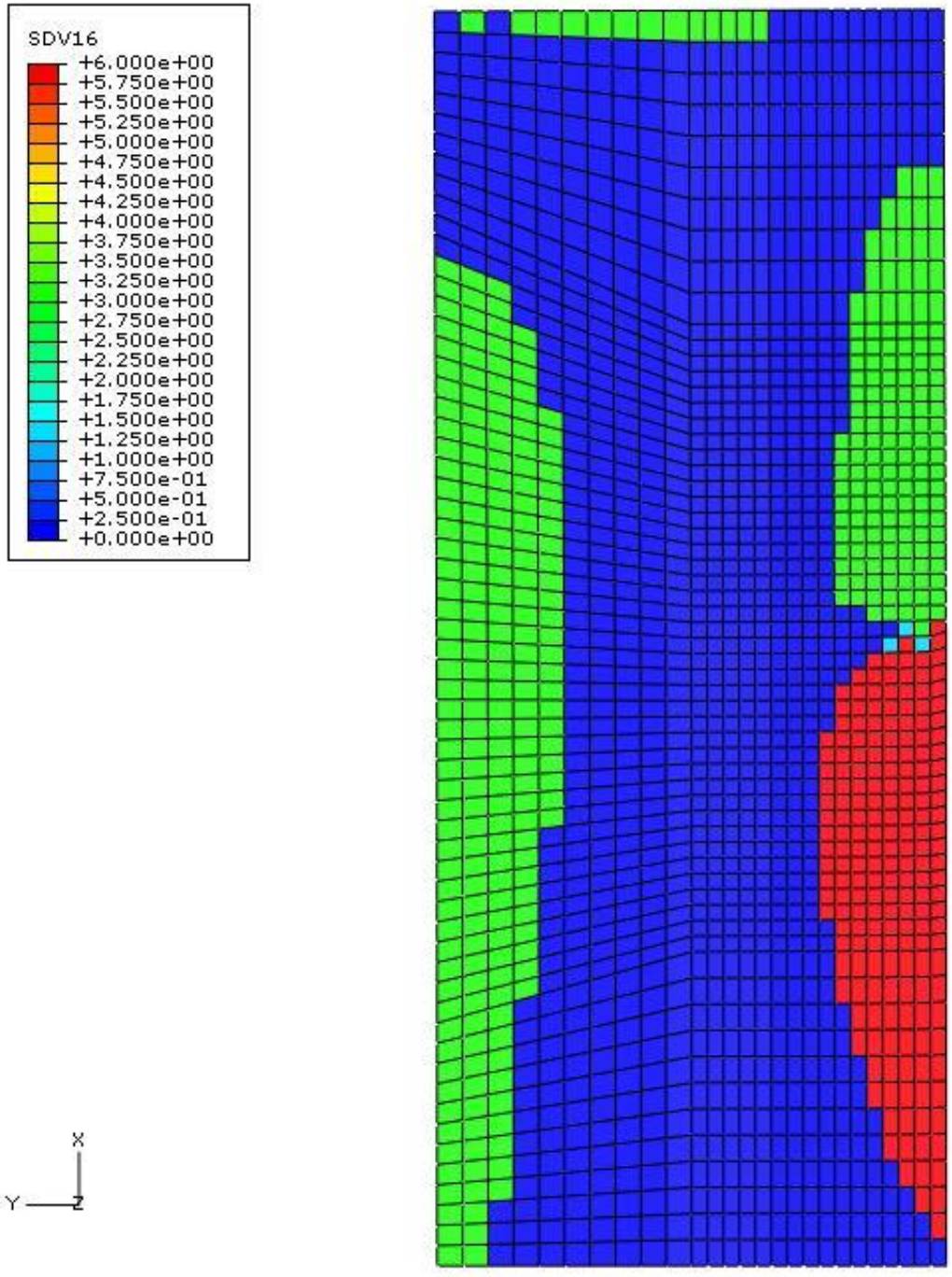

Figure 4.10 Contour plot of the direction of minimum $C_{i j}$ ratio, MINCIJN 
The area in the bottom right portion of the structure at the fixed half-face has $\mathrm{C}_{\mathrm{XY}}$ (red area of MINCIJN=6) as the lowest stiffness ratio, corresponding to the XY shear stiffness. The areas in green also have a stiffness ratio close to zero and correspond to a value of 3 in this plot. This result shows that there is a loss of stiffness in the $\mathrm{C}_{\mathrm{ZZ}}$ stiffness ratio, or global Z-direction. This is not a result of loading in the Zdirection, but a result of ply strains caused by Poisson's effects exceeding the low through-thickness tensile failure allowable.

In order to further investigate the critical losses in stiffness, a closer examination of each individual stiffness ratio is required. Upon inspection, the CXXR, CYYR, CZZR, and CXYR stiffness ratio parameters are low in the areas of interest. The contour plot of the CZZR ratio in Figure 4.11 confirms what is shown in Figure 4.10, that a large part of the sample has lost stiffness in the Z-direction. The plot of the $\mathrm{C}_{\mathrm{XY}}$ stiffness ratio, shown in Figure 4.12, also confirms what is shown in Figure 4.10, that the XY shear stiffness is reduced near the fixed face of the sample. 


$$
\begin{aligned}
& \text { SDV3 } \\
& \begin{array}{|r|r|}
+1.000 e+00 \\
+9.583 e-01 \\
+9.167 e-01 \\
+8.750 e-01 \\
+8.333 e-01 \\
+7.917 e-01 \\
+7.500 \mathrm{e}-01 \\
+7.083 \mathrm{e}-01 \\
+6.667 \mathrm{e}-01 \\
+6.250 \mathrm{e}-01 \\
+5.833 \mathrm{e}-01 \\
+5.417 \mathrm{e}-01 \\
+5.000 \mathrm{e}-01 \\
+4.583 \mathrm{e}-01 \\
+4.167 \mathrm{e}-01 \\
+3.750 \mathrm{e}-01 \\
+3.333 \mathrm{e}-01 \\
+2.917 \mathrm{e}-01 \\
+2.500 \mathrm{e}-01 \\
+2.083 \mathrm{e}-01 \\
+1.667 \mathrm{e}-01 \\
+1.250 \mathrm{e}-01 \\
+8.333 \mathrm{e}-02 \\
+4.167 \mathrm{e}-02 \\
+0.000 \mathrm{e}+00
\end{array}
\end{aligned}
$$
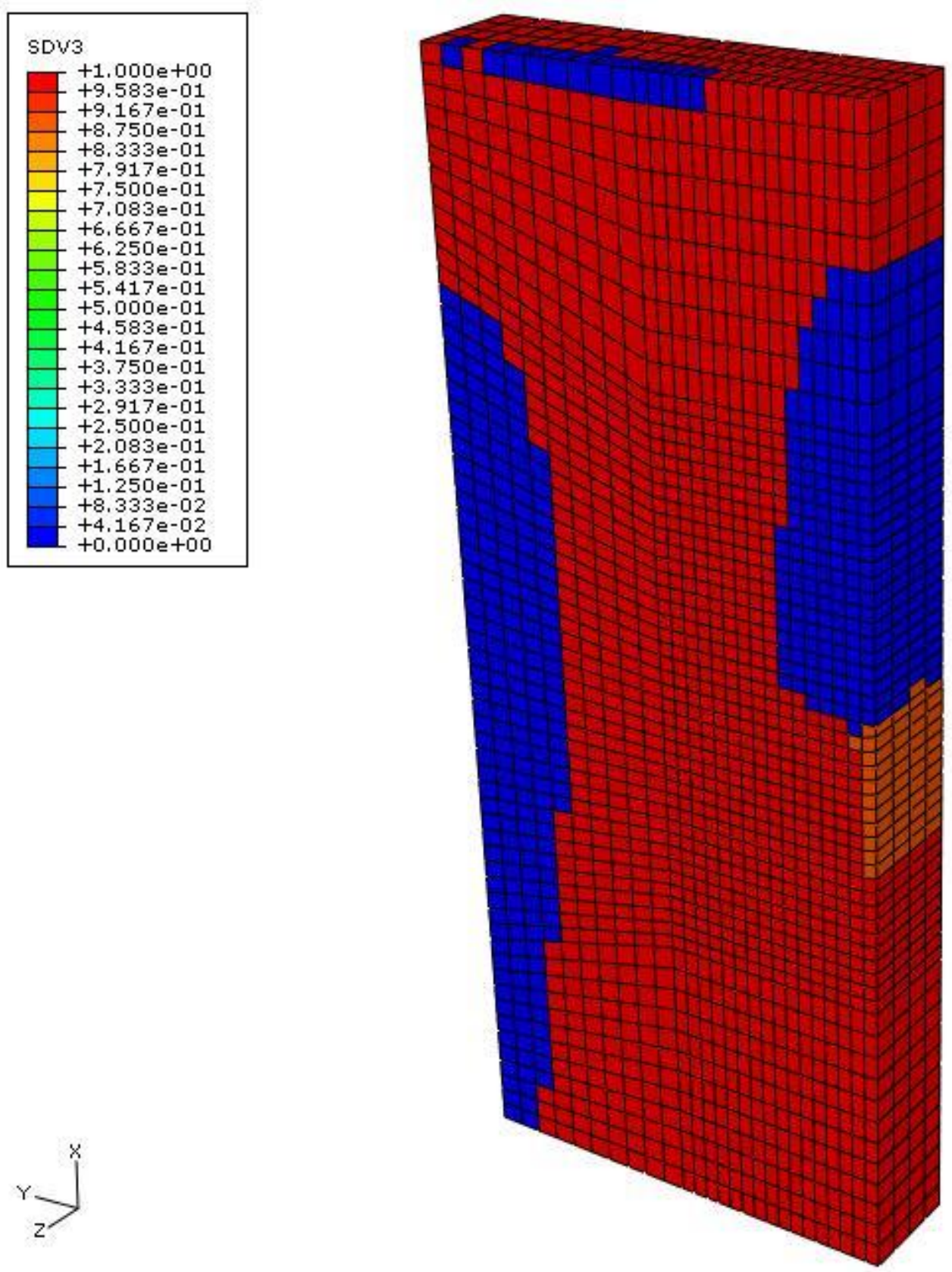

Figure 4.11 Plot of CZZ stiffness ratio, CZZR 

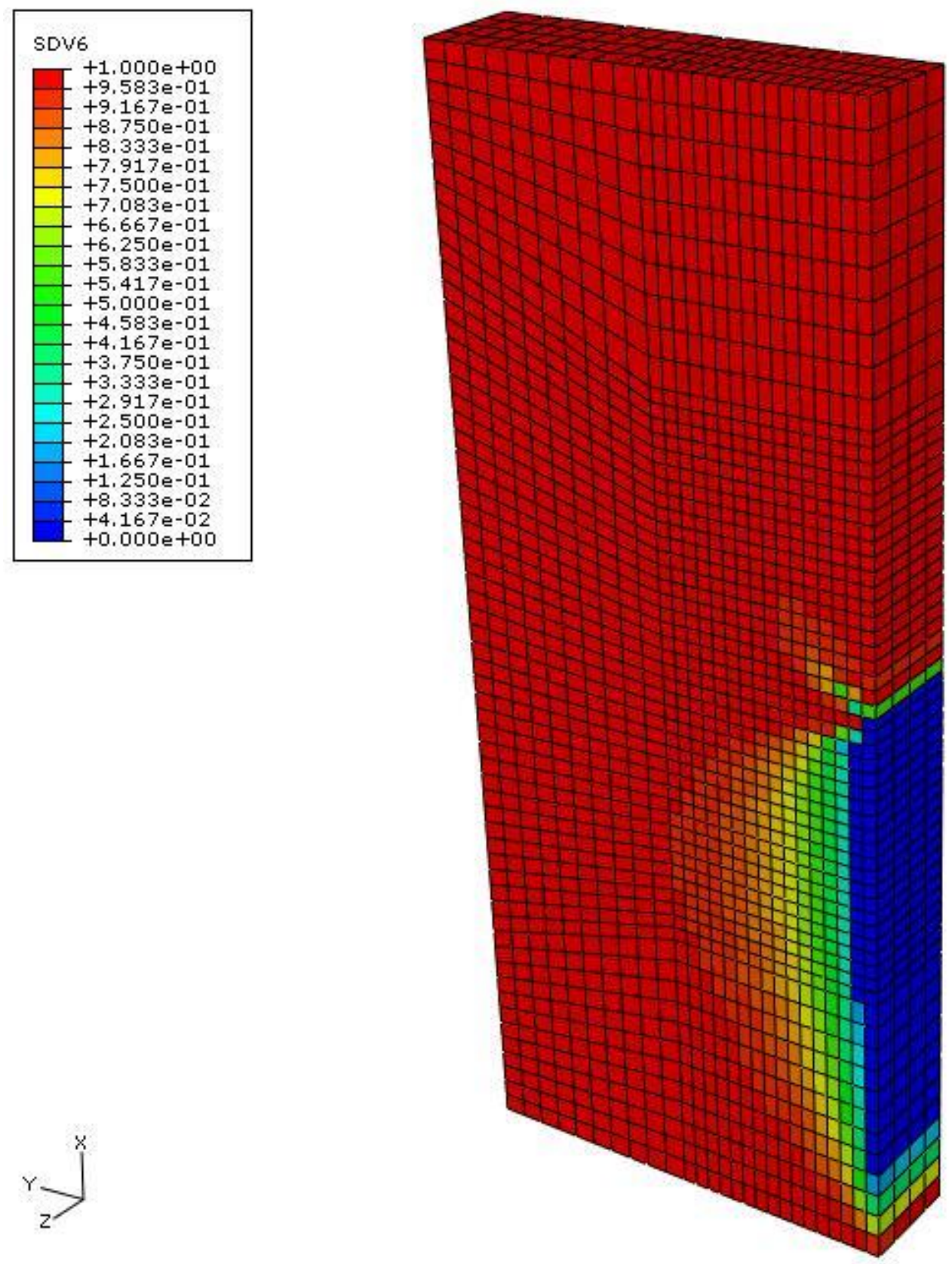

Figure 4.12 Plot of CXY stiffness ratio, CXYR

A closer examination of the plot of the $\mathrm{C}_{\mathrm{YY}}$ stiffness ratio shows that the upper portion of the fixed face also experiences a loss of stiffness in the Y-direction as 
shown in Figure 4.13. The limitation of the contour plot in Figure 4.10 is that only one value for each element can be displayed. In the upper portion of the fixed face, the loss of stiffness occurs in both the Y-and XY-directions although only the shear direction is indicated in this area in Figure 4.10.
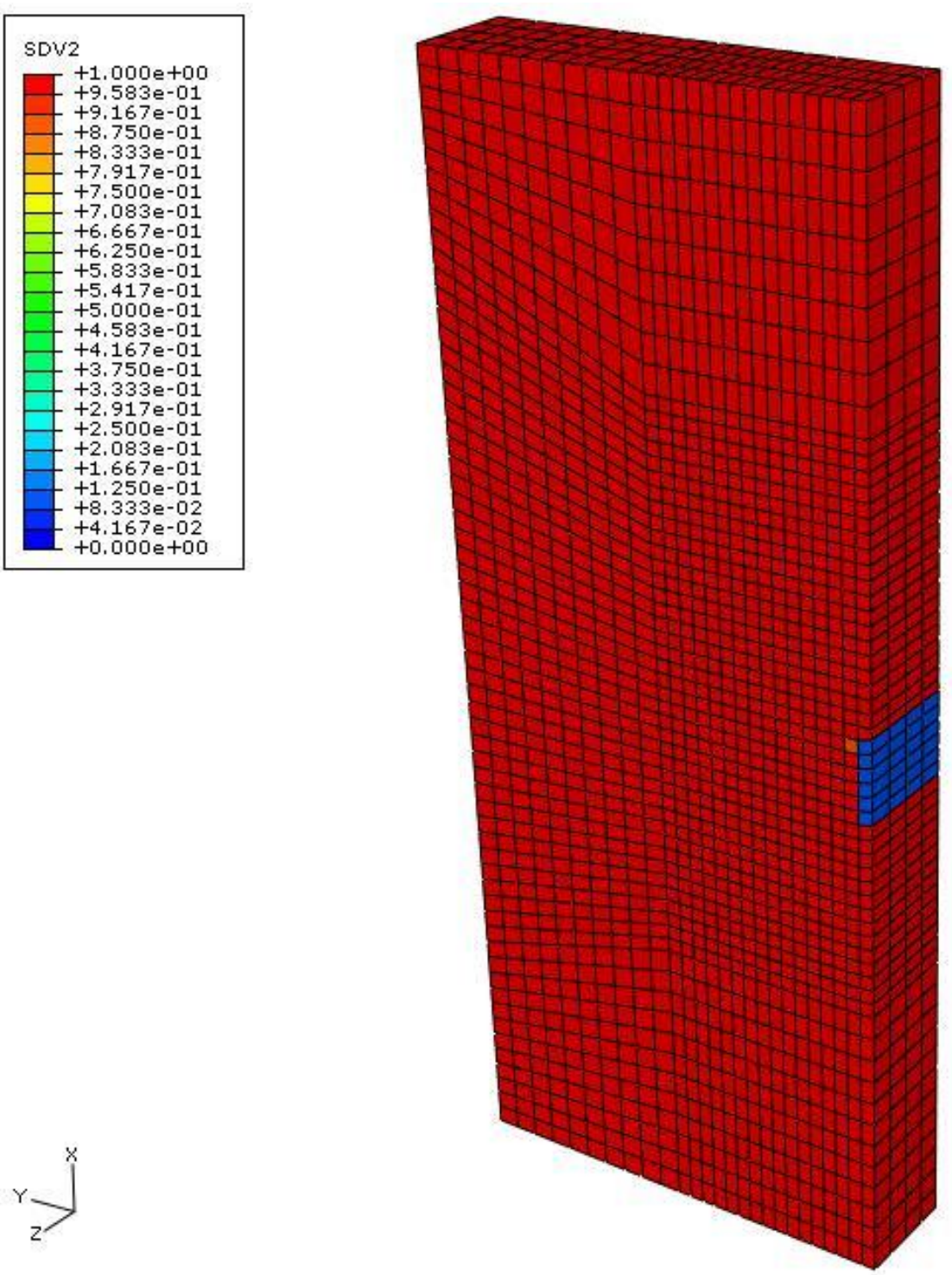

Figure 4.13 Plot of CYY stiffness ratio, CYYR 
A similar scenario occurs in the areas of Figure 4.10 that indicate Zdirection failure. Figure 4.14 shows the plot of the $\mathrm{C}_{\mathrm{XX}}$ stiffness ratio, in which a large part of the area that had stiffness loss in the Z-direction also has a loss of X-direction stiffness. Because the sample is loaded in this direction, this failure is important to the response of the structure.
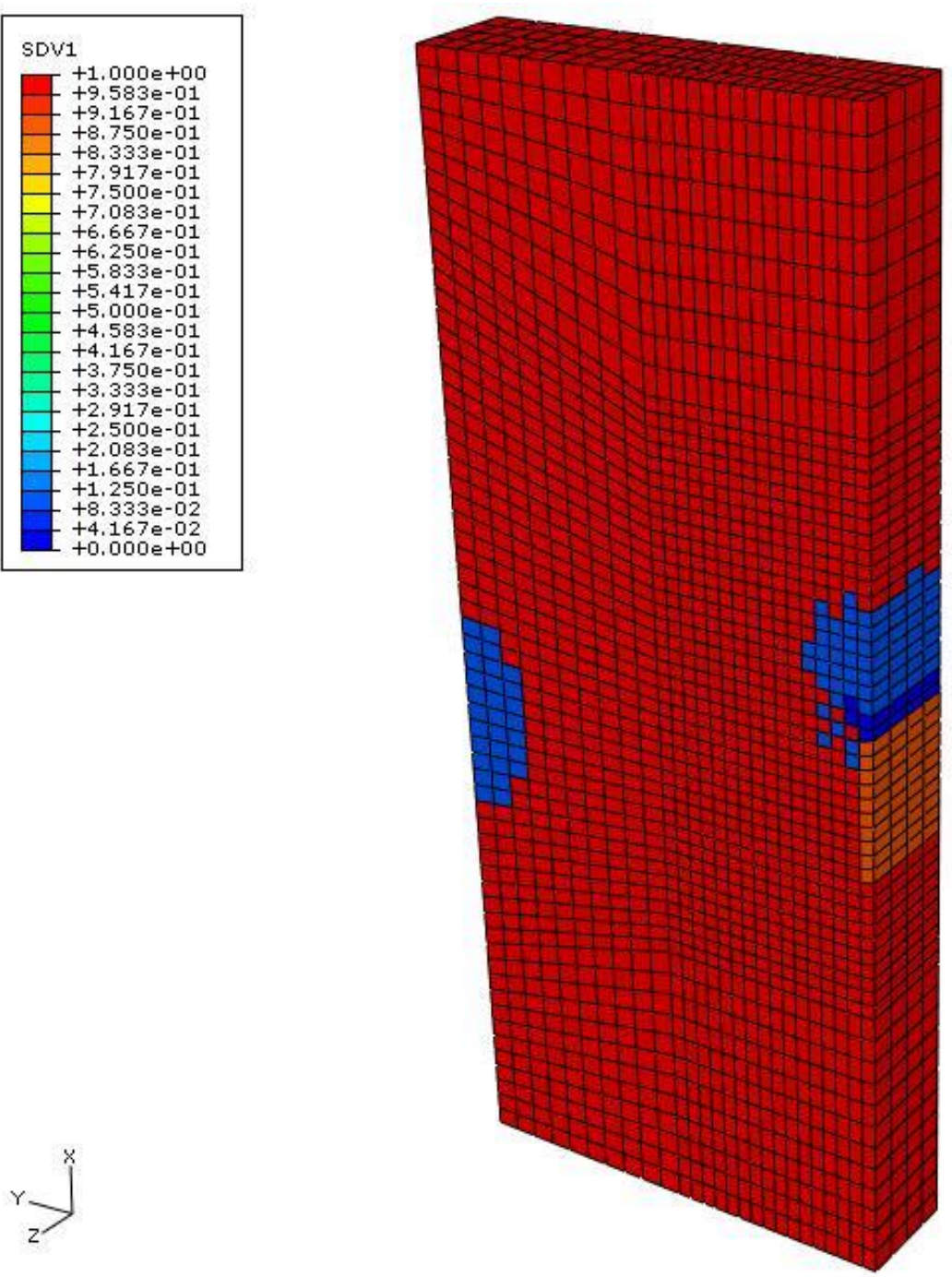

Figure 4.14 Plot of CXX stiffness ratio, CXXR 
The next step of the design methodology is to determine if there are any ply failures recorded. Because a large part of the sample has a stiffness ratio at or near zero, ply failures are to be expected. A plot of the number of failures that have occurred is shown in Figure 4.15. The upper portion of the fixed face has the most ply failures. This plot also shows areas that have a loss of stiffness in the X-direction are differentiated from those with only Z-direction failure, shown as the areas of orange and green, respectively.
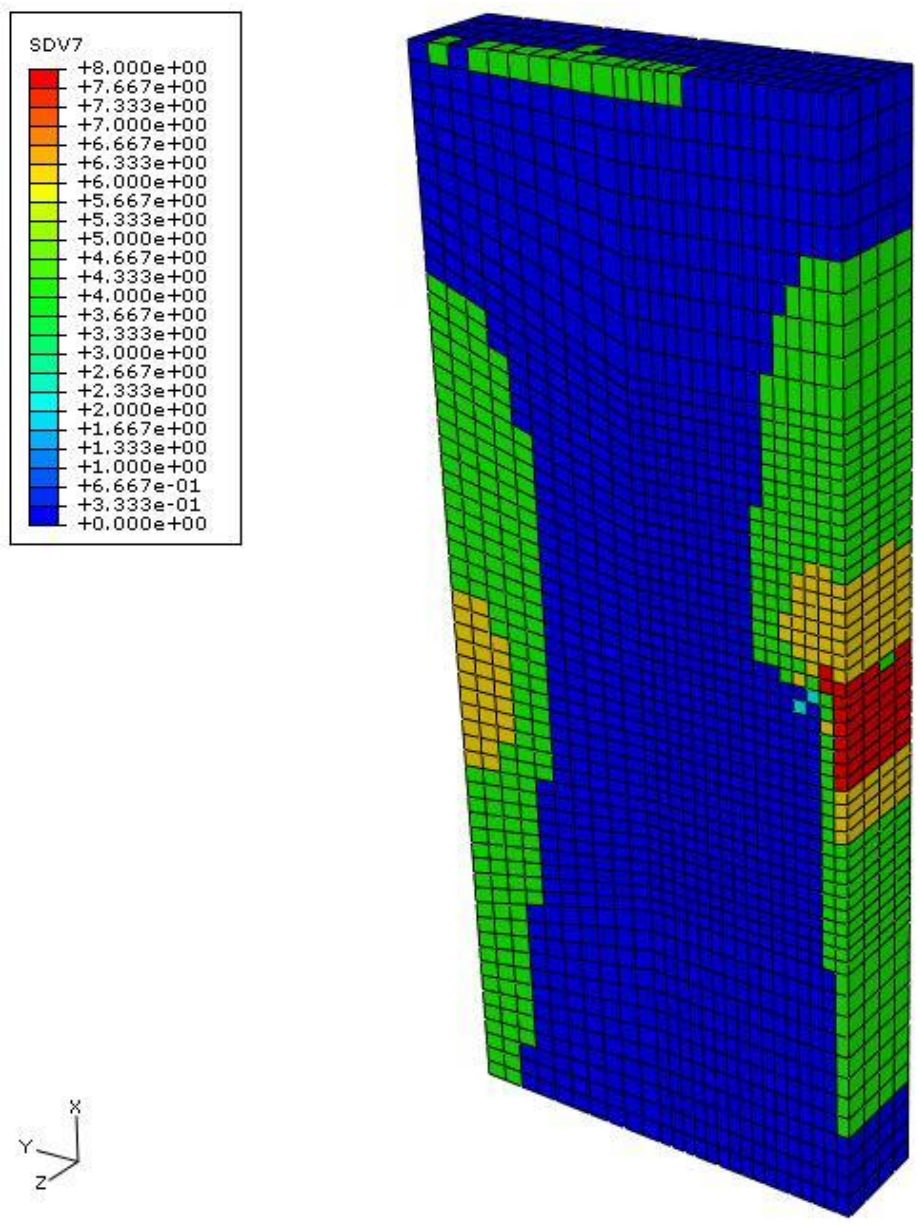

Figure 4.15 Contour plot of number of failures, NOF 
Continuing in the design methodology, the ply-level failure history of the sample is investigated. Ply-level failure behavior is the cause of the global stiffness loss shown in the stiffness ratio plots in Figures 4.11 to 4.14. Figure 4.16 displays the progression of the modes that are failing throughout the response of the structure. The failure modes shown in this figure refer to the ply-level coordinate system as described in the LAMPATNL output parameters section of this chapter.

In Figure 4.16, only the mode of failure for the last failed ply is displayed. Areas in dark blue $(\mathrm{FMODE}=0)$ have not failed, red $(\mathrm{FMODE}=9)$ indicates a failure mode of 12 shear, green areas $(\mathrm{FMODE}=5)$ have tensile failure in the 3-direction, the areas in pale green $(\mathrm{FMODE}=3)$ are 2-direction tensile failure, and the light blue areas $(\mathrm{FMODE}=2)$ indicate 1-direction compressive failure. It is important to understand which of the four plies correspond to the failure modes of Figure 4.16. A progression plot of the last failed ply is shown in Figure 4.17.

In Figure 4.17, the blue areas indicate that no failure has occurred, red areas $(\mathrm{FPLY}=4)$ indicate that the failure shown in Figure 4.16 occurred in the $0^{\circ}$ plies, and the light orange area (FPLY=3) indicates that the failure occurred in the $90^{\circ}$ plies. In order to describe the progression of failure in the sample, four regions are identified and highlighted on the sample below in Figure 4.18. The regions, shown in Figure 4.18 on a plot of FMODE at the end of the analysis, are used to refer to areas in the progression plots of Figure 4.16a-e and Figure 4.17a-e. 


$$
\text { Wind }
$$




$$
\text { andia }
$$




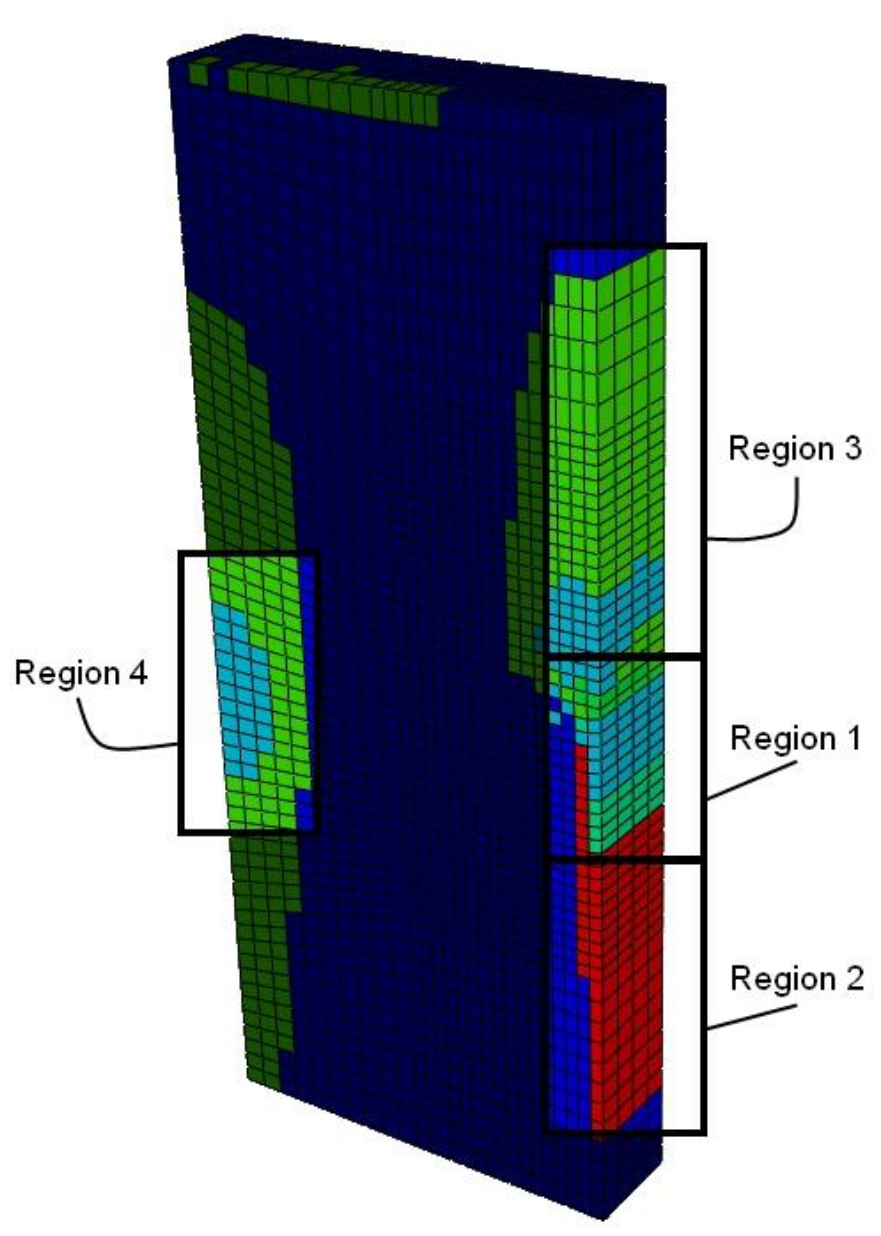

Figure 4.18 Diagram of regions

There are three phases of failure that occur in this sample. The first phase is in-plane shear failure in all of the plies that propagates from region 1, the top edge of the fixed face, downwards into region 2. This phase is displayed in plots a and b of Figures 4.16 and 4.17. The next phase includes tensile failure in the 3-direction in all plies that starts at the top of the fixed face (region 1) and continues up the right edge of the sample (region 3). This phase is shown in plots $\mathrm{c}$ and $\mathrm{d}$ of Figures 4.16 and 4.17. 
Additional tensile failure in the 3-direction occurs on the face opposing the fixed portion, shown in Region 4 of plots $\mathrm{c}$ and d. The final phase is compressive 1direction failure in the $0^{\circ}$ plies starting in Region 1 of plot c, expanding to Region 3 in plots $\mathrm{d}$ and e, and also occurring in Region 4 in plots $\mathrm{d}$ and $\mathrm{e}$.

Figures 4.9 through 4.17 display the information that is needed to gain insight into the ply-level failure behavior of the sample. This insight is used to make changes to the layup of the sample to meet the objectives of this case study. The current $\left[0^{\circ} / 90^{\circ}\right]_{\mathrm{S}}$ layup does not satisfy both of the objectives of the case study. The displacement at point $A$ is $0.0585 \mathrm{~m}$, which exceeds the target value of $0.05 \mathrm{~m}$. The areas of global XY shear failure (Figure 4.12) and global X-direction failure (Figure 4.14) are large and limiting these areas is the other important objective.

\subsubsection{Design iteration \#1}

The original $\left[0^{\circ} / 90^{\circ}\right]_{\mathrm{s}}$ layup of the laminate is insufficient in both the displacement objective and limiting the extent of stiffness loss. The design is first changed to a $\left[0_{2} / \pm 45^{\circ}\right]_{\mathrm{S}}$ layup. The $0^{\circ}$ plies of the laminate are essential in providing enough longitudinal stiffness to satisfy the displacement objective. Using $\pm 45^{\circ}$ plies is aimed at addressing the area of shear failure along the right fixed boundary condition. The fiber direction of these plies is aligned more in the global X-direction than the $90^{\circ}$ plies, adding to the stiffness of the structure in this direction. In the original design, the $90^{\circ}$ plies only provided minimal stiffness in the X-direction.

In order to determine if the new layup has improved upon the original design, the stiffness ratios are first examined. In Figure 4.19, the MINCIJ of the new design is compared to the original. The new design does not have areas with a complete loss in stiffness in any direction (dark blue areas). The new design has only 
a small area in the lower right corner where a minimum stiffness ratio has not changed (red area) from its original value. In the original design, the area of no loss of original stiffness is large.
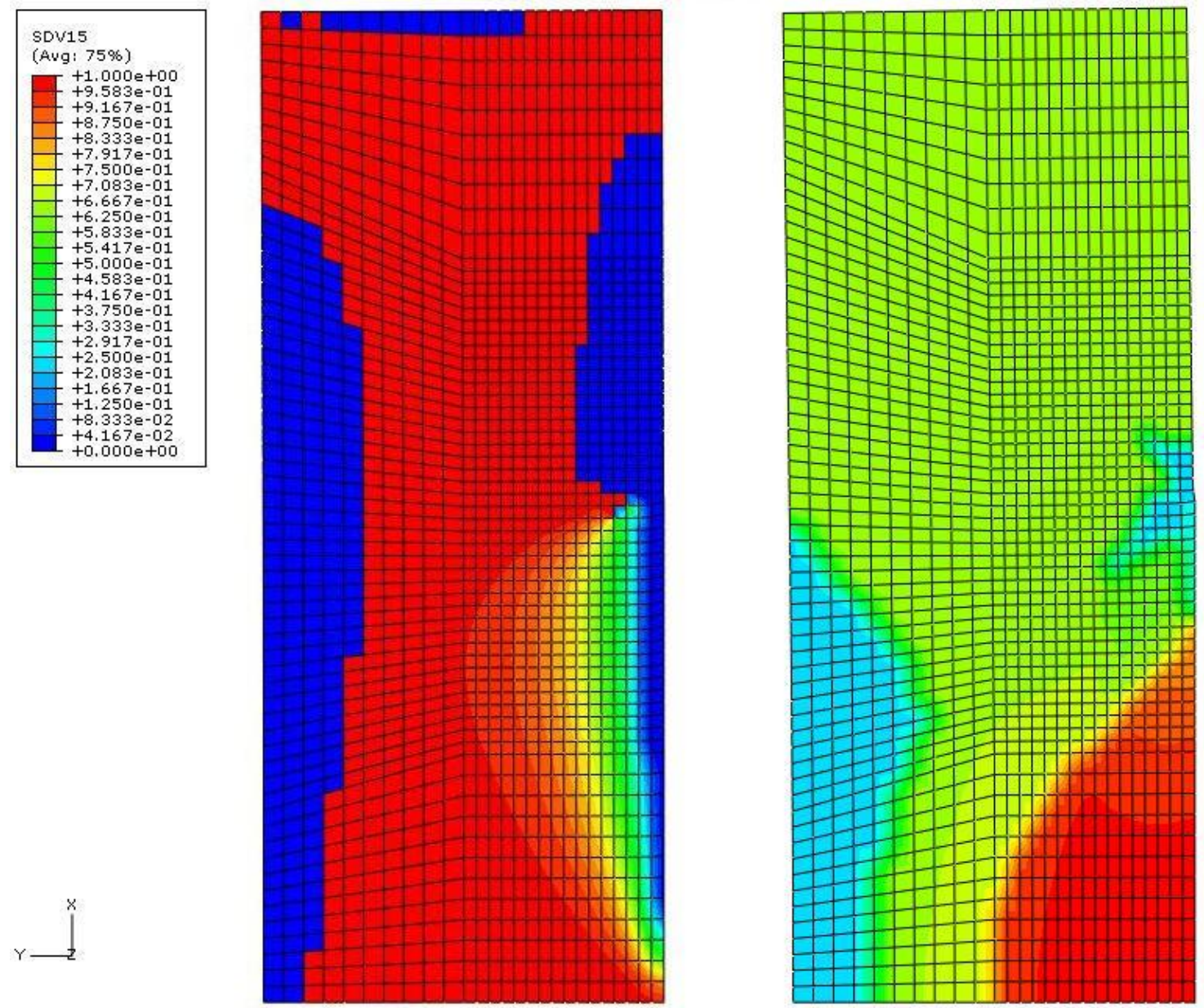

Figure 4.19 Comparison of minimum stiffness ratio MINCIJ $\left[0^{\circ} / 90^{\circ}\right]_{s}$ (left) vs. $\left[0_{2} / \pm 45^{\circ}\right]_{s}$ (right)

The majority of the sample in right plot of Figure 4.19 has some stiffness loss. The plot shown in Figure 4.20 is used to determine in which direction these 
losses are the greatest. In this contour plot, the areas in red signify the Y-direction (CYYR) and the areas in green signify the X-direction (CXXR), the blue area indicates that the minimum stiffness ratio was not below $80 \%$. While the stiffness in the Xdirection is critical to the response of the structure, stiffness loss in the Y-direction is not as critical because there is no loading in this direction though there will be a Poisson's effect.
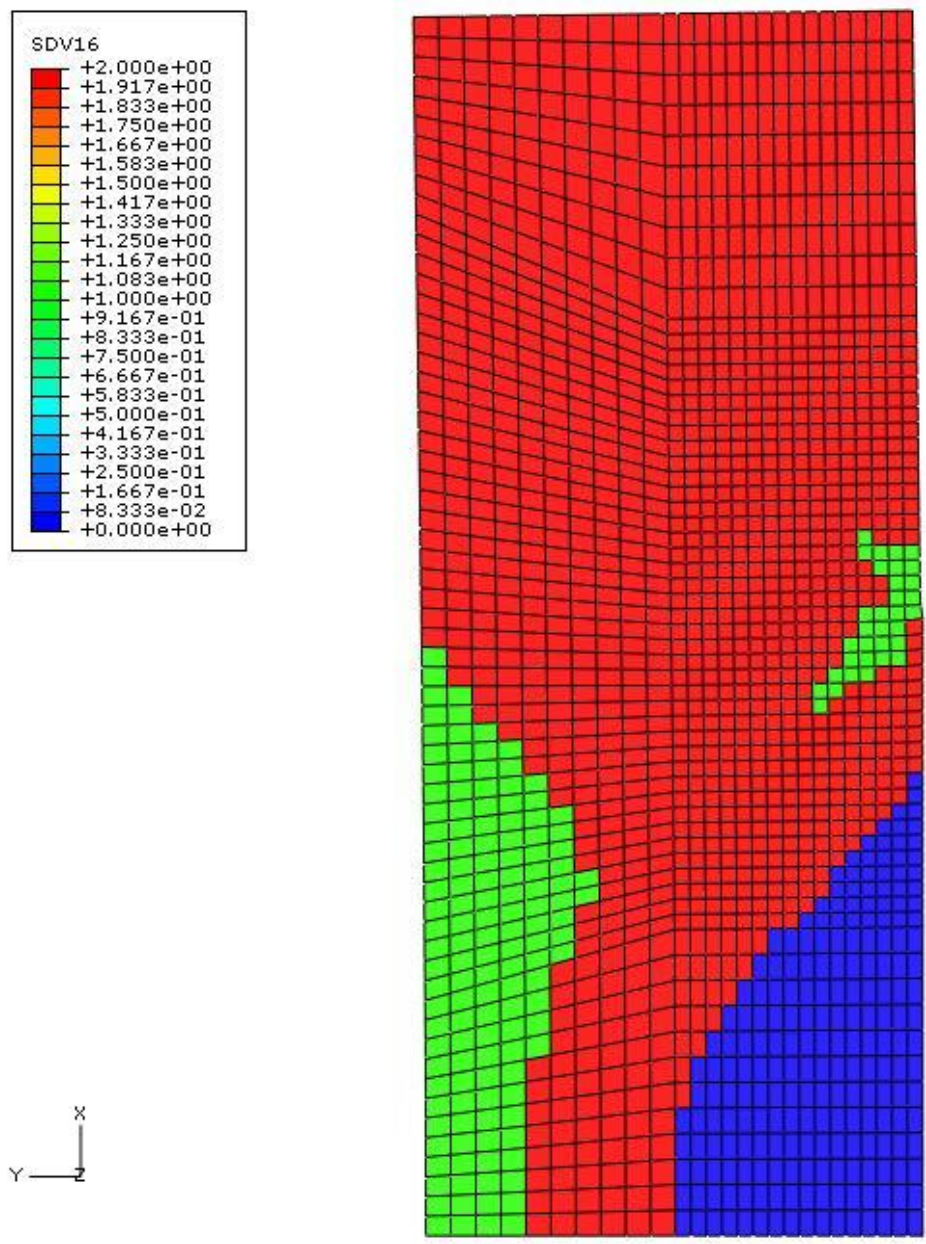

Figure 4.20 Plot of the direction of minimum $\mathrm{C}_{\mathrm{ij}}$ ratio MINCIJN for $\left[0_{2} / \pm 45\right]_{\mathrm{s}}$ layup 
A comparison of the individual stiffness ratios of $\mathrm{C}_{\mathrm{XX}}, \mathrm{C}_{\mathrm{YY}}, \mathrm{C}_{\mathrm{ZZ}}$, and $\mathrm{C}_{\mathrm{XY}}$ will determine the benefits, if any, of switching to this layup. The comparison plot of $\mathrm{C}_{\mathrm{XX}}$ in Figure 4.21 shows that while the stiffness loss in the $\mathrm{X}$-direction of the $\left[0_{2} / \pm 45\right]_{\mathrm{s}}$ sample covers larger area than the original design, the magnitude of stiffness loss in these areas is less. In this plot, the areas in light blue have a higher stiffness ratio than those in dark blue.
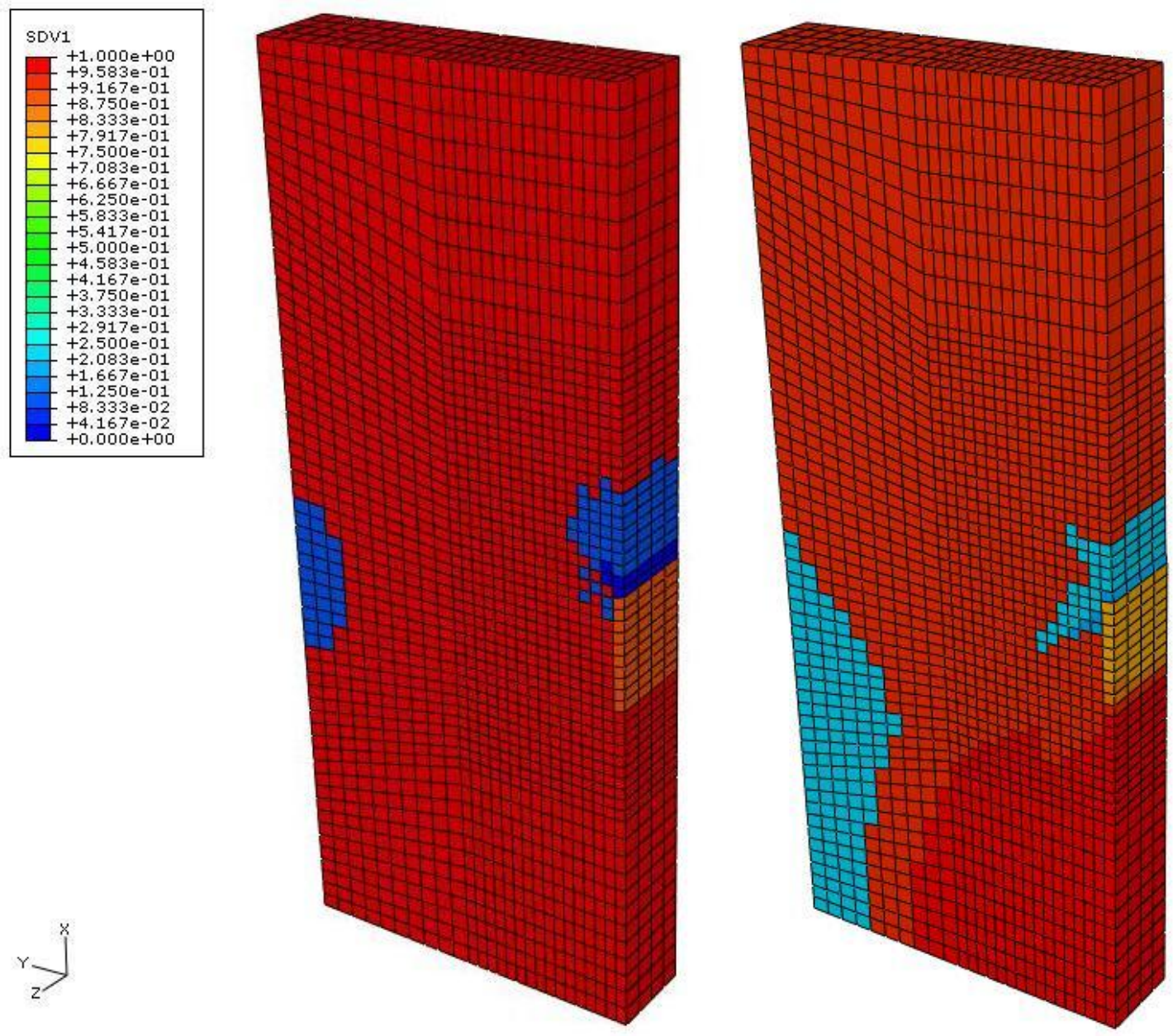

Figure 4.21 Plot of $\mathrm{C}_{\mathrm{XX}}$ stiffness ratio $\mathrm{CXXR}$ comparing $\left[0^{\circ} / 90^{\circ}\right]_{\mathrm{s}}$ (left) to $\left[0_{2} / \pm 45\right]_{\text {s }}$ (right) 
Comparing the $\mathrm{C}_{Y Y}$ stiffness ratios of the sample in Figure 4.22, it is seen that the new layup has a large area where stiffness has been reduced. This reduced stiffness is a result of the $0^{\circ}$ plies failing in the transverse matrix direction, which causes a small reduction in stiffness in this area.
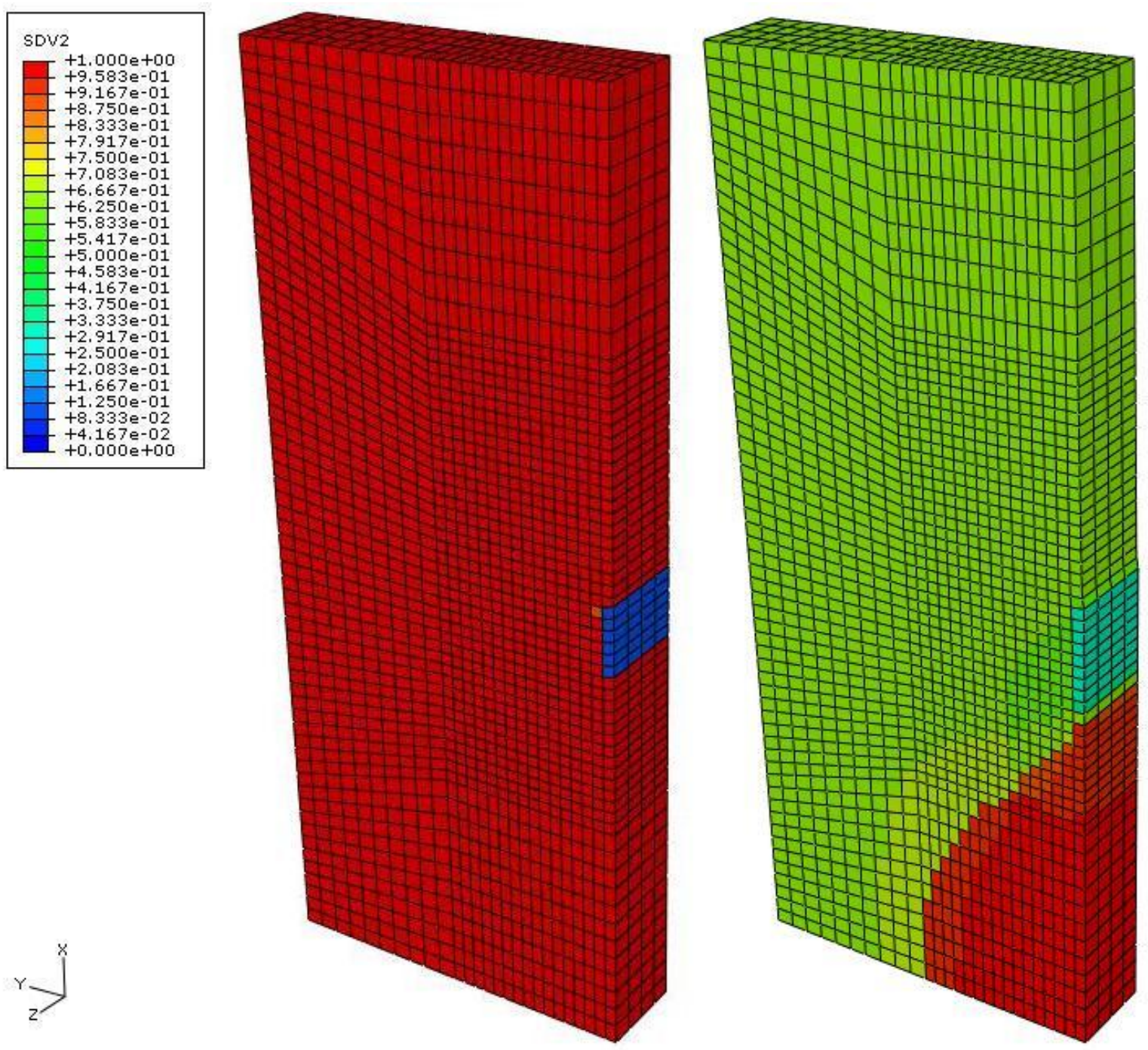

Figure 4.22 Plot of $\mathrm{C}_{\mathrm{YY}}$ stiffness ratio (CYYR) comparing $\left[0^{\circ} / 90^{\circ}\right]_{\mathrm{s}}$ (left) to $\left[0_{2} / \pm 45\right]_{\mathrm{s}}$ (right) 
Similarly, the comparison of $\mathrm{C}_{\mathrm{ZZ}}$ ratio shown in Figure 4.23 illustrates that the complete failure of some elements in the Z-direction has been replaced by slight softening over the entire structure. The response of the sample in this direction is determined by the global XZ Poisson ratio and the new layup has less coupling in this direction.
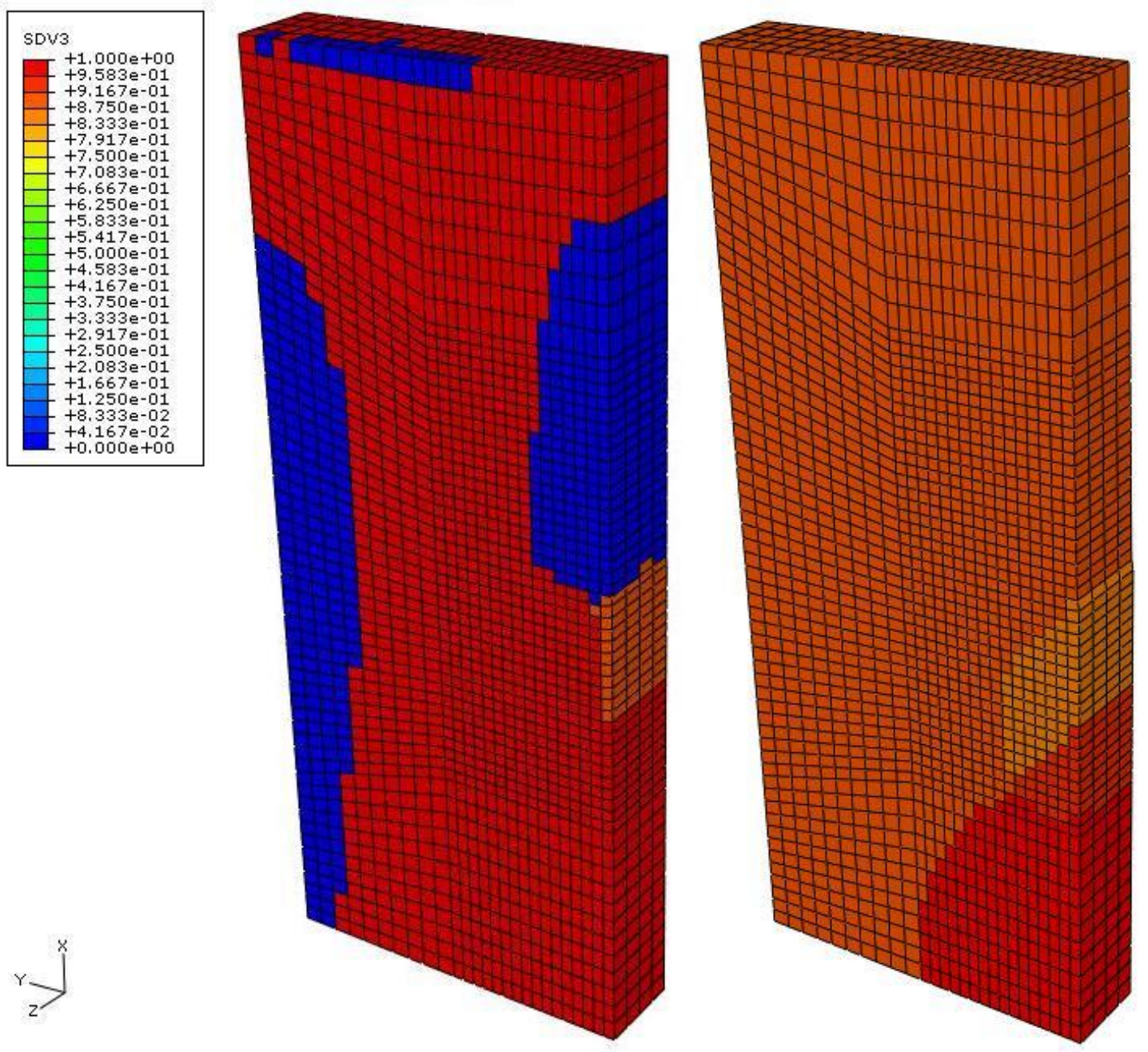

Figure 4.23 Plot of $\mathrm{C}_{\mathrm{ZZ}}$ stiffness ratio $(\mathrm{CZZR})$ comparing $\left[0^{\circ} / 90^{\circ}\right]_{\mathrm{s}}$ (left) to $\left[0_{2} / \pm 45\right]_{s}$ (right) 
Finally, an examination of the global XY shear stiffness ratio between the original and modified layups is shown in Figure 4.24. The modified layup shows dramatic improvements in limiting the extent and severity of shear failure along the fixed boundary.
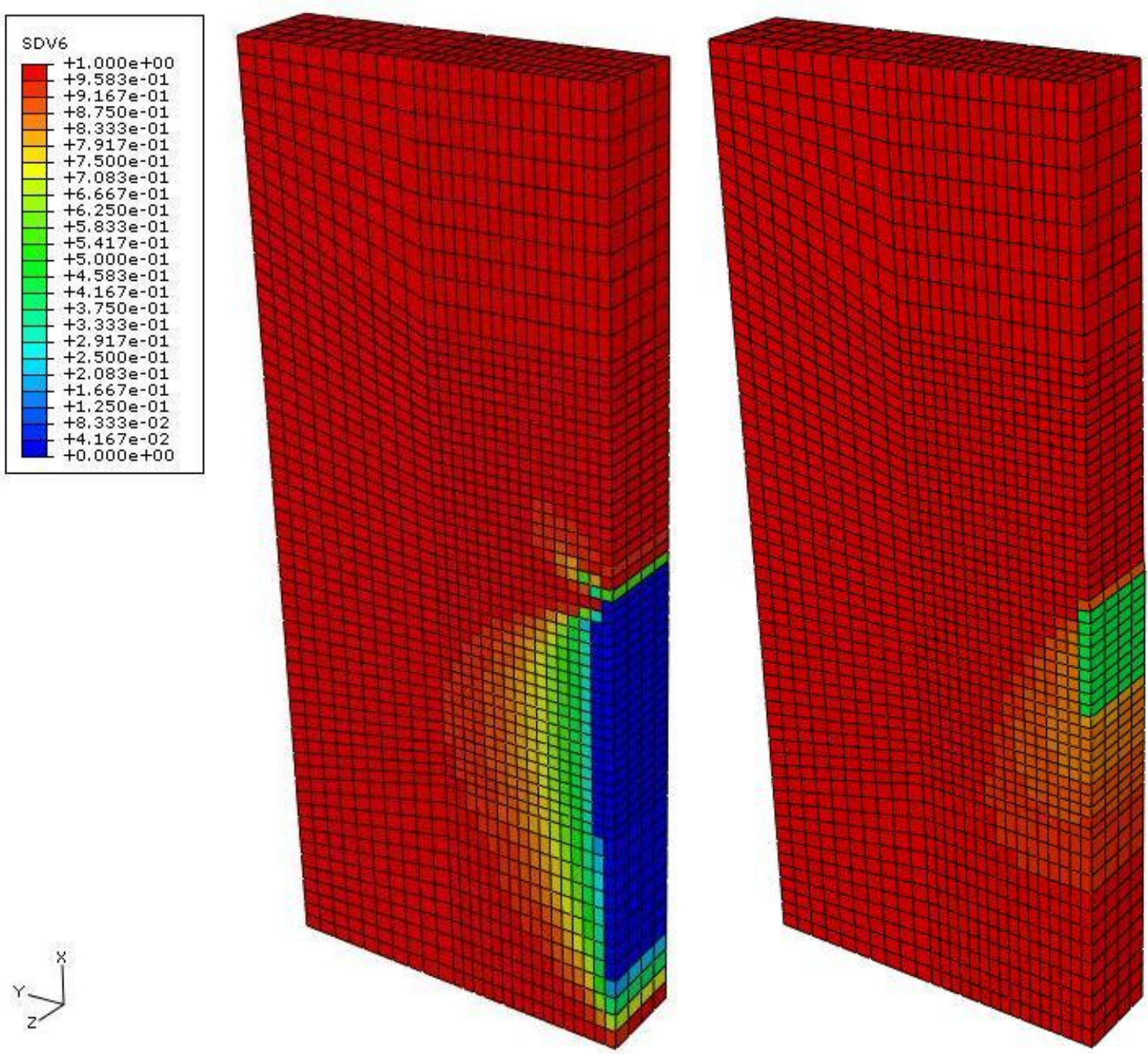

Figure 4.24 Plot of $\mathrm{C}_{\mathrm{XY}}$ stiffness ratio (CXYR) comparing $\left[0^{\circ} / 90^{\circ}\right]_{\mathrm{S}}$ (left) to $\left[0_{2} / \pm 45\right]_{s}$ (right) 
The results of this first design iteration are a reduction in the area and magnitude of $\mathrm{XY}$ shear stiffness loss, a reduction in magnitude of $\mathrm{Z}$ stiffness loss, more widespread but less severe Y stiffness loss, and a decrease in the magnitude of stiffness loss in the X-direction. The displacement of point A for this layup is however, $0.0647 \mathrm{~m}$; which is worse than the first layup tested. While there is improved performance in the stiffness objectives, the displacement objective is still not met for this layup.

\subsubsection{Design iteration \#2}

For the next design iteration, the stiffness in the longitudinal direction of the structure must be improved in order to meet the displacement objective. A laminate in a $\left[0_{2} / \pm 35^{\circ}\right]_{\mathrm{s}}$ layup is chosen because the $\pm 35^{\circ}$ plies are needed to address the XY shear failures that occur along the fixed boundary of the part. These plies also increase the global X-direction stiffness of the sample since their fibers are oriented more in this direction than the previous design.

The first condition to check is the displacement objective. Examining the results of this sample shows that the $\mathrm{X}$ displacement at point $\mathrm{A}$ is once again not within the desired objective, at $0.0585 \mathrm{~m}$. An investigation into the stiffness ratio parameters shows that there is an improved performance in the $\mathrm{X}$ stiffness, slightly less desirable performance in the $\mathrm{Y}$ and $\mathrm{Z}$ directions, and similar performance in the XY shear stiffness when compared to the first design iteration. 


\subsubsection{Design iteration \#3}

The next layup needs to increase the stiffness of the laminate in the Xdirection while continuing to prevent shear stiffness loss. A laminate in a $\left[0_{2} / \pm 25^{\circ}\right]_{\mathrm{s}}$ layup satisfies both these criteria and is used for this design iteration.

The first check for the layup is to compare the displacement at point $\mathrm{A}$ to the targeted value. A displacement of $0.0475 \mathrm{~m}$, less than the targeted value, is recorded at this point. With this objective satisfied, an examination of the four key stiffness ratios is needed to confirm that the performance of the layup meets the other objective.

Like the first design iteration, an examination of the MINCIJ of this layup is compared to the original (see Figure 4.25). The majority of the sample with the new layup has a significant loss in stiffness in at least one direction. However, in contrast with the original layup, this layup does not have large areas of complete stiffness loss. The new layup has only one element, near the top of the fixed edge, with complete stiffness loss. 

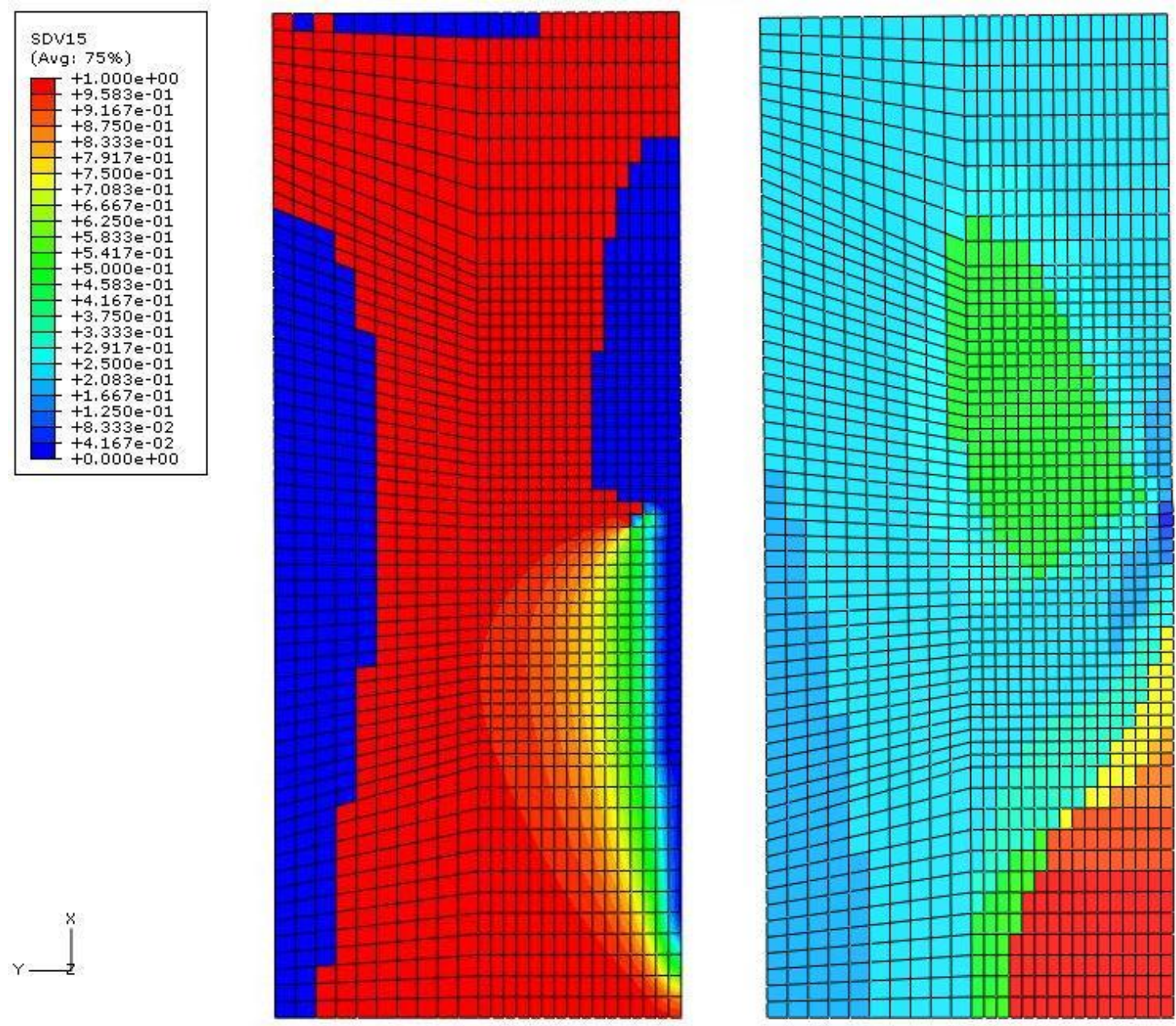

Figure 4.25 Comparison of minimum stiffness ratio MINCIJ, $\left[0^{\circ} / 90^{\circ}\right]_{\mathrm{s}}$ (left) vs. $\left[0_{2} / \pm 25^{\circ}\right]_{\mathrm{s}}$ (right)

The plot shown in Figure 4.26 displays that the Y-direction, here shown in pale green, is the predominate loss of stiffness direction. Stiffness loss in the Ydirection is not critical because there is no loading in this direction. 

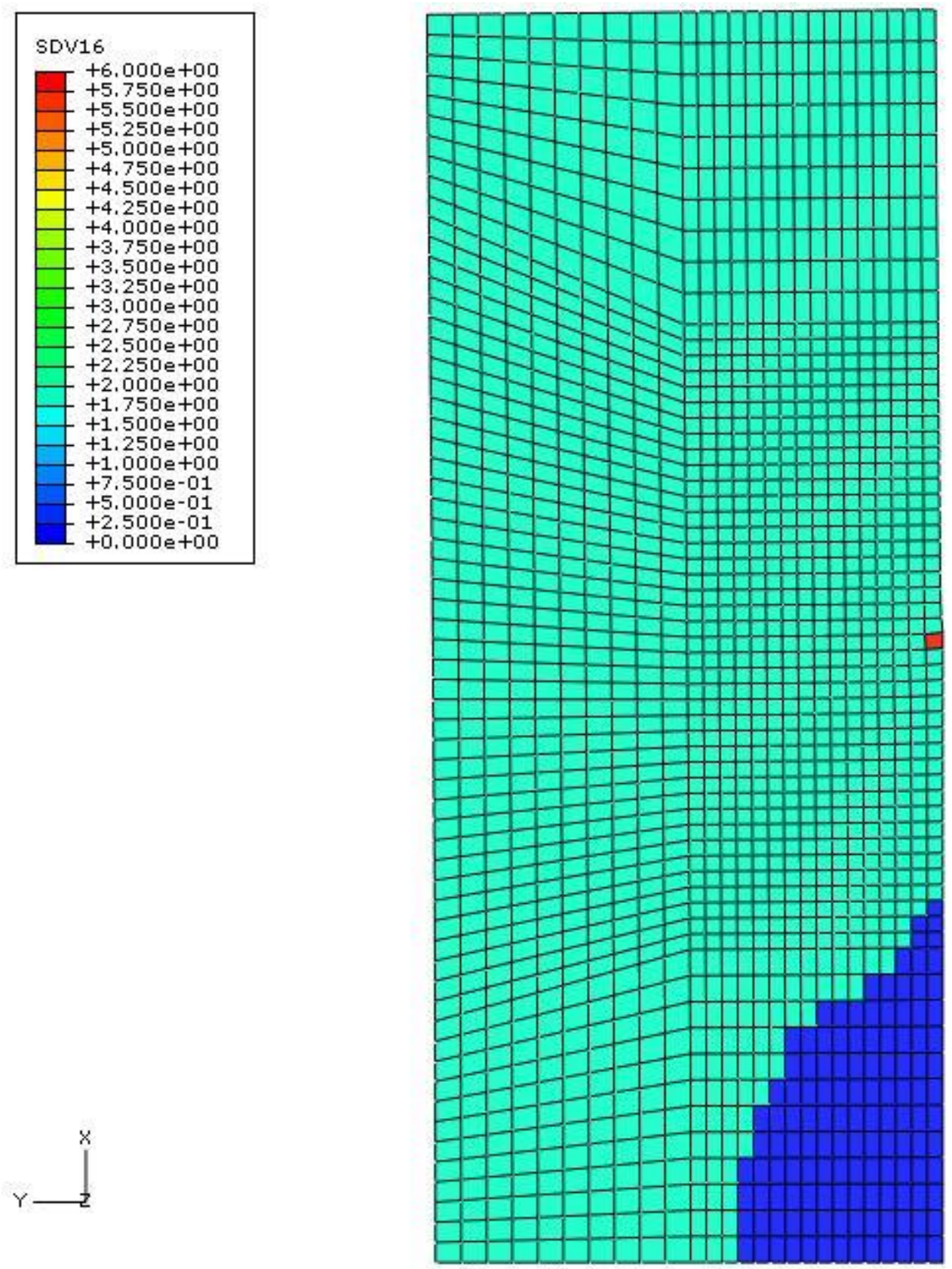

Figure 4.26 Plot of the direction of minimum $C_{\mathrm{ij}}$ ratio MINCIJN for $\left[0_{2} / \pm 25\right]_{\mathrm{s}}$ layup 
A comparison of the individual stiffness ratios of $\mathrm{C}_{\mathrm{XX}}, \mathrm{C}_{\mathrm{YY}}, \mathrm{C}_{\mathrm{ZZ}}$, and $\mathrm{C}_{\mathrm{XY}}$ is once again performed. The comparison plot of $\mathrm{C}_{\mathrm{XX}}$ in Figure 4.27 shows that the stiffness loss in the X-direction has been minimized. In this plot, the areas in blue have a high stiffness loss and the areas in red have no stiffness loss.
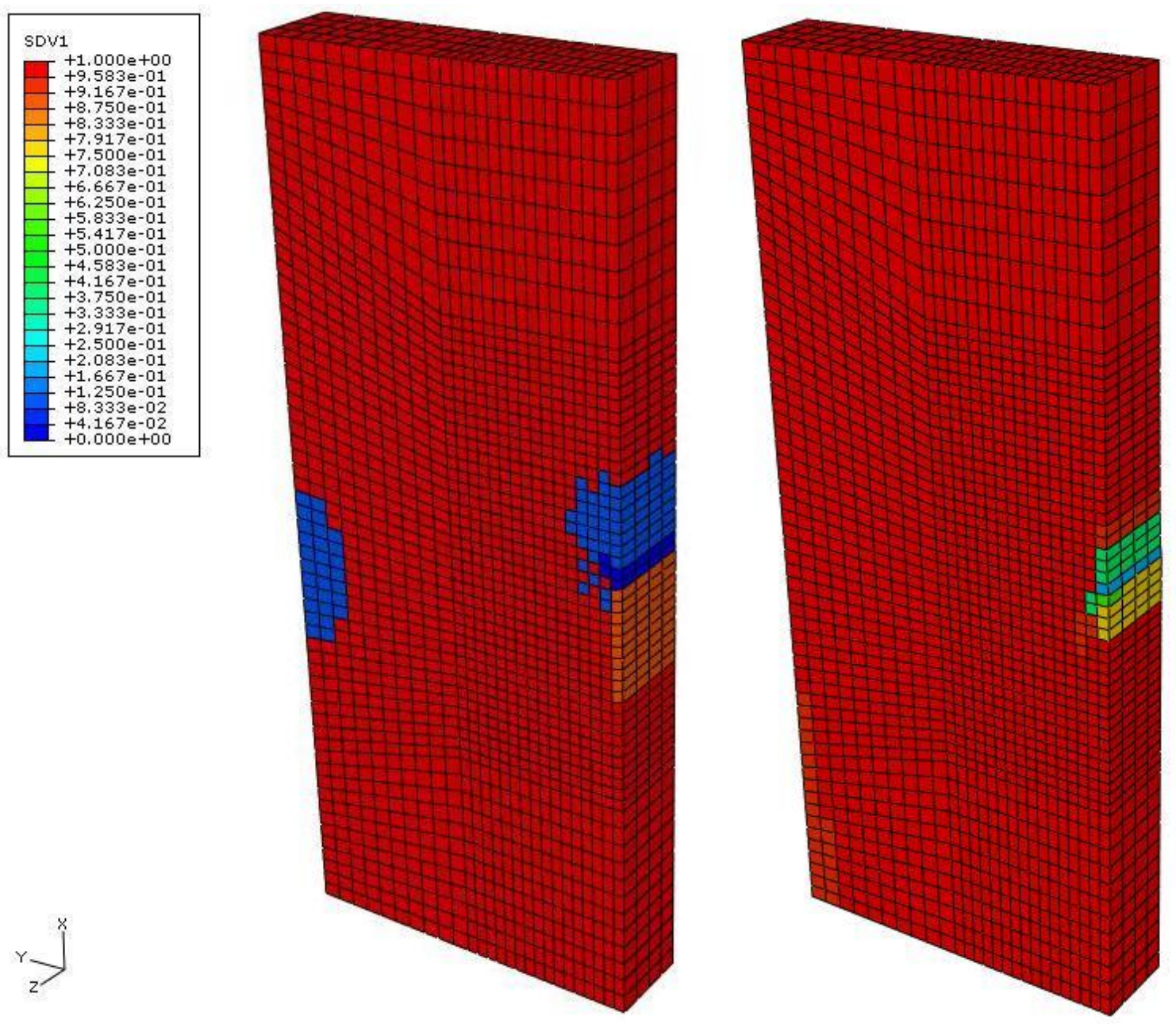

Figure 4.27 Plot of $\mathrm{C}_{\mathrm{XX}}$ stiffness ratio (CXXR) comparing $\left[0^{\circ} / 90^{\circ}\right]_{\mathrm{s}}$ (left) to $\left[0_{2} / \pm 25\right]_{\mathrm{s}}$ (right) 
Comparing the $\mathrm{C}_{Y Y}$ stiffness of the sample in Figure 4.28, it is seen that the new layup has a large area where stiffness has been reduced. Because stiffness in this direction is not critical to the overall response of the sample, this result is not a concern.
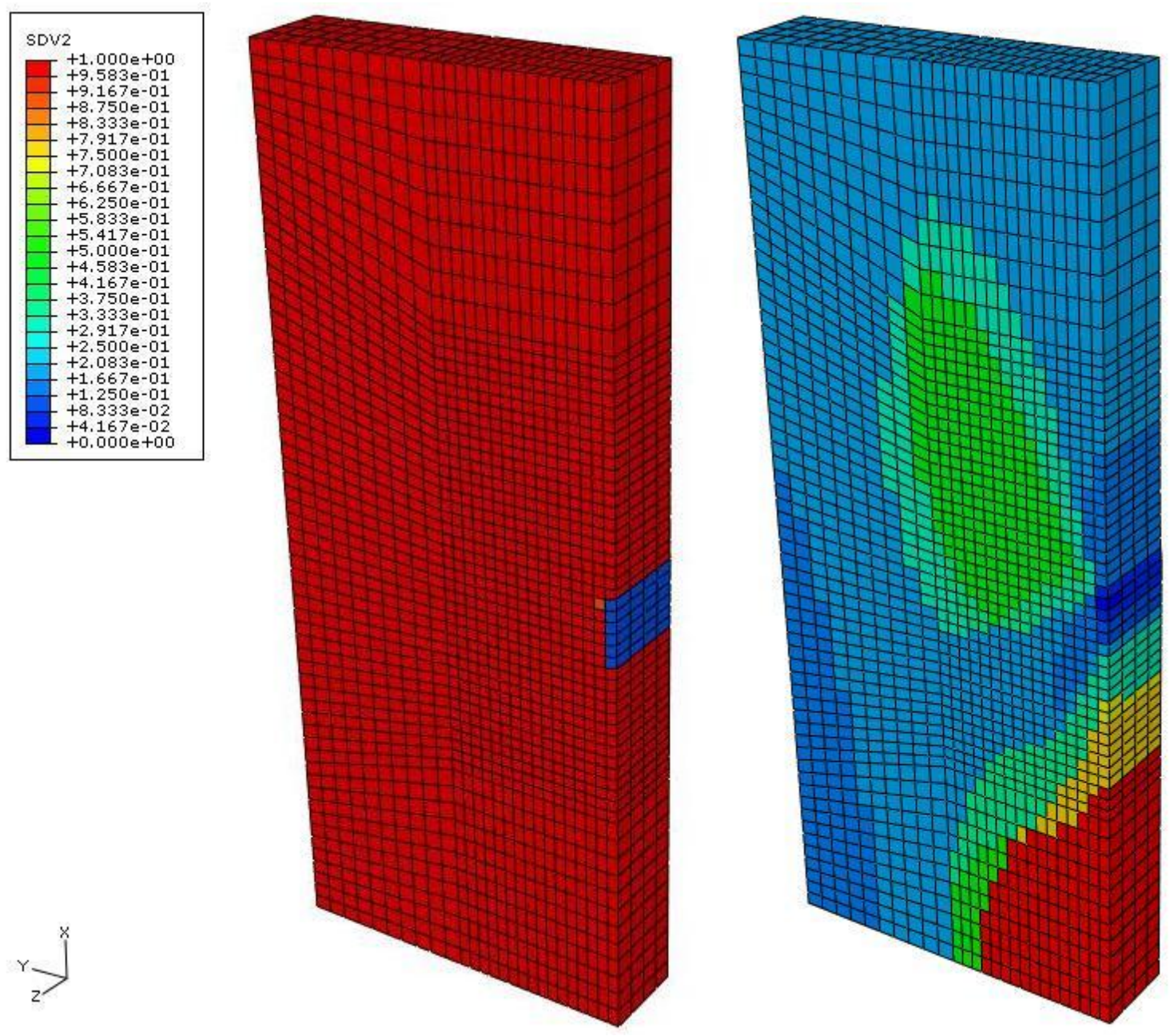

Figure 4.28 Plot of $\mathrm{C}_{Y Y}$ stiffness ratio (CYYR) comparing $\left[0^{\circ} / 90^{\circ}\right]_{\mathrm{s}}$ (left) to $\left[0_{2} / \pm 25\right]_{\text {s }}$ (right) 
Similar to the first design iteration, the comparison of $\mathrm{C}_{\mathrm{Zz}}$ shown in Figure 4.29 illustrates that the complete failure of some elements in the Z-direction has been replaced by slight softening over the entire structure.
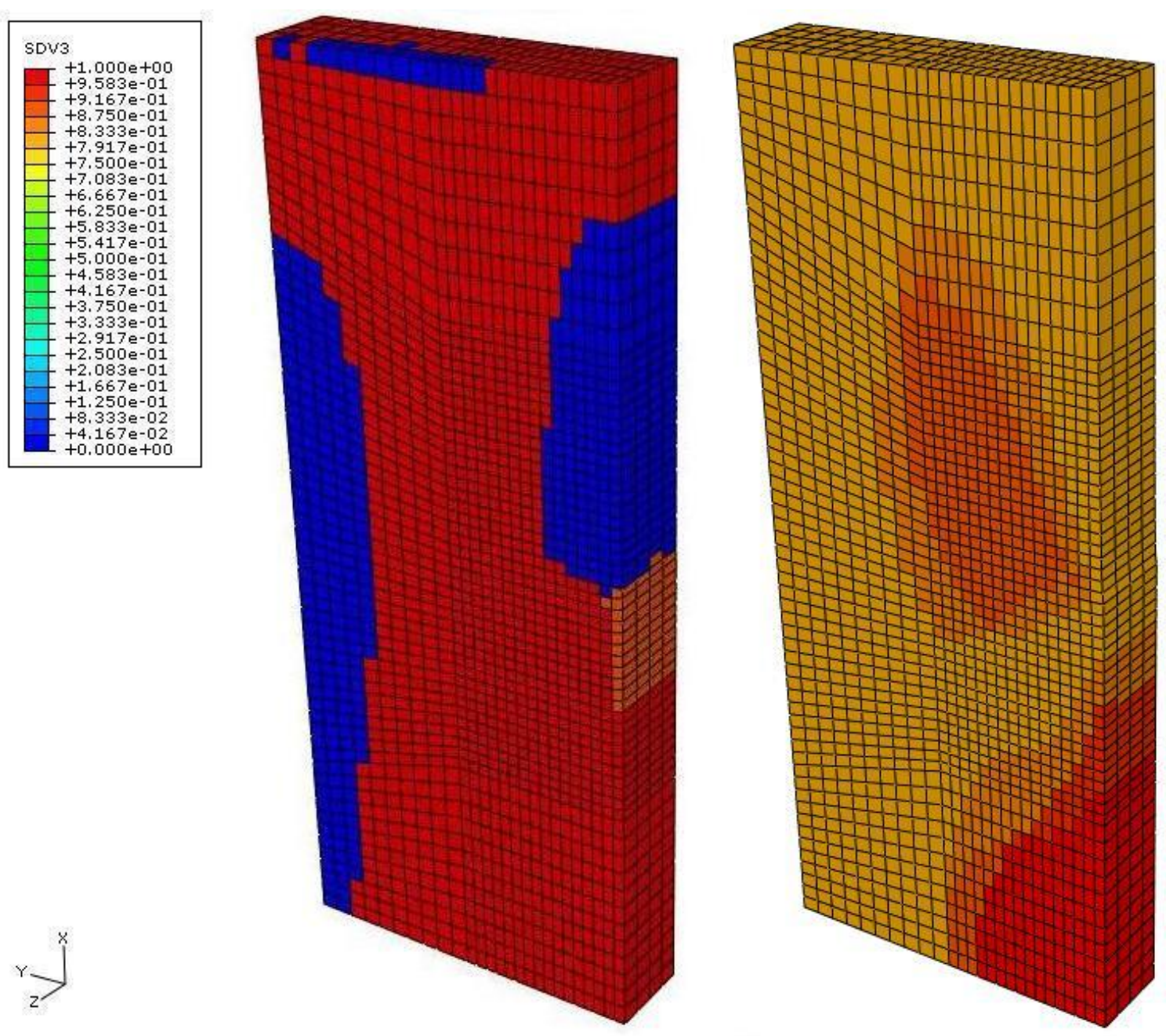

Figure 4.29 Plot of $\mathrm{C}_{\mathrm{ZZ}}$ stiffness ratio (CZZR) comparing $\left[0^{\circ} / 90^{\circ}\right]_{\mathrm{s}}$ (left) to $\left[0_{2} / \pm 25\right]_{s}$ (right) 
Finally, an examination of the XY shear stiffness ratio between the original and modified layups is shown in Figure 4.30. The modified layup shows improvements in limiting the extent and severity of shear failure along the fixed boundary when compared to the original layup. This layup does not perform as well as the first design iteration, but it does eliminate the shear failure region.
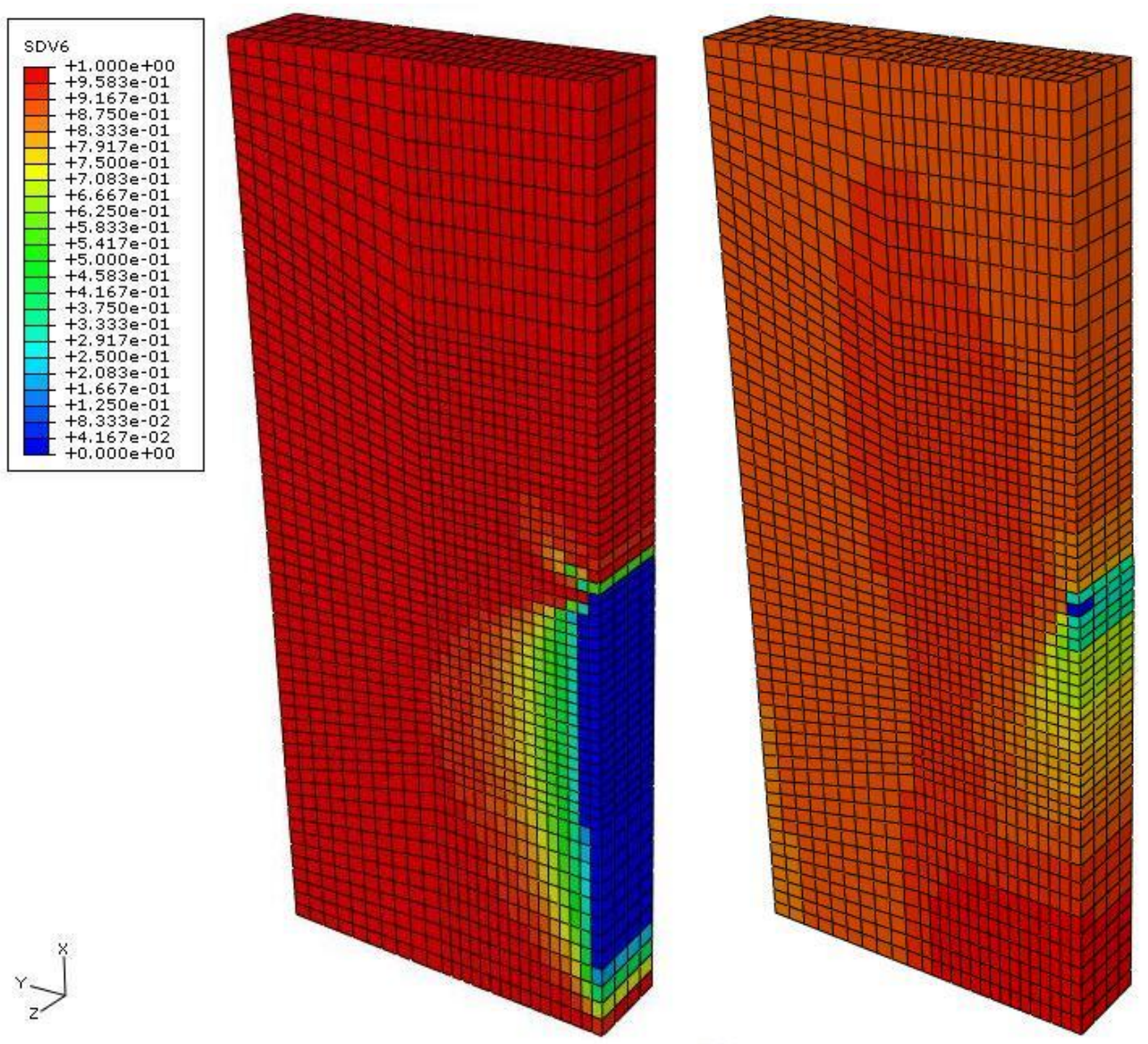

Figure 4.30 Plot of $\mathrm{C}_{\mathrm{XY}}$ stiffness ratio (CXYR) comparing $\left[0^{\circ} / 90^{\circ}\right]_{\mathrm{s}}$ (left) to $\left[0_{2} / \pm 25\right]_{s}$ (right) 
This layup is able to satisfy both objectives set at the start of the case study. With a displacement of 0.0475 at point $\mathrm{A}$, the sample is within the targeted value of 0.05 . The modifications to the layup limit the areas of total stiffness loss of the structure in the global X and XY shear directions.

This case study demonstrates the utility of the stiffness ratio, last failed mode, and last failed ply LAMPATNL output parameters. These parameters helped to improve the understanding of the complex interactions between progressive ply failure and global stiffness reduction in the laminate. Areas of critical stiffness loss were easily identified using the linear scale of the minimum stiffness ratio parameter. The progression of ply failures, determined from the design methodology, provided a clear understanding of the response of the structure. Modifications to the $\left[0^{\circ} / 90^{\circ}\right]_{\mathrm{s}}$ layup were made based on the insight gained from the mode and ply failure history. These modifications enabled the designer to quickly achieve the performance objectives of the analysis using only three design iterations.

\subsection{Case study \#2}

\subsubsection{Description}

The second case study is three dimensional model of an open hole sample that is subjected to multiaxial, in-plane loading. The open hole configuration was selected because it is a standard example used to examine progressive failure models for composites $[18,19,21-25,27,29,30]$. This problem is also common in composite applications and the effects on the structural response due to changes in material, layup, and width-to-diameter ratio are important to understand. A diagram of the 
sample is shown in Figure 4.31. The diameter of the hole is 1 and the width of the sample in both the $\mathrm{X}$ - and $\mathrm{Y}$-directions is 5, resulting in width-to-diameter ratio of 5.

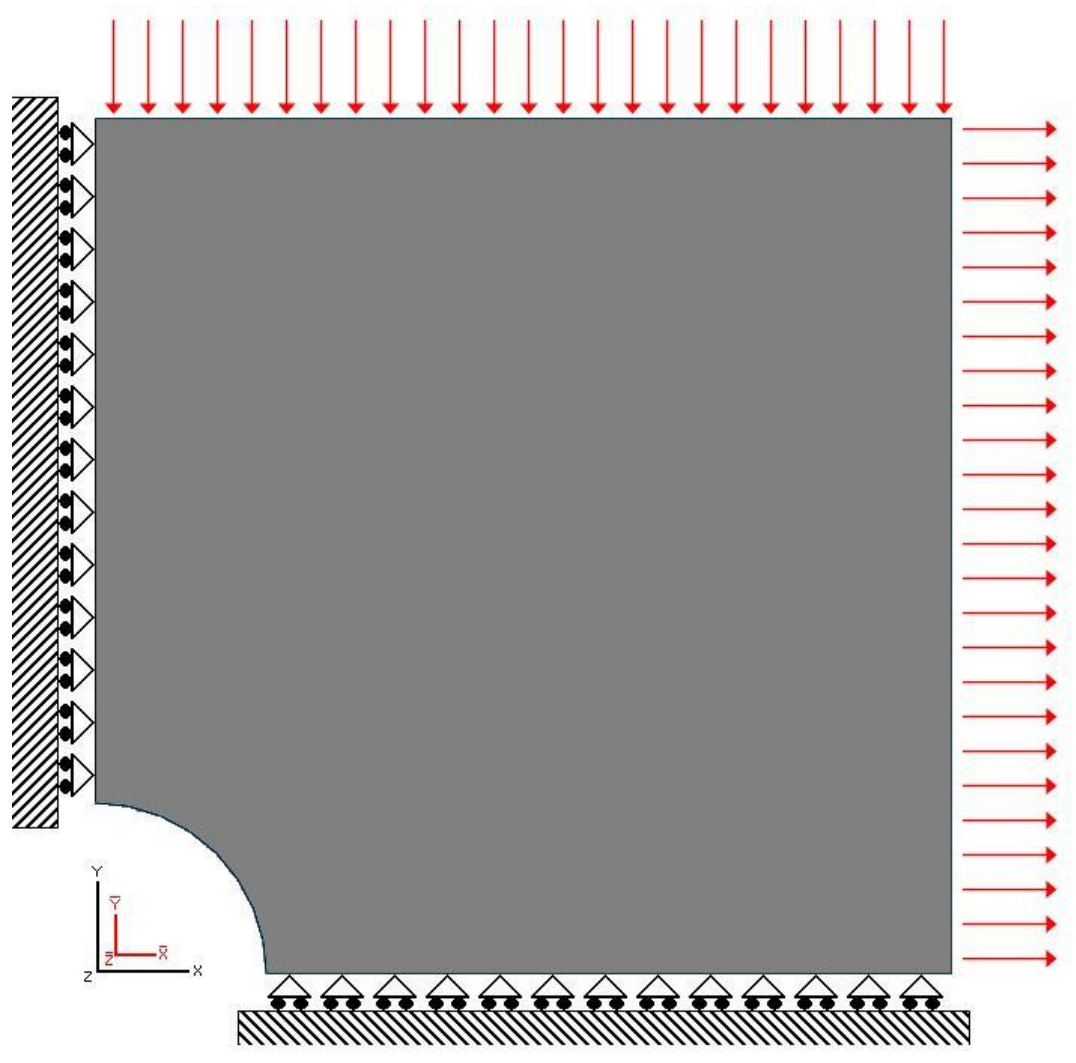

Figure 4.31 Diagram of open hole sample

The original laminate is an S-Glass/Epoxy material in a $\left[0^{\circ} / 90^{\circ} / \pm 45^{\circ}\right]_{\mathrm{s}}$, or quasi-isotropic, layup. The Ramberg-Osgood parameters and maximum strain allowables for this material are shown in Tables 3.4 and 3.5, respectively $[2,36]$. The mesh for this model contains 6768 elements and 8905 nodes. The finite element model has symmetry boundary conditions along the left face and bottom face. A uniform pressure load of $300 \mathrm{MPa}$ is applied to the right exterior faces in the positive 
$\mathrm{X}$ direction, creating tensile stresses in that direction. Another pressure load of 150 $\mathrm{MPa}$ is applied to the top exterior faces in the negative $\mathrm{Y}$ direction, creating compressive stresses in that direction.

The objectives in this design case study are to limit the displacement of the point at the upper right corner of the structure to less than $0.05 \mathrm{~m}$ in the positive $\mathrm{X}$ direction and $0.04 \mathrm{~m}$ in the negative $\mathrm{Y}$-direction. Based upon the performance of the quasi-isotropic layup, modifications to the laminate may be needed to achieve these

objectives. Any change to the laminate must maintain the same material, weight, and thickness from the original layup. These changes are made based on information gained from the process outlined in the design methodology.

\subsubsection{Results of original design}

Following the procedure of the design methodology, the first contour plot examined is a plot of the minimum $\mathrm{C}_{\mathrm{ij}}$ ratio MINCIJ, shown in Figure 4.32. 


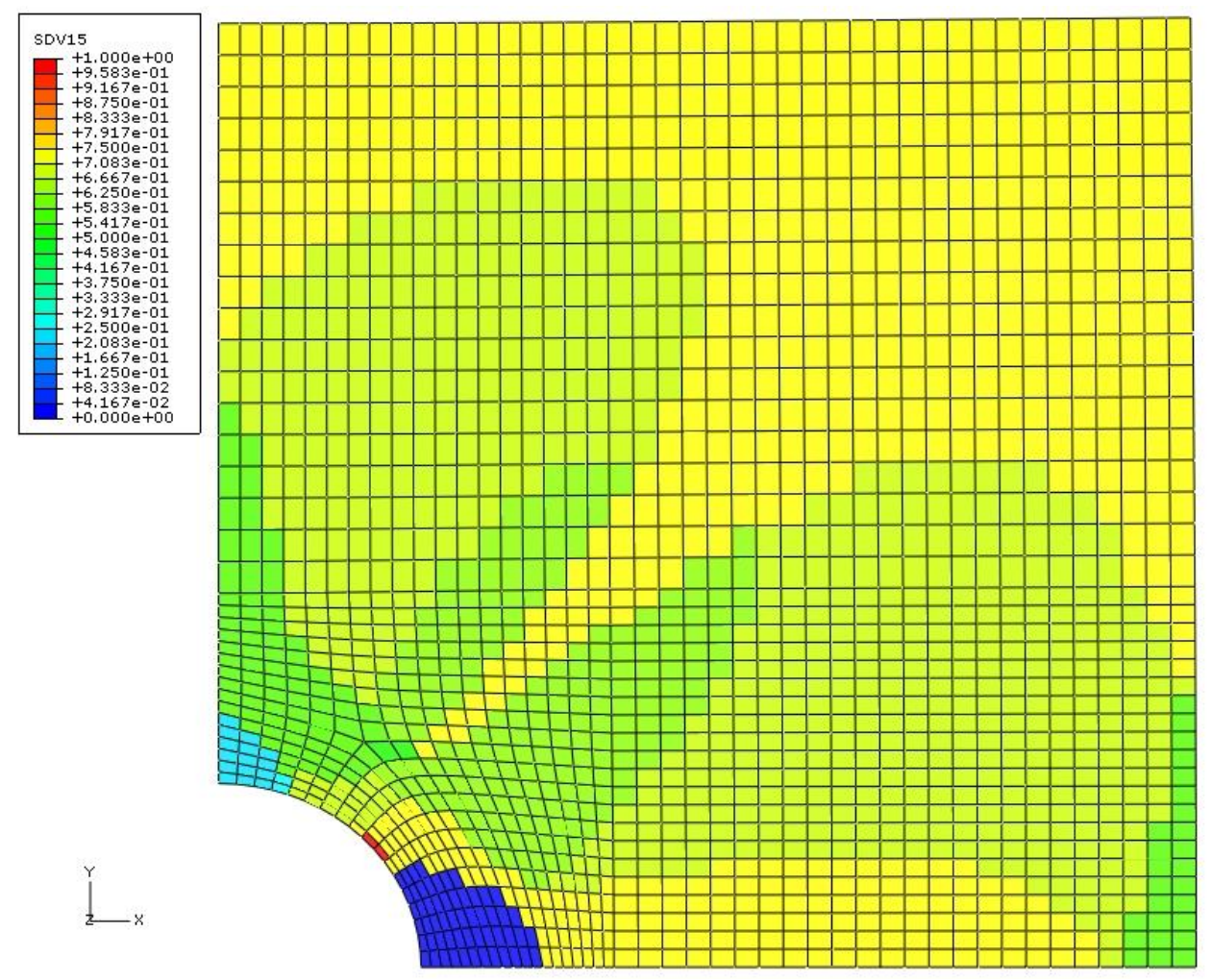

Figure 4.32 Contour plot of minimum $\mathrm{C}_{\mathrm{ij}}$ stiffness ratio MINCIJ

The yellow and bright green areas of the sample represent a stiffness ratio of around $60 \%-70 \%$, the pale blue area has a stiffness ratio of $10 \%-20 \%$, the dark blue area has $0 \%$ stiffness ratio, and the red area (2 elements) is near $100 \%$ stiffness ratio.

The multiaxial loading that is applied to this sample causes stress concentrations at both sides of the open hole and, as expected, the stiffness ratio is lowest in these areas. Almost the entire sample has a $30 \%$ reduction of stiffness in at least one direction. To determine which directions are represented in Figure 4.32, a plot of the minimum stiffness ratio number MINCIJN is needed. This plot is shown in Figure 4.33. 


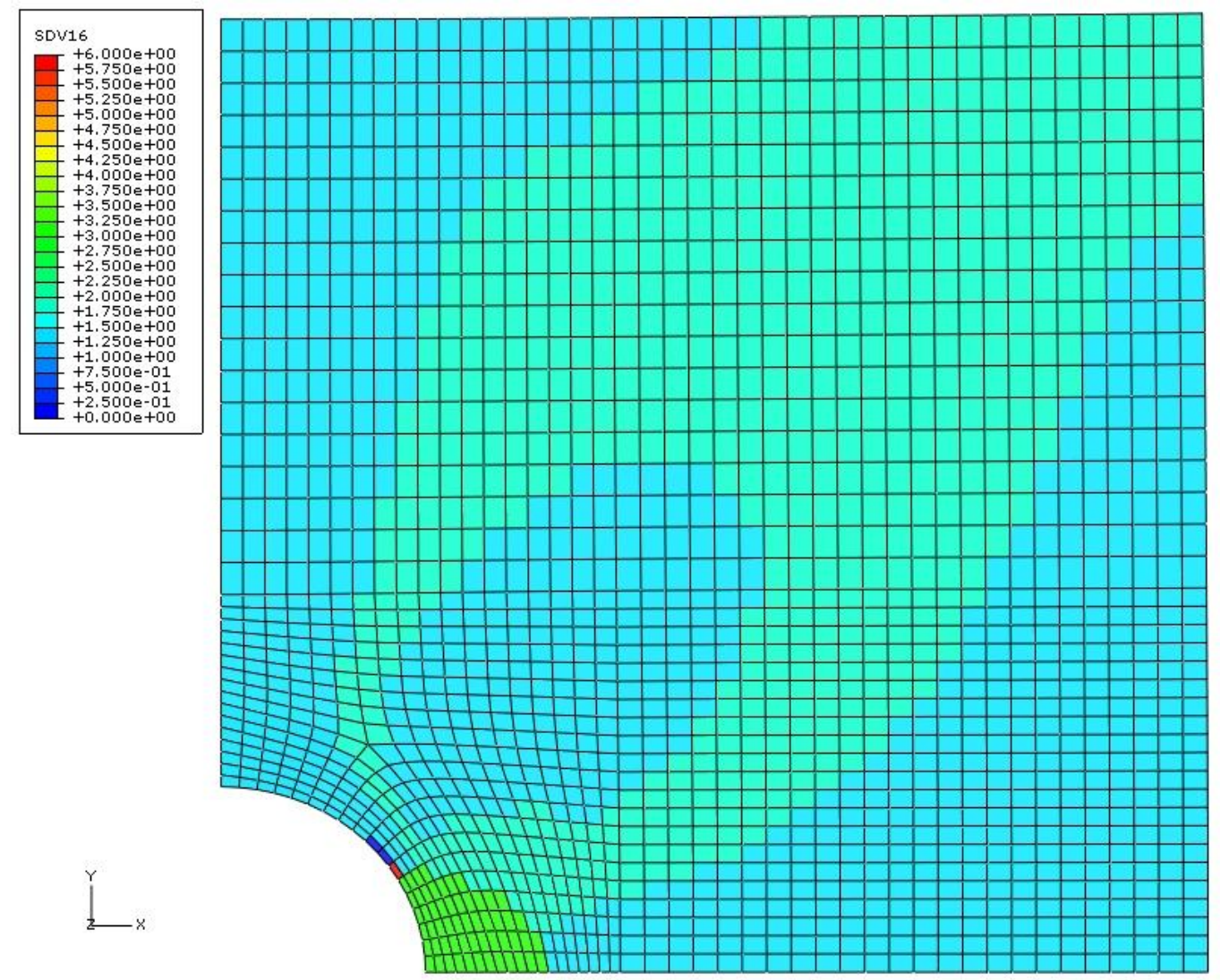

Figure 4.33 Contour plot of the direction of minimum $\mathrm{C}_{\mathrm{ij}}$ ratio MINCIJN

In this figure, light blue (MINCIJN=1) represents the $\mathrm{X}$-direction, pale green (MINCIJN=2) represents the Y-direction, and bright green (MINCIJN=3) represents the Z-direction. The important information from this plot is that the area of stiffness ratio close to $10 \%$ at the top of the hole corresponds to the global X-direction and the area of complete loss in stiffness to the right of the hole corresponds to the Zdirection. The rest of the sample that has a $30 \%$ reduction in stiffness is a combination of the $\mathrm{X}$ - and Y-directions.

The reduction of stiffness at the top and right of the hole are an indication that failure probably has occurred in these areas. The contour plot of the number of 
failures in Figure 4.34 shows that these areas have the highest amount of ply failures in the sample. As a result, an investigation into all of the critical stiffness ratios is needed because the stiffness reduction may have occurred in multiple directions in addition to what is indicated in Figures 4.32 and 4.33.
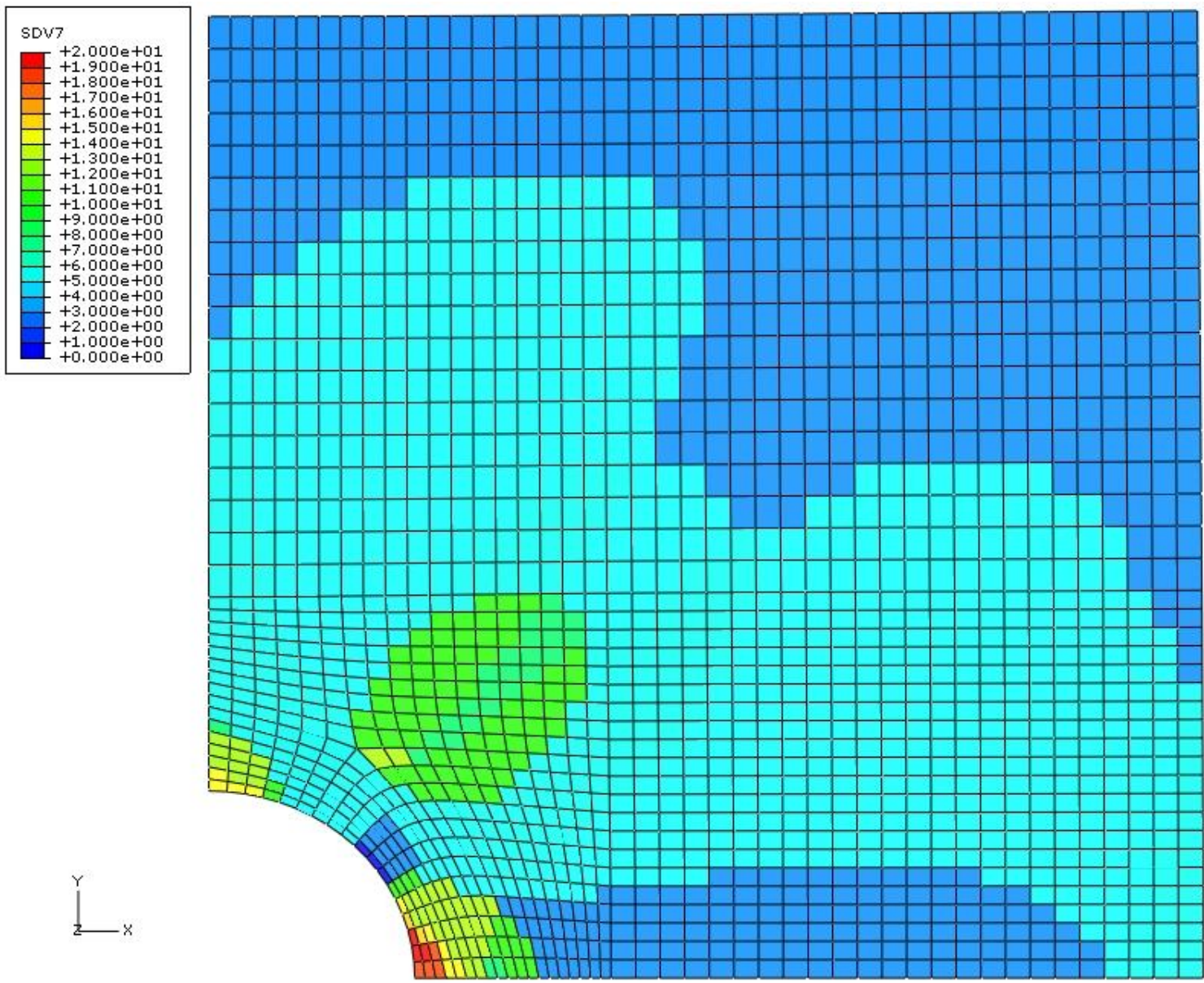

Figure 4.34 Contour plot of number of failures, NOF

The multiaxial loading combined with $\mathrm{XZ}$ and $\mathrm{YZ}$ Poisson ratio effects contributes to strains in the Z-direction of the sample. The softening and failure of the 
laminate in the through-thickness direction is shown in Figure 4.35. The majority of this sample has a $15 \%$ reduction in stiffness, the area above the open hole has been reduced by $35 \%$, and the area to the right of the hole has a complete loss in stiffness. This stiffness is not important to the overall response of the sample, but its contribution to the minimum stiffness ratio shown in Figures 4.32 and 4.33 could mask the reduction in other important stiffness ratios.

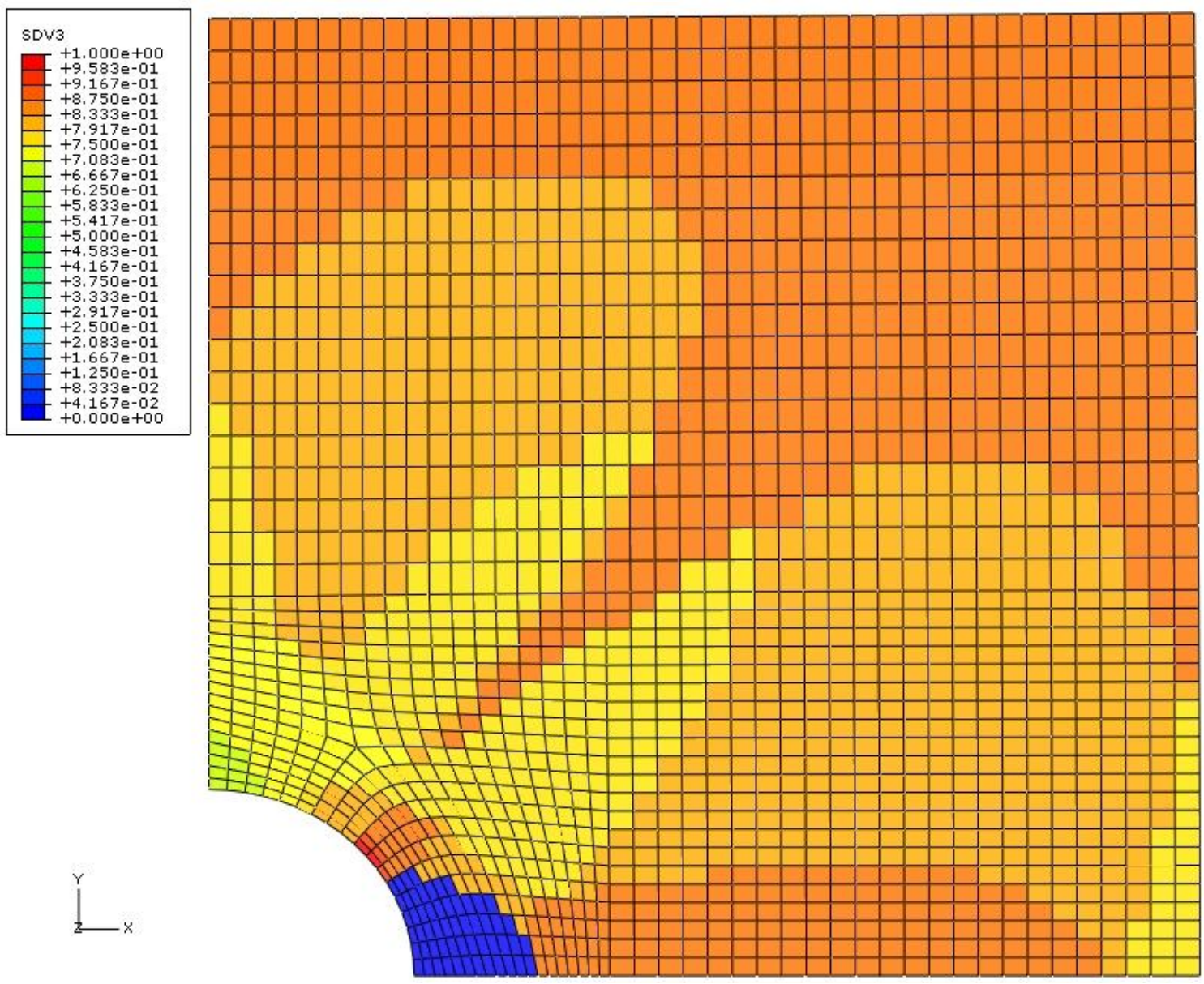

Figure 4.35 Plot of $\mathrm{C}_{\mathrm{ZZ}}$ stiffness ratio (CZZR) 
The next stiffness ratio examined is the $\mathrm{C}_{\mathrm{XX}}$ ratio that is shown in Figure 4.36. The three areas to note in this plot are the top of the hole, the right of the hole, and the remainder of the sample. At the top of the hole, the $\mathrm{C}_{\mathrm{XX}}$ stiffness has been reduced to $15 \%$ of its original value. To the right of the hole and in the rest of the sample, this stiffness ranges from $50 \%$ to $75 \%$ of its original value. It is important to note that in the area to the right of the hole, this stiffness ratio has only been reduced to $50 \%$ of its original stiffness. This suggests that, although some plies in this region may have failed in the global X-direction, the $0^{\circ}$ plies in this direction have not failed in fiber tension. The ply failure history of this sample is documented later in this section. 


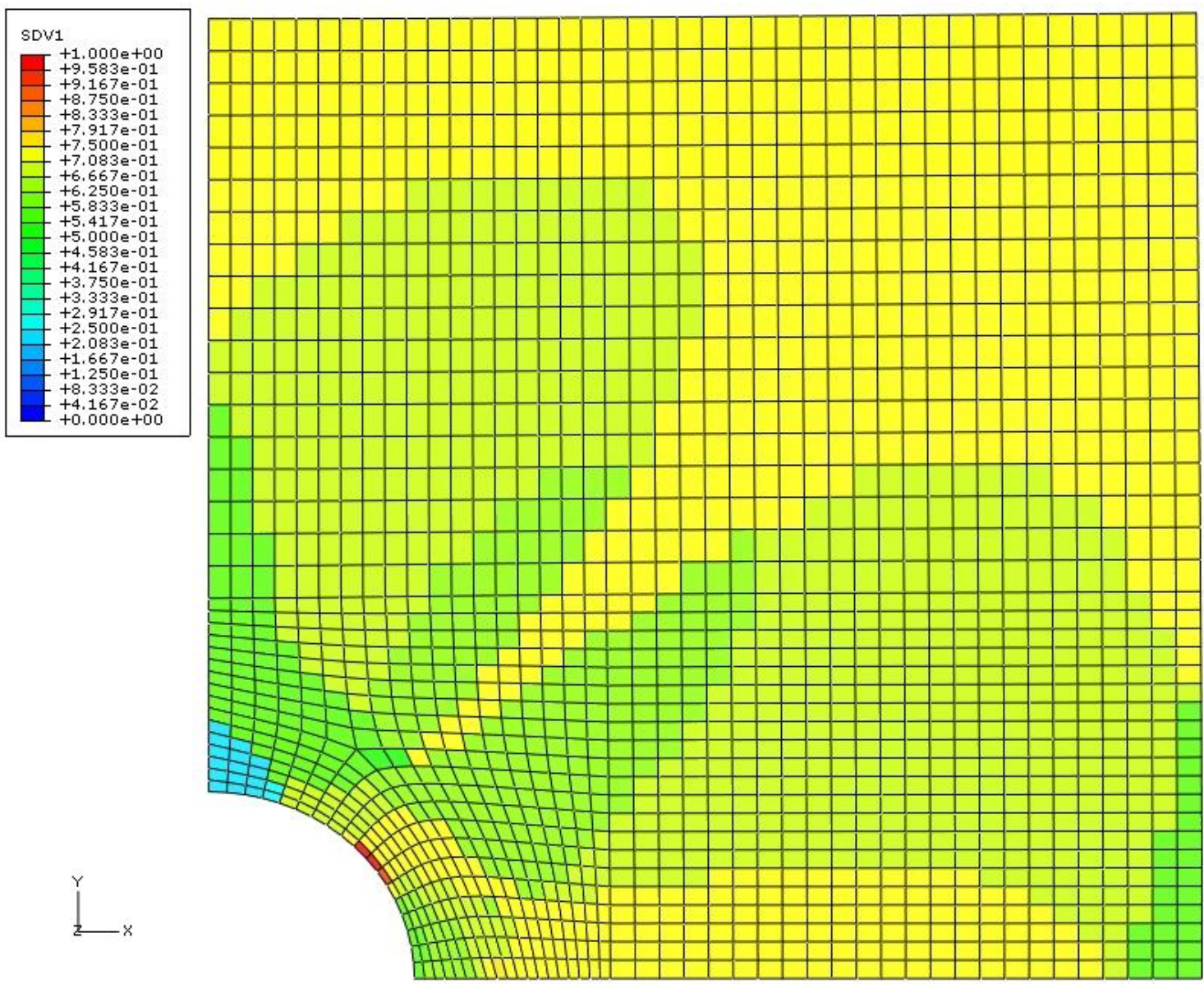

Figure 4.36 Plot of $\mathrm{C}_{\mathrm{XX}}$ stiffness ratio (CXXR)

The plot of the $\mathrm{C}_{\mathrm{YY}}$ stiffness ratio in Figure 4.37 has similar characteristics to the previous plot. At the right of the hole, the $\mathrm{C}_{\mathrm{YY}}$ stiffness has been reduced to $15 \%$ of its original value. This significant drop in stiffness is not apparent when looking at the minimum stiffness ratio plots. To the top of the hole and in the remainder of the sample, this stiffness ranges between $50 \%$ and $75 \%$ of its original value. 


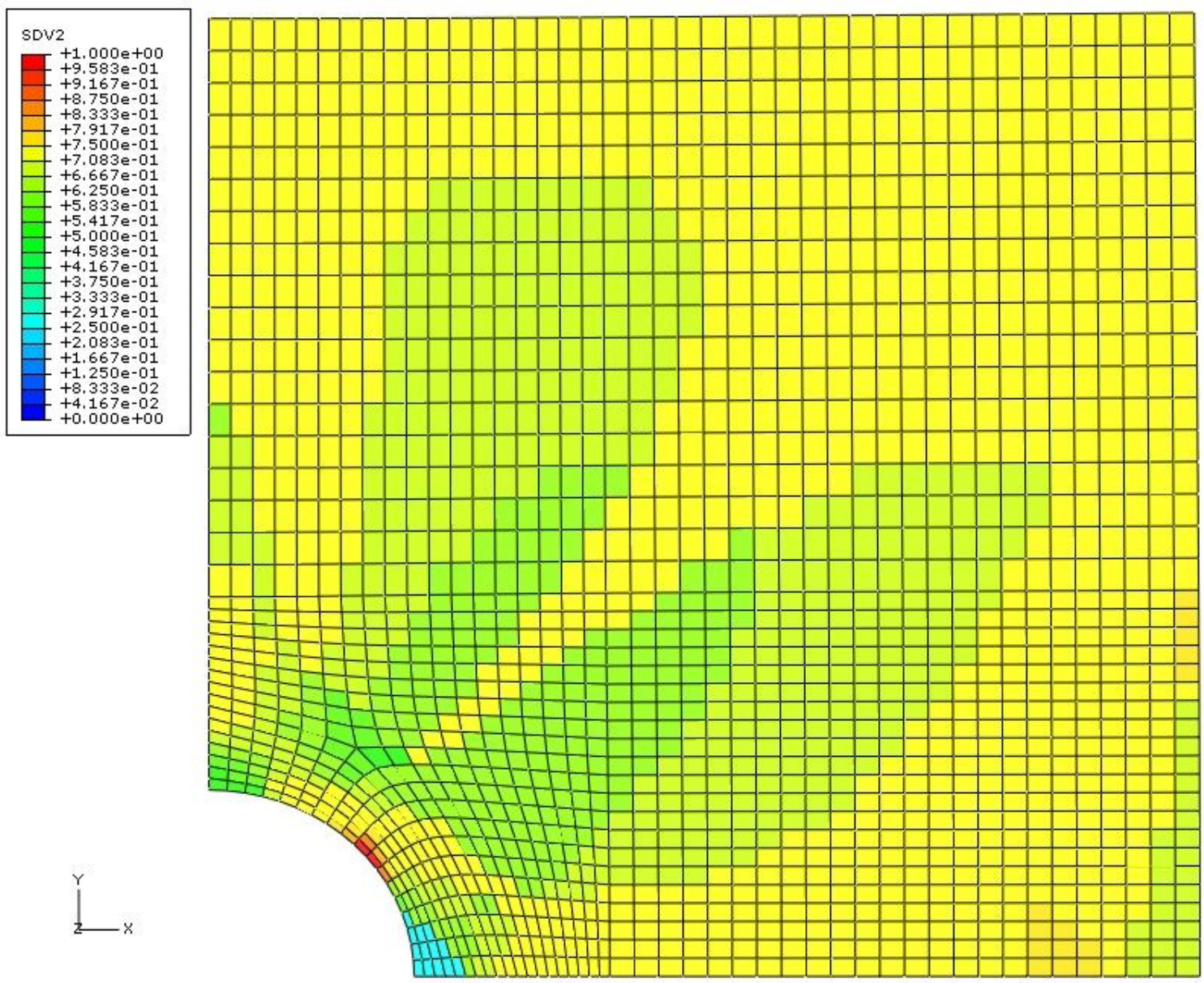

Figure 4.37 Plot of $\mathrm{C}_{Y Y}$ stiffness ratio (CYYR)

The final stiffness ratio that is important to the response of the structure is the $\mathrm{C}_{\mathrm{XY}}$ stiffness ratio, which represents the $\mathrm{XY}$ shear stiffness. In Figure 4.38, the majority of the sample has less than 5\% stiffness loss in this direction. Areas in close proximity to the hole in the sample have been reduced to $65 \%$ of the original shear stiffness. 


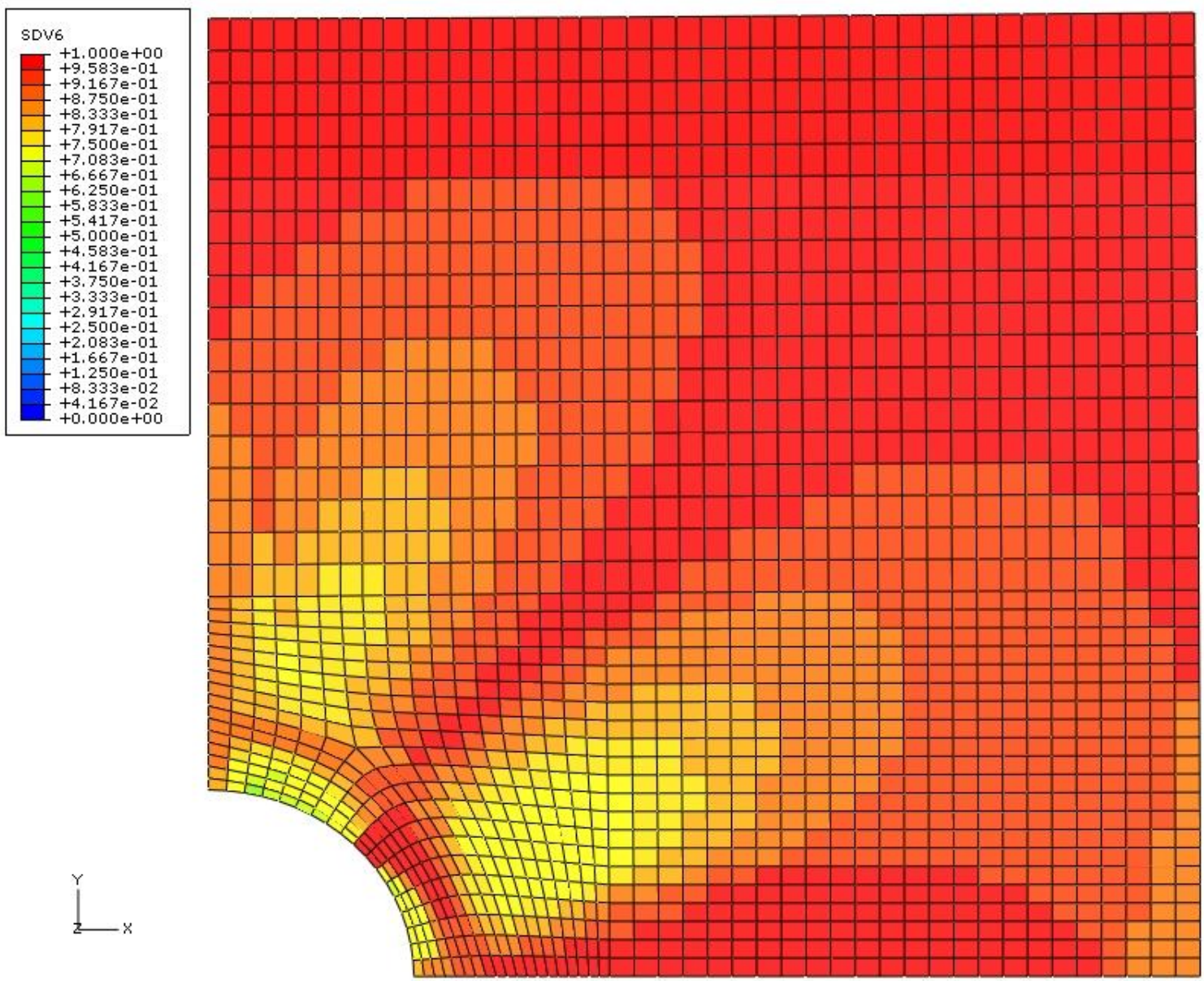

Figure 4.38 Plot of $\mathrm{C}_{\mathrm{XY}}$ stiffness ratio (CXYR)

The progression of failure through the sample must be understood before making changes to the layup. A progression plot of the last failed mode is shown in Figure 4.39. For this plot, dark blue indicates no failure (FMODE=0), the blue areas (FMODE=1) indicate 1-direction tensile failure, the light blue areas (FMODE=2) indicate 1-direction compressive failure, the areas in pale green (FMODE=3) are 2direction tensile failure, bright green areas $(\mathrm{FMODE}=5)$ have tensile failure in the 3direction, and red (FMODE=9) indicates a failure mode of 12 shear. 
A progression plot of the last failed ply is shown in Figure 4.40. In this figure, grey areas indicate no failure recorded (FPLY $=0$ ), yellow areas refer to the $90^{\circ}$ plies $(\mathrm{FPLY}=7)$, red areas to the $0^{\circ}$ plies $(\mathrm{FPLY}=8)$, blue areas to the $-45^{\circ}$ plies $(\mathrm{FPLY}=5)$, and finally pale green areas refer to $+45^{\circ}$ plies (FPLY=6). 

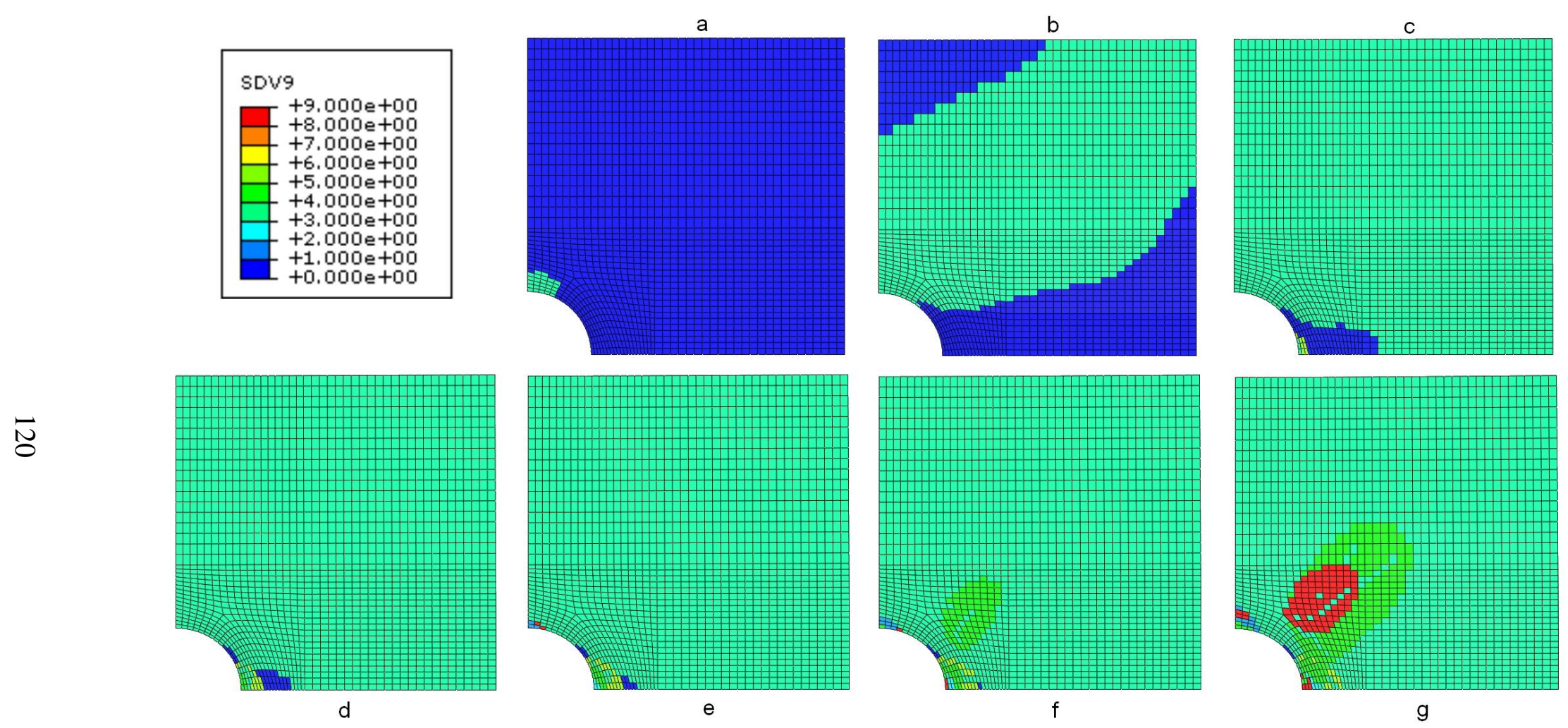

Figure 4.39 Plot of progression of last failed mode FMODE 

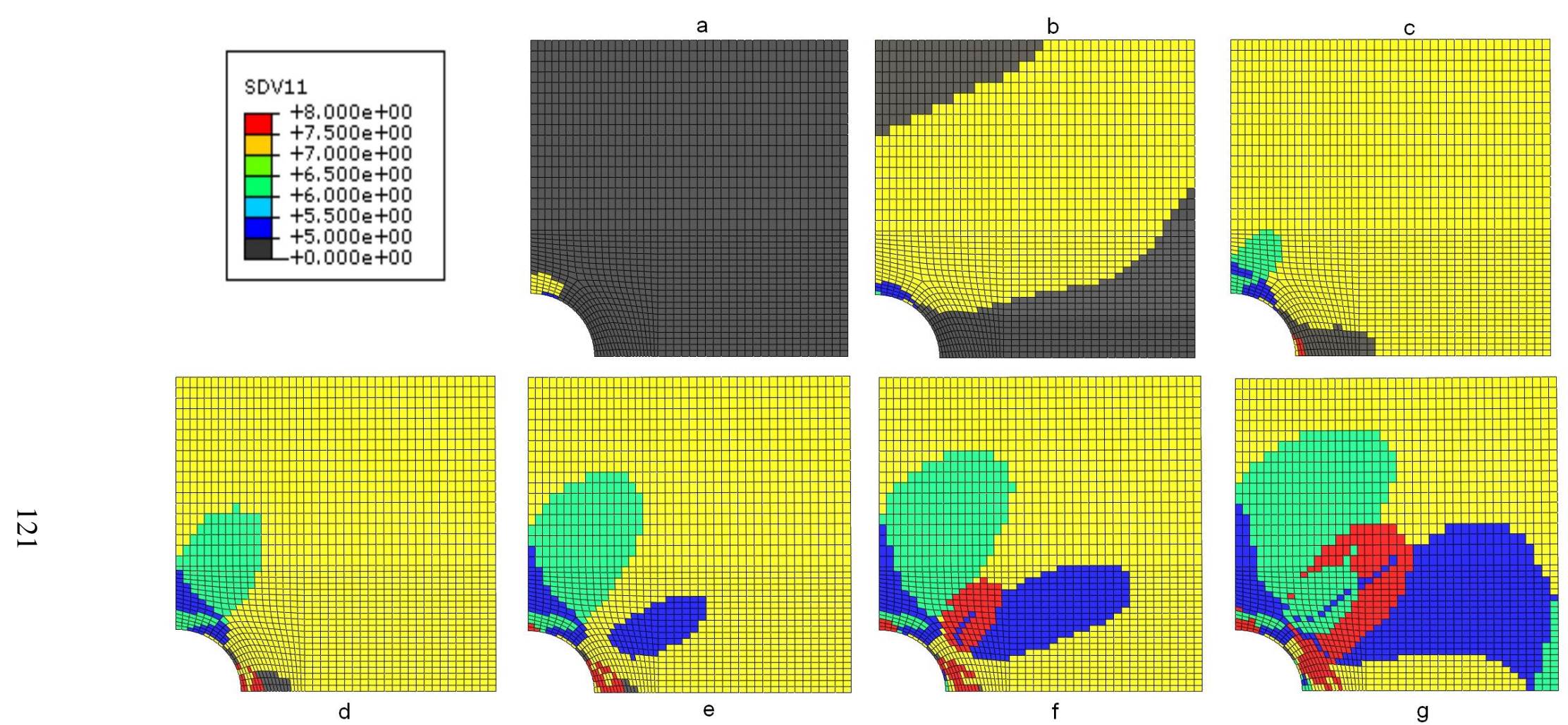

Figure 4.40 Plot of progression of last failed ply FPLY 
The quasi-isotropic layup of the laminate makes the interpretation of these plots more difficult than the first case study. In order to better describe the progression of failure in the sample, five regions are identified and highlighted on the sample below in Figure 4.41. The regions, shown in Figure 4.41 on a plot of FMODE at the end of the analysis, are used to refer to areas in the progression plots of Figure $4.39 \mathrm{a}-\mathrm{g}$ and Figure 4.40a-g.

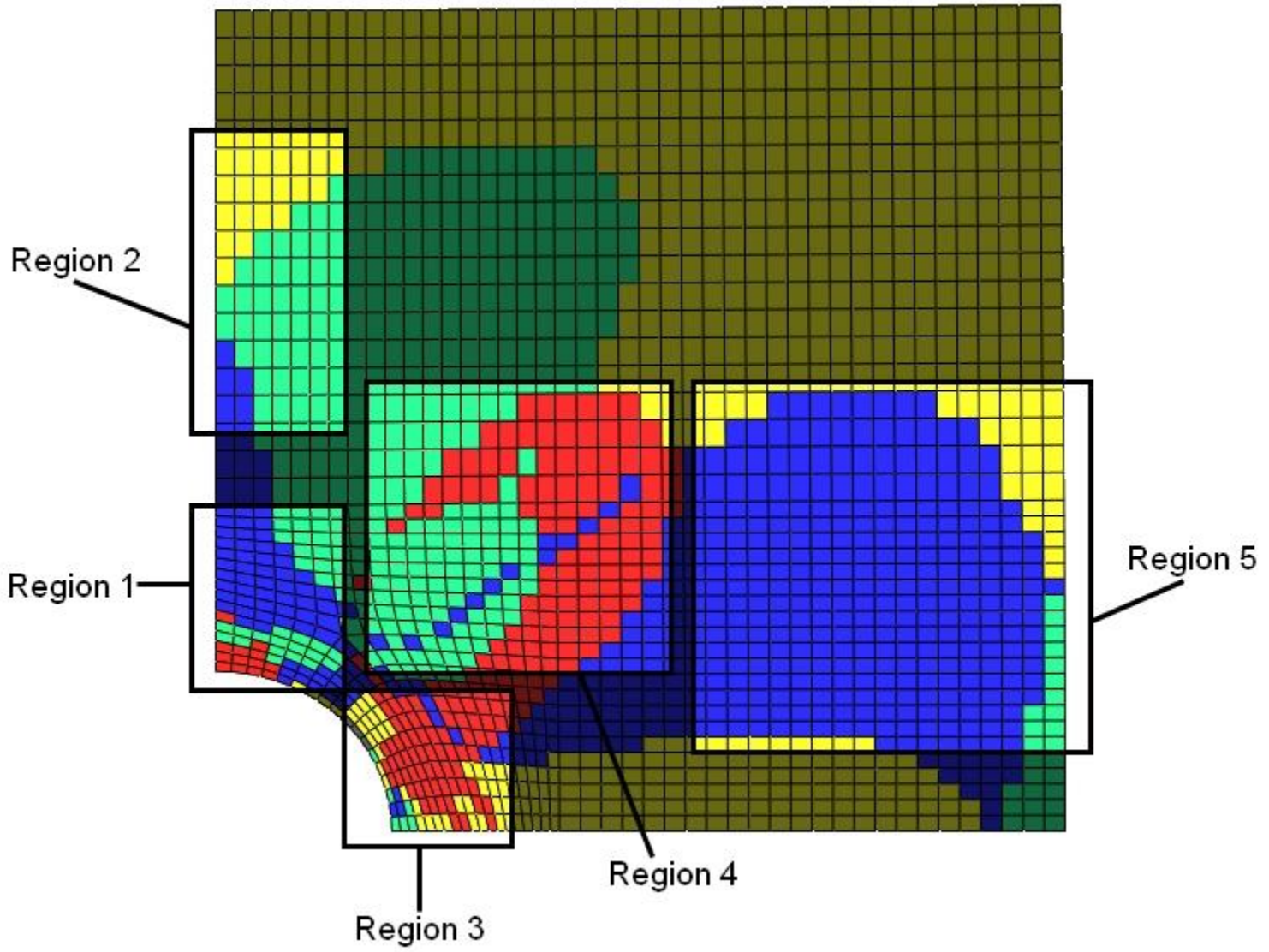

Figure 4.41 Diagram of regions 
Failure begins in this sample in region 1, the top portion of the hole, with transverse (2-direction) tensile failure in the $90^{\circ}$ plies (see plot a of Figures 4.39 and 4.40) and propagates across almost the entire sample, shown in the yellow areas of Figure 4.40 plots $\mathrm{b}$ and $\mathrm{c}$. The next failures again start in region 1 during plot $\mathrm{b}$ and are transverse tensile failure in the $\pm 45^{\circ}$ plies. These failures expand outward to region 2 throughout the rest of the loading as shown in the green and blue areas in regions 1 and 2 of Figure 4.40 plots c to g. An area of tensile 3-direction failure in all

plies starts in region 3, to the right of the hole, in plot c and expands to encompass this region from plots d to $\mathrm{g}$. Also in this region, both compressive transverse failure in the $0^{\circ}$ plies and tensile transverse failure in the $90^{\circ}$ plies occur from plots $\mathrm{d}$ to $\mathrm{g}$. A pocket of transverse tensile failure in the $\pm 45^{\circ}$ plies (blue area in region 4 of Figure 4.40e), followed by compressive transverse failure in the $0^{\circ}$ plies (red area in region 4 of Figure 4.40f), arises and expands in region 4. These areas of failure expand into region 5 through plots $f$ and $g$. Finally, 12 shear failure occurs in the $\pm 45^{\circ}$ plies, which is the red area in region 4 of Figure $4.39 \mathrm{~g}$.

The quasi-isotropic layup results in a displacement of $0.074 \mathrm{~m}$ in the positive $\mathrm{X}$-direction and $0.046 \mathrm{~m}$ in the negative $\mathrm{Y}$-direction. These values are not within the desired displacement objective in both directions, so changes to the layup must be made to address these problems. In addition, there is a large area of failure in this sample and minimizing this area is essential in meeting the displacement objective.

\subsubsection{Design iteration \#1}

Any changes to the original layup must simultaneously improve stiffness in the global X-and Y-directions, because each displacement objective has not been 
met. To achieve this, no additional plies can be added to the new layup. In the $\left[0^{\circ} / 90^{\circ} / \pm 45^{\circ}\right]_{\mathrm{s}}$ layup, the $0^{\circ}$ plies are essential to the response in the X-direction as are the $90^{\circ}$ plies for the response to the Y-direction. Changing the remaining $\pm 45^{\circ}$ plies to additional $0^{\circ}$ and $90^{\circ}$ plies would help achieve the displacement objectives, but there is XY shear failure already in the sample and losing the cross-plies would increase this failure. A change to the $\pm 45^{\circ}$ is needed to address either the $\mathrm{X}$-direction or the $\mathrm{Y}$ direction. Since the displacement in the X-direction is farther from its objective, orienting the fibers more in this direction will be beneficial.

A $\left[0^{\circ} / 90^{\circ} / \pm 30^{\circ}\right]_{\mathrm{S}}$ layup is tested in this design iteration. A check of the displacements at the top right corner of the sample shows improvements in both directions. The displacement in the positive $\mathrm{X}$-direction is 0.052 , greater than the targeted value. The displacement in the negative Y-direction is 0.0405 , slightly greater than the targeted value.

This analysis shows a decrease in the magnitude of the displacement in the Y-direction. This result is unexpected because cross-ply fibers are oriented less in this direction when compared to the original layup, yet the displacement in this direction has decreased. In the original analysis, there were several areas of the sample that had transverse tensile failure in the $\pm 45^{\circ}$ plies. These failures were caused by the tensile loading in the X-direction of the sample and result in the 2-direction stiffness in these plies to be discounted. The overall stiffness of the structure in the Y-direction is softened, causing more deflection.

A comparison between the original layup and the current layup of the $\mathrm{C}_{\mathrm{YY}}$ stiffness ratios at the end of loading is shown in Figure 4.42. The initial stiffness of the new layup in the Y-direction is less than that of the original layup, but the stiffness 
ratio at the end of loading is greater. The area at the top of the open hole retains $30 \%$ more stiffness when compared to original layup. The bulk of the sample has a stiffness ratio ranging from $70 \%$ to $95 \%$, compared to $50 \%$ to $75 \%$ in the original layup. The area to the right of the hole (region 3 ) exhibits more stiffness loss than the original layup, a $5 \%$ ratio compared to a $15 \%$ ratio.
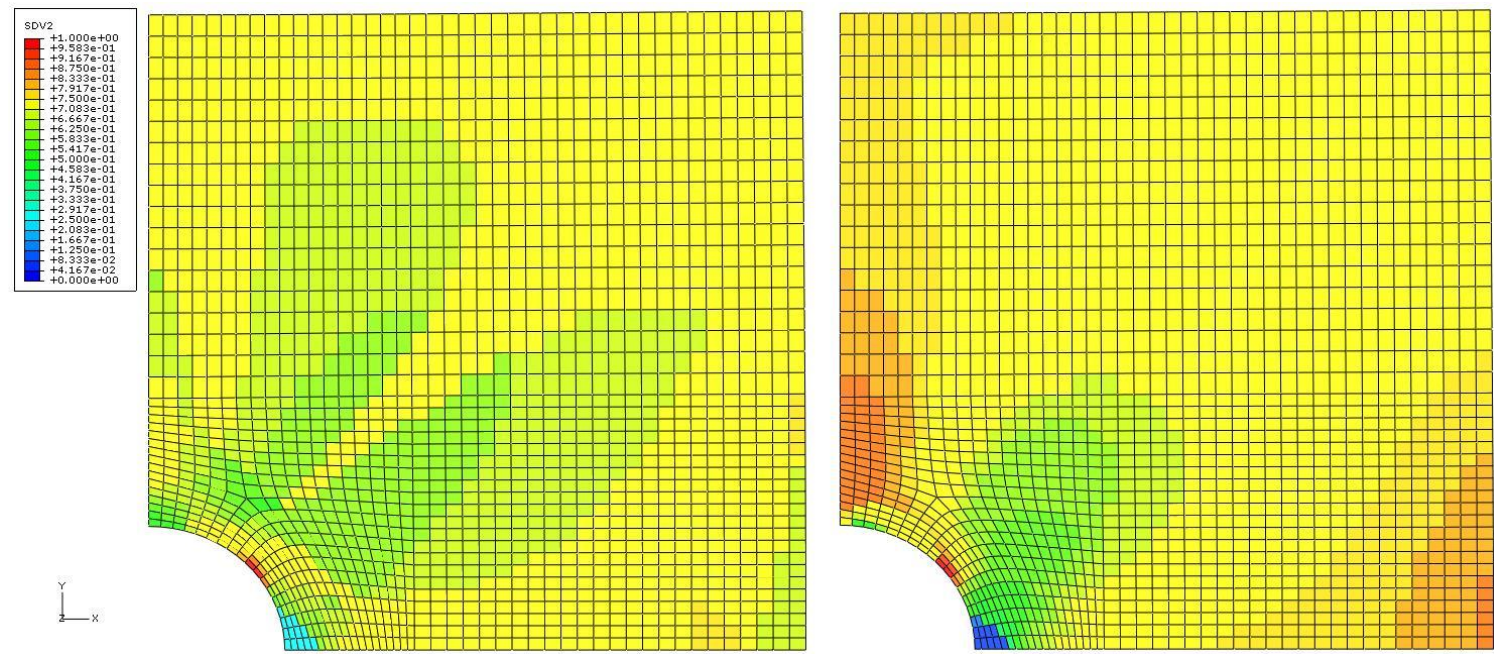

Figure 4.42 Plot of $\mathrm{C}_{\mathrm{YY}}$ stiffness ratio (CYYR) comparing $\left[0^{\circ} / 90^{\circ} / \pm 45^{\circ}\right]_{\mathrm{S}}$ (left) to $\left[0^{\circ} / 90^{\circ} / \pm 30^{\circ}\right]_{\mathrm{s}}$ (right)

The prevention of stiffness loss in the new layup comes from limiting the transverse tensile failure in the $\pm 30^{\circ}$ plies, illustrated below in Figure 4.43. The plot shows the last failed ply at the end of loading. The areas in dark blue and pale green represent cross-plies that have failed. The corresponding failure mode in these areas is transverse (2-direction) tensile failure. In the left plot of Figure 4.43, the transverse cross-ply failure region is large, expanding across the lower portion of the sample (region 5) and up from the top of the hole (regions 1 and 2). In the right plot of Figure 
4.43 , the area of cross-ply failure is only a small portion on the top edge of the hole (region 1), significantly smaller than the original layup.
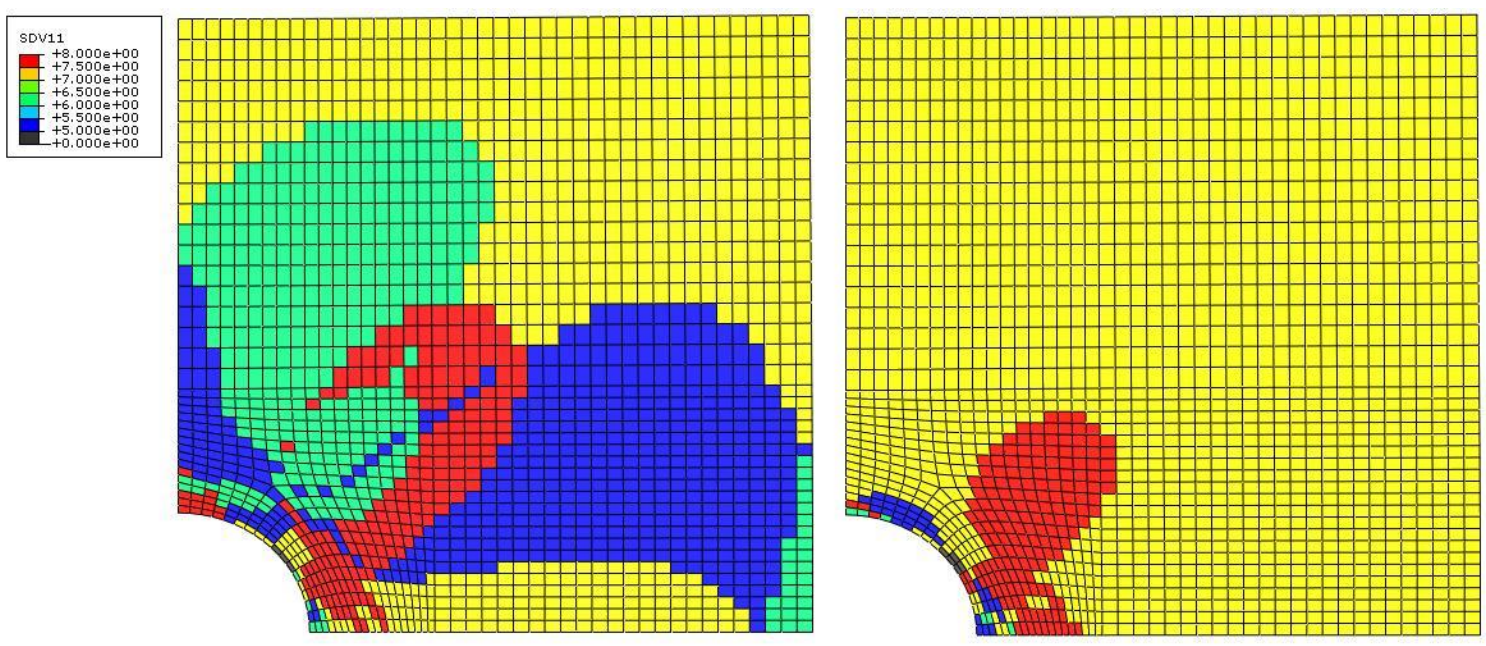

Figure 4.43 Plot of last failed ply (FPLY) comparing $\left[0^{\circ} / 90^{\circ} / \pm 45^{\circ}\right]_{s}$ (left) to $\left[0^{\circ} / 90^{\circ} / \pm 30^{\circ}\right]_{\mathrm{s}}$ (right)

\subsubsection{Design iteration \#2}

Building on the results and insights of the first design iteration, additional changes need to be made to the layup to meet the desired performance objectives. The displacement of the corner point in the negative Y-direction must be below $0.04 \mathrm{~m}$, so improving the stiffness and reducing progressive failure in this direction is once again needed. Based on the first iteration, aligning the fibers further into the $\mathrm{X}$-direction will prevent transverse tensile failure in these plies, minimizing stiffness loss in the Ydirection, and decreasing the magnitude of the Y-displacement.

The layup used for this design iteration is $\left[0^{\circ} / 90^{\circ} / \pm 20^{\circ}\right]_{\mathrm{s}}$, which increases the fiber orientation of the plus/minus plies by $10^{\circ}$ over the previous iteration. The 
resulting displacements of the upper right corner of the sample are $0.041 \mathrm{~m}$ in the positive $\mathrm{X}$-direction and $0.0342 \mathrm{~m}$ in the negative $\mathrm{Y}$-direction. Both displacements are within their respective target values, so this layup has achieved the performance objectives. Comparisons of the critical stiffness ratios will display the improvements in reducing the progressive failure within the structure.

The comparison of the minimum $\mathrm{C}_{\mathrm{ij}}$ stiffness ratio MINCIJ is shown in Figure 4.44. When compared to the original layup, the improvements are not apparent. The light blue area representing a $15 \%$ stiffness ratio in the new layup (Figure 4.44 right) is smaller and confined close the edge of the hole (region 1). The area of complete stiffness loss to the right of the hole (region 3) is larger in the new layup. Throughout the rest of the sample, the minimum stiffness ratios are greater than that of the original design.
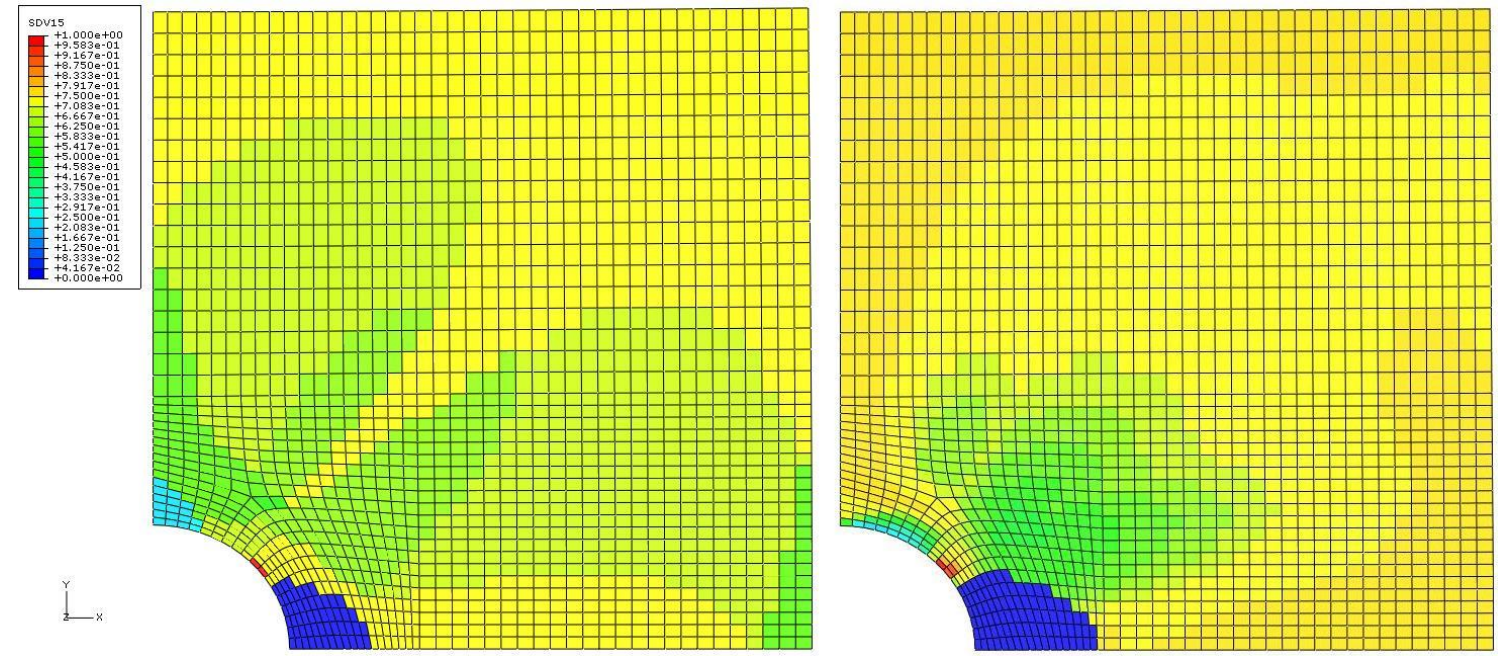

Figure 4.44 Comparison of minimum stiffness ratio (MINCIJ), $\left[0^{\circ} / 90^{\circ} / \pm 45^{\circ}\right]_{\mathrm{s}}$ (left) to $\left[0^{\circ} / 90^{\circ} / \pm 20^{\circ}\right]_{\mathrm{s}}$ (right) 
A contour plot of the direction of minimum $\mathrm{C}_{\mathrm{ij}}$ stiffness ratio MINCIJN is shown in Figure 4.45. The areas in red signify the XY shear ratio, pale green signify the Y-direction, light blue (1 element) is the $\mathrm{X}$-direction, and bright green is the $\mathrm{Z}$ direction. Dark blue areas have a minimum stiffness ratio greater than $80 \%$ and the direction is not recorded.

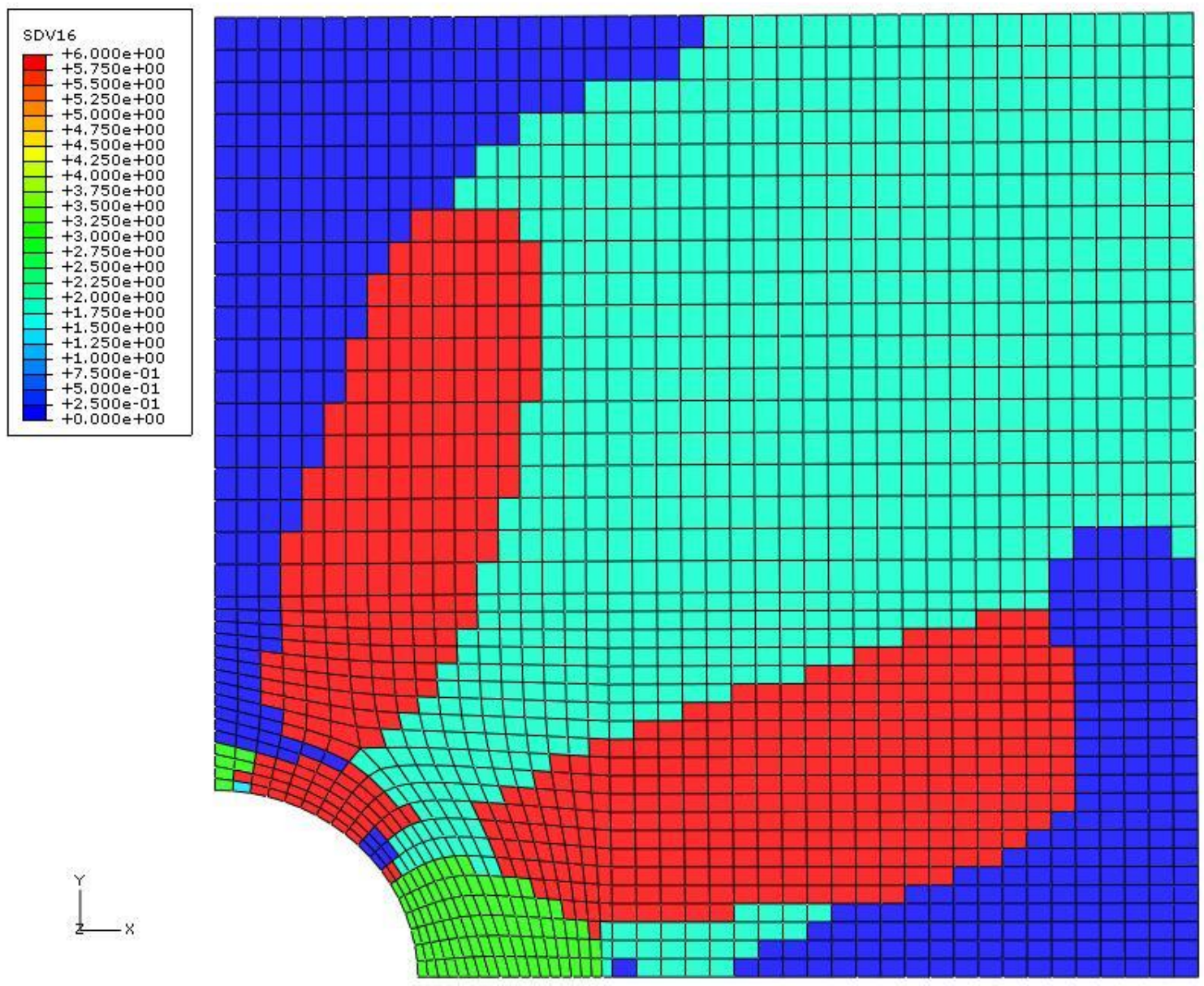

Figure 4.45 Plot of the direction of minimum $\mathrm{C}_{\mathrm{ij}}$ ratio MINCIJN for $\left[0^{\circ} / 90 \% \pm 20^{\circ}\right]_{\mathrm{S}}$ layup 
The plot of $\mathrm{C}_{\mathrm{XX}}$ stiffness ratio in Figure 4.46 shows the improved performance of the new layup in this direction. With the $\pm 20^{\circ}$ fibers aligned more in the $\mathrm{X}$-direction than the quasi-isotropic layup, the new layup is expected to have less softening and failure in this direction. The area of $85 \%$ stiffness loss in region 1, the top of the hole, for the original layup has been reduced to one element along the edge of the hole in the new layup. The rest of the sample has become just 5\% to $25 \%$ compliant, an improvement on the $25 \%$ to $40 \%$ compliance of the original layup.
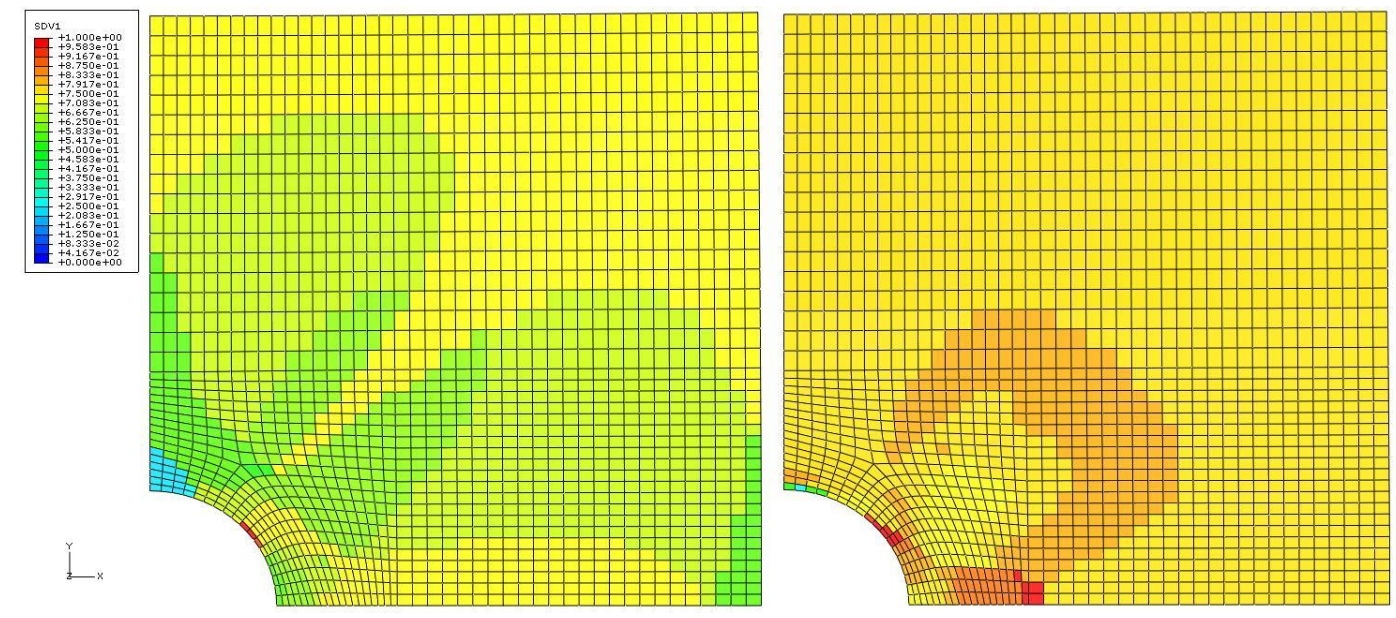

Figure 4.46 Plot of $\mathrm{C}_{\mathrm{XX}}$ stiffness ratio (CXXR) comparing $\left[0^{\circ} / 90^{\circ} / \pm 45^{\circ}\right]_{\mathrm{S}}$ (left) to $\left[0^{\circ} / 90^{\circ} / \pm 20^{\circ}\right]_{s}$ (right)

Like the first design iteration, the $\mathrm{C}_{\mathrm{YY}}$ stiffness ratios shown in Figure 4.47 improve upon the original layup. Limiting the transverse tensile failure in the $\pm 20^{\circ}$ plies improves the performance of the sample in the Y-direction. The area of stiffness loss around the right side of the hole (region 3) is slightly more severe than 
the original layup, but the improvement in stiffness loss over the entire sample outweighs this drawback.
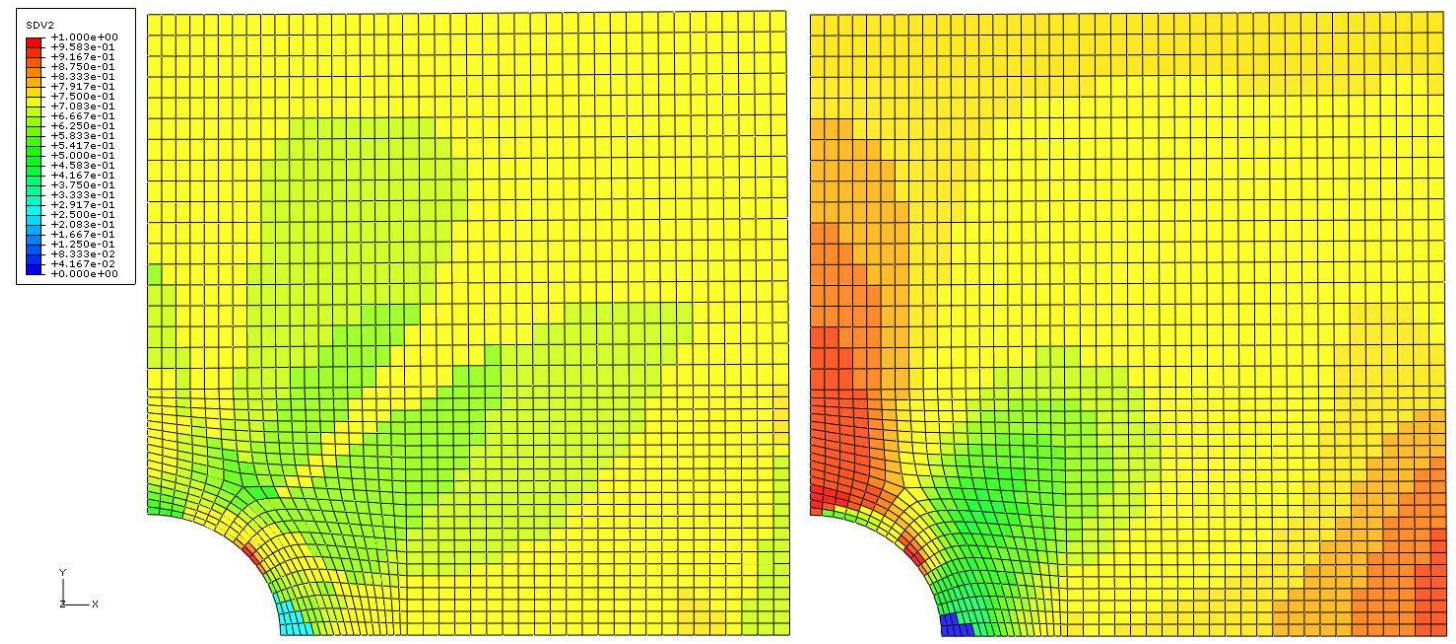

Figure 4.47 Plot of $\mathrm{C}_{\mathrm{YY}}$ stiffness ratio (CYYR) comparing $\left[0^{\circ} / 90^{\circ} \% 45^{\circ}\right]_{S}$ (left) to $\left[0^{\circ} / 90^{\circ} / \pm 20^{\circ}\right]_{\mathrm{s}}$ (right)

The $\mathrm{C}_{\mathrm{ZZ}}$ stiffness ratio plot in Figure 4.48 shows improvement from the original layup throughout the entire structure. The area of complete stiffness loss in right plot of Figure 4.44 is shown here as stiffness loss in the Z-direction. The $\mathrm{XZ}$ and YZ coupling of this material causes strain in the Z-direction, but this is not a critical direction because there is no loading in this direction. 

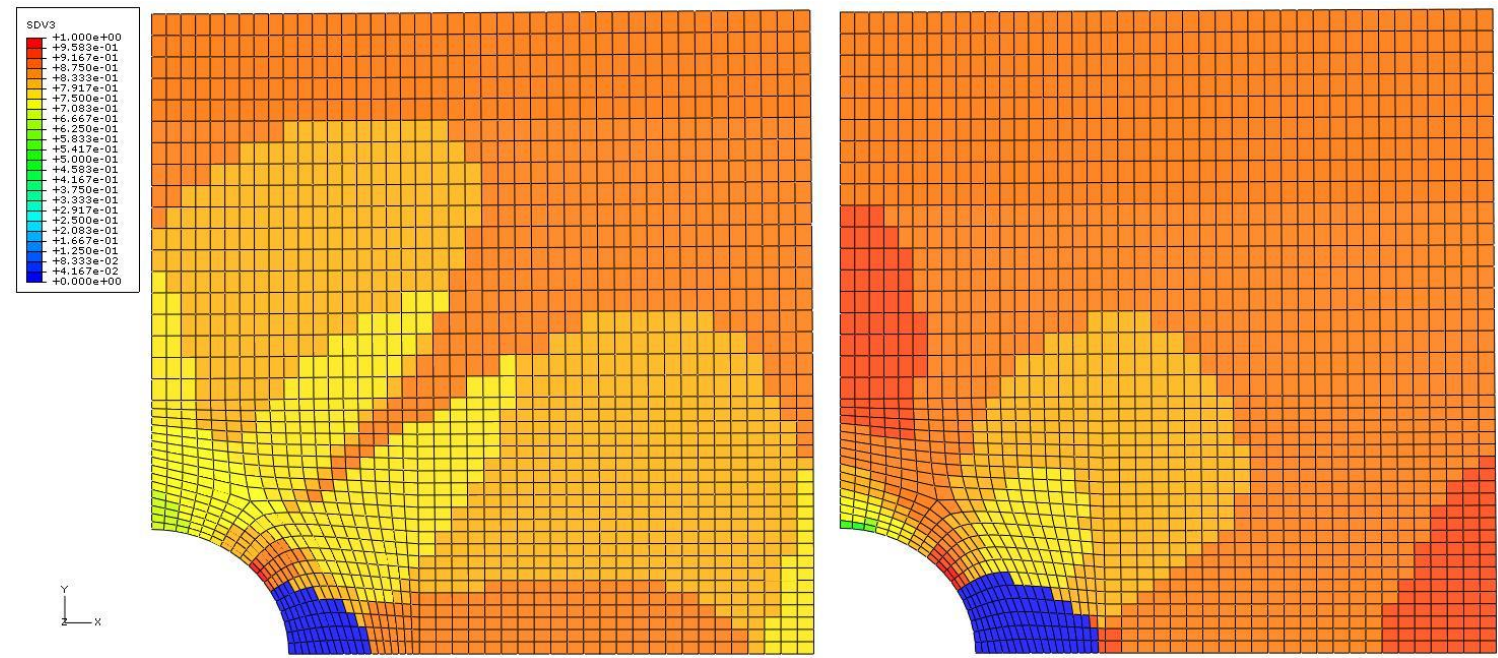

Figure 4.48 Plot of $\mathrm{C}_{\mathrm{ZZ}}$ stiffness ratio $(\mathrm{CZZR})$ comparing $\left[0^{\circ} / 90^{\circ} / \pm 45^{\circ}\right]_{\mathrm{s}}$ (left) to $\left[0^{\circ} / 90^{\circ} \% \pm 20^{\circ}\right]_{s}$ (right)

The one aspect where stiffness loss has increased from the original design to the new design is the $\mathrm{XY}$ shear stiffness. The plot of the $\mathrm{C}_{\mathrm{XY}}$ stiffness ratio shown in Figure 4.49 illustrates the extent of shear stiffness loss. While the original layup had very little area of concern, the new design has a $15 \%$ stiffness ratio around the upper edge of the hole (region 1) and a stiffness ratio between $50 \%$ to $85 \%$ throughout the rest of the structure. 

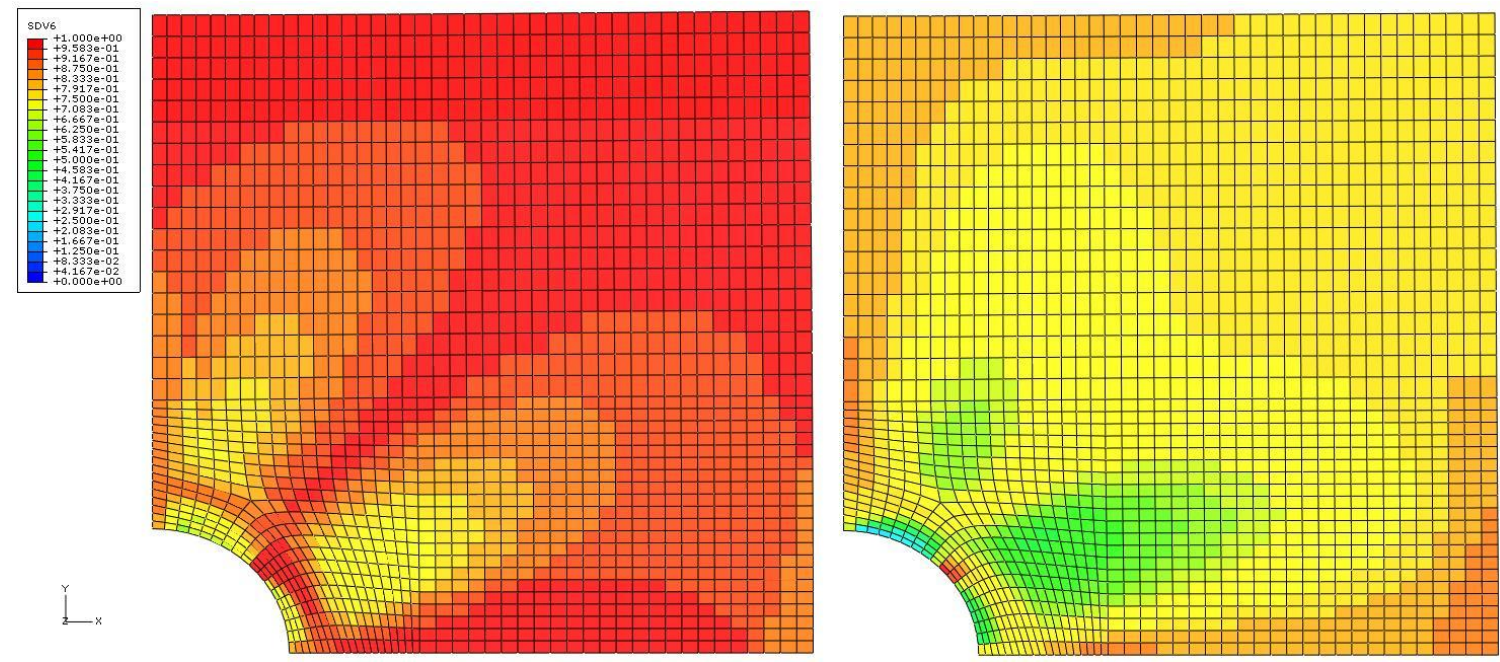

Figure 4.49 Plot of $\mathrm{C}_{X Y}$ stiffness ratio $(\mathrm{CXYR})$ comparing $\left[0^{\circ} / 90^{\circ} / \pm 45^{\circ}\right]_{\mathrm{s}}$ (left) to $\left[0 \% 90^{\circ} / \pm 20^{\circ}\right]_{s}$ (right)

The $\left[0^{\circ} / 90^{\circ} / \pm 20^{\circ}\right]_{\mathrm{s}}$ layup achieves the displacement performance

objectives of the analysis. These objectives are achieved by increasing the stiffness of the structure in the $\mathrm{X}$-direction and limiting the amount of transverse tensile failure in the plus/minus plies of the layup. Comparisons of the stiffness ratios between the original and new layup display improvements in reducing the amount of stiffness loss in the sample.

This case study shows that the approach outlined in the design methodology improves the understanding of the complex material nonlinearity and progressive ply failure response of the open hole sample. The stiffness ratio parameters provide a straightforward measure of material degradation and reduce the complexity of the results when compared to the safety factor output parameter of the original LAMPATNL program. Areas of critical stiffness loss were easily identified using the minimum stiffness ratio parameter. The failed mode and ply plots for this 
sample identified transverse tensile failure in the $\pm 45^{\circ}$ plies of the quasi-isotropic layup as a cause of stiffness loss in the global Y-direction. Modifications to the $\left[0^{\circ} / 90^{\circ} / \pm 45^{\circ}\right]_{\mathrm{S}}$ layup were made to address this failure. These modifications enabled the designer to quickly achieve the performance objectives of the analysis. 


\section{Chapter 5}

\section{CONCLUSIONS}

\subsection{Conclusions}

The development of a methodology to design and analyze thick section composite structures using nonlinear ply properties, progressive ply failure, and a homogenizing-dehomogenizing technique (the "smearing-unsmearing" approach) was the goal of this research. An investigation into the ability of ABAQUS, ANSYS, and MSC.Nastran to model composite materials with anisotropic nonlinear behavior, support progressive ply failure using multiple failure criteria, homogenize laminates to obtain effective properties, and dehomogenize the laminate to apply ply based failure theories was conducted. The results of this investigation showed that none of the programs contained all of these abilities. Additional composite modeling software, such as GENOA and Heilus:MCT, were also researched and yielded similar conclusions.

Presented in this work was background on the various capabilities and limitations of the "LAM" series of codes, LAM3D, LAM3DNLP, LAMPAT, and LAMPATNL. These codes are able to model thick section composite structures using nonlinear ply properties, progressive ply failure, and the "smearing-unsmearing" approach. In the "LAM" codes, ply-level material nonlinearity is represented by using the Ramberg-Osgood equation. Progressive ply failure uses the ply discount method in combinations with ply-based failure criteria. The "smearing-unsmearing" approach 
uses the theory and assumptions of Chou [37] to calculate laminate and ply-level stress-strain response.

Out of these codes, LAMPATNL had been integrated into ABAQUS using a user material subroutine. LAMPATNL is the finite element implementation of the nonlinear, analytical model LAM3DNLP. There were several modifications to the procedure of LAM3DNLP in order for it to function in the finite element environment as LAMPATNL. The modifications include changes to the procedure for calculating ply-level stresses and strains, continuously updating of the Poisson's ratios to satisfy material stability conditions, and changes to the post-failure behavior of the code. Until the discussions in this research, these changes were never documented and their implications were never discussed.

The original LAMPATNL user material was not able to accurately track the failure history of the elements of the structure. Also, support of elements was limited to axisymmetric and plane strain types. A major contribution from this research was the addition of the ability to track the failure history by element number, integration point, ply, and direction. LAMPATNL and the other "LAM" codes were developed to analyze thick section composite structures, so three-dimensional analysis capabilities were needed. Another contribution of this research was expanding the user material to support three-dimensional 8-node linear brick elements.

In addition to the undocumented changes to LAM3DNLP when it was implemented in LAMPATNL, a full validation of the stress-strain response output of this user material was also never provided. With four materials and six different layups, a total of 13 load cases were simulated using LAMPATNL and compared to results generated by LAM3DNLP. Both linear and nonlinear ply properties were 
tested for these load cases to ensure full compatibility with both LAM3D and LAM3DNLP. None of the example cases presented for validation of LAMPATNL deviate from the values produced by LAM3DNLP.

\subsection{Summary of results}

LAMPATNL had the original output parameters of safety factor, critical mode, and critical ply. It was extremely difficult to determine the areas and directions of failure in the structure at the end of analysis using these parameters alone. An example was provided to illustrate the difficulty of using the safety factor to analyze a composite structure. The most important contribution of this research was the stiffness ratio parameters output by the UMAT. These parameters improved the visualization of progressive failure and stiffness loss and significantly increased the utility of LAMPATNL.

The validated LAMPATNL user material subroutine was then used to analyze thick section composite structures. Another unique contribution of this research was the newly developed design methodology, which outlined the process of designing a structure using the UMAT. The methodology used stiffness ratios and failure progression to provide insight into the failure mechanics of the laminate. Changes to the layup of the composite were made based upon the objectives of the analysis using the information provided by the design methodology.

Two example cases were used to evaluate the process of the design methodology. The first case study was a $\left[0^{\circ} / 90^{\circ}\right]_{s}$ layup of AS4/3501-6 subjected to compression and in-plane shearing. The objective of this case was to limit the displacement in the X-direction. This objective was achieved by increasing the orientation of fibers in X-direction and limiting failure in the sample. The resulting 
design for this case was a $\left[0_{2} / \pm 25^{\circ}\right]_{\mathrm{S}}$ layup. This layup was able to achieve the performance objective of the case study by limiting the amounts of shear and tensile failure and increasing the longitudinal stiffness in the sample.

The second case study was an open hole sample of S-Glass/Epoxy in a quasi-isotropic layup subjected to multiaxial in-plane loading. The failure progression of this structure revealed that transverse tensile failure in the $\pm 45^{\circ}$ plies resulted in decreased stiffness in the Y-direction. Increasing the orientation of the plus/minus plies into the X-direction leads to improved stiffness in both directions due to the limiting of transverse tensile failure in these plies. A $\left[0^{\circ} / 90^{\circ} / \pm 20^{\circ}\right]_{\mathrm{S}}$ layup was determined to meet both objectives of the analysis while keeping the ply amount constant and therefore not adding weight to the structure.

\subsection{Future work}

The documentation and validation of the LAMPATNL user material subroutine provides a basis to start analyzing thick section composite structures. The design methodology provides a template for using LAMPATNL to modify nonlinear composite layups using progressive ply failure analysis. The two case studies illustrated the application of the user material to design the layup of two structures under complex loading. The expansion of the LAMPATNL to analyze other cases of thick section composite structures is one subject of future work. In addition to the design and analysis of these structures, experimental validation of the resulting design modifications from LAMPATNL is also an important step.

Another subject of future work from this research is expanding the LAMPATNL user material to explicit dynamic loading. Currently, the UMAT developed for ABAQUS is only compatible with the implicit solver. This solver is 
used to simulate the response of structures under static or implicit dynamic loading. Modifications to the LAMPATNL code that interfaces with ABAQUS are required for the user material to function in the explicit solver environment. Further expansion in the dynamic modeling field necessitates the addition of rate dependent material behavior. The current constitutive model used for LAMPATNL is strain dependent. Additional work would be required to develop and validate a strain rate dependent constitutive model.

The ability to model residual thermal stresses that resulted from processing the composite materials was present in the LAM3D code. These thermal modeling features were largely abandoned in the transition to nonlinear materials and were similarly absent in the LAMPAT and LAMPATNL. With the framework of this capability still in place, thermal modeling features could be reintroduced without much difficultly. Strength predictions of metal matrix composite structures were shown to be effected from initial thermal stresses in the structure [40]. Expanding the ability of the user material to model thermal effects is a goal of future LAMPATNL development.

As discussed in the Theoretical considerations section of Chapter 3, there are changes to the procedure of calculating ply-level stresses and strains from LAM3DNLP to LAMPATNL. In that section, it was noted that these changes do not affect in-plane stress-strain predictions but may have implications for hybrid composites and laminates exposed to out-of-plane loading. In order to implement LAM3DNLP into the finite element code, it was required to not calculate the out-ofplane ply strain in accordance with the original theory. Further research is required to 
determine and discuss the effects, if any, of setting all ply strains equal to total laminate strains. 


\section{REFERENCES}

1. Travis A. Bogetti, Christopher P.R. Hoppel, William H. Drysdale, Threedimensional effective property and strength prediction of thick laminated composite media, Army Research Laboratory Technical Report 911, October 1995

2. Travis A. Bogetti, Christopher P.R. Hoppel, Vasyl M. Harik, James F. Newill, Bruce P. Burns, Predicting the nonlinear response and progressive failure of composite laminates, Composites Science and Technology, Volume 64, Issues 3-4, March 2004, Pages 329-342

3. Travis A. Bogetti, Christopher P.R. Hoppel, Bruce P. Burns, LAMPAT: A software tool for analyzing and designing thick laminated composite structures, Army Research Laboratory Technical Report 890, September 1995

4. B.M. Powers, T.A. Bogetti, W.H. Drysdale, J.M. Staniszewski, M. Keefe, Finite Element Based Multi-scale Modeling of the Nonlinear Response and Failure of Thick-Section Composite Structures, American Society for Composites 24th Annual Technical Conference held jointly with Canadian Association for Composite Structures and Materials, September 2009

5. SIMULIA, ABAQUS 6.6 release notes Section 7.8, Providence, RI, 2006

6. SIMULIA, ABAQUS 6.7 ABAQUS/CAE User's Manual Section 12.4.4, Providence, RI, 2007

7. SIMULIA, ABAQUS 6.7 Analysis User's Manual Sections 17-18, Providence, RI, 2007

8. SIMULIA, ABAQUS 6.7 Analysis User's Manual Section 19.3.1, Providence, RI, 2007

9. ANSYS Inc., ANSYS Release 11.0 Documentation Section 13.1.1, Canonsburg, PA, 2007

10. ANSYS Inc., ANSYS Release 11.0 Documentation Section 13.1.3, Canonsburg, PA, 2007

11. MSC.Software Corporation, MSC Virtual Product Development Solution in Aeronautic Industry, State of the Art Composites Modeling/Simulation, EMEA Aerospace Center of Competence, May 2009

12. Alpha Star Corporation, GENOA 4.4 Product Fact Sheet, Long Beach, CA, 2009

13. Firehole Technologies, Inc., Helius:MCT Version 2.0 for ABAQUS User's Guide, Section 1.1, Laramie, WY, July 2009

14. Firehole Technologies, Inc., Helius:MCT Version 2.0 for ABAQUS User's Guide, Appendix A.4, Laramie, WY, July 2009

15. Componeering, Inc., ESAComp 4.0 New features datasheet, Helsinki, Finland, March, 2009

16. NEi Software, NEi Nastran Progressive Ply Failure Analysis, Westminster, CA, 2009 
17. Cranes Software, Inc., NISA II/Composite Product Fact Sheet, Troy, MI, 2008

18. Ireneusz Lapczyk, Juan A. Hurtado, Progressive damage modeling in fiberreinforced materials, Composites Part A: Applied Science and Manufacturing, Volume 38, Issue 11, CompTest 2006, November 2007, Pages 2333-2341

19. Zhifeng Zhang, Haoran Chen, Lin Ye, Progressive failure analysis for advanced grid stiffened composite plates/shells, Composite Structures, Volume 86, Issues 1-3, Fourteenth International Conference on Composite Structures ICCS/14, November 2008, Pages 45-54

20. S. Michael Spottswood, Anthony N. Palazotto, Progressive failure analysis of a composite shell, Composite Structures, Volume 53, Issue 1, July 2001, Pages 117-131

21. C. Huhne, A.-K. Zerbst, G. Kuhlmann, C. Steenbock, R. Rolfes, Progressive damage analysis of composite bolted joints with liquid shim layers using constant and continuous degradation models, Composite Structures, Volume 92, Issue 2, January 2010, Pages 189-200

22. De Xie, Sherrill B. Biggers Jr., Progressive damage arrest mechanism in tailored laminated plates with a cutout, Acta Mechanica Solida Sinica, Volume 21, Issue 1, February 2008, Pages 62-72

23. G. Labeas, S. Belesis, D. Stamatelos, Interaction of damage failure and postbuckling behavior of composite plates with cut-outs by progressive damage modelling, Composites Part B: Engineering, Volume 39, Issue 2, March 2008, Pages 304-315

24. K. I. Tserpes, P. Papanikos, TH. Kermanidis, A three-dimensional progressive damage model for bolted joints in composite laminates subjected to tensile loading, Fatigue \& Fracture of Engineering Materials \& Structures, Volume 24, Issue 12, April 2001, Pages 663-675

25. K. I. Tserpes, G. Labeas, P. Papanikos, Th. Kermanidis, Strength prediction of bolted joints in graphite/epoxy composite laminates, Composites Part B:

Engineering, Volume 33, Issue 7, October 2002, Pages 521-529

26. C. Schuecker, H.E. Pettermann, A continuum damage model for fiber reinforced laminates based on ply failure mechanisms, Composite Structures, Volume 76, Issues 1-2, Fifteenth International Conference on Composite Materials - ICCM-15, October 2006, Pages 162-173

27. Ch. Hochard, J. Payan, C. Bordreuil, A progressive first ply failure model for woven ply CFRP laminates under static and fatigue loads, International Journal of Fatigue, Volume 28, Issue 10, The Third International Conference on Fatigue of Composites, October 2006, Pages 1270-1276

28. Rajamohan Ganesan, Dai Ying Liu, Progressive failure and post-buckling response of tapered composite plates under uni-axial compression, Composite Structures, Volume 82, Issue 2, January 2008, Pages 159-176 
29. Hakan Kilic, Rami Haj-Ali, Progressive damage and nonlinear analysis of pultruded composite structures, Composites Part B: Engineering, Volume 34, Issue 3, April 2003, Pages 235-250

30. Shiladitya Basu, Anthony M. Waas, Damodar R. Ambur, Prediction of progressive failure in multidirectional composite laminated panels, International Journal of Solids and Structures, Volume 44, Issue 9, 1 May 2007, Pages 2648-2676

31. Alexandros E. Antoniou, Christoph Kensche, Theodore P. Philippidis, Mechanical behavior of glass/epoxy tubes under combined static loading. Part II: Validation of FEA progressive damage model, Composites Science and Technology, Volume 69, Issue 13, Smart Composites and Nanocomposites Special Issue with Regular Papers, October 2009, Pages 2248-2255

32. Zheng-Ming Huang, Failure analysis of laminated structures by FEM based on nonlinear constitutive relationship, Composite Structures, Volume 77, Issue 3, February 2007, Pages 270-279

33. M.J. Hinton, A.S. Kaddour, P.D. Soden, A further assessment of the predictive capabilities of current failure theories for composite laminates: comparison with experimental evidence. Composites Science and Technology, Volume 64, Issues 3-4, March 2004, Pages 549-588

34. M.J. Hinton, A.S. Kaddour, P.D. Soden, A further assessment of the predictive capabilities of current failure theories for composite laminates: additional contributions. Composites Science and Technology, Volume 64, Issues 3-4, March 2004, Pages 449-476

35. Travis A. Bogetti, Christopher P.R. Hoppel, Vasyl M. Harik, James F. Newill, Bruce P. Burns, Predicting the nonlinear response and progressive failure of composite laminates: correlation with experimental results. Composites Science and Technology, Volume 64, Issues 3-4, March 2004, Pages 477-485

36. A.S. Kaddour and M.J. Hinton, Instructions to contributors of the second World-Wide Failure Exercise (WWFE-II) Part (A). In progress, March 2008

37. Chou P.C., J. Carleone, C.M. Hsu, Elastic constants of layered media. Journal of Composite Materials, Volume 6, Pages 80-93, 1972.

38. Sun C.T., Liao W.C., Analysis of thick section composite laminates using effective moduli. Journal of Composite Materials, Volume 24, Page 977, 1990.

39. SIMULIA, ABAQUS 6.7 Analysis User's Manual Section 17.2.1, Providence, RI, 2007

40. R.J. Arsenault, M. Taya, Thermal residual stress in metal matrix composite. Acta Metallurgica, Volume 35, Issue 3, March 1987, Pages 651-659 


\section{APPENDIX REPRINT PERMISSION LETTER}

To Whom It May Concern:

As the primary author of the papers "Three-dimensional effective property and strength prediction of thick laminated composite media" published in Army Research Laboratory Technical Report 911 and "Predicting the nonlinear response and progressive failure of composite laminates" published in Composites Science and Technology 64, I grant Jeffrey Staniszewski permission to use any figures contained in these two reports.

Signed,

Dr. Travis A. Bogetti

U.S. Army Research Laboratory

302-831-6324 